\title{
RECOVERY OF SUBTIDAL BENTHIC MACROINVERTEBRATE COMMUNITIES FOLLOWING NATURAL AND EXPERIMENTAL DISTURBANCES
}

\author{
Kerstin Kröger
}

2003

\begin{abstract}
A thesis
submitted to the Victoria University of Wellington in fulfilment of the requirements for the degree of Doctor of Philosophy in Ecology
\end{abstract}

Victoria University of Wellington New Zealand 


\section{FAUST:}

Habe nun, acfi! Pfillosopfiie,

Juristerei und Medizin,

Und leider auch Theologie

Durchaus studiert, mit heißem Bemüfn.

Da stef ich nun, ich armer Tor!

Und bin so Klug als wie zuvor;

Heiße Magister, freiße Doktor gar

Und ziefie schon an die zefien Jafir

Herauf, herab und quer und Krumm

Meine Schüler an der Nase herum-

Und sefe, daß wit nichts wissen Können!

Das will mir schier das Herz verbrennen.

Zwar bin ich gescheiter als all die Laffen,

Doktoren, Magister, Schreiber und Pfaffen;

Mich plagen Keine Skrupel noch Zweifel,

Fürchte mich weder vor Hölle noch Teufel-

Dafür ist mir auch alle Freud entrissen,

Bilde mir nicht ein, was Rechts zu wissen,

Bilde mir nicht ein, ich könnte was lefiren,

Die Menschen zu bessern und zu bekefiren.

Auch fiab ich weder Gut noch Geld,

Noch Efr und Herrlichkeit der Welt;

Es möchte Kein Hund so länger leben!

Drum hab ich mich der Magie ergeben,

O6 mir durch Geistes Kraft und Mund

Nicht manch Gefieimnis würde kund;

Daß ich nicht mehr mit sautem Schweiß

Zu sagen brauche, was ich nicht weiß;

Daß ich erkenne, was die Welt

Im Innersten zusammenfiäl,

Schau alle Wirkenskraft und Samen,

Und tu nicht mefir in Worten kramen.

Faust - Der Tragödie erster Teil, Johann Wolfgang Goethe, 1808 


\section{Acknowledgements}

Many people have contributed to this dissertation by giving me their help, their advice, and their time. My gratitude goes to all of them.

Thanks go to my supervisors Jonathan Gardner and Bob Wear for giving me the chance to come out to New Zealand and to rise to the challenge of this project. Thank you for your support.

I would like to express my gratitude to the taxonomists who helped me with the identification of my many fascinating creepy-crawlies: Geoff Read (NIWA Wellington), Chris Glasby (Museum and Art Gallery of the Northern Territory, Darwin, Australia), Brigitte Hilbig (Universität Hamburg), Keith Probert (University of Otago) and Lesley Bolton-Ritchie (Victoria University, Wellington) helped me with the polychaetes, Bruce Marshall (TePapa, Wellington) checked my mollusc reference collection, Niel Bruce (NIWA, Wellington) helped identifying the tiny isopods, Stephen Eager (Victoria University Wellington) identified the ostracods, and Oscar Vicente (Instituto Estudios Ceutíes, Spain) identified the yet to be described anthozoan Scolanthus sp.

Without the helping hands and eyes of Susie Wood, Kirsty Dickson and especially Joanne Long the sieving and sorting of the piles of sediment would have taken forever and the lab would have been a rather lonely place. Joanne, thank you so much for your friendship, your invaluable work, your brilliant ideas, your enthusiasm and your great patience with me whenever we went diving.

For the warm friendship, the on-going support and help, the introduction into the dubious delights of polychaete and amphipod ID, and the big welcome we got every time in Blenheim, I would like to thank Lesley Bolton-Ritchie especially.

A very special Thank You goes to Robert Williamson, skipper of the 'Raukawa Challenger', diver, diving instructor, field technician, computer support and equipment designer. Robert, without you this work would not have been possible. 
I am especially indebted to Ashley Rowden (NIWA Wellington) who took on the honorary role of being my sounding board, helped me with many fruitful discussions, cups of coffee, good ideas, encouragement, and good advice.

Thanks to everybody at NIWA who gave me his or her help so generously. Special thanks go to Miles Dunkin and Melissa Bowen for helping me with charts and graphs, to Michael Manning for statistical help, to Anne-Nina Lörz for proof-reading, panic-prevention and chocolate provisions, and to everybody, especially Kelly, who was forced to listen to my rumbles about disturbances.

Peter Enderlein was my first-class rescuer with last-minute statistical advice and Katrin Linse worked her way through a lot of draft material - tausend Dank dafür (both British Antarctic Survey, Cambridge).

Ian Welch fought bravely on my side in the last battle to format and print this dissertation.

This work was funded by a Victoria University of Wellington Post-graduate Targeted Scholarship for PhD study.

Bruce, this dissertation is dedicated to you. You were my solid rock throughout the ups and downs of the last four years and never ceased believing that one day I would submit my thesis. By now you are a qualified sediment siever and you know much more about taxonomy, multivariate statistics and experimental design than you ever wanted to or dreamed of. You supported me all the time, spent many weekends and evenings with the masochistic delights of sieving samples, provided me with wine when required and kept me basically going by giving me strength and bringing me back to reality whenever needed.

\section{Be aware, fellow ecologists:}

working on disturbance ecology might turn you

into a disturbed ecologist!!! 


\section{Abstract}

The recovery processes of subtidal benthic macroinvertebrate communities following large-scale natural and meso-scale experimental disturbances were studied in Wellington Harbour, New Zealand, a temperate semi-enclosed embayment.

This is the first time that long-term effects ( $>1$ year post-disturbance) of a naturally occurring toxic plankton bloom have been investigated in the Southern hemisphere. For 2 years macroinvertebrate communities were studied at three sites of differing hydrodynamic regime. Samples were taken with a Van Veen grab and washed through a $500 \mu \mathrm{m}$ mesh. Community recovery following the bloom was site-specific. Multivariate analyses revealed that at two sites community recovery was not completed $>3$ years post-bloom, whereas at the third site the community composition oscillated from year to year, but did not show any signs of a sequential recovery process. The hydrodynamic regime was identified as a major factor influencing the observed recovery processes. Communities exposed to an active hydrodynamic regime were less affected by the bloom and recovered faster, as they were naturally in a perpetual state of recovery as indicated by a dominance of $r$-selected species. The community at the hydrodynamically less active site was more affected by the bloom. Complete recovery to the pre-disturbance climax community dominated by $K$-selected species was estimated to take 4-5 years, if not interrupted by other disturbances.

For the first time a defaunation experiment was conducted in a hydrodynamically active site to mimic the effects of a plankton bloom on the benthic macroinvertebrate community. Three sediment plots of $25 \mathrm{~m}^{2}$ were covered by plastic tarpaulins, thereby creating a benthic die-off caused by oxygen depletion. This method of defaunation had not been used in the subtidal before. Community recovery was studied for 1 year and compared with community composition in undisturbed control plots. Macroinvertebrate samples were taken by diver-operated cores and washed through a $500 \mu \mathrm{m}$ mesh. Recovery was slow until after 70 days when abundance and number of species increased synchronously in disturbed and control plots. Multivariate 
analyses showed that community composition fluctuated strongly in the first 100 days. After 1 year, although disturbed and control communities were converging, differences in community composition were still significant. Time for complete recovery was estimated to be approximately 2 years.

Predictions of current succession models were generally fulfilled in both studies. Recovered communities were similar in their composition to either pre-disturbance or surrounding communities. The major deviation from model predictions was that no abundance peak of opportunistic species occurred in either study. Timing of the disturbance, in both studies past the major macroinvertebrate recruitment peak, and the hydrodynamic regime were identified as major factors influencing recovery processes of the communities studied. Such deviation from model predictions indicates that the general models cannot take into account the multiplicity and complexity of factors influencing recovery processes. Thus, their applicability in predicting recovery times and endpoints for specific disturbances at specific locations is limited. Location-specific models might be a useful alternative.

Recommendations are made to combine uni- and multivariate techniques to assess recovery processes due to their different sensibilities to changes in community composition. 


\section{Contents}

\section{CHAPTER 1}

General Introduction. 1

1.1 The Role of Disturbance in Community Ecology …................................................. 1

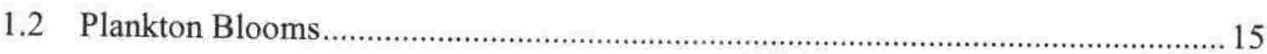

1.3 Wellington Harbour - The Physical Setting ........................................................... 17

1.4 The 1998 Wellington Harbour Toxic Plankton Bloom ..........................................22

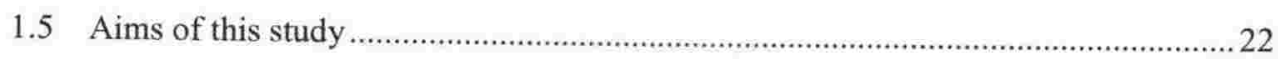

\section{CHAPTER 2}

Long-term Effects of a Toxic Algal Bloom on Subtidal Soft-Sediment Macroinvertebrate Communities in Wellington Harbour, New Zealand.

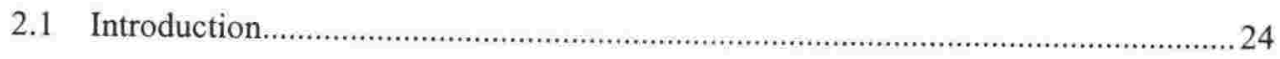

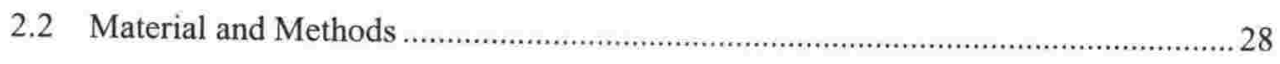

2.2.1 Wellington Harbour - The Physical Setting ..................................................28

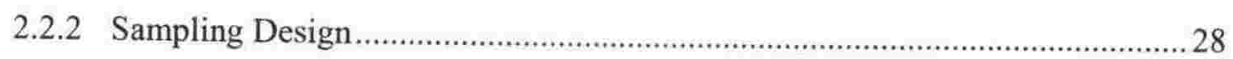

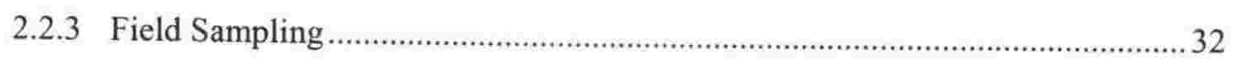

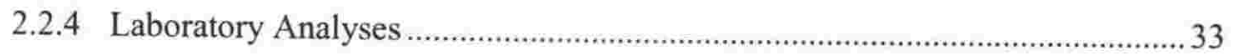

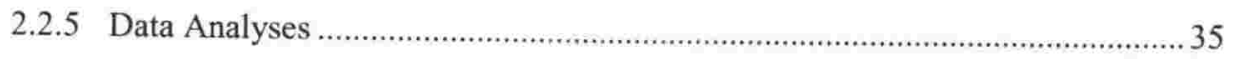

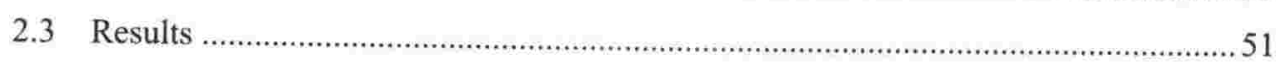

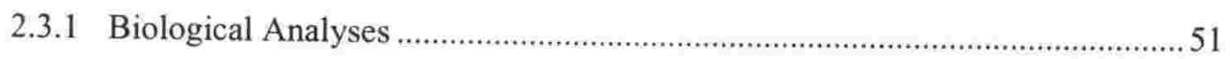

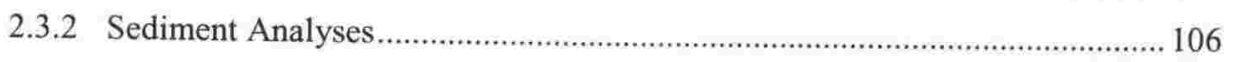

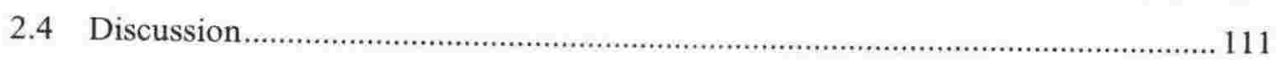

\section{CHAPTER 3}

Recovery of a Macroinvertebrate Community in Experimentally Defaunated Subtidal Soft Sediments

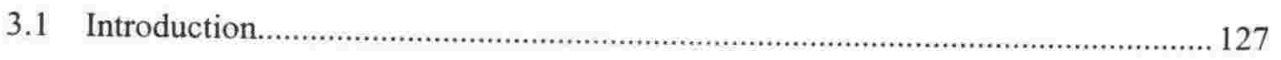

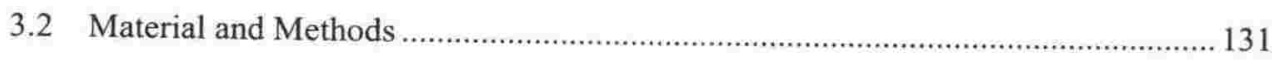

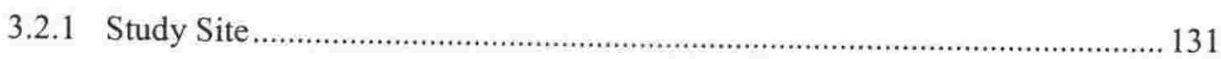

3.2.2 Experimental Set-up and Sampling ......................................................... 132

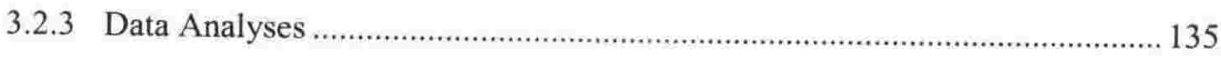

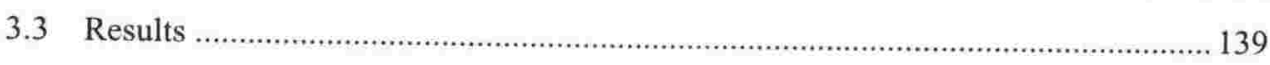

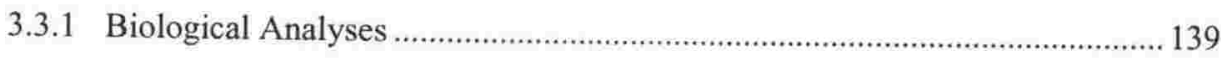

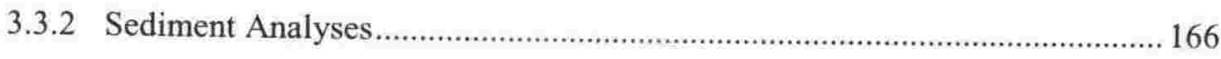

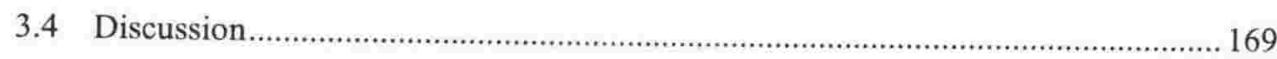

\section{CHAPTER 4}

General Discussion. 


\section{List of Figures}

\section{CHAPTER 1}

Figure 1.1. Chart of Wellington Harbour

Figure 1.2. Surface cell concentrations of Karenia brevisulcata.

\section{CHAPTER 2}

Figure 2.1. Total number of individuals (May 1998-March 1999) 53

Figure 2.2. Total number of individuals (August 1999-May 2001).

Figure 2.3. Harbour Basin. Mean abundance of 5 dominant taxa

Figure 2.4. Oriental Bay. Mean abundance of 5 dominant taxa 59

Figure 2.5. Entrance Channel. Mean abundance of 5 dominant taxa.

Figure 2.6. Harbour Basin. Number of individuals

Figure 2.7. Harbour Basin. Number of species 62

Figure 2.8. Harbour Basin. Shannon's diversity

Figure 2.9. Harbour Basin. Pilou's evenness

Figure 2.10. Harbour Basin. Fisher's alpha

Figure 2.11. Harbour Basin. Simpson's $-\ln D$

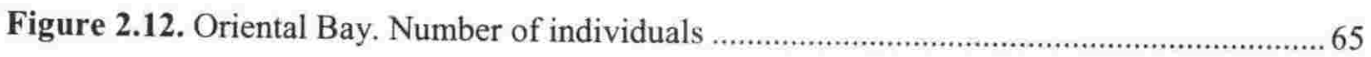

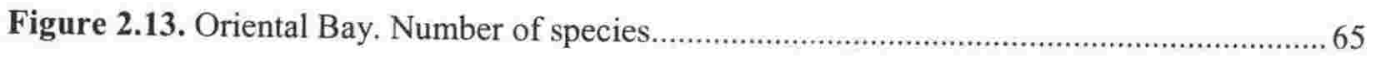

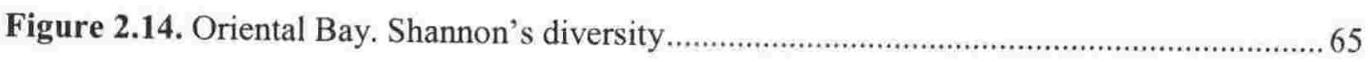

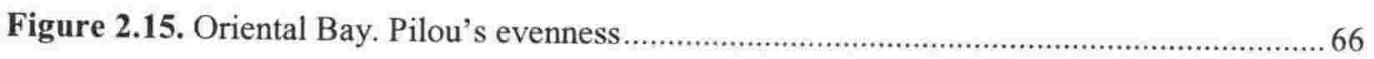

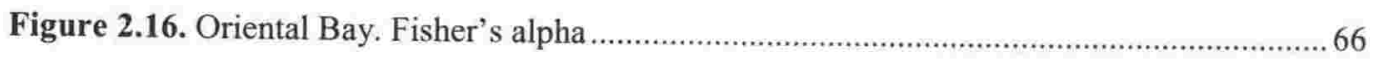

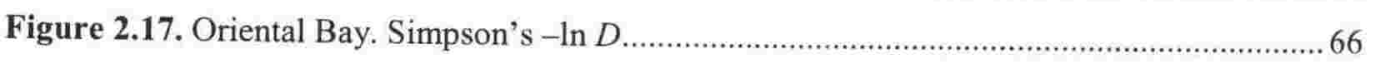

Figure 2.18. Entrance Channel. Number of individuals ............................................................ 70

Figure 2.19. Entrance Channel. Number of species............................................................. 70

Figure 2.20. Entrance Channel. Shannon's diversity.............................................................. 70

Figure 2.21. Entrance Channel. Pilou's evenness.................................................................... 71

Figure 2.22. Entrance Channel. Fisher's alpha ………….................................................. 71

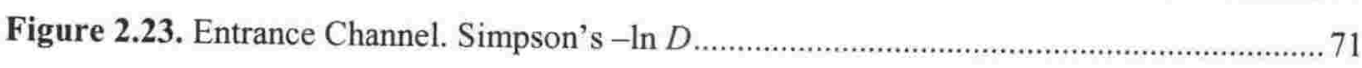

Figure 2.24. Dendrogram for 3 sites (pre- + post-bloom; $\geq 800 \mathrm{~mm}$ ) ......................................... 73

Figure 2.25. MDS ordination for 3 sites (pre- + post-bloom; $\geq 800 \mathrm{~mm}$ ) …............................... 74

Figure 2.26. MDS ordination for 3 sites (August 1999-May 2001; $\geq 500 \mathrm{~mm}$ ) ............................ 75

Figure 2.27. Harbour Basin. MDS ordination (pre- + post-bloom; $\geq 800 \mathrm{~mm}$ ) ........................... 77

Figure 2.28. Harbour Basin. Dendrogram (August 1999-May 2001; $\geq 500$ mm) ......................... 78

Figure 2.29. Harbour Basin. MDS ordination (August 1999-May 2001; $\geq 500 \mathrm{~mm}$ ) …................ 78

Figure 2.30. Oriental Bay. MDS ordination (pre- + post-bloom; $\geq 800 \mathrm{~mm}$ ) ............................... 79

Figure 2.31. Oriental Bay. Dendrogram (August 1999-May 2001; $\geq 500 \mathrm{~mm}$ ) ........................... 80

Figure 2.32. Oriental Bay. MDS ordination (August 1999-May 2001; $\geq 500 \mathrm{~mm}$ ) ..................... 80 
Figure 2.33. Entrance Channel. MDS ordination (pre- + post-bloom; $\geq 800 \mathrm{~mm}$ ) 81

Figure 2.34. Entrance Channel. Dendrogram (August 1999-May 2001; $\geq 500 \mathrm{~mm}$ ) 82

Figure 2.35. Entrance Channel. MDS ordination (August 1999-May 2001; $\geq 500 \mathrm{~mm}$ ) 82

Figure 2.36. Harbour Basin. MDS ordinations for factors year and season 84

Figure 2.37. Oriental Bay. MDS ordinations for factors year and season 85

Figure 2.38. Entrance Channel. MDS ordinations for factors year and season 86

Figure 2.39. Harbour Basin. MDS ordination; samples linked in temporal order 103

Figure 2.40. Oriental Bay. MDS ordination; samples linked in temporal order 104

Figure 2.41. Entrance Channel. MDS ordination; samples linked in temporal order 105

Figure 2.42. Organic matter content ( $\%)$ for 3 sites 107

Figure 2.43. Bubble plot of \% OM for 3 sites 107

Figure 2.44. MDS ordination of \% OM for 3 sites 109

Figure 2.45. MDS ordination of $\%$ OM for each site 110

\section{CHAPTER 3}

Figure 3.1. Total number of individuals and biomass per group 141

Figure 3.2. Mean abundance and biomass per group 142

Figure 3.3. Mean abundance of 5 dominant taxa 144

Figure 3.4. Mean $N, S, B, H^{\prime}$ and $J^{\prime}$.'... 145

Figure 3.5. Dendrograms for abundance, biomass and production data 149

Figure 3.6. MDS ordinations for abundance, biomass and production data 150

Figure 3.7. MDS ordinations for factors treatment and sampling day 152

Figure 3.8. Changes in $r$-value 153

Figure 3.9. MDS ordinations; samples linked in temporal order. 165

Figure 3.10. Mean organic matter content (\%) 167

Figure 3.11. Spearman rank correlation of $H^{\prime}$ and $\% \mathrm{OM}$ 168 


\section{List of Tables}

\section{CHAPTER 1}

Table 1.1. Examples of natural disturbances in marine systems ....................................... 3

Table 1.2. Examples of anthropogenic disturbances in marine systems ............................ 4

\section{CHAPTER 2}

Table 2.1. Species list. 55

Table 2.2. Oriental Bay. Tukey HSD post-hoc comparisons for $N$........................................ 64

Table 2.3. Oriental Bay. Tukey HSD post-hoc comparisons for $S$....................................... 67

Table 2.4. Oriental Bay. Tukey HSD post-hoc comparisons for $J^{\prime}$....................................67

Table 2.5. Entrance Channel. Tukey HSD post-hoc comparisons for $J$ '................................69

Table 2.6. ANOSIM. Differences in community structure among 3 sites .............................. 76

Table 2.7. Two-way crossed ANOSIM (factors) for 3 sites. ............................................ 83

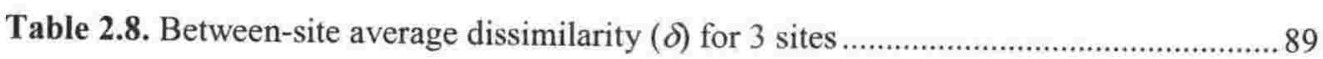

Table 2.9. Site-specific average similarity $(S)$ for 3 sites.............................................. 90

Table 2.10. Site-specific annual average similarity $(S)$ for 3 sites ................................... 93

Table 2.11. Site-specific between-year average dissimilarity $(\delta)$ for 3 sites........................96

Table 2.12. Relative dispersion and IMD for 3 sites (pre- + post-bloom; $\geq 800 \mathrm{~mm}$ )......... 101

Table 2.13. Relative dispersion and IMD for 3 sites (August 1999-May 2001; $\geq 500$ mm).. 102

Table 2.14. Sediment characteristics for 3 sites ................................................................ 108

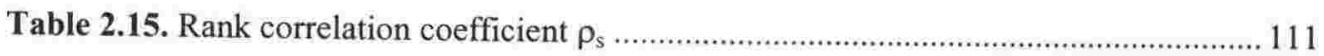

\section{CHAPTER 3}

Table 3.1. Species list 140

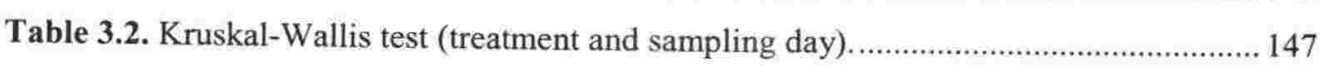

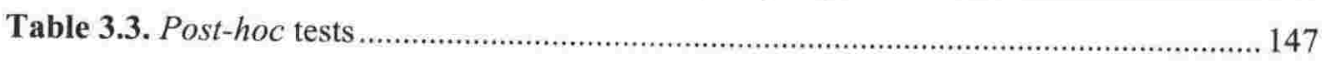

Table 3.4. Kruskal-Wallis test (temporal differences) ...................................................... 148

Table 3.5. Two-way crossed ANOSIM (treatment and sampling day) .............................. 151

Table 3.6. ANOSIM. Pairwise comparisons of production data ....................................... 152

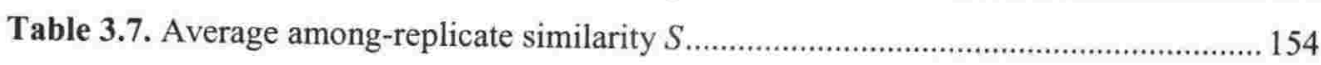

Table 3.8. Average similarity $(S)$ for each sampling day ............................................ 156

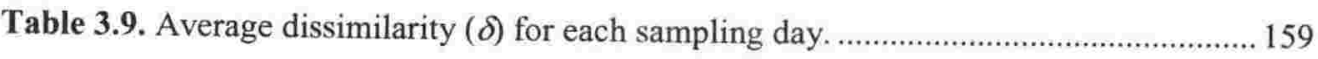

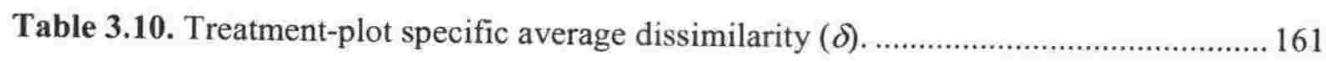

Table 3.11. Relative dispersion and IMD ................................................................. 164

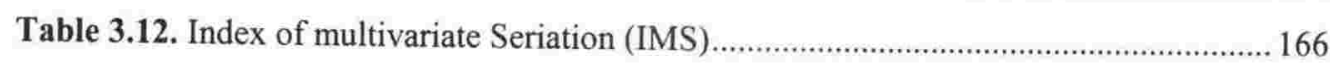

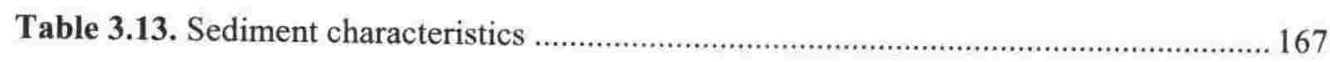

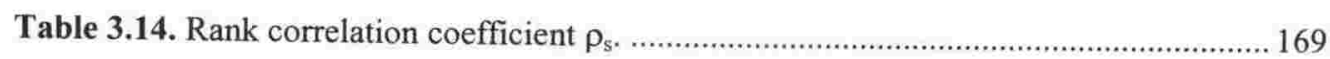

\section{CHAPTER 4}

Table 4.1. General factors influencing benthic recovery processes. 


\section{List of Appendices}

All appendices can be found on the accompanying $\mathrm{CD}$.

\section{CHAPTER 2}

Appendix 1. List of taxonomic experts consulted for species identification

Reference list of identification literature used

Appendix 2. Best fit curves

Appendix 3. Species list

Appendix 4. Mean abundances

Appendix 5. Univariate diversity indices

Appendix 6. Post-hoc tests for univariate diversity indices

Appendix 7. SIMPER results: dissimilarities $(\delta)$ and discriminatory species between sites

Appendix 8. SIMPER results: site-specific similarities $(S)$ and typifying species

Appendix 9. SIMPER results: site-specific annual similarities $(S)$ and typifying species

Appendix 10. SIMPER results: site-specific annual dissimilarities ( $\delta)$ and discriminating species

\section{CHAPTER 3}

Appendix 11. Species list

Appendix 12. Mean abundances, mean biomass and mean production

Appendix 13. Univariate diversity indices

Appendix 14. Kruskal-Wallis and post-hoc tests for univariate diversity indices

Appendix 15. $\mathrm{ABC}$ plots and $W$ statistic

Appendix 16. SIMPER results: similarities $(S)$ and typifying species

Appendix 17. SIMPER results: dissimilarities $(\delta)$ and discriminating species

Appendix 18. Organic matter content (\%): Kruskal-Wallis and post-hoc tests 


\section{Chapter 1 \\ General Introduction}

\subsection{The Role of Disturbance in Community Ecology}

When an ecosystem experiences a disturbance, functions within the system get disrupted (Cairns \& Dickson 1975). Such a disruption can affect any level of the system: the disturbance can disrupt populations by killing individuals, communities by reducing their diversity, and ecosystems by intercepting processes such as energy transfer (Lake 1990). Thus, a disturbance is one of the main factors changing and structuring biological communities and influencing variations in species diversity by creating open space and affecting the strength and outcome of interspecific competition (e.g., Connell 1978; Huston 1979). Therefore, a disturbance functions as a major source of temporal and spatial variability in communities and is also an agent of natural selection in the evolution of life histories (Sousa 1984).

Due to the plurality of disturbances and the manifold effects even a single disturbance event can have on the many levels of an ecosystem, an encompassing and clear-cut definition has proved difficult to formulate. Sousa (1984) termed disturbance as 'a discrete, punctuated killing, displacement, or damaging of one or more individuals (or colonies) that directly or indirectly creates an opportunity for new individuals (or colonies) to become established.' The author thereby refers to the effect of an external force, i.e., the damage or mortality itself, as the disturbance. According to Pickett and White (1985) a disturbance "is any relatively discrete event in time that disrupts ecosystem, community, or population structure and changes resources, substrate availability, or the physical environment'. Thus, here the external agent or force is viewed as the disturbance. In this dissertation I propose to follow the widely used definition of Pickett \& White (1985), and regard the creation of space by displacement of organisms and the increased availability of resources as consequences of disturbances, and not as the disturbance itself. 
All communities past and present are exposed to disturbances of various kinds, scales, intensities and frequencies. Hence, disturbances are likely to play a vital role in changing and structuring communities. Omitting anthropogenic disturbances, the spectrum of physical disturbances in the terrestrial environment includes fire (Romme 1982; Christensen 1985), droughts (Hough \& Forbes 1943; Visher 1949), floods (Giller et al. 1991), storms (Brokaw 1984), hail (Houston 1999), volcanic eruptions (Turner et al. 1997), and landslides (Garwood et al. 1979). Examples of physical disturbances in the marine environment are storms (Underwood 1999), subtidal sediment slumps (Slattery \& Bockus 1997), desiccation (Connell 1961), freshwater flooding (Jokiel et al. 1993), ice scour (Peck et al. 1999), and wave shock and battering by drift logs (Dayton 1971). Such natural physical disturbances range mostly on spatial scales of $\mathrm{km}^{2}$ whereas biological disturbances, particularly in the marine environment, often operate on smaller spatial scales, e.g., sediment reworking by infaunal organisms (Gray 1974) or by foraging predators such as crabs (Warwick et al. 1990) or gulls and ducks (Savidge \& Taghon 1988). Examples of terrestrial biological disturbances include burrowing animals such as badgers (Platt 1975), insect outbreaks (Schowalter 1985), and disease (Anderson \& Anderson 1963) of which the latter two can also operate on larger spatial scales. Often, there is no clear-cut distinction possible between whether a disturbance is of physical or biological origin. For instance, the proximal cause for tree falls in forests are storms, but the trees could have been already weakened by senescence (Runkle 1985). Similarly, the susceptibility of macroalgae to damage by hydrodynamic forces is increased by wounds inflicted by grazing or boring organisms (Koehl \& Wainwright 1977) or by heavy epiphytic growth (D'Antonio 1985). Disturbances in marine systems are as varied as in terrestrial systems. All marine systems, from intertidal hard and soft substrates to the deep sea, and in these systems organisms of all sizes from microbes to top predators, are affected by both natural and anthropogenic disturbances (Table 1.1 and Table 1.2). 
Table 1.1 Examples of naturally occurring disturbances in marine systems, the habitat where they can occur and examples from the literature. This list is by no means complete either in terms of disturbances listed or in examples given. Derived from Sousa (2001).

\begin{tabular}{|c|c|c|}
\hline Agent of disturbance & Habitat or Assemblage & Examples \\
\hline \multicolumn{3}{|c|}{ Physical: predominantly large-scale } \\
\hline \multirow[t]{6}{*}{ Storm waves and currents } & Soft sediment & Rees et al. (1977) \\
\hline & Emergent rocky shore & Lubchenco \& Menge (1978) \\
\hline & & Paine \& Levin (1981) \\
\hline & Boulder field & Sousa (1979) \\
\hline & Coral reef & Aronson \& Precht (1995) \\
\hline & Seagrass bed & Reusch \& Chapman (1995) \\
\hline Benthic storms & Deep-sea soft sediment & Thistle (1988) \\
\hline \multirow{3}{*}{$\begin{array}{l}\text { Sediment scour and } \\
\text { smothering }\end{array}$} & Emergent rocky shore & McGuiness (1987) \\
\hline & Subtidal hard substrate & Airoldi (1996) \\
\hline & Coral reef & Wesseling et al. (1999) \\
\hline Drifting logs & Emergent rocky shore & Dayton (1971) \\
\hline \multirow[t]{3}{*}{ Ice scour } & Subtidal soft sediment & Peck et al. (1999) \\
\hline & Emergent rocky shore & Barnes (1999) \\
\hline & Seagrass bed & Schneider \& Mann (1991) \\
\hline \multirow[t]{2}{*}{ Subtidal sediment slumps } & Hard substrate & Slattery \& Bockus (1997) \\
\hline & Soft sediment & VanBlaricom (1982) \\
\hline Freshwater flooding & Coral reef flat & Jokiel et al. (1993) \\
\hline Ocean warming & Intertidal + plankton & Southward et al. (1995) \\
\hline \multirow[t]{2}{*}{ Extended aerial exposure } & Coral reef flat & Connell et al. (1997) \\
\hline & Emergent rocky shore & Seapy \& Littler (1982) \\
\hline \multirow[t]{3}{*}{ Oxygen depletion } & Fjord & Fallesen et al. (2000) \\
\hline & Estuary & Rainer (1981) \\
\hline & Subtidal soft sediment & Bonsdorff \& Pearson \\
\hline \multicolumn{3}{|c|}{ Biological: predominantly small-scale } \\
\hline Sediment excavation by & Subtidal soft sediment & Oliver et al. (1984), Thrush \\
\hline foraging predators & & (1986) \\
\hline \multirow[t]{3}{*}{ Bioturbation } & Subtidal soft sediment & $\begin{array}{l}\text { Rhoads (1974), Dahlgren et } \\
\text { al. (1999) }\end{array}$ \\
\hline & $\begin{array}{l}\text { Subtidal soft-sediment } \\
\text { meiofauna }\end{array}$ & Findlay et al. (1990) \\
\hline & Deep-sea soft sediment & Varon \& Thistle (1988) \\
\hline Plankton blooms & Coastal embayment & Vieira et al. (1992) \\
\hline Disease & Seagrass bed & Rasmussen (1977) \\
\hline
\end{tabular}


Table 1.2 Examples of anthropogenic induced disturbances in marine systems, the habitat where they can occur and examples from the literature. This list is by no means complete either in terms of disturbances listed or in examples given.

\begin{tabular}{|c|c|c|}
\hline Agent of disturbance & Habitat or Assemblage & Examples \\
\hline \multicolumn{3}{|l|}{ Physical } \\
\hline \multirow[t]{3}{*}{ Fishing and Dredging } & Subtidal soft sediment & $\begin{array}{l}\text { Swartz et al. (1980), Kenchington } \\
\text { et al. (2001), Eleftheriou \& } \\
\text { Robertson (1992) }\end{array}$ \\
\hline & Intertidal soft sediment & Riesen \& Reise (1982) \\
\hline & Seagrass bed & Peterson et al. (1987) \\
\hline Sediment extraction & $\begin{array}{l}\text { Inter- and subtidal soft } \\
\text { sediment }\end{array}$ & van der Veer et al. (1985) \\
\hline Dredge disposal & Subtidal soft sediment & Maurer et al. (1986) \\
\hline Mine tailings & Subtidal soft sediment & $\begin{array}{l}\text { Burd et al. (2000), Kline \& } \\
\text { Stekoll (2001) }\end{array}$ \\
\hline \multicolumn{3}{|l|}{ Pollution } \\
\hline Eutrophication & $\begin{array}{l}\text { Subtidal soft sediment } \\
\text { microorganisms }\end{array}$ & Meyer-Reil \& Köster (2000) \\
\hline \multirow[t]{2}{*}{ Fish-farm biodeposits } & $\begin{array}{l}\text { Subtidal soft sediment } \\
\text { Meiofauna }\end{array}$ & Mirto et al. (2002) \\
\hline & Macrofauna & Karakassis et al. (1999) \\
\hline \multirow[t]{2}{*}{ Storm water drains } & Intertidal soft sediment & Botherway \& Gardner (2002) \\
\hline & Estuary & Morrisey et al. (2003) \\
\hline \multirow[t]{3}{*}{ Oil pollution } & Seagrass and kelp beds & Dean \& Jewett (2001) \\
\hline & Sea otters & Monson et al. (2000) \\
\hline & Subtidal soft sediment & Elmgren et al. (1983) \\
\hline Chemical & Subtidal soft sediment & Rakocinski et al. (2000) \\
\hline \multicolumn{3}{|l|}{ Biological } \\
\hline \multirow[t]{4}{*}{ Species introduction } & Subtidal hard substrate & Willan (1987) \\
\hline & Subtidal soft sediment & Carlton et al. (1990) \\
\hline & Phytoplankton & $\begin{array}{l}\text { Nehring (1998), McMinn et al. } \\
\text { (1997) }\end{array}$ \\
\hline & Subtidal sediment & Buttermore \& Turner (1994) \\
\hline
\end{tabular}




\section{Definition of Community}

Before the role of disturbances on communities is assessed further, a working definition of the term 'community' in the context of the present study is necessary. Much controversy has arisen over the nature and definition of biotic communities (Mills 1969). The term has to encompass such varying concepts as communities being separable units, of interaction between the community members and also between the members and the environment, and of communities having evolved in relation to their environment. In a very wide sense one could term a community a functional unit of interdependent organisms living in any given area (Odum 1959), but this definition is rather vague. As Elton put it so succinctly, "the term animal community is really a very elastic one, since we can use it to describe on the one hand the fauna of equatorial forest (sic), and on the other hand the fauna of a mouse's caecum' (1927).

In 1877, Karl Möbius, while working at Kiel, coined the term 'biocoenosis' to describe the animal communities of oyster beds. Later on, the Danish scientist C.G.J. Petersen (1913) described eight benthic communities from Scandinavian waters, naming them after the most numerous and most conspicuous species. But, according to Thorson (1957), Petersen recognised 'communities' as statistical units only and did not comment on community interactions or functions. Thorson developed Petersen's ideas further by identifying 'parallel communities', i.e., "communities inhabiting the same kind of bottom at similar depths, characterized by different species of the same genera, but replacing each other in accordance with the geographical region' (1957). Thereby communities are ecological units mainly governed by the environment. Hence, the same environmental conditions should give rise to the same parallel community. However, Thorson's view of a community does not include communities characterised by many, but not very abundant species such as tropical or deep-sea communities, or communities that are dynamic in terms of species abundance. Mills (1969), in an early review on the concept of animal communities in the marine environment, includes the interaction of community members with each other and with the environment in his definition of community. The view that assemblages are discrete units with sharp boundaries separating them is changing towards a view that assemblages are continua of 
species occurring along environmental gradients with each species having different optima (Gray 1981). Underwood (1986) points out that most definitions of a community are somewhat arbitrary. According to the author a community should show consistency through time and space and interdependence of the species in the community. Giller \& Gee (1987) list a range of community definitions and relate the multitude of existing definitions to the fact that communities have been defined on different organisational levels, i.e., on locational, trophic and taxonomic levels depending on the focus of the particular study. The authors point out that a community definition should include important community properties such as temporal and spatial limits and the presence of interactions amongst the species of a community. In the present study I follow the definition of Fauth et al. (1996) of a community being a collection of species that have overlapping distributions over space and time within an area (e.g., habitat or depth range). Organisms in a community interact with each other directly or indirectly via predation or competition and in response to changes in the environment.

\section{Disturbance and Diversity}

Various explanations and conceptual models have been proposed to elucidate the complex relationships between disturbance and diversity. The Spanish ecologist Ramón Margalef recognised that the diversity of a community is related to its successional stage. Margalef (1968) proposed that immature or early successional communities are characterised by low species diversity and fluctuate in composition under the direct impact of the physical environment. At the opposite end of the scale, mature or late successional communities are characterised by high diversity and a relative constancy in composition. The American Howard L. Sanders embodied similar concepts in his stability-time hypothesis (1968) to explain differences in diversity between communities. The stability-time hypothesis states that communities in predominantly physically controlled environments are low in diversity, analogous to Margalef's immature communities. In contrast, communities evolving under constant environmental conditions, i.e., communities which have a history of low physiological stress, are high in diversity. The temporal stability of the community enables species to 
co-exist and share resources due to a high extent of niche-diversification, i.e., high levels of interspecific competition. Sanders (1968) used the stability-time hypothesis to explain the apparently higher species diversity found in deep-sea macrobenthic samples compared to shallow water samples. However, the timestability hypothesis has been criticised for the criteria upon which it is based (Peters 1976) and the assumptions made by Sanders to evaluate the data (Abele \& Walters 1979a, b).

Whereas the stability-time hypothesis assumes an equilibrium state, that is, after disturbance the community returns to the same pre-disturbance equilibrium state and persists in that state unless disturbed again, the intermediate disturbance hypothesis (Grime 1973; Connell 1978) presumes that communities seldom reach an equilibrium state. The intermediate disturbance hypothesis postulates that highest community diversity is maintained at intermediate temporal and intensity levels of disturbance. If disturbances occur more frequently or are too severe, diversity remains low because only a few species can reach maturity between disturbance events. If disturbance levels are too low, diversity declines due to a few competitively dominant species eliminating or outliving the other species. Only if communities are disturbed at intermediate levels does diversity remain high. Along with the intermediate disturbance hypothesis Connell (1978) introduced the compensatory mortality hypothesis to explain how disturbance can maintain local diversity. According to the compensatory mortality hypothesis, factors such as predation or higher susceptibility to external disturbance or disease promote diversity among competing species if predators feed preferentially upon the superior competitor. Thus, the superior competitor does not reach sufficiently high densities to displace inferior competitors, and diversity is maintained. Paine (1966) experimentally demonstrated the importance of selective predation by the starfish Pisaster ochraceus on the competitively dominant mussel Mytilus californianus in maintaining high species diversity in the rocky intertidal of the Pacific coast of the USA, and coined the term keystone species for such selective predators. The intermediate disturbance hypothesis is one of the most accepted principles in ecology (Hoopes \& Harrison 1998) and has received support from work in a variety of communities such as marine phytoplankton (Sommer 1995), sessile rocky shore biota (Sousa 1979), forest vegetation (Hiura 1995) and river 
macroinvertebrates (Townsend et al. 1997). The high diversity commonly encountered in deep-sea sediments has also been explained by disturbances at intermediate levels (Gage 1996, 1997). However, the proposed diversity pattern following a disturbance does not seem to be universal. For instance, Huxham et al. (2000) experimentally disturbed intertidal soft-sediment communities at different frequencies, but did not observe an increase in diversity in any of the treatments. Also, a recent meta-analysis has shown that the diversity-disturbance relationship does not always peak as would be expected (Mackey \& Currie 2001). Mackey \& Currie found that sampling methodology (e.g., number of individuals censused, size of sampling areas) appears to significantly influence the shape of the diversity-disturbance relationship to be observed. Petraitis et al. (1989) give an elegant synthesis of the various hypotheses relating disturbance and diversity, and for a recent comprehensive review in the context of marine systems see Sousa (2001).

Disturbances are also important in the context of macro-evolution (Alvarez et al. 1980; Raup 1992). Research on the recovery of biodiversity following mass extinction events and smaller biotic crises has shown that recovery patterns bear high resemblance to patterns of ecological succession after disturbances. The immediate aftermath of a mass extinction, the survival stage, is characterised by very low diversity and a dominance of geographically widespread generalists. Immediately after extinction, the origination rate of species, i.e., the rate at which new species evolve, is low, accelerating only as diversification creates new niches, and finally peaking when the structure of the ecosystem is sufficiently developed to slow further diversification (Kirchner \& Weil 2000). Disturbances of global extent, such as meteorite impacts (Valen 1984), drastic climatic changes (Fischer 1984) or continental drift (Valentine 1971; Schopf 1979) can thus influence biodiversity over geological time spans.

\section{Successional Patterns Following Disturbance}

When a community is grossly disturbed - a forest cleared by an avalanche, a rocky shore community abraded by ice-scour, a coral reef destroyed by a hurricane - succession commences, i.e., a sequence of communities 
develops which replace one another with time in the disturbed area (Rosenzweig 1995). Typically this development begins with pioneering species, which are replaced by more mature communities until a relatively stable community has evolved that is considered to be in equilibrium with the environment (Odum 1959). This progressive change of species is accompanied by a change in the physical environment, which is often caused by the succeeding species themselves. For instance, the first plants to arrive on newly formed sand dunes are often marram grasses. The marram grass initially stabilises the dune surface and adds organic detritus to the sand, thereby modifying the environment and facilitating other species, which would not be able to survive without such habitat modifications (Ricklets 1983).

Early ecological work focussed on quantifying species successions following disturbances, predominantly in plant communities, rather than on examination of the role of disturbances in shaping successional processes (e.g., Jones 1945; Watt 1947). As early as 1916, the American ecologist F. Clements had outlined a theory of the basic features of succession which stated that every succession would invariably lead to a climatically controlled stable-state climax community typical for the area. Deviations from the climax community as caused by, for instance, fire, animal grazing or human interference, were thought to represent interrupted stages, i.e., immature communities, in transition towards the local climax community. A disturbed community would invariably return to the local climax formation, assuming no further interruption by disturbance, by repeating the same successional stages. This monoclimax theory (Clements 1916, 1936) was later replaced by a view that whilst regional patterns of climax communities exist, the community composition at any one locality depends on the particular environmental conditions at that site (Whittaker 1953).

The American ecologist E.P. Odum (1969) developed a conceptual model of species succession in which succession is regarded as an interacting complex of processes. Odum viewed succession as a predictable process of community development leading to a stabilised ecosystem. Although the physical environment sets the limit for this process, the community controls succession to a certain extent by modifying the physical environment. The author pointed out that species characteristic of the different successional stages share certain life histories. Species of early successional stages are small, have short life cycles 
and are generalists, i.e., they are $r$-selected, whereas species of mature successional stages are $K$-selected, i.e., they are large, have long and complex life cycles and occupy narrow niches. The terms $r$ and $K$ refer to the logistic equation for population growth with $r$ being the intrinsic (unlimited or exponential) rate at which a population can increase and $K$ being the carrying capacity, i.e., the maximum population density that can be supported by a habitat. Generally, $r$-selected species thrive in unpredictable environments and are able to respond quickly to favourable conditions by rapid growth and reproduction. Their high mortality rates are density-independent and they tend to be poor competitors. In contrast, $K$-selected species dominate in predictable and relatively stable environments, have low and density-dependent mortalities and tend to be good competitors with high niche-diversification (MacArthur \& Wilson 1967; Pianka 1970).

Johnson $(1970,1973)$ proposed a conceptual model explaining the often observed temporal and spatial heterogeneity of communities caused by disturbances. According to Johnson's model, communities are continually exposed to small-scale local disturbances even under relatively constant environmental conditions. Thus, different parts of the community are in different successional stages of recovery, rendering a mosaic structure in response to a history of disturbances. Although Johnson developed his model using marine soft-sediment data, the application of the model is by no means restricted to this habitat (freshwater phytoplankton: Richerson et al. 1970; stream invertebrates: Crowl et al. 1997; coral reef fish communities: Acosta \& Robertson 2002; forest plant communities: Nowak et al. 2002; ant communities: Bestelmeyer \& Wiens 2003).

Gray $(1977,1981)$ applied the physical principle of neighbourhood and global stability to describe successional patterns following disturbances. In global stability a community always returns to the same community composition with the same species dominating. In neighbourhood stability the community can return to multiple stable points, i.e., following a disturbance, community composition can be different with different species dominating. According to Gray (1981), the extent of the disturbance and the scale of its effects influence whether a community experiences global or neighbourhood stability. 
Traditionally, biological disturbance, such as competition and predation were seen as driving forces behind species or community succession. Grassle \& Sanders (1973) and Grassle \& Grassle (1974) highlighted the importance of lifehistory characteristics of species in determining successional dynamics in softsediment communities. However, no model existed explaining the underlying causes of species succession until Connell \& Slatyer (1977) proposed three alternative testable models of successional species replacement called the facilitation, tolerance and inhibition models. The facilitation model states that only certain pioneer species can establish themselves after a disturbance. These species modify the environment so that it becomes less suitable for other early successional species, but more suitable for late successional species, thereby facilitating the successional changes. The tolerance and inhibition models are based on the assumption that any species surviving initial colonisation can establish populations. In the tolerance model early successional species have little or no effect on subsequent recruitment of late successional stages, but modify the environment so that it becomes less suitable for early successional species. The late successional stages are better adapted to exploit limited resources and therefore competitively exclude the pioneer species. The third model, the inhibition model, posits that the first occupants exclude or inhibit later colonists as long as the former are healthy and undamaged. Thus, successional replacement occurs gradually by the deaths of early occupants (Connell \& Slatyer 1977). Facilitation tends to be important in physically stressful environments where stress-tolerant species ameliorate conditions (Zajac \& Whitlach 1982b; Gallagher et al. 1983; Harris et al. 1984; Bertness \& Leonard 1997), whereas tolerance and inhibition tend to predominate in areas of more moderate physical conditions (Zajac \& Whitlach 1982b; Chesney 1985; Whitlach \& Zajac 1985). However, Connell \& Slatyer's models have been criticised for oversimplifying successional processes (Day \& Osman 1981; Dean 1981; Pickett et al. 1987) by not accounting for important effects influencing species successions in the models such as predation (Day \& Ostman 1981) and the physical structure provided by other colonists (Dean 1981). Pickett et al. (1987) emphasise that the models of Connell \& Slatyer explain successional changes of particular species but do not explain multispecies successions in a community. Additionally, each model allows only one pathway of succession, either 
facilitation, tolerance or inhibition. This particular pathway then is repeated in each species change in the succession until the climax is reached. However, such pathways may change depending on the species involved, e.g., the succession from species A to species B can be caused by facilitation, but the change from species B to species C can be caused by inhibition.

Pearson \& Rosenberg (1976, 1978) and Rhoads et al. (1978) developed independently two conceptual models of species succession in marine soft sediments which have become cornerstones in the assessment of environmental impacts (Thrush \& Whitlach 2001). The Pearson \& Rosenberg model is based on large-scale (several $\mathrm{km}^{2}$ ) organic pollution (organic waste disposal) and focuses on recovery processes in space. Rhoads et al. developed their model following physical disturbance on both small (recolonisation trays with defaunated sediment, $0.1 \mathrm{~m}^{2}$ ) and larger scales (dredge disposal, $29000 \mathrm{~m}^{2}$ ) and it focuses on recovery processes in time. Both models are very similar in predicting a specific sequence of successional stages following a disturbance, whereby species are specifically adapted to the environmental conditions encountered at each stage. By physically altering their habitat, i.e., through bioturbation or by stabilising the sediment surface (Probert 1984), species are able to influence the success of later colonists. Following a disturbance, species typical of the first successional stage (Stage I) are small, often tubiculous organisms with high reproduction rates and short life cycles, which live in the uppermost sediment layers. These early opportunists, often capitellid and spionid polychaetes, can occur in abundances much higher than in adjacent undisturbed sediments. Stage II is a transitory stage and is comprised of both opportunistic Stage I species and increasing numbers of longer-lived species (Stage III). Pronounced fluctuations of the assemblage composition are typical of Stage II. The final successional stage, Stage III, is characterised by a diverse assemblage with many long-lived, larger, often deep-burrowing animals occurring in relatively low densities. In short, the succession proceeds from a species-poor community of primarily $r$ selected species to a diverse community of $K$-selected species. Whereas Stage I and Stage III are highly predictable in species composition, Stage II is unpredictable in this regard. The validity of the models of Pearson \& Rosenberg (1976, 1978) and Rhoads et al. (1978) have been endorsed by numerous studies following natural and experimental disturbances of soft-sediment environments 
(Arntz \& Rumohr 1982; Bonsdorff \& Österman 1985; Gamenick et al. 1996; Rosenberg et al. 2002). However, results from other studies have shown that in particular the model predictions for Stage I are not always fulfilled (Kaplan et al. 1975; Thrush et al. 1996; Beukema et al. 1999; Karakassis et al. 1999). The underlying causes for such deviations (mainly an absence of peak abundances of one or a few opportunistic species) are not clear, but they could be linked to the nature and the timing of the disturbance.

The successional change of species along the $r-K$ continuum and the increased heterogeneity of community composition during the recovery process (successional Stage II) can be used to assess effects of disturbances (pollutioninduced and otherwise) on marine macrobenthic communities. The Abundance/Biomass comparison (ABC) method (Warwick 1986; Warwick et al. 1987 ) is based on the difference in the distribution of numbers of individuals among species and the distribution of biomass among species when a community is disturbed. In a rarely disturbed mature benthic community the competitive dominants of the community are $K$-selected with a large body size and long lifespan. Although such species dominate in terms of biomass, their abundance is relatively low. In contrast, a recently disturbed community is dominated by $r$ strategists in numerical terms, but their biomass is reduced due to their small body size. Multivariate methods such as the Index of Multivariate Dispersion (IMD, Warwick \& Clarke 1993) and the Index of Multivariate Seriation can be used to detect increased variability in community composition, which is a sign of disturbance (IMS, Clarke et al. 1993).

Whereas Person \& Rosenberg $(1978,1987)$ ascribed species succession in the marine environment primarily to a gradient of organic enrichment, recent work has shown that species succession is influenced by various abiotic and biotic factors which often interact (e.g., Zajak \& Whitlach 1985). Such factors include, among others, seasonality (Zajac \& Whitlach 1982a, b, 1989; Dittmann et al. 1999; Ford et al. 1999), hydrodynamics (Rhoads et al. 1978; Eckman 1983; Butman 1987, 1989), mobility of the colonisers (Günther 1992; Whitlach et al. 1998) and biotic interactions (Connell \& Slatyer 1977). The nature of a disturbance itself, due to its variability in frequency, extent, magnitude, and its effects on the organisms of a community also has a strong influence on the ensuing species succession and the recovery time (Thistle 1981). 
O'Neill (1999) argued that due to the variability in factors such as nature, frequency and extent of the disturbance, environmental conditions and availability of pioneering species, recovery processes are highly unpredictable even within simple systems. For example, if disturbance events occur too frequently for a community to recover between events, or if disturbances lead to severe long-term physical or chemical changes in the habitat, the recovery abilities of a community might be overwhelmed and a state different from the pre-disturbance state might be attained. Irreversible changes in the marine environment can be induced by naturally occurring disturbances, e.g., storminduced changes in drainage patterns of coral reefs (Connell et al. 1997) or displacement of substrata due to tectonic activity (Castilla 1988), as well as by anthropogenic disturbances such as physical or chemical modifications of the habitat, e.g., drainage of ports and shipping channels (Yu \& Zhang 1999) or widespread eutrophication, which can lead to large-scale anoxia (Diaz \& Rosenberg 1995).

In the context of this dissertation, one example of naturally occurring disturbances is of particular interest. Phytoplankton blooms can impact negatively on most biological communities in the systems they occur in, and in this dissertation their effect on marine benthic macroinvertebrate communities will be assessed.

In 1998 a toxic plankton bloom occurred in Wellington Harbour, New Zealand and caused high mortalities amongst the harbour's biota, especially the benthic macroinvertebrates (Chang 1998a, b; Wear \& Gardner 2001). Because large parts of the harbour's biota were affected, the bloom created a natural recolonisation experiment on relevant, i.e., natural scales. This mensurative experiment provided the opportunity to address important ecological questions about large-scale naturally occurring disturbances and the ensuing community recovery and species succession. How long are recovery times for the benthic macroinvertebrate communities after such a disturbance? Does the length of recovery times differ among communities? If so, why are they differing? What are the factors influencing recovery? Are these factors the same in different habitats? If pre-disturbance data exist: are post-disturbance communities different from pre-disturbance communities? Thus, the plankton bloom in 
Wellington Harbour provided the opportunity to contribute to our understanding of naturally occurring large-scale disturbances and their long-term effects on subtidal macrobenthic communities.

Plankton blooms present an increasing threat to coastal ecosystems (Smayda 1990) and thus the likelihood increases for benthic communities to be negatively impacted by such a disturbance. The nature of plankton blooms and their relevance as a disturbance are presented in the next section, which is followed by descriptions of the physical setting of Wellington Harbour and of the toxic bloom that occurred in the harbour in 1998.

\subsection{Plankton Blooms}

Planktonic algae are of crucial importance to aquatic systems as primary producers and as a food source for filter-feeding organisms such as bivalves and many invertebrate and vertebrate larvae. Under certain conditions algae can proliferate to such an extent, that they form dense blooms. In the marine environment plankton blooms occur naturally in open and coastal waters from the tropics to the polar regions. Although optimal bloom conditions vary among species, certain biological, physical and chemical factors have been identified as crucial for bloom initiation. The main factors appear to be a horizontally stabilised and vertically stratified water mass, warm and calm weather with a high irradiance rate, and enhanced inorganic and organic nutrient loading (Paerl 1988; Roelke \& Buyukates 2001). Under certain conditions phytoplankton blooms can turn into disturbances, i.e., they cause damage to aquatic living resources and ecosystems. In such situations, blooms are referred to as harmful algal blooms or HABs (van den Bergh et al. 2002).

Taxa that can form HABs represent considerable physiological and phylogenetic diversity because they include photoautotrophic, mixotrophic or obligate heterotrophic species (Smayda 1997) and even macroalgae (Rafaelli et al. 1998; Blomster et al. 2002). In freshwater, cyanobacteria are the major agents of plankton blooms, many of them displaying toxic properties. In marine systems dinoflagellates, diatoms, silicoflagellates, prymnesiophytes and raphidophytes 
are known to form HABs, with dinoflagellates being the most noxious group (Paerl 1988). Approximately 300 phytoplankton species can occur in such high numbers that they discolour the surface of the sea and form 'red tides'. Approximately 40 species are actually toxic or harmful as a result of, for instance, their phycotoxins or the physical damage they can cause to other organisms such as destruction of gill structures in fish (Hallegraeff 1993).

The spatial and temporal scales of HABs and therefore the scales of the negative impacts they can cause on other communities are difficult to assess. The spatial scale seems to range from blooms being localised to, for instance, small bays (Southgate et al. 1984) and river mouths (Chang 1999b) to extending over several $1000 \mathrm{~km}^{2}$ (Granéli et al. 1991; Tester \& Steidinger 1997). Whereas most small-scale-HABs seem to be ephemeral, lasting only a few weeks due to nutrient depletion or changes in weather or current conditions (e.g., Rhodes et al. 1993), some blooms last for many months (NCCOS 2003).

HABs can impact on aquatic organisms, human health and aquaculture enterprises in several ways. Some bloom organisms do not produce toxins but physically damage or clog gills of finfish and bivalves. Such blooms are detrimental to aquaculture systems and can lead to substantial financial losses (e.g., Chang et al. 1991). Toxic plankton blooms, in particular blooms of neurotoxin-producing genera such as the dinoflagellate Karenia (Chang et al. 1998b), can impact negatively on benthic macroinvertebrates and macroalgae. But toxic blooms are also globally responsible for up to 2000 human poisoning incidents annually with a mortality rate of 15\% (Hallegraeff 1993).

Although an extensive literature on phytoplankton blooms exists, the effects of blooms on benthic communities have received little attention so far. On benthic communities, blooms can impact negatively in several ways. Besides their potential toxicity and other detrimental features, algal blooms can exert an additional negative effect when bloom decay sets in. The subsequent bacterial decomposition of the bloom matter and the organisms killed by the bloom (e.g., fishes) can lead to hypoxic and even anoxic conditions at the sediment-water interface (Paerl 1988). Such conditions might result in widespread mortalities of the benthic fauna (Thistle 1981; Diaz \& Rosenberg 1995), and thereby have wider implications with regard to community structure and function (Beukema et al. 1999). Unlike many other disturbances, for instance, storms, pollution or 
sediment disposal, the disturbance caused by a toxic bloom is a discrete event for benthic communities without long-term modifications of the environment such as changes in sediment properties or the build-up of residual toxicants such as heavy metals.

Over the past three decades, the occurrence of HABs has expanded in frequency, intensity and geographic distribution (Smayda 1990). Part of this expansion might be a reflection of the increased scientific awareness (Hallegraeff 1993), which in turn is fuelled by the on-going exploitation of coastal areas through aquaculture. Aquaculture operations act as sensitive 'bioassay systems' for harmful blooms (Hallegraeff 1993), but they can also contribute to localised eutrophication of the water (Gowen \& Rosenthal 1990; Dehadrai 1997). Cargo vessel ballast water (Baldwin 1993; Hayden 1995; McMinn et al. 1997) and the transport of shellfish stock to new areas (Dijkema 1992) have contributed to the geographical spread of harmful algae. However, the main factor contributing to the increase in $\mathrm{HABs}$ is the eutrophication of coastal waters from domestic, industrial and agricultural wastes (e.g., Lam \& Ho 1987; Paerl 1988; Smayda 1990). Hence, the occurrence of harmful algal blooms is spreading and thereby the risk of wide-spread die-offs of benthic macroinvertebrate communities is increasing.

\subsection{Wellington Harbour - The Physical Setting}

Wellington Harbour or Te Whanganui-a-Tara ('The Great Harbour of Tara') is an approximately circular semi-enclosed embayment at the southern end of the North Island, New Zealand $\left(41^{\circ} 16^{\prime} \mathrm{S}, 174^{\circ} 51^{\prime} \mathrm{E}\right.$, Figure 1.1). The harbour covers an area of ca. $85 \mathrm{~km}^{2}$ with a mean water depth of $14 \mathrm{~m}$ and a maximum depth of $32 \mathrm{~m}$ south-west and south-east of Matiu-Somes Island (Heath 1977). It is linked to Cook Strait via the ca. $8 \mathrm{~km}$ long Entrance Channel in the south. Tides in the harbour are semi-diurnal and of small amplitude (max. $1.5 \mathrm{~m}$ ). The tidal exchange is estimated to be $60 \times 10^{6} \mathrm{~m}^{3}$ or $4.5 \%$ of the total harbour volume. On average, the harbour waters get exchanged every 11 days 
(Maxwell 1956). The flood tide flows clockwise around the harbour, whereas the weaker ebb tide flows anti-clockwise, thus the predominant flow is clockwise (Brodie 1958).

The Hutt River, which enters in the north-east corner of the harbour, is the main freshwater contributor with an average daily flow of $23 \mathrm{~m}^{3} \mathrm{~s}^{-1}$ (Goff 2000). This freshwater forms a lens over the more saline harbour water and extends to about $5 \mathrm{~m}$ depth as far south as Matiu-Somes Island (Booth 1975). Generally, the harbour waters are well mixed and the salinity of the central basin seldom falls below $30 \mathrm{ppt}$, although surface salinities can be as low as 25 ppt due to high freshwater inflow. Seawater temperatures of the harbour are generally isothermal with a minimum of $8-9^{\circ} \mathrm{C}$ in winter (July/August) and a maximum of $18-19^{\circ} \mathrm{C}$ in summer (January/February) (Booth 1975).

Sediments of the harbour consist mainly of clay, silt, sand and shell fragments. The deeper parts of the central basin are covered by a thick layer of silt and clay with a carbonate content of 10\% (Van der Linden 1967; Carter 1977). Coarser sediments are restricted to the harbour entrance (Carter 1977) and nearshore areas like Oriental Bay (Wear 1997). According to Goff (1997), sediment deposited in the harbour derives mainly from the greywacke bedrock that covers most of the Wellington region with the Hutt River and its catchment being the foremost sediment contributor. Most of the fine suspended material, however, is transported directly out of the harbour (Van der Linden 1967). Sedimentation rates in the harbour vary and have doubled in the last 50 years principally due to urban growth and changing land use (Goff 2000). Wellington's extreme wind patterns and their influence on the current patterns are more influential in the deposition of sediments than the tidal patterns (Goff 2000). In the harbour entrance the transport of the predominantly sandy bedload is directed northward due to the predominantly southern swell moving onto the Wellington shelf (Van der Linden 1967; Carter \& Lewis 1995). Most of this sand is deposited at the north margin of the so-called Eastbourne platform, a broad shallow platform on the eastern side of the Entrance Channel (Carter 1977). 


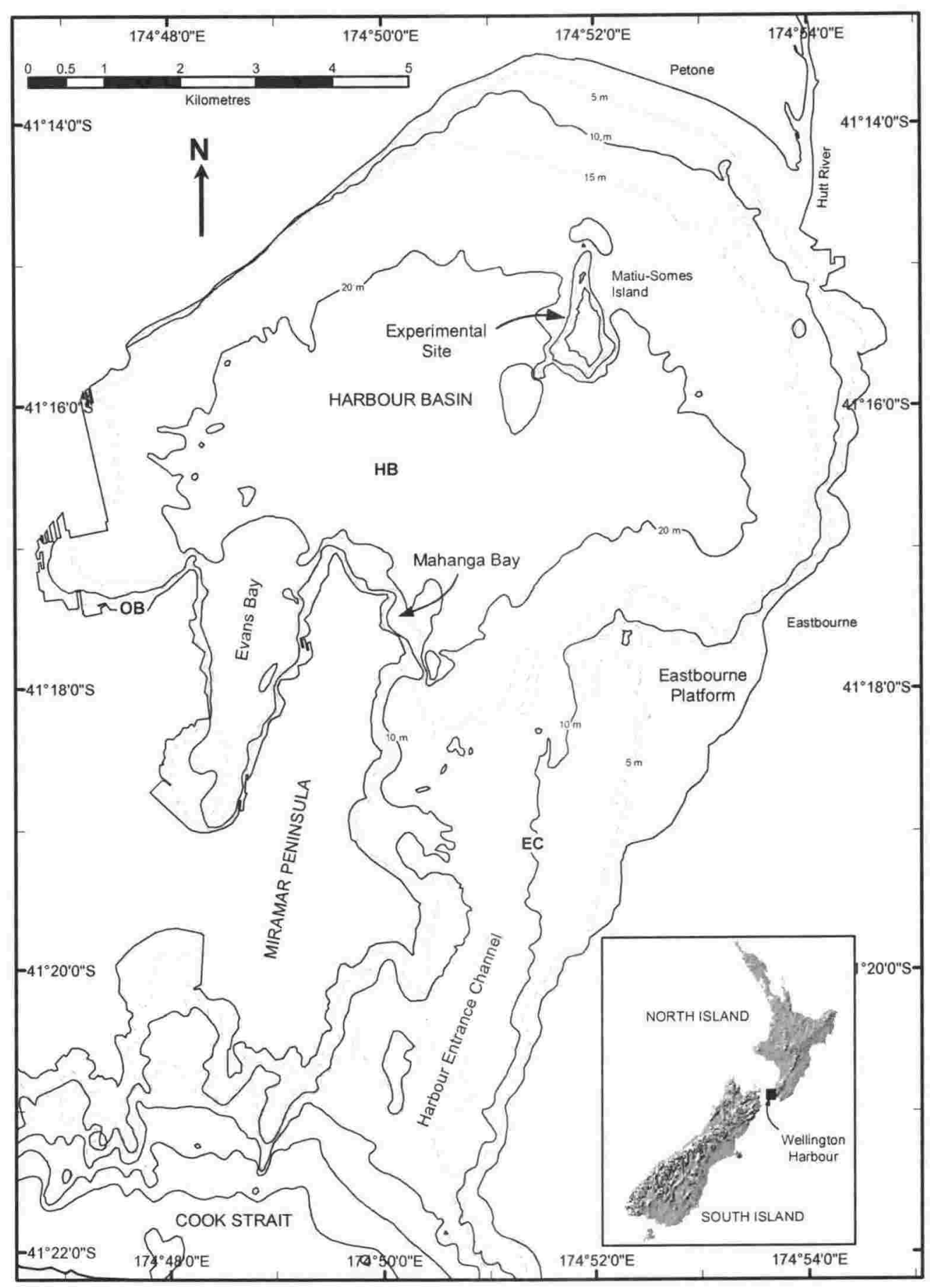

Figure 1.1 Chart of Wellington Harbour, North Island, New Zealand with sampling sites of Chapter 2 and Chapter 3 marked. $\mathrm{HB}=$ Harbour Basin, $\mathrm{OB}=$ Oriental Bay and $\mathrm{EC}=$ Entrance Channel. 
Maxwell (1956), Booth (1975) and recently Helson (2001) suggested that Wellington Harbour is at least partially isolated from Cook Strait. These authors ascribed this separation to the different hydrographic regimes of Cook Strait and Wellington Harbour. The water in the harbour tends to be richer in nutrients, contains more chlorophyll $a$ and shows higher variations in temperature, whereas Cook Strait water is derived from three oligotrophic currents. Such partial isolation of the hydrographic regime of Wellington Harbour is of importance in the context of the origin of the initial benthic recolonisers in the harbour after a large-scale disturbance such as the toxic plankton bloom, which occurred in 1998.

\subsection{The 1998 Wellington Harbour Toxic Plankton Bloom}

In early March 1998 a toxic bloom of the naked dinoflagellate Karenia brevisulcata (Chang) Hansen \& Moestrup (Djaugbjerg et al. 2000), formerly Gymnodinium brevisulcatum (Chang 1999a), occurred in Wellington Harbour, New Zealand, leading to high mortalities among the harbour's marine biota (Chang 1998a). It was the first time that an algal bloom of such devastating extent had been recorded in Wellington Harbour. In early February 1998, cell concentrations of $K$. brevisulcata in the harbour rose and reached bloomconcentrations in mid-March with about $2.0 \times 10^{7}$ cells $1^{-1}$. Highest concentrations recorded in the harbour ranged from ca. $3.3 \times 10^{7}$ cells $1^{-1}$ at

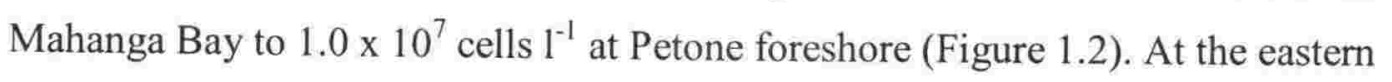
side of the harbour entrance, cell concentrations were slightly lower with $3.7 \mathrm{x}$ $10^{6}$ cells. At Turakirae Head, just south of the harbour entrance, cell concentrations of $6.4 \times 10^{4}$ cells $1^{1}$ were measured (Chang et al. 1998a). The bloom was short-lived and by the end of March, cell concentrations had already fallen by one to two orders of magnitude.

The outbreak of $K$. brevisulcata in Wellington coincided with unusually high seawater temperatures $\left(3^{\circ} \mathrm{C}\right.$ above long term mean) related to the El Niño Southern Oscillation (Uddstrom \& Oien 1999) and abnormal calm wind patterns, 
which possibly helped to establish a sufficiently stable water column (Chang et al. 2001).

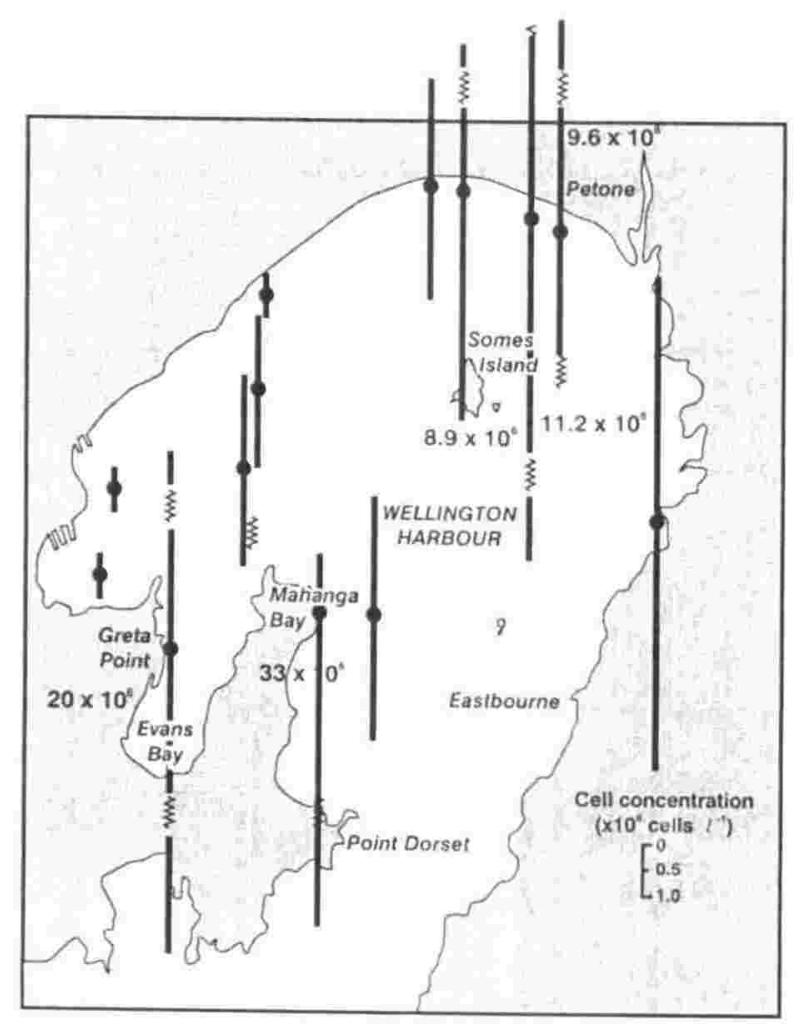

Figure 1.2 Surface cell concentrations of Karenia brevisulcata in Wellington Harbour on 11.03.1998. Bars represent surface cell concentrations. From Chang et al. (2001) with friendly permission of the authors.

Marine life of all trophic levels began to die by the end of February 1998. Underwater video records taken at the end of March 1998 revealed dead polychaetes, molluscs, echinoderms, crustaceans and many fishes littering the harbour floor. Infaunal polychaetes and bivalves had emerged to the substratum surface and many sublittoral species had migrated to the intertidal zone. There was little evidence of bioturbation, an indication that infaunal species were alive and active, in the immediate post-bloom period, and the seabed in 5-20 $\mathrm{m}$ water depth was coated by a yellow-green film of dead and dying phytoplankton (Wear \& Gardner 2001). In the weeks following the die-off, large numbers of dead and dying molluscs were washed up, predominantly, on the northern and eastern shores of the harbour. The yet undescribed neuro-toxin produced by $K$. 
brevisulcata is highly potent (Chang, NIWA, pers. comm.), and brine shrimps, paua larvae, polychaetes, juvenile turbots and seahorses, as well as micro- and macroalgae, were killed within a few days when experimentally exposed to the toxin (Chang et al. 1998b). Humans were also affected by the bloom and complained of respiratory distress, and eye and skin irritations (Chang 1998a).

Wear and Gardner (2001) described the immediate impact of the bloom on the benthic communities by comparing unpublished base-line data (Haddon \& Wear 1993; Wear \& Anderlini 1995) of six subtidal and one intertidal sampling station in the harbour with data obtained in May 1998 shortly after the bloom. The recovery process of benthic communities was followed for 12 months at nine subtidal stations (Gardner \& Wear submitted). The results of the aforementioned studies showed that the impact on benthic communities was spatially variable. Stations where benthic communities were most impacted were all characterised by medium/fine sand to silt, high levels of organic carbon content and low levels of wave and current energy on the bottom. Benthic communities that were apparently least affected by the bloom occurred at locations which were more sandy, had a lower organic carbon content and were situated in more hydrodynamically exposed areas (Wear \& Gardner 2001; Gardner \& Wear submitted).

\subsection{Aims of this study}

The aim of this dissertation is to further our understanding of the effects of severe naturally occurring disturbances on subtidal benthic macroinvertebrate communities. The occurrence of a large-scale toxic plankton bloom in Wellington Harbour in 1998 created the opportunity to study such a disturbance and its long-term effects on soft-sediment benthic communities and to ask fundamental ecological questions about community recovery and species succession. This aim will be achieved with the following objectives: 
1. To examine the long-term ( $>1$ year post-disturbance) effects of a naturally occurring severe disturbance i.e., a toxic phytoplankton bloom, on subtidal macroinvertebrate communities in Wellington Harbour, New Zealand, and to elucidate the role of some of the factors that influence the recovery processes via a mensurative approach (Chapter 2).

2. To investigate the short-term $(\sim 1$ year $)$ recovery processes of shallow subtidal benthic macroinvertebrate communities in an energetic hydrodynamic regime following an induced disturbance via a manipulative experiment (Chapter 3).

3. To summarise and discuss the results of the mensurative and the manipulative experiment in the context of the current understanding of the role of disturbance in the marine environment, and propose future research objectives (Chapter 4). 


\section{Chapter 2}

\section{Long-term Effects of a Toxic Algal Bloom on Subtidal Soft-Sediment Macroinvertebrate Communities in Wellington Harbour, New Zealand}

\subsection{Introduction}

Benthic assemblages in the marine environment are subjected to a range of natural and anthropogenic disturbances, which vary in their frequency, extent and magnitude (Thistle 1981). Indeed, disturbances have been found to play an important role in the structuring of communities (Connell \& Slayter 1977) in a variety of benthic habitats such as rocky shores (Dayton 1971; Underwood 1999), intertidal mud flats (Reise 1985), sandy beaches (Wetzel et al. 2002) and deep-sea sediments (Grassle \& Sanders 1973). Johnson (1973) suggested that marine benthic communities are "continually varying in response to a history of disturbance... and therefore different parts are at different levels of succession'. Consequently, benthic communities are often viewed as a mosaic of patches caused by previous disturbances (Thistle 1981; Thrush \& Whitlach 2001).

Many naturally occurring and anthropogenic disturbances, which operate on various spatial and temporal scales (Whitlach et al. 1998b) and their effects on benthic communities have been described (Sousa 2001 and references therein). On a small spatial scale $\left(<1 \mathrm{~m}^{2}\right)$ most disturbances are caused by foraging movements of benthic predators, e.g., crustaceans (Thrush 1986b; Warwick et al. 1990) and rays (VanBlaricom 1982), or sediment reworking by infaunal deposit feeders, e.g., enteropneusts, ophiuroids and echiurans (Flint \& Kalke 1986). Meso-scale disturbances $\left(1-100 \mathrm{~m}^{2}\right)$ are usually due to natural physical disruption of the sediment by, for instance, tidally induced sand movement (Grant 1983) or by anthropogenic actions like bottom fishing and dredging (Bonsdorff 1980; Peterson et al. 1987b; Thrush et al. 1995). However, biotic agents such as the foraging of marine mammals can also operate at this meso- 
scale (Oliver et al. 1984). Natural physical processes are generally responsible for large-scale disturbances $\left(100 \mathrm{~m}^{2}-\mathrm{km}^{2}\right)$, such as storms (Eagle 1975; McCall 1977; Dobbs \& Vozarik 1983; Harris et al. 1984; Livingston et al. 1999), icescour (Peck et al. 1999), exceptionally low winter temperatures (Dittmann et al. 1999), and anoxic or hypoxic events (Hall 1994; Norkko \& Bonsdorff 1996a; Powilleit \& Kube 1999; Wetzel et al. 2002). But human activity, such as trawling (Churchill 1989), spoil and mining waste disposal (Probert 1975; Kline \& Stekoll 2001), and organic or oil pollution (Pearson \& Rosenberg 1978; Warwick \& Clarke 1991), can also induce large-scale disturbances.

Another naturally occurring disturbance that can influence benthic communities results from toxic algal blooms. Blooms can vary in their effects on benthic communities, but wide-spread mortality of pelagic and benthic organisms is often a consequence of a bloom formation (Hallegraeff 1993). Such mortality can be caused by the direct effect of the toxins on the organisms (Chang et al. 1998c), by clogging of respiratory structures, or by hypoxic or even anoxic conditions at the sediment-water interface due to the decomposition of those organisms killed directly by the bloom (Simon \& Dauer 1972). Organic enrichment of the sediment caused by the amassed dead organisms including settling dead or dying phytoplankton cells, may influence the subsequent recolonisation by benthic organisms of the affected habitat (Thistle 1981; Smith 1985; Snelgrove 1992).

Although much has been reported on harmful algal blooms and their effects on human health, aquaculture and tourism (Hallegraeff 1993; Van Dolah et al. 2001; van den Bergh et al. 2002), literature on the effects on benthic communities and their subsequent recovery is rather sparse. Simon \& Dauer (1972) and Dauer \& Simon (1976) reported the defaunation and subsequent repopulation of a subtropical intertidal sandy habitat in upper Tampa Bay, Florida, caused by an outbreak of the dinoflagellate Gymnodinium breve (Davis). Annual defaunation, presumed to be due to anoxia, and the recolonisation patterns of the soft-sediment benthic communities have also been described for other parts of Tampa Bay (Santos \& Simon 1980a, b). In 1979, the dinoflagellate Gyrodinium aureolum, Hulburt caused dramatic mortalities among a wide variety of taxa, including littoral floral and faunal species, in Dunmanus Bay, Ireland (Southgate et al. 1984). An outbreak of the prymnesiophycean 
Chrysochromulina polylepis Manton \& Parke over much of the Skagerrak and Kattegat in 1988 resulted in massive damage to farmed and wild fish, rocky shore algae and animals, and in significant reductions in abundance and number of species in benthic communities down to $180 \mathrm{~m}$ water depth along the southern Norwegian coast (Olsgard 1993). Gjösæter et al. (2000) evaluated the long-term effects of the same bloom, especially in regard to population dynamics of softbottom benthic communities and local fish species such as cod.

In February and March 1998 Wellington Harbour, New Zealand experienced an unprecedented outbreak of the toxic dinoflagellate Karenia brevisulcata (Djaugbjerg et al. 2000). The bloom affected almost all biota in the harbour, resulting in high mortalities of fish, benthic epi- and infauna and even algae (Chang et al. 1998a, b). Unusually high water temperatures related to the El Niño Southern Oscillation and abnormal calm wind patterns were important factors in triggering the bloom in the harbour (Chang et al. 2001). According to Chang et al. (2001) the bloom originated along the northern east coast of the North Island and was transported south with the East Auckland and the East Cape currents. Marine life in Wellington Harbour began to die off by the end of February 1998 with cell concentrations of $K$. brevisulcata peaking in mid-March with ca. $2.0 \times 10^{7}$ cells $1^{-1}$. In early April, cell concentrations had already fallen to $5.0 \times 10^{2}$ cells $1^{-1}$. By the end of March large numbers of dead fish, crustaceans, molluscs, polychaetes and echinoderms covered the seafloor in northern parts of the harbour and hardly any indication of bioturbation was evident (Wear \& Gardner 2001). Animals showed behavioral adaptations typical for anoxic conditions as described by Diaz \& Rosenberg (1995), i.e., deeper burrowing polychaetes and molluscs emerged out of the substrate and sublittoral species moved into the low intertidal zone.

The immediate impact of the bloom on the benthic macroinvertebrate communities and the first year of community recovery were investigated by Wear \& Gardner (2001) and Gardner \& Wear (submitted) by comparing their results to unpublished pre-bloom data (Haddon \& Wear 1993; Wear \& Anderlini 1995). The authors' findings indicated that the impact of the bloom on the benthic communities was spatially variable. Communities of fine sand/silt sediments in depositional areas showed higher reductions in mean abundance and 
mean number of species than communities of sandy sediments being exposed to relatively energetic current regimes. Gardner \& Wear (submitted) concluded that community recovery in Wellington Harbour proceeded relatively rapidly and that the recovery trajectories would lead to a state consistent with the pre-bloom state.

While many experimental studies have mimicked disturbances on small spatial and temporal scales (Zajac \& Whitlach 1982a, b; Thrush et al. 1992; Norkko \& Bonsdorff 1996b; Lu \& Wu 2000), results of such studies cannot be applied to a larger scale without problems, because factors controlling benthic recolonisation and succession are likely to be scale-dependent (Thrush et al. 1996; Whitlach et al. 1998b). Conducting replicated field experiments on relevant scales is obviously limited by logistical and ethical restraints. Thus, the possibility to conduct a natural (or mensurative) experiment (Hurlbert 1984) afforded by the occurrence of a harmful algal bloom is a rare opportunity to widen our understanding of macrobenthic recolonisation and succession processes following a large-scale natural disturbance. The seizing of such an opportunity is especially important in the context of an apparent global increase in the occurrence of toxic algal blooms (Hallegraeff 1993).

Underwood et al. (2000) stressed the importance of well-designed and carefully analysed mensurative experiments in testing a priori hypotheses about ecological patterns. Mensurative experiments obviously cannot provide evidence about underlying causes or processes of observed changes in population structure. However, they are valid experimental tests - if carried out in a quantitative hypothesis-testing framework - and therefore can lead on to manipulative experiments to gain insight into causes and processes (Underwood et al. 2000).

The Wellington Harbour bloom affords the unique opportunity to document the long-term effects of a toxic bloom on the subtidal benthic communities of a large (ca. $85 \mathrm{~km}^{2}$ ) semi-enclosed embayment in a temperate region. Therefore, a three-year study was instigated, following the immediate evaluation of post-bloom effects (Wear \& Gardner 2001; Gardner \& Wear submitted), which aimed to test the following hypothesis: Macroinvertebrate community composition of a subtidal soft-sediment habitat continues to change 
$>1$ year after a toxic algal bloom, and that such change is site-specific, i.e., sites vary in their development of community composition depending upon their degree of exposure to different hydrodynamic conditions. In order to test the aforementioned hypothesis patterns of community change were followed at three sites of contrasting hydrodynamic conditions in Wellington Harbour during the period of August 1999-May 2001.

\subsection{Material and Methods}

\subsubsection{Wellington Harbour - The Physical Setting}

A detailed description of Wellington Harbour's physical setting including a chart is provided in Chapter 1, section 1.3.

\subsubsection{Sampling Design}

\section{Sampling Sites}

Several authors have stressed the importance of control sites in experimental design and monitoring programmes, e.g., Hurlbert (1984), Clarke \& Green (1988), Underwood (Underwood 1992, 1996, 2000) and Hewitt et al. (2001). Such sites act as temporal or spatial 'controls' or references and are not to be affected by the impact to be studied, but match as closely as possible in terms of physical, chemical and biological variables to the impacted sites so that comparisons can be drawn. In the context of the present study it was impossible to find control sites fulfilling the above-mentioned criteria within Wellington Harbour, because the toxic bloom had affected the whole of the harbour. Even in the Entrance Channel, which links the harbour to Cook Strait, concentrations of Karenia brevisulcata reached $7.6 \times 10^{5}$ cells $1^{-1}$ in March 1998 (Chang et al. 2001). Thus, this region could not be used as a control site. 
Hewitt et al. (2001) pointed out the importance of the spatial scale of an impact, which determines not only the size of the monitored impact (and any control) sites, but also the appropriate proximity of control to impact sites. In the context of the present study this would have meant several control sites would have been located within other natural harbours similar to Wellington Harbour. Such a sampling programme would have been beyond the scope and resources of this project.

The sampling sites had been chosen by Wear \& Gardner (2001) and are based on contract research work conducted prior to 1998. For more details see Wear \& Gardner (1998). The data from these research contracts used in the present study are referred to as pre-bloom data.

Because the immediate impact of the bloom on the harbour's benthos (Wear \& Gardner 2001) and the first year of post-bloom benthic recolonisation in the harbour had already been studied (Gardner \& Wear submitted), I chose seven of these authors' sites to investigate the long-term impacts of the toxic bloom of 1998 on the benthic community to ensure continuity among the studies. However, due to logistical constraints, it was not possible to sample all seven sites for the full duration of the study. Thus, only data from three sites, chosen with regard to their degree of exposure to different hydrodynamic conditions, were analysed and considered here.

\section{Harbour Basin (HB)}

This site is located in the central basin of Wellington Harbour $\left(41^{\circ} 15\right.$. $\left.85^{\prime} \mathrm{S}, 174^{\circ} 50.02^{\prime} \mathrm{E}\right)$. HB is Station NDS-3 of Wear \& Anderlini (1995) and Station 2 of Wear \& Gardner (2001) and Gardner \& Wear (submitted). Prebloom data are the stations NDS-1 to NDS-5 of Wear \& Anderlini (1995). Water depth is $20 \mathrm{~m}(\mathrm{CD})$. The site is characterised by a sediment consisting mainly of silt and clay fractions with an organic matter content of 4-5\%, and low levels of current and wave energy (Wear \& Gardner 2001). 


\section{Oriental Bay $(O B)$}

Oriental Bay is a shallow site $(1.8 \mathrm{~m} \mathrm{CD})$ approx. $100 \mathrm{~m}$ offshore from an inner city beach in the western part of the Harbour $\left(41^{\circ} 17.51^{\prime} \mathrm{S}, 174^{\circ} 47.70^{\prime}\right.$ E). OB is Station 5 of Wear \& Gardner (2001) and Gardner \& Wear (submitted). Stations selected for pre-bloom data are the subtidal endpoints of the three transects of Wear (1997a) and the endpoints of the transects A and B of Wear (1997b). The substrate at OB consists of compacted fine and coarse sand with shell debris and scattered small pebbles (Wear 1997) with a comparatively low organic matter content of $c a .1 .4 \%$. Oriental Bay is exposed to periods of pronounced wave energy mixing due to the prevailing northerly winds and the shallowness of the site (Gardner \& Wear submitted).

\section{Entrance Channel (EC)}

This site is approximately in the middle of the north-south axis of the Entrance Channel $\left(41^{\circ} 19.04^{\prime} \mathrm{S}, 174^{\circ} 51.24^{\prime} \mathrm{E}\right)$ with a water depth of $11.3 \mathrm{~m}$ (CD). EC is Station HM25 of Haddon \& Wear (1993) and Station 4 of Wear \& Gardner (2001) and Gardner \& Wear (submitted). The five pre-bloom stations randomly chosen by Wear \& Gardner (2001) are stations 14, 15, 16, 17 and 25 of Haddon \& Wear (1993). The sediment is mobile fine to medium sand with a low organic matter content of approx. $1.5 \%$ (Wear \& Gardner 2001; Gardner \& Wear submitted). During southerly storms the substrate can be exposed to strong current and wave energy leading to substantial sediment movement (Carter 1977; Carter \& Lewis 1995).

\section{Sampling Times}

The objective of the present study was to determine the long-term effects of a toxic bloom on the macroinvertebrate community, i.e., year-to-year changes in species composition, which are presumed to result from recolonisation and succession as the benthic community recovers from the bloom. However, seasonal variability in species abundance had to be accounted for within the year- 
to-year changes because this small-scale variability can confound larger-scale comparisons (Underwood 1991; Morrisey et al. 1992). Sampling each site once a year could have led to serious over-estimation (e.g., after a settlement event) or under-estimation (e.g., after high mortalities due to adverse weather conditions) of abundances. Hence, $\mathrm{OB}$ and EC were sampled every three months. Time intervals of three months were deemed to represent 'seasons' and sampling was carried out in August (winter), November (spring), February (summer) and May (autumn). Sampling commenced in August 1999 and finished in May 2001. At $\mathrm{OB}$, it was not always possible to retrieve samples at the intended time due to adverse weather conditions, logistic reasons or positioning errors. However, sampling occasions still conformed to the concept of 'season'.

Wear \& Gardner (2001) stated that the HB macroinvertebrate community was strongly impacted by the toxic bloom (low numbers of individuals and species post-bloom). Therefore, samples were taken monthly at this site from August 1999 to August 2000 in order to obtain a detailed picture of the community dynamics (e.g., potential settlement events). Preliminary multivariate analyses of the monthly macroinvertebrate abundance data revealed only seasonal differences, and thus for the period August 2000 to May 2001, it was decided thereafter to adopt the 'seasonal' sampling regime of the $\mathrm{OB}$ and $\mathrm{EC}$ sites.

\section{Sample Replication}

Although Ferraro et al. (1994) and others have suggested that there are statistical and sometimes practical advantages to taking many small sampling units (e.g., hand held cores) instead of few bigger ones (e.g., $0.1 \mathrm{~m}^{2}$ Van Veen grabs), it was decided that in order to aid direct comparison, the sampling protocol already established by Wear \& Gardner (2001) and Gardner \& Wear (submitted), which had been dictated by pre-bloom sampling protocols, would be followed. Five replicate samples of $0.1 \mathrm{~m}^{2}$ Van Veen grabs were taken on each sampling occasion. However, the possibility of sub-sampling was investigated by taking five Van Veen grab samples in September 1999 from the Harbour Basin 
site. Two sediment cores $(10 \mathrm{~cm}$ diameter, $20 \mathrm{~cm}$ penetration depth) were obtained per grab (total of ten core sub-samples). The contents of each of the core samples and of each of the remainder of the grab samples were processed and identified separately. Rarefaction curves were plotted to compare the number of cores/grabs needed to reach the same sampling efficiency (number of species) as a single Van Veen grab. Results indicated that the use of only two cores per grab would result in a high degree of under-sampling of species when compared with the whole $0.1 \mathrm{~m}^{2}$ grab content. More core samples could not be retrieved per grab due to the limiting size of the opening flaps of the grab. Because of this species under-representation, it was decided not to adopt the sub-sampling method, a decision which also made possible a comparison with the pre- and initial post-bloom samples (Wear \& Gardner 2001; Gardner \& Wear submitted). Best-fit cumulative curves (cumulative number of new, i.e., previously unsampled, species plotted against number of grabs) were used to calculate the necessary number of grab samples needed to sample the macrofauna representatively without under-sampling the rarer species (e.g., Wear \& Gardner 2001). The curves indicated that by using four replicates the resulting loss of species would be negligible since the curve would still be in the upper $10 \%$ of the asymptote (Appendix 2). Hence, although five replicate grabs were taken, only four of them (randomly chosen) were used in the present analyses.

\subsubsection{Field Sampling}

Sampling was conducted from the research vessel 'Raukawa Challenger' between August 1999 and May 2001. To relocate the sampling sites differential GPS with a nominal accuracy of $\pm 2.0 \mathrm{~m}$ was used. Samples of the seabed were taken with a Van Veen grab (surface area $0.1 \mathrm{~m}^{2}$ ) at the sites HB and EC. The Van Veen grab is a standard device for sampling benthic macroinvertebrates recommended by ICES (Rumohr 1990) due to its comparative reliability and simplicity of handling at sea. Its 'bite' is near vertical (Gallardo 1965) and the grab is assumed to obtain undisturbed samples. Penetration depth depends on sediment type and hence the grab performs well in muddy sediments. For the 
compacted fine sand at the shallow $O B$ site the grab could not be used. At this site divers collected sediment by scooping it from a $0.1 \mathrm{~m}^{2}$ area (substrate depth of $\sim 100 \mathrm{~mm}$ ) into containers. On being winched on board, separate sediment subsamples for organic matter content (ca. $25 \mathrm{~g}$ ) and grain size analyses (ca. $100 \mathrm{~g}$ ) were taken from the undisturbed surface of the grab sample or diver-retrieved container sample. The remaining content of each Van Veen grab was then transferred to a 201 container and sample volume estimated (samples with less than 51 volume were rejected due to their likely substrate penetration depth of $<200 \mathrm{~mm}$ ). Sample containers were covered with a lid, transported to the Island Bay Marine Laboratory and samples processed immediately. After a plankton bloom, organic enrichment of the sediment can be expected due to sedimenting phytoplankton cells and amassing dead and dying organisms killed by the bloom (Simon \& Dauer 1972; Pearl 1988; Hallegraeff 1993; Rhodes et al. 1993), hence organic matter content samples ( $\mathrm{n}=3$ per site) were taken every time biological samples were obtained. Samples for grain size analyses were taken twice a year $(\mathrm{n}=1$ per site).

Additionally, monthly plankton samples $(n=3)$ were taken from the Harbour Basin site between January and November 2000 using a WP2 freefall net with a mesh size of $125 \mu \mathrm{m}$. Samples were fixed in $5 \%$ buffered formalinseawater solution (buffer: borax). The reason for taking plankton samples was to relate the larval recruitment pool in the plankton to benthic settlement processes. Unfortunately, time constraints prohibited the identification of the contents of the plankton samples. These samples remain stored in the Island Bay Marine Laboratory for potential future analyses.

\subsubsection{Laboratory Analysis}

Macroinvertebrate samples were washed gently with seawater through stacked $500 \mu \mathrm{m}$ and $1000 \mu \mathrm{m}$ mesh sieves at the Island Bay Marine Laboratory. Individual fractions were kept separate. Unless otherwise stated, the analyses contained in this chapter were carried out on the combined fractions (500 $\mu \mathrm{m}$ $+1000 \mu \mathrm{m})$. 
Although the initial post-bloom samples (Wear \& Gardner 2001; Gardner $\&$ Wear submitted) were washed through $800 \mu \mathrm{m}$ mesh, stacked sieves with 500 and $1000 \mu \mathrm{m}$ mesh diameter were used in the present study. Considering that one of the objectives of this study was to determine benthic recruitment following a disturbance, small individuals are expected to be an important component of the samples. Washing the samples through either an 800 or $1000 \mu \mathrm{m}$ mesh would have resulted in the loss of these small individuals. By using 500 and $1000 \mu \mathrm{m}$ mesh, results of the present study could also be compared with other studies since these two mesh sizes are recommended for, and most commonly used in, benthic studies (Ferraro et al. 1989; Rumohr 1990; 1994; James et al. 1995).

All material retained in the sieves was fixed with a $5 \%$ borax-buffered formalin-seawater solution for a minimum period ( 24 hours) before it was washed in freshwater and transferred to $70 \%$ ethanol for storage. Rose Bengal was added, which stains pink any recently living organic matter, to aid the sorting process.

Sorting was carried out under a dissecting microscope (either Olympus SD 30 with magnification $10 \times 3$, or Zeiss 475052 with magnification $10 \times 0.8$ 5.0). For species identification, the latter microscope and a Zeiss compound microscope were used. Specimens were identified to lowest possible taxonomic level following recommendations of Olsgard et al. (1998) for baseline studies and ecologically orientated surveys. In some instances, identification was based on 'morphospecies', i.e., morphologically distinct individuals were treated as distinct species. A reference collection was established while identifying the samples. For difficult taxa, especially polychaetes, expert help was sought. The sampling regime in this study did not allow for the quantitative sampling of nematodes and nemerteans. The latter especially tend to fragment, which makes it difficult to count and identify them. Therefore these two groups were omitted from analysis. Literature used in species identification and a list of taxonomical experts consulted is given in Appendix 1.

For organic matter content analysis, sediment samples were gently homogenised after obvious organisms had been removed. Samples were dried for $3 \mathrm{~d}$ at $60^{\circ} \mathrm{C}$ and their dry weight taken before ashing them in a muffle furnace 
for 24 hours at $450^{\circ} \mathrm{C}$. The ash-free dry weight was recorded and the organic matter content was calculated by subtracting the ash-free dry weight from the dry weight (Holmes \& McIntyre 1984).

For grain size distribution analysis, sediment samples were dried at $60{ }^{\circ} \mathrm{C}$ for $3 \mathrm{~d}$, weighed and washed gently through a set of stacked Wentworth grade sieves (Endecott) to a lower limit of $63 \mu \mathrm{m}$. The separate fractions were re-dried for $3 \mathrm{~d}$ at $60{ }^{\circ} \mathrm{C}$ before retaking their weight (Holmes \& McIntyre 1984). All weights were taken using an Ainsworth AC-series balance with an accuracy of $\pm 0.0001 \mathrm{~g}$.

Mean grain size, sorting coefficient, skewness, kurtosis and granulometry were calculated for each sample using the Grain-Size 1-2 software programme (Barrett \& Brooker 1989) using Folk \& Ward's indices (Folk \& Ward 1957).

\section{Pre-bloom Samples}

At $\mathrm{HB}$ and $\mathrm{EC}$ quantitative pre-bloom data exist whereas the $\mathrm{OB}$ prebloom data is qualitative. Re-identification of existing samples (HB and EC) was not possible due to samples being partially dried-up.

\section{Initial Post-Bloom Samples}

Although samples from the initial recolonisation process after the toxic bloom (May 1998-March 1999) have been analysed by Gardner \& Wear (submitted), the authors kindly permitted the re-identification of those samples to standardise the taxonomy between their study and the present work (Harbour Basin 14, Oriental Bay 15 and Entrance Channel 15 samples).

\subsubsection{Data Analyses}

\section{Biological}

Because the present study concentrates on the long-term recovery of the macrobenthic community following the toxic bloom in 1998, most analyses have been conducted using the late-stage post-bloom data only (August 1999-May 
2001). Some analyses (cluster, MDS ordination, Indices of Multivariate Dispersion and Multivariate Seriation) were done separately for pre- and all postbloom data and late-stage post-bloom data only in order to test whether recovery can also be assessed without reference data.

Data were primarily analysed using the software package Plymouth Routines in Multivariate Ecological Research (PRIMER) version 5.2.4 (Clarke \& Gorley 2001). PRIMER was developed to analyse multivariate community ecology and environmental science data (a multitude of species and environmental variables), which are mainly non-parametric. Unless otherwise stated, Clarke \& Warwick's (2001) recommendations for statistical analyses were followed. A good overview of the statistical background of non-parametric multivariate analyses is given in Clarke (1993). Further statistical tests were performed using STATISTICA (version 6.0: Statsoft, Tulsa, Oklahoma, USA).

\section{Univariate Diversity Indices and Analysis}

Clarke \& Warwick (2001) and others have pointed out that speciesdependent multivariate analyses are more sensitive to discriminating between sites or times of sampling than species-independent univariate diversity indices such as number of species $S$ or Shannon's Diversity $H^{\prime}$. It was decided however, to apply univariate methods to compare their sensitivity with the results of the multivariate methods and also to integrate the results of both methods for a better interpretation of the data.

A wide array of univariate diversity indices is used in the literature and Magurran (1988) and Rosenzweig (1995) provide detailed discussions on the merits and shortcomings of different diversity indices. The PRIMER routine DIVERSE was used to calculate the following indices for each late-stage postbloom replicate sample: total number of individuals $(N)$, total number of species $(S)$, Shannon diversity $H^{\prime}(\ln )$, evenness $J^{\prime}$ (which is derived from $H^{\prime}$ ), Fisher's alpha and Simpson's concentration index $D$, which is used in the form of $-\ln D$. These indices were chosen for several reasons. Some indices are more sensitive towards either the species richness or the evenness component of community structure. Evenness, or equitability, is a measure of how evenly individuals of a 
sample are distributed among different species. Therefore $H^{\prime}$, which is more biased towards species richness, i.e., is more affected by rare species, and $J^{\prime}$, which is more influenced by the evenness component, were chosen. $N, S, H^{\prime}$ and $J^{\prime}$ are widely used despite their sensitivity to sample size (Magurran 1988). Such sensitivity is not desirable when comparing results from studies using different methods and/or different sample sizes. The infrequently used indices Fisher's alpha and Simpson's concentration index $D$ are not influenced by sample size, with Fisher's alpha having good discriminant ability.

The following formula was used to calculate Shannon diversity $H^{\prime}$, which is probably the most widely used diversity index in marine benthic studies:

$$
H^{\prime}=-\sum p_{i} \ln \left(\mathrm{p}_{i}\right)
$$

where $p_{i}=$ proportion of the $i^{\text {th }}$ species. $H^{\prime}$ increases with a greater number of species and a more even distribution among species.

Pielou's evenness $J$ ', equivalent to $E$ elsewhere, e.g., Wear \& Gardner (2001), is derived from $H^{\prime} . J^{\prime}$ is the ratio of observed diversity to maximum diversity:

$$
J^{\prime}=H^{\prime}(\text { observed }) / H^{\prime} \max
$$

where $H^{\prime}$ max is the maximum possible diversity which would be achieved if all species were equally abundant $(\ln S)$. The value of $J$ ' is between 0 and 1.0 with 1.0 indicating a situation where all species are equally abundant.

Fisher's alpha (Fisher et al. 1943) is an index of diversity, being low when the number of species in the sample is low and high when the number of species is high. It assumes a log-series distribution of abundance (majority of species are represented by one individual), but is still a satisfactory measure of diversity when the underlying species abundances do not follow that distribution (Taylor 1978). Alpha is a constant that depends on diversity alone. It can be derived from the formula

$$
\alpha=\frac{N(1-x)}{x}
$$

where $N=$ total number of individuals. The variable $x$ depends on sample size and can be estimated from

$$
\mathrm{S} / N=\{(x-1) / x\} \ln (1-x)
$$

where $S=$ total number of species. In practice $x$ is almost always $>0.9$ and never $>1.0$ (Magurran 1988). 
Simpson's index of concentration (Simpson 1949) is a measurement of the probability of any two individuals drawn at random from an infinitely large community belonging to different species:

$$
D=\sum p_{i}^{2}
$$

where $p_{i}=$ the proportion of individuals in the $i^{\text {th }}$ species. This formula is biased and the corrected sample-size independent formula is:

$$
D=\sum\left(n_{i}^{2}-n_{i}\right) /\left(N^{2}-N\right)
$$

where $N=$ total number of individuals and $n_{i}=$ the number of individuals in the $i^{\text {th }}$ species. At the maximum value of $D=1$, all individuals belong to the same species. At $D=0$, all species have exactly one individual. Since an index that increases with declining diversity is counter-intuitive, the expression $-\ln D$ is used here: as $-\ln D$ increases, so does diversity (Rosenzweig 1995). Simpson's index is sensitive to changes in the abundance of the most common species, but less sensitive to species richness.

To analyse the indices for differences over time at each site, one-way analyses of variance (ANOVA) were performed. Cochran's test and graphical tests (means versus variance, probability plots) were employed a posteriori to test for homoscedasticity and a normal distribution of the data. Results indicated that in most cases data assumptions for ANOVA were not violated. Underwood (1981) pointed out that ANOVA is very robust to departure from normality of data and to homogeneity of variances (albeit less robust), especially when sample sizes are equal.

Variances were found to be heterogeneous for Fisher's alpha for Harbour Basin and Entrance Channel (EC) and Simpson's - $\ln D$ for Entrance Channel. In the case of Fisher's alpha, ANOVA results proved to be non-significant. Hence results are valid despite variances being heterogeneous (Underwood 1981). At EC, ANOVA results for Simpson's $-\ln D$ proved to be significant. Despite the robustness of ANOVA to departure from homogeneity of variances, the result in this case has to be interpreted with caution, since gross heterogeneity of variances can increase the probability of Type 1 errors, i.e., rejection of the null hypothesis of no difference between means when the hypothesis is, in fact, true (Underwood 1981). Tukey's HSD post-hoc multiple range tests were conducted 
to identify the periods of significant differences over time when the ANOVA results proved to be significant $(p<0.05)$.

\section{Multivariate Analyses}

\section{Data Transformation}

In multivariate analyses of ecological data transformation plays a different role than in univariate analyses. Whereas in the latter the choice is a statistical one (mainly to fulfil data assumptions), in the former it is a biological one: how do we wish to weight the effects of common and of rare species? With increasing severity of transformation (from untransformed via square- and fourth-root to presence-absence transformation), the influence of dominant species is down-weighted, whereas rare species gain more influence. Therefore, the degree of transformation chosen is as important to the outcome of analyses as the taxonomic level to which the fauna is identified (Olsgard et al. 1997).

In a recolonisation scenario one would expect the first stages of the recovering community to be dominated by a few opportunistic species and therefore a mild or even no transformation should be used. Gardner \& Wear (submitted) have shown that one year post-bloom, benthic communities in the harbour were recovering with species numbers increasing and individual species contributing less to community dissimilarity with increasing time after the bloom. Their data do not indicate a fauna dominated by a few opportunistic species. For some sites, e.g., Harbour Basin, the number of species was even higher one year after the bloom than before the bloom. Hence, a mild transformation does not seem appropriate for data obtained 18 months beyond the beginning of the recolonisation process. A transformation, which allows for a wider view of the community where the influence of rare species is increased, seems to be more suitable and therefore it was decided to use a fourth-root transformation. Such transformation reduces the effect of numerical dominant species in relation to less dominant species and differentiates between sites with many and few rare species (Clarke \& Green 1988). 
Data were standardised for between-site analyses only, in order to allow for the different sampling method employed at Oriental Bay. Standardisation was performed by dividing the abundance of each species by the total sample abundance and multiplying the value by 100 to give the percentage of total abundance.

For analyses including pre- and post-bloom data, data were aggregated to a higher taxonomic level (order) to allow for potential inconsistencies in species identification between pre- and post-bloom samples (Clarke \& Warwick 2001). In order to accommodate for the different mesh-size used in the initial postbloom samples $(800 \mu \mathrm{m})$, only the $1000 \mu \mathrm{m}$ fraction of the late-stage post-bloom samples (August 1999-May 2001) was used and data were presence-absence transformed (Clarke \& Warwick 2001).

\section{Cluster and Ordination}

Between-sample similarity matrices for abundance data were computed using the Bray-Curtis coefficient (Bray \& Curtis 1957). For detailed discussions on the use of the Bray-Curtis coefficient especially in marine ecology see Field et al. (1982), Clarke (1993) and Clarke \& Warwick (2001) among others. Note, that similarity $S$ and dissimilarity $\delta$ are, as Clarke \& Warwick (2001) put it, 'just opposite sides of the same coin' and are a function of one another according to

$$
\delta=100-S .
$$

The PRIMER routine CLUSTER was used to perform hierarchical agglomerative clustering with group-average linking of the similarity values and produce dendrograms depicting how (dis)similar samples were (Clarke \& Warwick 2001). Non-metric multi-dimensional scaling (MDS) was used to construct ordinations or 'maps' of the samples (PRIMER routine MDS). The inter-sample distances on the MDS plot represent the corresponding dissimilarities between the samples, i.e., the further apart two samples are in the MDS plot, the more dissimilar are their macroinvertebrate communities. Scaling, reflection and orientation are arbitrary for an MDS plot. The successful representation of highdimensional data in a low-dimensional plot is indicated by the stress value. A rule of thumb for interpreting stress levels is: stress $<0.05$, excellent representation; stress $<0.1$, good ordination; stress $0.1-0.2$, still a usable picture 
but too much reliance should not be placed on the details; stress $>0.2$, plots could be dangerous to interpret, compare with dendrogram; stress $>0.35$, samples are effectively randomly placed with no relation to the original similarity ranks. Stress levels tend to rise with increasing number of samples, meaning that data sets composed of many samples are intrinsically more difficult to interpret (have higher stress values) than data sets of few samples.

Both clustering and MDS were carried out for all three sites combined, with and without pre- and immediate post-bloom data (May 1998-March 1999), and for each site separately.

\section{Significance Testing}

To test the null hypothesis of "no difference in the faunal assemblages of the three sites' a one-way analysis of similarity (ANOSIM) was performed on the fourth-root transformed Bray-Curtis similarities of the $>1$ year post-bloom samples (August 1999-May 2001) using the PRIMER programme ANOSIM. ANOSIM (Clarke \& Green 1988) is a non-parametric permutation procedure which compares the rank similarities of replicate samples within sites with the rank similarities of samples between sites. The computed test-statistic $R$ represents the degree of difference between the sites. $R$ can be derived from

$$
\begin{aligned}
& R=\left(r_{\mathrm{B}}-r_{\mathrm{W}}\right) /(M / 2) \\
& \text { and } M=n(n-1) / 2
\end{aligned}
$$

where $r_{\mathrm{B}}$ is the average of rank similarities from all pairs of replicates between sites, $r_{\mathrm{W}}$ is the average of rank similarities among replicates within sites and $n$ is the total number of samples. Theoretically, $R$ can take values between 1 and -1 . $R=1$ when all replicate samples within a group are more similar to each other than to any samples from other groups. If similarities between and within sites are on average the same, $R$ will be approximately zero. The significance of $R$ is then calculated by a permutation test. By arbitrarily rearranging the site labels, further $R$-values are computed (999 permutations out of $\left.(k n) ! /\left[(n !)^{\mathrm{k}} k !\right)\right]$ possible permutations with $n=$ number of samples and $k=$ number of sites). These are compared to the observed $R$-values ( $R_{\text {observed }}$ ). If the null hypothesis of no difference between sites is true, there should be little change between $R_{\text {observed }}$ 


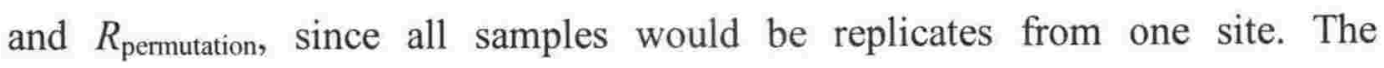
significance level is determined by comparing $R_{\text {observed }}$ to its permutation distribution: if only $t$ of the $T R_{\text {permutation }}$ are as large or larger than $R_{\text {observed, then }}$ $\mathrm{H}_{0}$ can be rejected at a significance level of

$$
100(t+1) /(T+1) \%
$$

where $T$ is the large number of repeated generations of $R_{\text {permutation. }}$.

The programme ANOSIM first calculates a global $R$ for all sites. If the null hypothesis is rejected (i.e., if 'sites are different'), the pairwise comparisons of all sites are performed in the same way as for the global $R$ statistic. This analysis and the two-way crossed ANOSIM analyses were performed using data obtained from Aug 1999-May 2001 (>500 $\mu \mathrm{m})$.

Two-way crossed ANOSIM analyses (Warwick et al. 1990) were carried out for each site separately to test the effect of the factors year (year 1,2,3) and season (spring, summer, autumn, winter) on the faunal assemblages. Samples were allocated to the factors in the following way:

- factor year: 1999 samples = year 1;2000 samples = year 2; 2001 samples = year 3 all post-bloom.

- factor season: spring = September, October, November; summer = December, January, February; autumn = March, April, May; winter $=$ June, July and August.

The two null hypotheses tested were:

- $\mathrm{H}_{0} 1$ : no difference of faunal assemblage among years 1,2 and 3, allowing for any difference among seasons, and

- $\mathrm{H}_{0} 2$ : no difference of faunal assemblages among seasons, allowing for any difference among years.

To test $\mathrm{H}_{0} 1$, an $R$ statistic was calculated for each season separately (as if for a one-way test for the effect of years), and the resulting values were averaged to a global $R$. By re-ordering the labels for the years within each season, $R_{\text {permutation }}$

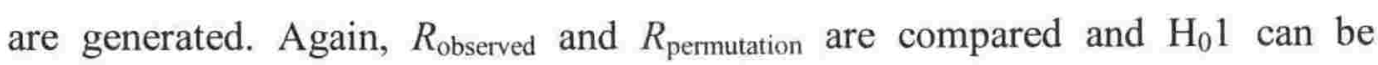
rejected if $R_{\text {observed }}$ is greater than $R_{\text {permutation. Pairwise comparisons were carried }}$ out between the three years. $\mathrm{H}_{0} 2$ can then be tested, allowing for the fact that there are differences between the years (in case $\mathrm{H}_{0} 1$ has been rejected), in the 
same way as just described for $\mathrm{H}_{0} 1$, except that the roles of years and seasons are reversed. A low number of samples (or replicates) influences the significance levels of global tests and pairwise comparisons, because not enough permutations of $R_{\text {permutation }}$ can be generated. Some pairwise comparisons for Oriental Bay and Entrance Channel could not be performed because too few samples were available.

\section{Species Analysis}

The PRIMER routine SIMPER (similarity percentages) was employed to identify the species contributing most to the observed differences in community structure at the three sites in Wellington Harbour. Both the species contributing to the average dissimilarity between groups (discriminatory species) and contributing to the average similarity within groups (typifying species) were identified using the SIMPER routine (Clarke 1993; Clarke \& Warwick 2001).

The starting point for both SIMPER analyses was the Bray-Curtis (dis)similarity matrix between all pairs of between-group samples. For identifying the discriminatory species, the average dissimilarity $\delta$ between all inter-group pairs of group 1 and group 2 samples (every group 1 sample is paired with every group 2 sample) was generated. This average was then broken down into the separate contributions from each species $\delta i$.

For two samples, $j$ and $k$, the contribution of the $i^{\text {th }}$ species, $\delta_{j k}(i)$, to the BrayCurtis dissimilarity $\delta_{j k}$ of the two samples is:

$$
\delta_{j k}(i)=100\left|y_{i j}-y_{i k}\right| / \sum_{i=1}^{p}\left(y_{i j}+y_{i k}\right)
$$

where $y_{i j}$ is the transformed abundance of the $i^{\text {th }}$ species in the $j^{\text {th }}$ sample and $p$ is the number of species. To obtain the average contribution $\delta_{i}$ from the $i^{\text {th }}$ species to the overall dissimilarity $\delta$ between groups 1 and $2, \delta_{j k}(i)$ is averaged over all pairs $(j, k)$ with $j$ in the first and $k$ in the second group. Normally, many pairs of samples $(j, k)$ contribute to the average $\delta_{i}$. The standard deviation $\operatorname{SD}\left(\delta_{i}\right)$ of the $\delta_{j k}(i)$ values is a measure of how consistently a species contributes to $\delta_{i}$ across all such pairs. A good discriminator species not only contributes much to the dissimilarity between the two groups, but also does so consistently. Therefore $\delta_{i}$ 
is large for such a species, but $\operatorname{SD}\left(\delta_{i}\right)$ is small. Thus, the ratio of $\delta_{i} / \operatorname{SD}(\delta i)$ is large. The ten species contributing most to $\delta$ are presented in the result section.

Computing the contribution of each species to the average similarity within a group of samples identifies species typifying this group. The more abundant a species is within a group, the more it will contribute to the withingroup similarity. The average similarity within a group is $S$ and the average contribution of the $i^{\text {th }}$ species is $S_{i}$. The contribution $S_{i}$ is defined by taking the average of $\mathrm{S}_{j k}(i)$ over all pairs of samples $(j, k)$ within a group:

$$
S_{j k}=\sum_{i=1}^{p} S_{j k}(i)
$$

with $p=$ number of samples.

A species typifying a group is found consistently at high abundances in the samples. The similarity of this species should have a low standard deviation $\mathrm{SD}\left(S_{i}\right)$ and thus the ratio $S_{i} / \mathrm{SD}\left(S_{i}\right)$ should be high. The ten species contributing most to $S_{i}$ are presented in the result section. However, the same species can be found to typify more than one group of samples and therefore is not necessarily a good discriminator between two groups of samples. The SIMPER procedure is an explanatory tool only and does not provide a statistical testing framework. Its use is limited to a priori defined groups of samples with confirmed differences in their community structure (statistical tests such as ANOSIM) and only two groups of samples can be compared at a time.

Average similarities and average dissimilarities between the three sites in Wellington Harbour were computed and the discriminatory species identified (species abundance data standardised and fourth-root transformed). Site-specific annual community similarities and site-specific inter-annual dissimilarities were computed. Species contributing most to site-specific annual community structure changes were also identified (discriminatory and typifying species). Species abundance data were unstandardised and fourth-root transformed for site-specific analyses. 


\section{Temporal and Spatial Variability in Assemblage Composition}

Increased variability in the multivariate structure of faunal assemblages has been identified as a sign of perturbation (Warwick \& Clarke 1993). This increase can originate from an increase in the variability of abundances of the same set of species, as well as from changes in the species composition. Univariate diversity indices, due to their inability to recognize species identities, can only detect the former, whereas multivariate analyses exploit both sources of variability. Warwick \& Clarke (1993) have developed the comparative Index of Multivariate Dispersion (IMD) as a measure of this variability. Originally, the index was employed to contrast variability of replicate samples from disturbed sites versus control sites in environmental impact studies, but recently the IMD has been applied successfully as a measure of inter-annual variability in a longterm monitoring programme of Tees Bay and the Tees Estuary in the UK (Warwick et al. 2002).

The Wellington Harbour toxic bloom of 1998 clearly caused an initial disturbance of the benthic communities (Wear \& Gardner 2001). Therefore, the IMD was employed to describe potential spatial and temporal changes in variability in the faunal communities of the three sites studied in the harbour. For spatial differences in variability the relative dispersion is given for each site. Site-specific temporal changes in variability between the pre-bloom samples, years 0 (1998), 1, 2 and 3 were described as relative dispersion for each year. The IMD was determined by pairwise inter-year comparisons of the relative dispersions in order to investigate whether annual variability had changed, i.e., decreased or increased, since the toxic bloom had occurred. The IMD is a pairwise comparison and contrasts the average rank of the similarities of one set of samples $\left(r_{1}\right)$ with the average rank among another set of samples $\left(r_{2}\right)$, having re-ranked the full triangular similarity matrix whereby all between-group similarities are ignored. Thus the IMD can be derived from

$$
\text { IMD }=2\left(r_{1}-r_{2}\right) /\left(N_{1}+N_{2}\right)
$$

where

$$
N_{1}=n_{1}\left(n_{1}-1\right) / 2, \quad N_{2}=n_{2}\left(n_{2}-1\right) / 2
$$

and $n_{1}, n_{2}$ are the number of samples in group one and two respectively. The IMD is standardised to have a maximum value of +1 when all dissimilarities among 
samples of group one are higher than any dissimilarities among samples of group two. When IMD $=-1$, the reverse is the case. Values near zero indicate no difference between the two groups.

For the comparison of several groups (e.g., three sites) a dispersion sequence is applied and the dispersion of each group is expressed. Let $r_{i}$ be the mean of the $N_{\mathrm{i}}$ with $N_{\mathrm{i}}=n_{\mathrm{i}}\left(n_{\mathrm{i}}-1\right) / 2$ rank similarities among the $n_{\mathrm{i}}$ samples within the $i^{\text {th }}$ group $(i=1,2, \ldots, g)$. The triangular matrix has been re-ranked (as described for the comparison of two groups), ignoring all between-group similarities. $N$ equals the number of similarities involved in the ranking process with $N=\Sigma_{\mathrm{i}} N_{\mathrm{i}}$. The dispersion sequence is

$$
r_{1} / k, \quad r_{2} / k, \ldots, \quad r_{g} / k
$$

and describes the relative variability within each of the $g$ groups whereby a larger value indicates a larger dispersion. $k$ is the mean of all $N$ ranks involved $=(N+$ 1)/2. Note that the IMD is a comparative index and not a statistical framework to test for differences of variability between groups. The IMD was computed in the PRIMER routine MVDISP (Clarke \& Gorley 2001) using fourth-root transformed abundance data, which were standardised for the comparison of the three sites. When computing the IMD for pre-and all post-bloom samples, data were aggregated to order level and presence-absence transformed.

\section{Assemblage Seriation}

The structure of faunal communities usually exhibits a relative regular pattern of change due to biological (e.g., reproduction, predation, competition) and environmental factors (e.g., wave-energy, sedimentation). Clarke et al. (1993) applied the term 'seriation' to describe this form of sequential pattern of community change. The assumption is that the community structure tends to drift to the same extent in any equal time period. Disturbances of any kind can modify the above-mentioned factors and therefore may affect patterns of seriation, i.e., a breakdown in the seriation patterns can occur. Clarke et al. (1993) suggested breakdown of seriation as a measure of community stress and identified this in a disturbed coral reef-assemblage in Thailand. The authors developed the Index of 
Multivariate Seriation (IMS) as a measure of the extent to which community change conforms to a linear sequence.

The IMS is defined as a Spearman rank correlation $(\rho)$ between the corresponding elements of two rank (dis)similarity matrices. The first matrix is based on Bray-Curtis similarity coefficients computed for all pairs from the $n$ species abundance samples for each site. The second matrix is formed from the equally spread inter-point distances of the $n$ points along a line. If the community changes (first matrix) exactly match this linear sequence (i.e., sample 1 with regard to its faunal assemblage is more similar to sample 2 than to sample 3 and less similar to sample 4 than to sample 3 , etc. with sample 1 and the last sample being most dissimilar), then the IMS $=1$. If the IMS is zero, then no biotic pattern is perceptible. Whether the near-zero values are positive or negative is of no significance.

To test the null hypothesis $\left(\mathrm{H}_{0}\right)$ of no seriation, a permutation procedure (similar to the significance test of $R$ in the ANOSIM analyses) was performed separately for pre- and all post-bloom samples combined and for late-stage postbloom samples (August 1999-May 2001) only. The reason for this has already been stated for the IMD. If no seriation exists $\left(\mathrm{H}_{0}\right.$ is true), the sample labelling is completely arbitrary. Further IMS values can be calculated by randomly rearranging the sample labels in one of the two similarity matrices (holding the other fixed). These are compared to the observed IMS value. If only $t$ of the $T$ randomly selected permutations of IMS values are greater than or equal to the observed IMS value, $\mathrm{H}_{0}$ can be rejected at a significance level of

$$
100(t+1) /(T+1) \%
$$

The number of permutations performed was 999 .

The IMS can be computed for linear and cyclical seriation. For the latter, the inter-point distances of the second matrix are arranged in a cycle (instead of a line) and one can test whether community structure returns to the approximate same point it had before the breakdown of seriation occurred. The change of community structure would describe a circle, i.e., sample 1 and the last sample would be very similar. This is especially useful for establishing temporal trends but requires pre-breakdown or pre-disturbance samples. Although pre-bloom samples were available, time constraints and the generally poor condition of pre- 
bloom samples did not allow for a re-identification to standardise the taxonomy between them and the late-stage post-bloom samples. Hence, an analysis of cyclical seriation was not carried out, but a linear seriation was performed to establish whether changes in community structure at the three sites occurred in the form of a sequential linear pattern.

A similarity matrix was computed for each site using fourth-root transformed abundance data (group-averaged for months) for the late-stage postbloom samples. The similarity matric for pre- and all post-bloom samples was computed using order-level aggregated presence-absence transformed data. The IMS values were computed for all three sites separately using the PRIMER routine RELATE (Clarke \& Gorley 2001). MDS ordinations were plotted for each site and the sample points were linked in temporal order to help visualise the degree of seriation, i.e., the extent of community change between each consecutive sampling date. In the study presented here, samples were not taken at equally distanced points in time (especially Harbour Basin: change of sampling regime from monthly to three-monthly in August 2000) and the number of samples per year changed. However, the IMS is not particularly sensitive to the resulting differing variances per year since they influence significant sequential time drifts (high Spearman rank correlation $\rho$ ) only by diluting this effect (Clarke 2002, pers. comm.).

\section{Linking Biological To Environmental Data}

Correlations of univariate measures of community composition, such as Shannon's diversity index $H^{\prime}$, with environmental variables (median grain size, sorting coefficient, \% mud) were not possible because samples for environmental data were taken infrequently.

To visualise a possible relationship between environmental variables and biological patterns, values of the environmental variables can be superimposed on a MDS ordination ('bubble plot') of the corresponding biological samples (Field et al. 1982). The variables are represented as symbols of differing sizes according to their values. In the resulting MDS ordination the symbol representing the value of the environmental variable is plotted in place of the 
label for the biological sample. Thus, a potential relation of the biological and the environmental data can be visualised. Organic matter content (\%) was the only environmental variable for which a bubble plot could be created because replicate samples were taken every time biological samples were taken. Replicate numbers between organic matter content samples $(n=3)$ and biological samples $(n=4)$ differed, thus, only a subset of the biological samples (samples with a matching sample for organic matter content) was used for the bubble plot. The species abundance data were standardised and $4^{\text {th }}$-root transformed to create the MDS ordination.

In order to elucidate how well the community structures derived from the multivariate biological analyses are 'explained' by environmental variables, the PRIMER routine BIOENV was applied. The BIOENV routine links biological data to multivariate environmental data by correlating the rank similarity matrices derived from species abundance or biomass data to the environmental data (Clarke \& Ainsworth 1993). The premise here is that pairs of samples with rather similar values for environmental variables (e.g., median grain size, organic matter content, salinity, etc.) should have similar species compositions. Thus, placing of samples in MDS ordinations (based upon the appropriate (dis)similarity matrix) of the biological and the abiotic data should be similar. By selecting different combinations of environmental variables in the analysis, an 'optimal match' between the biological and environmental ordinations can be determined. For this optimal match only the relevant environmental variables are included. For a thorough introduction into, and discussion of, the BIOENV procedure refer to Clarke \& Ainsworth (1993).

To measure the agreement of pattern between the biological and the environmental data, the ranks of the similarity matrices underlying the MDS ordinations are compared through a rank correlation coefficient. Note that the matrices are based on different similarity coefficients: Bray-Curtis for biota and Euclidean distance (natural distance between any two points in multidimensional space) for environmental variables. The correlation coefficient is the Spearman rank correlation $\rho_{s}$ :

$$
\rho_{s}=1-\frac{6}{N\left(N^{2}-1\right)} \sum_{i=1}^{N}\left(r_{i}-r_{i}\right)^{2}
$$

where $\left\{r_{i} ; i=1, \ldots, N\right\}$ are the ranks of all the sample similarities derived from 
biological data and $\left\{s_{i} ; i=1, \ldots N\right\}$ are the ranks of all sample similarities derived from environmental data. $N=n(n-1) / 2$ and $n$ is the number of samples. The constant terms ensure that $\rho_{s}$ lies in the range of -1 to +1 . When the two sets of ranks are in complete opposition $\rho_{s}=-1$, and when they are in complete agreement $\rho_{s}=1$. Values of $\rho_{s}$ around zero indicate the absence of any match between the two rank matrixes. To match the biotic and environmental patterns, combinations of the environmental variables are considered. With each step another variable is added to the combination, i.e., $k$ variables at a time $(k=$ $1,2,3, \ldots, v)$ with $v=$ number of all environmental variables. $\rho_{s}$ displays the highest value for the best matching combination. Each additional, but irrelevant, environmental variable will decrease the value of $\rho_{s}$. Note, that the rank similarities $\left\{r_{i}\right\}$ or $\left\{s_{i}\right\}$ are not a set of independent variables (they are based on a large number $(N)$ of strongly interdependent similarity calculations) and standard statistical tests for $\rho_{s}$ are therefore invalid (Clarke \& Ainsworth 1993).

Preferably, a fully matching set of biological and environmental data should be collected for the BIOENV analysis, but regrettably, that was not possible for the present study. Thus, the BIOENV routine was used here in a slightly different way, i.e., only one environmental variable, organic matter content (\%) was tested. As explained above, replicate numbers between organic matter content samples $(n=3)$ and biological samples $(n=4)$ differed and the same subset of biological samples as for the bubble plot was used in the BIOENV analyses. Hence, the biota similarity matrixes used for BIOENV analyses are different from the matrices used for analysing the biological patterns in the previous analyses (dendrogram, MDS, ANOSIM, etc.). With only one environmental variable available, the explanatory power of the BIOENV results is obviously limited. In an observational study such as this, conclusions about potential causality should be drawn very carefully because the measured variable might be highly correlated to another potentially causal, but unmeasured variable. Thus, the BIOENV procedure is an explanatory tool and applying significance tests to the results is problematic due to a lack of model assumptions underlying this analysis (Clarke \& Ainsworth 1993; Clarke \& Warwick 2001). However, the same permutation procedure, that has been described for the analysis of assemblage seriation, can be used to test the null hypothesis that there 
was no relationship between the biotic information and the organic matter content of the sediment, i.e., that $\rho$ was effectively zero (Clarke \& Ainsworth 1993; Clarke \& Warwick 2001).

MDS ordinations based on the organic matter content data were computed for between and within-site comparisons before BIOENV analyses were carried out again for all three sites together (biological data standardised and fourth-root transformed) and for each site separately (biological data fourthroot transformed).

\subsection{Results}

\subsubsection{Biological Analyses}

\section{Abundance $(N)$ and Number of Species $(S)$}

Overall, 96,201 individuals belonging to 269 putative species were identified from 160 samples taken at three sites in Wellington Harbour. A species list is presented in Table 2.1 and average abundances $( \pm \mathrm{SD})$ are presented in Appendix 3. Forty-four of the samples (referred to as initial post-bloom samples) were taken by Wear \& Gardner (2001) and Gardner \& Wear (submitted) and have been re-identified to standardise the taxonomy between the aforementioned studies and this thesis. Because a coarser mesh diameter $(800 \mu \mathrm{m})$ was used for the initial post-bloom samples whereas $500 \mu \mathrm{m}$ and $1000 \mu \mathrm{m}$ sieves were used in the present study, results were kept separate.

Initial post-bloom samples (May 1998, November 1998, March 1999)

The 44 re-identified initial post-bloom samples from all three sites yielded 12,401 individuals belonging to 121 putative species (Figure 2.1). Polychaetes were the most numerically abundant group $(80.7 \%)$, followed by crustaceans (12.9\%) and molluscs (4.9\%). The three other groups (anthozoans, echinoderms and others) accounted for $0.7 \%, 0.6 \%$ and $0.2 \%$ of $N$, respectively. 
It should be noted, when comparing $N$ of the initial post-bloom samples with $N$ from samples taken from August 1999 onwards, that a coarser mesh-size was used in sieving the initial post-bloom samples.

\section{Harbour Basin (HB)}

For the initial post-bloom samples $N$ was 872 and $S$ was 46 . Polychaetes were the most dominant group $(N=66.3 \%)$ followed by crustaceans $(16.6 \%)$ and molluscs (13.4\%). The most abundant species were the polychaete Terebellides cf. stroemii $(42.4 \%)$, the bivalve Theora lubrica $(10.0 \%)$ and the polychaete Onuphis aucklandensis (5.4\%).

\section{Oriental Bay $(O B)$}

At Oriental Bay 1,691 individuals belonging to 70 species were sampled. Polychaetes accounted for more than $50 \%$ of these individuals, with crustaceans being the second most dominant group (23.4\%), followed by molluscs (18.3\%). The capitellid Barantolla sp. was the most abundant species $(17.4 \%)$. The tubebuilding polychaete Owenia fusiformis $(10.8 \%)$ and the glycerid Hemipodus simplex $(8.1 \%)$ ranked second and third, respectively, in abundance.

\section{Entrance Channel (EC)}

For this site the initial post-bloom samples yielded 9,838 individuals belonging to 65 species. Polychaetes were by far the most abundant group $(N=87.0 \%)$. Crustaceans ranked second in abundance with $10.7 \%$, followed by molluscs (1.9\%). Owenia fusiformis dominated the sampled fauna $(83.4 \%$ of all individuals). The next most abundant species were the burrowing ghost shrimp Callianassa filholi (mainly juveniles) with $6.9 \%$ and the undescribed polychaete Aglaophamus sp. 3 with $2 \%$.

\section{August 1999 - May 2001}

A total of 83,800 individuals was identified to putative species level ( $S=263$ ) from 116 benthic samples taken from August 1999 to May 2001 at three 
sites in Wellington Harbour (Figure 2.2). Overall, polychaetes were the most abundant group with $N=49.7 \%$, followed by crustaceans $(25.0 \%)$ and molluses $(21.2 \%)$. Other groups (anthozoans, echinoderms and others) were found in much lower abundances $(2.5 \%, 0.5 \%$ and $1.1 \%$, respectively).

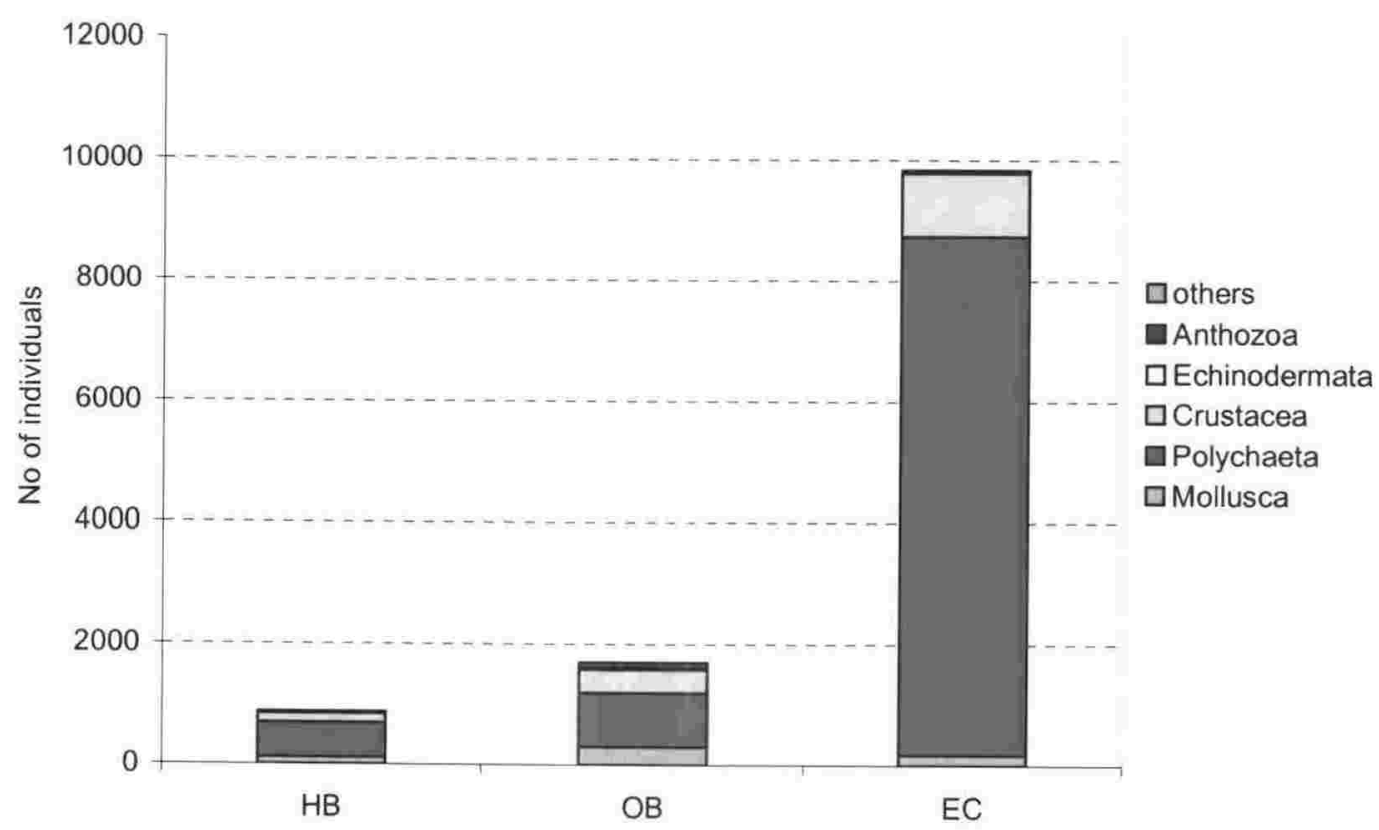

Figure 2.1 Total number of individuals $(N)$ per group from 44 benthic samples taken at 3 sites ( $\mathrm{HB}=$ Harbour Basin, $\mathrm{OB}=$ Oriental Bay, $\mathrm{EC}=$ Entrance Channel) in Wellington Harbour from May 1998 to March 1999. Sieve fractions: $>800 \mu \mathrm{m}$. Samples were taken by Wear \& Gardner (2001) and Gardner \& Wear (submitted). OB and EC: $n=15, \mathrm{HB}: \mathrm{n}=14$ across all sampling occasions.

\section{Harbour Basin}

At the Harbour Basin site (HB) 25,108 individuals of 156 putative species were identified from 60 samples taken on 15 sampling occasions. With $59.8 \%$ of total individuals at $\mathrm{HB}$, polychaetes were the most abundant group, followed by crustaceans $(20.3 \%)$ and molluses $(13.4 \%)$, the latter having hardly changed in abundance compared to the initial post-bloom samples. The most abundant species were the amphipod Phoxocephalidae sp. I (13.0\%) and the polychaetes Maldane theodori (10.5\%) and ?Aphelochaeta sp. (8.6\%). 


\section{Oriental Bay}

Fewer samples were taken at Oriental Bay (24 samples on 6 sampling occasions), but they contained the most individuals of the three sites sampled ( $N=43,657$ individuals) and also the highest number of species (165 identified species). Half of the fauna consisted of polychaetes (50.4\%). Molluscs formed the second most abundant group (27.5\%) and crustaceans ranked third (18.3\%). Most abundant species were the capitellid Barantolla sp. (18.4\%), the ostracod Dolasterope quadrata (11.6\%) and the polychaete Owenia fusiformis (10.6\%).

\section{Entrance Channel}

At Entrance Channel, 15,035 individuals of 157 species were identified from 32 samples taken at eight sampling occasions. Crustaceans numerically dominated the fauna with $52.3 \%$ of total abundance, followed by polychaetes (30.9\%), and molluses (16.0\%). The cirratulid polychaete Prionospio yuriel was the most abundant species (12.8\%), followed closely by the bivalve Corbula zelandica $(10.7 \%)$, and the amphipod Paraphoxus sp. A (10.4\%).

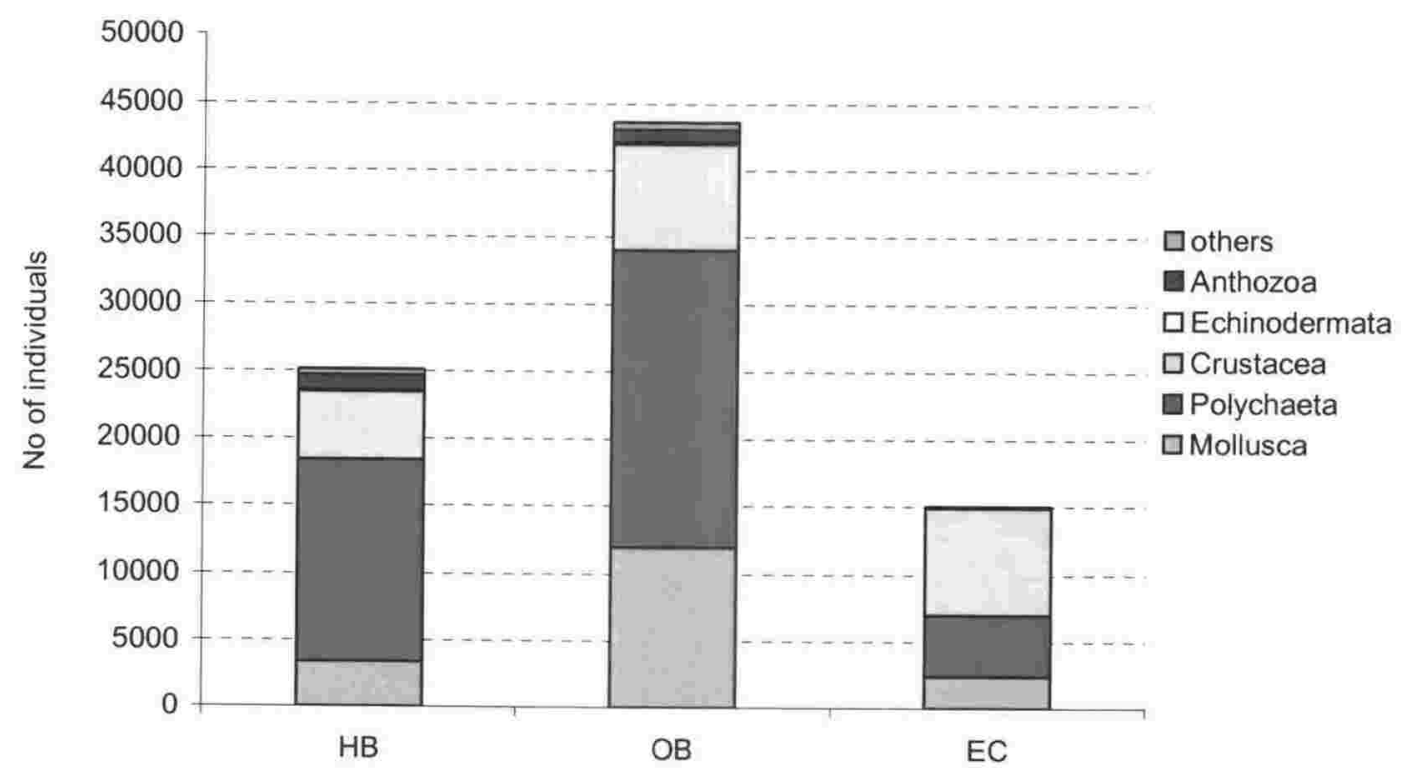

Figure 2.2 Total number of individuals $(N)$ per group from 116 samples taken at 3 sites $\mathrm{HB}=$ Harbour Basin, $\mathrm{OB}=$ Oriental Bay, $\mathrm{EC}=$ Entrance Channel) in Wellington Harbour from August 1999 to May 2001. Sieve fraction: $>500 \mu \mathrm{m}$. Note that results are based on different numbers of samples (HB: $n=60$ at 15 sampling occasions, $O B: n=24$ at 6 sampling occasions, EC: $\mathrm{n}=32$ at 8 sampling occasions). 
Table 2.1 Species list of re-identified immediate and late-stage post-bloom samples

\begin{tabular}{|c|c|c|c|}
\hline Class & Species & Class & Species \\
\hline Anthozoa & Scolanthus sp. & Polyplacophora & Acanthochitona zelandica \\
\hline Anthozoa & Anthozoa sp. A & Polyplacophora & Notoacmea sp. juv. \\
\hline Anthozoa & Cerianthid sp. A & Polyplacophora & Buccinulum linea \\
\hline Bivalvia & Nucula hartvigiana & Polyplacophora & Cantharidella tesselata \\
\hline Bivalvia & Ennucula strangei & Gastropoda & Cantharidus purpureus \\
\hline Bivalvia & Neilo australis & Gastropoda & Diloma subrostrata \\
\hline Bivalvia & Modiolarca impacta & Gastropoda & Micrelenchus artizona \\
\hline Bivalvia & Zelithophaga truncata juv. & Gastropoda & Trochus tiaratus \\
\hline Bivalvia & Modiolus areolatus & Gastropoda & Turbo smaragdus \\
\hline Bivalvia & Pratulum pulchellum & Gastropoda & Cirsonella densilirata \\
\hline Bivalvia & Corbula zelandica & Gastropoda & Anabathron hedleyi \\
\hline Bivalvia & Scintillaona zelandica & Gastropoda & Nozeba emarginata \\
\hline Bivalvia & Mylitella vivens & Gastropoda & Caecum digitulum \\
\hline Bivalvia & ?Montacuta vitrea aupouria & Gastropoda & Struthiolaria papulosa \\
\hline Bivalvia & Melliteryx parva & Gastropoda & Sigapatella tenuis \\
\hline Bivalvia & Athritica bifurca & Gastropoda & Tanea zelandica \\
\hline Bivalvia & Divaricella huttoniana & Gastropoda & Xymene pusillus \\
\hline Bivalvia & Gonimyrtea concinna & Gastropoda & Austrofusus glans \\
\hline Bivalvia & Scalpromatra scalpellum & Gastropoda & Cominella adspersa \\
\hline Bivalvia & Zenatica acinaces & Gastropoda & Gumina dolichostoma \\
\hline Bivalvia & Paphies australis & Gastropoda & Odostomiun sp. A \\
\hline Bivalvia & Gari lineolata & Gastropoda & Odostomiun sp. B \\
\hline Bivalvia & Gari stangeri & Gastropoda & Turbonella sp. 1 \\
\hline Bivalvia & Soletellina nitida & Gastropoda & Turbonella sp. 2 \\
\hline Bivalvia & Soletellina sp. juv. & Gastropoda & Philine angasi \\
\hline Bivalvia & Leptomya retiaria & Gastropoda & Retusa oruaensis \\
\hline Bivalvia & Theora lubrica & Gastropoda & Philine powelli \\
\hline Bivalvia & Anisodonta alata & Peracarida & Gammaridae sp. A \\
\hline Bivalvia & Ascitellina urinatoria & Peracarida & Liljeborgiidae sp. A \\
\hline Bivalvia & Macomona liliana & Peracarida & Parawaldeckia sp. A \\
\hline Bivalvia & Serratina charlottae & Peracarida & Lysianassidae sp. A \\
\hline Bivalvia & Genaxinus cookianus & Peracarida & Lysianassidae sp. B \\
\hline Bivalvia & Diplodonta globus & Peracarida & ?Lysianassidae sp. C \\
\hline Bivalvia & Diplodonta zelandica & Peracarida & Paraphoxus sp. A \\
\hline Bivalvia & Dosina zelandica & Peracarida & Paraphoxus sp. B \\
\hline Bivalvia & Dosinia greyi & Peracarida & Phoxocephalidae sp. A \\
\hline Bivalvia & Dosinia lambata & Peracarida & ?Phoxocephalidae sp. A \\
\hline Bivalvia & Ruditapes largillierti & Peracarida & Phoxocephalidae sp. B \\
\hline Bivalvia & Tawera spissa & Peracarida & Phoxocephalidae sp. C \\
\hline Bivalvia & Myadora striata juv. & Peracarida & Phoxocephalidae sp. D \\
\hline Bivalvia & Thracia vegrandis & Peracarida & Phoxocephalidae sp. E \\
\hline Bivalvia & Bivalvia indet. & Peracarida & Phoxocephalidae sp. F \\
\hline Bivalvia & Leptochiton sp. A & Peracarida & Phoxocephalidae sp. G \\
\hline Bivalvia & Ischnochiton sp. A & Peracarida & Phoxocephalidae sp. H \\
\hline Bivalvia & Chiton sp. A & Peracarida & Phoxocephalidae sp. I \\
\hline Polyplacophora & Chiton sp. juv. & Peracarida & Phoxocephalidae sp. J \\
\hline Polyplacophora & Rhyssoplax sp. A & Peracarida & Phoxocephalidae sp. K \\
\hline Polyplacophora & Syphoneria australis & Peracarida & Phoxocephalidae indet \\
\hline
\end{tabular}


Table 2.1 continued

\begin{tabular}{|c|c|c|c|}
\hline Class & Species & Class & Species \\
\hline Peracarida & Amphipoda sp. A & Copepoda & Copepoda spp. \\
\hline Peracarida & Amphipoda sp. B & Malacostraca & Callianassa filholi \\
\hline Peracarida & Amphipoda sp. C & Malacostraca & Jaxea novaezealandiae \\
\hline Peracarida & Amphipoda sp. D & Malacostraca & Upogebia sp. \\
\hline Peracarida & Amphipoda sp. E & Malacostraca & Upogebia danai \\
\hline Peracarida & Amphipoda sp. F & Malacostraca & Pterygiosquilla \\
\hline Peracarida & Amphipoda sp. $\mathrm{H}$ & & armata schizodonta \\
\hline Peracarida & Amphipoda sp. I & Malacostraca & Cancer novaezelandiae \\
\hline Peracarida & Amphipoda sp. J & Malacostraca & Halicarcinus sp. \\
\hline Peracarida & Amphipoda sp. K & Malacostraca & Liocarcinus corrugatus \\
\hline Peracarida & ?Iphinotus typicus & Malacostraca & Macrophthalamus hirtipes \\
\hline Peracarida & Leptanthura sp. 1 & Malacostraca & Neommatocarcinus huttoni \\
\hline Peracarida & Leptanthura sp. 2 & Malacostraca & Nectocarcinus antarcticus juv. \\
\hline Peracarida & Pseudaega secunda & Malacostraca & Notomithrax minor juv. \\
\hline Peracarida & Eurydice aff semitruncata & Malacostraca & ?Ogyrides delli \\
\hline Peracarida & Natatolana rossi & Malacostraca & Periclimenes yaldwyni \\
\hline Peracarida & Natatolana sp. nov & Malacostraca & ?Petrolisthes elongatus juv. \\
\hline Peracarida & ?Munnogonium sp. 1 & Malacostraca & Pinnotheres novaezealandiae \\
\hline Peracarida & ?Munnogonium sp. 2 & Malacostraca & Paguridae spp. juv. \\
\hline Peracarida & ?Munna sp. 1 & Polychaeta & Ampharetinae sp. A \\
\hline Peracarida & Apseudidae sp. & Polychaeta & Ampharetidae sp. juv \\
\hline Peracarida & Gnathiidae 'pranzia' stage & Polychaeta & Aphrodita talpa \\
\hline Peracarida & Tanaidacea sp. A & Polychaeta & ?Euphantalis sp. A \\
\hline Peracarida & Tanaidacea sp. B & Polychaeta & Barantolla sp. \\
\hline Peracarida & Tanaidacea sp. D & Polychaeta & Heteromastus cf. filiformis \\
\hline Peracarida & Cumacea sp. A & Polychaeta & ?Capitomastus sp. \\
\hline Peracarida & Cumacea sp. B & Polychaeta & Notomastus sp. A \\
\hline Peracarida & Cumacea sp. C & Polychaeta & Capitella capitata \\
\hline Peracarida & Cumacea sp. D & Polychaeta & Arenicola sp. juv \\
\hline Peracarida & Cumacea sp. E & Polychaeta & Chaetozone sp. A \\
\hline Peracarida & Cumacea sp. G & Polychaeta & Chaetozone sp. B \\
\hline Peracarida & Caprellidae sp. A & Polychaeta & Monticellina sp. \\
\hline Ostracoda & Copytus novaezealandiae & Polychaeta & ?Aphelochaeta sp. \\
\hline Ostracoda & Cymbicopia hispida & Polychaeta & Cirratulidae sp. B \\
\hline \multirow[t]{2}{*}{ Ostracoda } & Cymbicopia & Polychaeta & Cirratulidae sp. C \\
\hline & zealandica/hispida & Polychaeta & Cossura consimilis \\
\hline Ostracoda & Dolasterope grisea & Polychaeta & Glycinde dorsalis \\
\hline Ostracoda & Dolasterope quadrata & Polychaeta & Glycera ovigera \\
\hline Ostracoda & Euphilomedes agilis & Polychaeta & Hemipodus simplex \\
\hline Ostracoda & Leuroleberis zelandica & Polychaeta & Goniada ?emerita \\
\hline Ostracoda & Scleroconcha sculpta & Polychaeta & Gyptis sp. A \\
\hline Ostracoda & Scleroconcha sp. & Polychaeta & Microphtalamus sp. A \\
\hline Ostracoda & Trachlyeberis lytteltonensis & Polychaeta & Ophiodromus angustifrons \\
\hline Ostracoda & Ostracoda sp. L & Polychaeta & Abyssoninoe galatheae \\
\hline Ostracoda & Ostracoda sp. M & Polychaeta & Lumbrineris sp. A \\
\hline Copepoda & Harpacticoidea sp. A & Polychaeta & Lumbricalus aotearoae \\
\hline
\end{tabular}


Table 2.1 continued

\begin{tabular}{|c|c|c|c|}
\hline Class & Species & Class & Species \\
\hline Polychaeta & ?Paraninoe brevipes & Polychaeta & Malacoceros sp. A \\
\hline Polychaeta & Scoletoma brevicirra & Polychaeta & ?Malacoceros sp. B \\
\hline Polychaeta & Magelona sp. A & Polychaeta & Microspio elegantulus \\
\hline Polychaeta & Asychis trifilosus & Polychaeta & Prionospio aucklandica \\
\hline Polychaeta & Asychis sp. A & Polychaeta & Prionospio ?cirrifera \\
\hline Polychaeta & ?Euclymene insecta & Polychaeta & Prionospio ?yuriel \\
\hline Polychaeta & Euclymene sp. A & Polychaeta & Prionospio sp. A \\
\hline Polychaeta & Maldane theodori & Polychaeta & Scolelepis sp. A \\
\hline Polychaeta & Maldanidae sp. D & Polychaeta & Spionidae sp. A \\
\hline Polychaeta & Maldanidae sp. G & Polychaeta & ?Lanice sp. A \\
\hline Polychaeta & Maldanidae sp. J & Polychaeta & Polycirrus sp. A \\
\hline Polychaeta & Aglaophamus ?macroura & Polychaeta & Terebellides cf. stroemii \\
\hline Polychaeta & Aglaophamus virilli & Polychaeta & Thelepus ?rugosum \\
\hline Polychaeta & Aglaophamus sp. 3 & Polychaeta & Thelepus sp. \\
\hline Polychaeta & Platynereis ?australis & Polychaeta & Flabelligera sp. A \\
\hline Polychaeta & Dorvilleidae sp. A & Polychaeta & ?Diplocirrus sp. A \\
\hline Polychaeta & Onuphis aucklandensis & Polychaeta & ?Pherusa sp. \\
\hline Polychaeta & Armandia maculata & Polychaeta & Spionidae sp. B \\
\hline Polychaeta & Travisia sp. & Polychaeta & Exogone ?heterosetosa \\
\hline Polychaeta & Orbinia papillosa & Polychaeta & Exogone sp. A \\
\hline Polychaeta & Orbiniidae sp. juv. & Polychaeta & Exogone sp. B \\
\hline Polychaeta & Owenia fusiformis & Polychaeta & Trochochaeta att. japonica \\
\hline Polychaeta & Pectinaria australis & Polychaeta & Syllidae sp. A \\
\hline Polychaeta & Phyllodocidae sp. A & Polychaeta & Syllidae sp. C \\
\hline Polychaeta & Phyllodocidae sp. B & Polychaeta & Syllidae sp. D \\
\hline Polychaeta & Phyllodoce sp. C & Polychaeta & Syllidae sp. E \\
\hline Polychaeta & Pilargis sp. A & Polychaeta & Syllidae sp. F \\
\hline Polychaeta & Lepidonotus sp. A & Sipunculida & Sipuncula sp. A \\
\hline Polychaeta & Lepidonotus sp. B & Echiuridea & Echiurus novaezelandiae \\
\hline Polychaeta & Polynoidea sp. & Priapulida & Priapulus australis \\
\hline Polychaeta & Euchone limnicola & Echinoidea & Echinocardium caudatum \\
\hline Polychaeta & Euchone sp. A & Ophiuroidea & Amphiura rosea \\
\hline Polychaeta & Megalomma sp. A & Asteroidea & ?Coscinasterias muricata juv. \\
\hline Polychaeta & Labiosthenolepis laevis & Asteroidea & Patiriella regularis \\
\hline Polychaeta & Sthenelais taurangaensis & Holothuroidea & Trochodota dendyi \\
\hline Polychaeta & Sigalion sp. A & Holothuroidea & Paracaudina chilensis \\
\hline Polychaeta & ?Spirorbis sp. A & Holothuroidea & Holothuridae sp. B \\
\hline Polychaeta & Boccardia sp. & Holothuroidea & Holothuridae sp. C \\
\hline Polychaeta & Carazziella phillipensis & Holothuroidea & ?Holothuridae sp. D \\
\hline Polychaeta & Paraprionospio cf. pinnata & Holothuroidea & Holothuria indet. \\
\hline Polychaeta & Polydora sp. A & Phoronida & Phoronis sp. \\
\hline Polychaeta & Laonice sp. A & & \\
\hline
\end{tabular}




\section{Distribution patterns (August 1999 - May 2001)}

\section{Harbour Basin (HB)}

Mean abundance patterns for the five most numerically dominant species of $\mathrm{HB}$ are presented in Figure 2.3. These patterns were relatively similar throughout the study period. In November 1999 (spring) all five species displayed increased abundances followed by a sharp drop of abundances over the next two months.

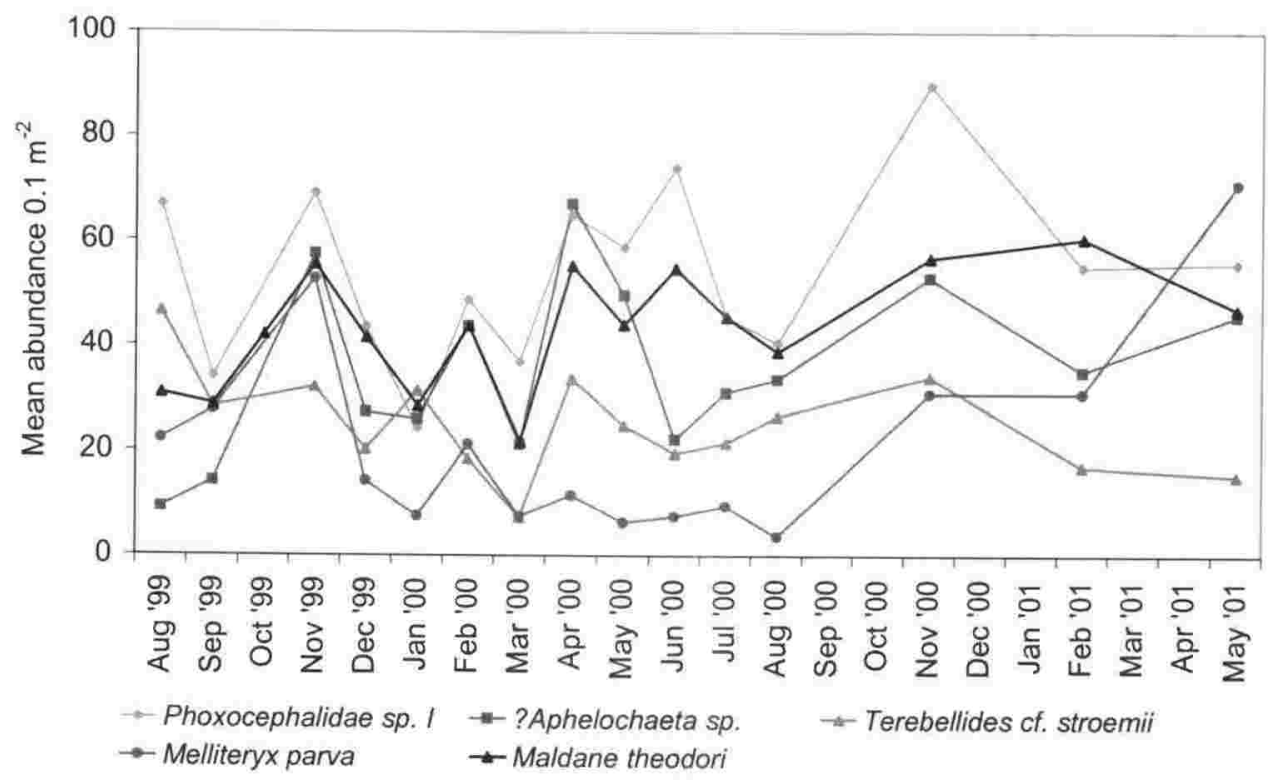

Figure 2.3 Harbour Basin. Mean abundance $0.1 \mathrm{~m}^{2}$ of the 5 most numerically dominant taxa. Standard deviations have been omitted for clarity reasons. For SD see Appendix $4 . n=4$ per sampling occasion. No data available for October 1999. From August 2000 sampling was conducted at 3-monthly intervals.

Through autumn 2000 abundances rose and peaked in April 2000 (except the bivalve $M$. parva). Densities remained low throughout winter 2000 (JuneAugust) and, as in 1999, peaked in November 2000, followed by a decline. Abundance patterns of Phoxocephalidae sp. I and $M$. theodori were very similar, with both species displaying more pronounced abundance fluctuations than the other species. The distribution of $M$. parva in May 2001 was rather patchy as indicated by the high standard deviation of \pm 114.2 (mean=70.6). 


\section{Oriental Bay $(O B)$}

Abundances of the five most numerically dominant species at OB (Figure 2.4) were in general much higher than at HB. Numbers of the capitellid Barantolla sp. and the ostracod D. quadrata increased considerably throughout the study period. The former increased in numbers from December 1999 onwards, remaining constant through the summer of 2000/2001, whereas the latter species showed peak abundances in February 2001. By May 2001 numbers of D. quadrata had decreased to pre-peak levels.

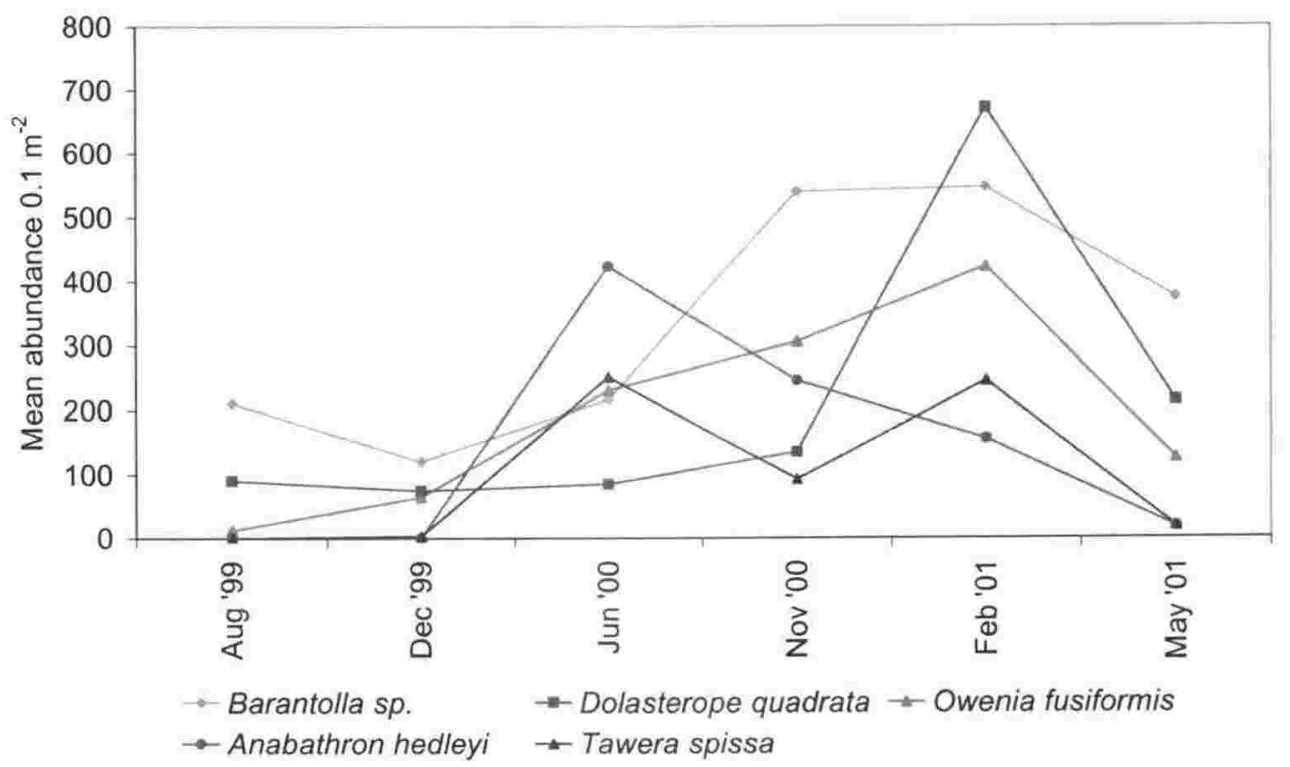

Figure 2.4 Oriental Bay. Mean abundance $0.1 \mathrm{~m}^{-2}$ of the 5 most numerically dominant taxa. Standard deviations have been omitted for clarity reasons. For SD see Appendix 4 . n=4 per sampling occasion.

The small gastropod A. hedleyi occurred at this site from June 2000 onwards. The species' high abundance in June 2000 gradually decreased and by May 2001 mean abundance was very low. D. quadrata, O. fusiformis and T. spissa showed distinct abundance peaks in February 2001. 


\section{Entrance Channel (EC)}

Species abundances for the five most abundant species at EC (Figure 2.5) peaked either in November of both years (the spionid $P$. ?yuriel, the crustaceans C. filholi and Phoxocephalidae sp. A) or in the following February (Paraphoxus sp. A only in 1999, the bivalve C. zelandica in February 1999 and 2000). The high abundances of the ghost shrimp $C$. filholi were mainly due to the occurrence of juveniles in the samples. Most species displayed lowest abundances in May.

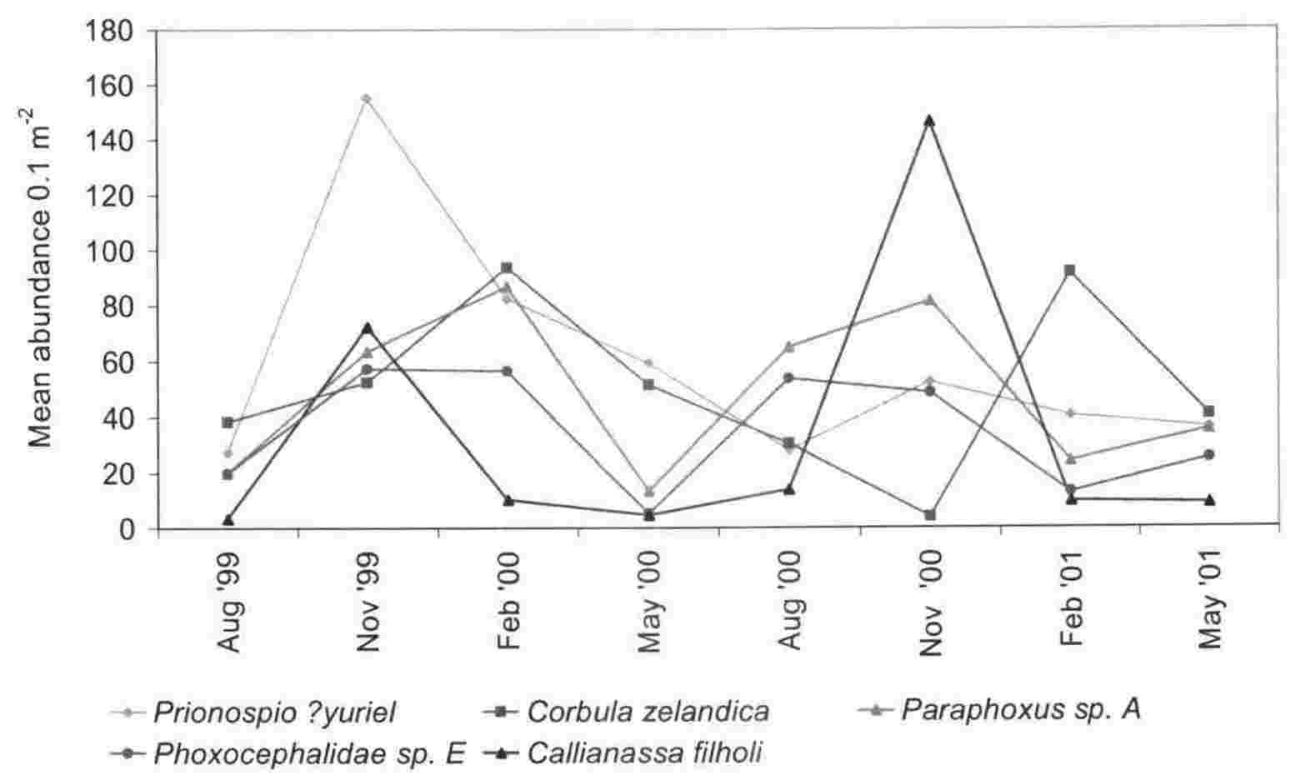

Figure 2.5 Entrance Channel. Mean abundance $0.1 \mathrm{~m}^{-2}$ of the 5 most numerically dominant taxa. Standard deviations have been omitted for clarity reasons. For SD see Appendix 4. n=4 per sampling occasion.

\section{Univariate Diversity Indices}

The following univariate diversity indices were computed for samples taken between August 1999 and May 2001: mean abundance $N$, mean number of species $S$, mean Shannon's diversity $H^{\prime}$, mean Pielou's evenness $J$, mean Fisher's alpha and mean Simpson's $-\ln D$. Analyses are based on values of four replicates per sampling occasion. Post-hoc test results are presented in Appendix 
6. Diversity indices of samples taken between May 1998-March 1999 are presented in Appendix 5.

\section{Harbour Basin (HB)}

The univariate diversity indices for $\mathrm{HB}$ as a function of time are presented in Figure 2.6-Figure 2.11. For the first eight months of the study mean abundance $(N)$ was relatively low with $300-400$ ind $0.1 \mathrm{~m}^{-2}$, except in November 1999 when maximum mean values were reached (608.8 ind. $0.1 \mathrm{~m}^{-2}$ ). Between March and April $2000 N$ increased and fluctuated between 400-520 ind. $0.1 \mathrm{~m}^{-2}$. In March 2000 abundance was lowest at $N=250$ ind. $0.1 \mathrm{~m}^{-2}$. ANOVA revealed significant differences of $N$ with time $(\mathrm{F}=3.143, \mathrm{MS}=41277.7, \mathrm{df}=14$, $p=0.002$ ), with $N$ in November 1999 being significantly different from $N$ in September 1999, January and March 2000.

For the mean number of species $(S) 0.1 \mathrm{~m}^{-2}$ maximum and minimum mean values occurred in November 1999 and March 2000 (50.3 and 32.5 species, respectively). Fluctuations in $S$ were most pronounced in the first eight months of the study, whereas from April $2000 S$ stabilised between 40-45 species $0.1 \mathrm{~m}^{-2}$. Significant differences in $S$ with time were observed $(F=2.709$, $\mathrm{MS}=62.1, \mathrm{df}=14, p=0.006)$. Post-hoc comparisons indicated that $S$ in March 2000 was significantly different from $S$ in November 1999 and February and May 2000.

Shannon's diversity index $\left(H^{\prime}\right)$ was highest in November $1999\left(H^{\prime}=3.11\right)$ and nearly as high in February $2000\left(H^{\prime}=3.107\right)$. This was followed by a drop in diversity to the minimum mean value of $H^{\prime}=2.91$ in March 2000. As with mean abundance and mean number of species, $H^{\prime}$ fluctuated less from April 2000 onwards than in the preceding period. Differences among months were nonsignificant $(\mathrm{F}=0.65, \mathrm{MS}=0.012, \mathrm{df}=14, p=0.81)$.

Pielou's evenness $(J)$ oscillated between 0.787 in May 2001 and 0.84 in March 2000. Evenness dropped to 0.792 in April 2000, but increased steadily afterwards until August 2000. No significant differences with time were detected ( $\mathrm{F}=0.84, \mathrm{MS}=0.001, \mathrm{df}=14, p=0.62$ ). 


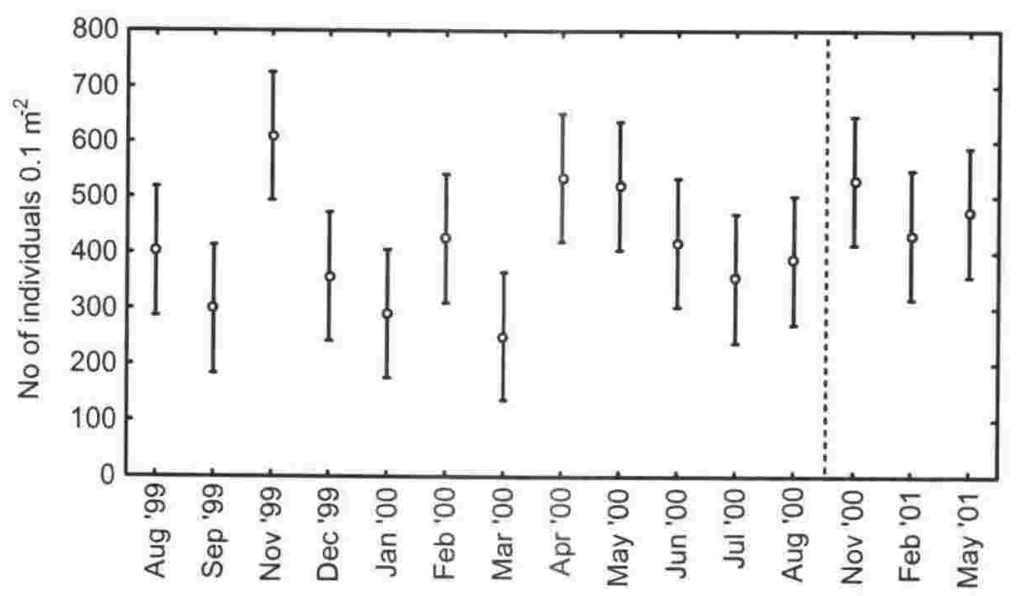

Figure 2.6 Harbour Basin: Number of individuals $(N) 0.1 \mathrm{~m}^{-2}$ (mean and $95 \%$ confidence limits).

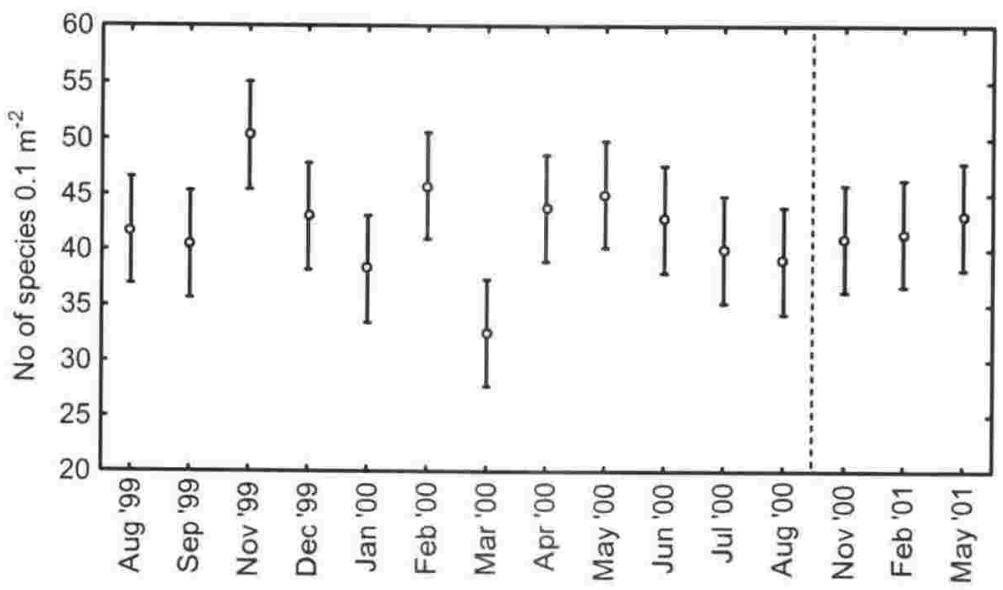

Figure 2.7 Harbour Basin: Number of species $(S) 0.1 \mathrm{~m}^{-2}$ (mean and $95 \%$ confidence limits).

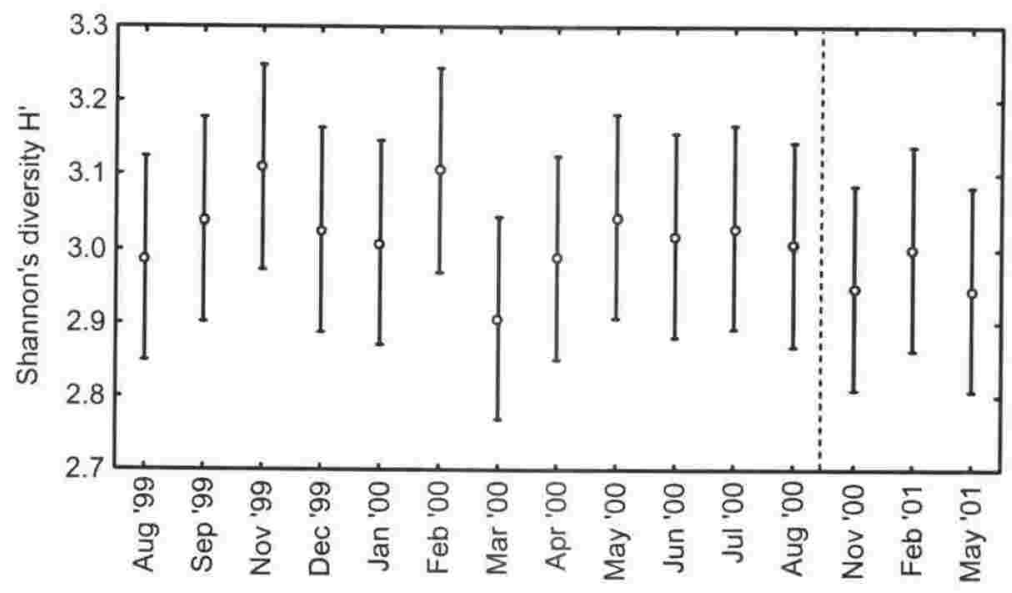

Figure 2.8 Harbour Basin: Shannon diversity $\left(H^{\prime}\right)$ (mean and $95 \%$ confidence limits). 


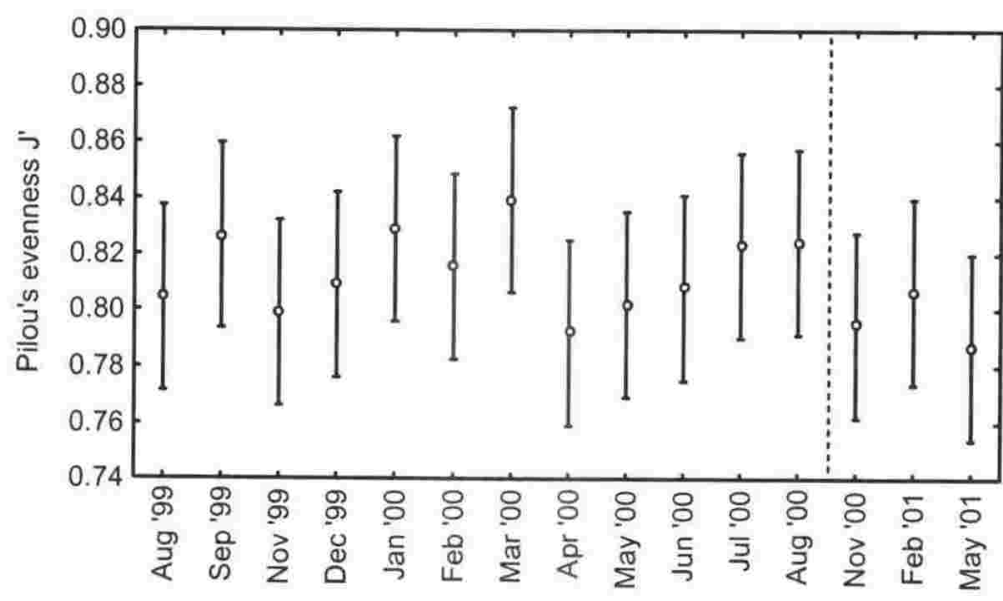

Figure 2.9 Harbour Basin: Pielou's evenness $(J)$ (mean and 95\% confidence limits).

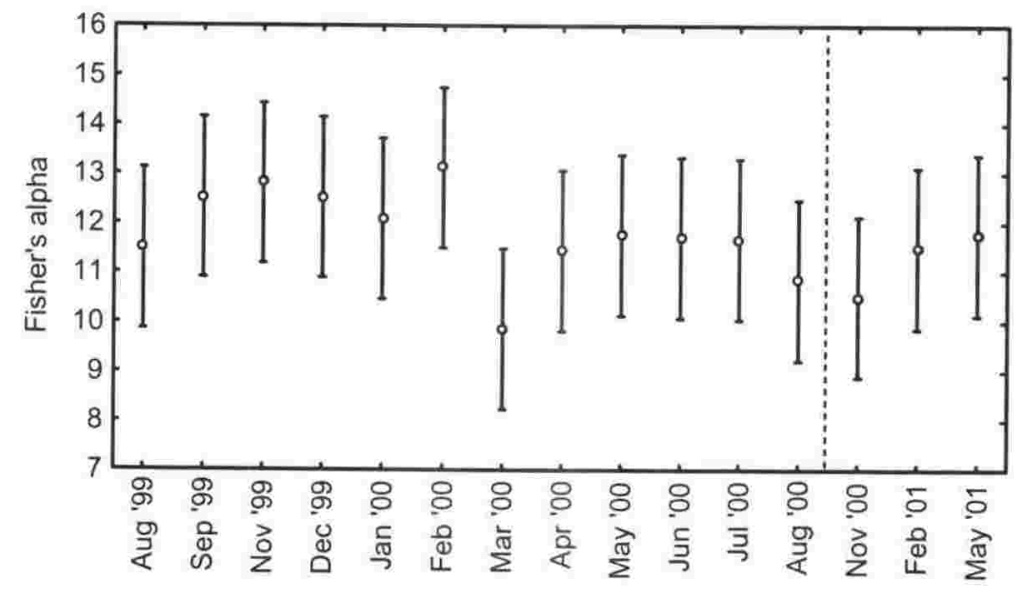

Figure 2.10 Harbour Basin: Fisher's alpha (mean and 95\% confidence limits).

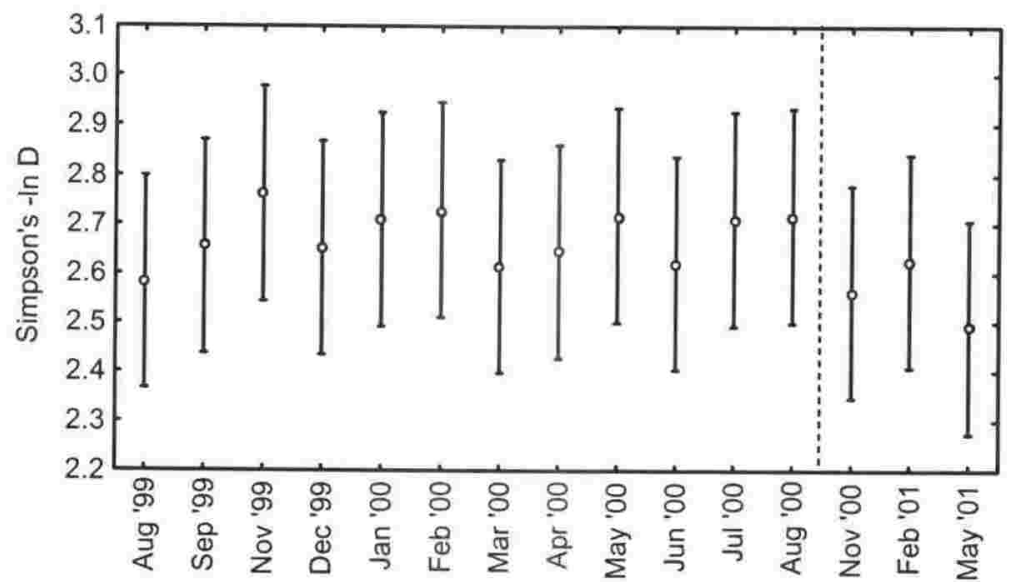

Figure 2.11 Harbour Basin: Simpson's $-\ln D$ (mean and 95\% confidence limits). 
Fisher's alpha was generally higher in the first seven months of the study. In February 2000 it reached the maximum mean value of 13.12 and dropped to 9.85 (minimum) in March 2000. Despite heteroscedasticity, the ANOVA result was valid, because it was not significant $(\mathrm{F}=1.151, \mathrm{MS}=2.998, \mathrm{df}=14, p=0.34)$.

Simpson's $-\ln$ D did not vary much at HB and ranged between 2.56 in May 2001 and 2.76 in November 1999. ANOVA results were non-significant $(\mathrm{F}=0.455, \mathrm{MS}=0.021, \mathrm{df}=14, p=0.94)$.

\section{Oriental Bay $(O B)$}

Results for the diversity indices at Oriental Bay are presented in Figure 2.12-Figure 2.17. Abundance $(N)$ increased progressively from a mean value of 691.3 ind. $0.1 \mathrm{~m}^{-2}$ in August 1999 (minimum) to a maximum of 3476 ind. $0.1 \mathrm{~m}^{-2}$ in February 2001. By May 2001 abundance had fallen to 1240 ind. $0.1 \mathrm{~m}^{-2}$. Differences in abundance among months proved to be highly significant $(\mathrm{F}=28.334, \mathrm{MS}=5003174, \mathrm{df}=5, p<0.001)$. Post-hoc comparisons showed every month with respect to $N$ to be different from at least two other months (Table 2.2).

Table 2.2 Oriental Bay: Results of Tukey HSD post-hoc comparisons for $N$ (mean number of individuals $0.1 \mathrm{~m}^{-2}$ ). ns=non-significant result.

\begin{tabular}{ccccccc}
\hline Month & Aug '99 & Dec '99 & Jun'00 & Nov'00 & Feb ‘01 & May ‘01 \\
\hline Aug '99 & & & & & & \\
Dec '99 & ns & & & & & \\
Jun '00 & 0.0015 & 0.0021 & & & & \\
Nov '00 & 0.0002 & 0.0002 & ns & & & \\
Feb ‘01 & 0.0002 & 0.0002 & 0.0035 & ns & & \\
May '01 & ns & ns & ns & 0.0025 & 0.0002 & \\
\hline
\end{tabular}

Mean number of species (S) increased steadily from August 1999 (46.5 species) until February 2001 (highest number of species at 78.0). By May 2001, mean number of species had fallen to $S=62.0$. Differences in $S$ among months were significant $(\mathrm{F}=16.596, \mathrm{MS}=618.44, \mathrm{df}=5, p<0.001)$. As with mean abundances, $S$ for every month was different from at least one other month (Table 2.2). 


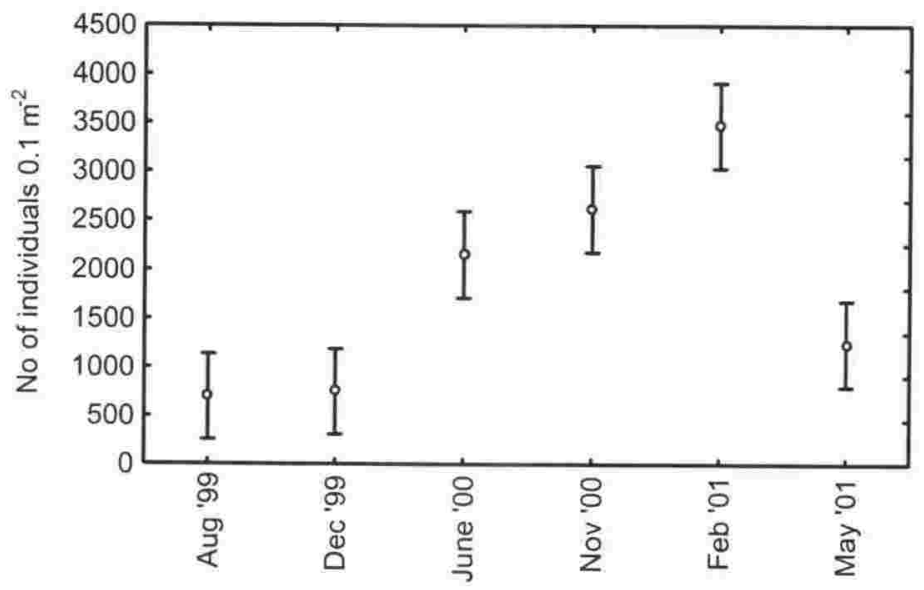

Figure 2.12 Oriental Bay: Number of individuals $(N) 0.1 \mathrm{~m}^{-2}$ (mean and $95 \%$ confidence limits).

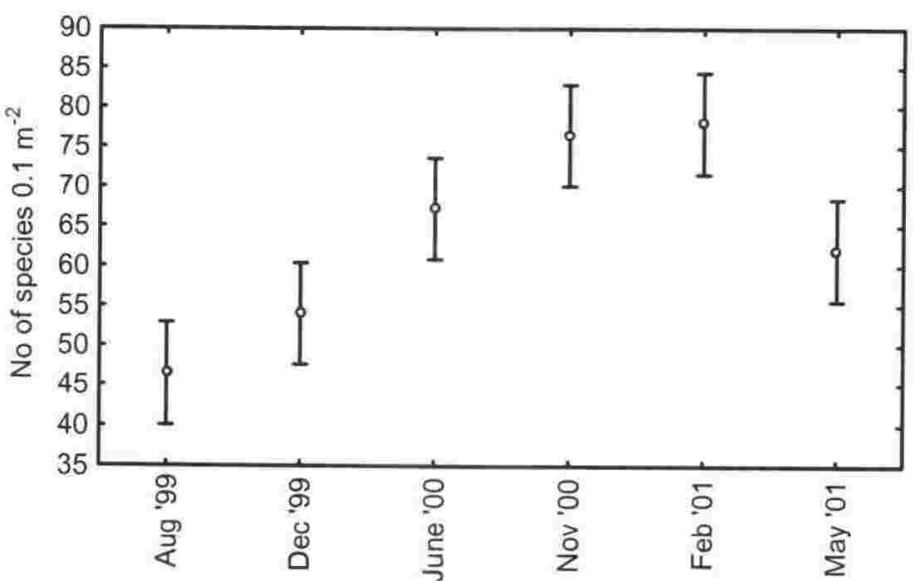

Figure 2.13 Oriental Bay: Number of species $(S) 0.1 \mathrm{~m}^{-2}$ (mean and $95 \%$ confidence limits).

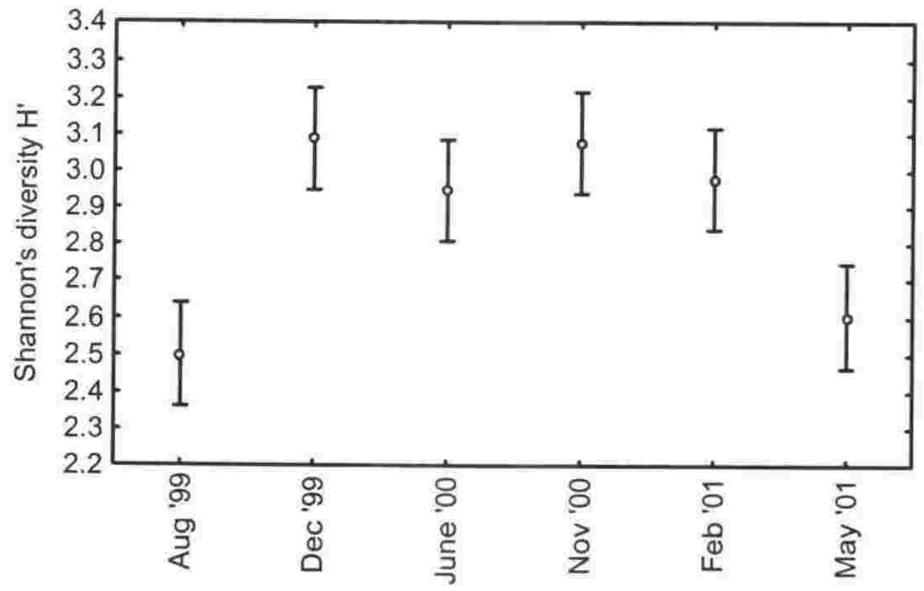

Figure 2.14 Oriental Bay: Shannon's diversity $\left(H^{\prime}\right)$ (mean and $95 \%$ confidence limits). 


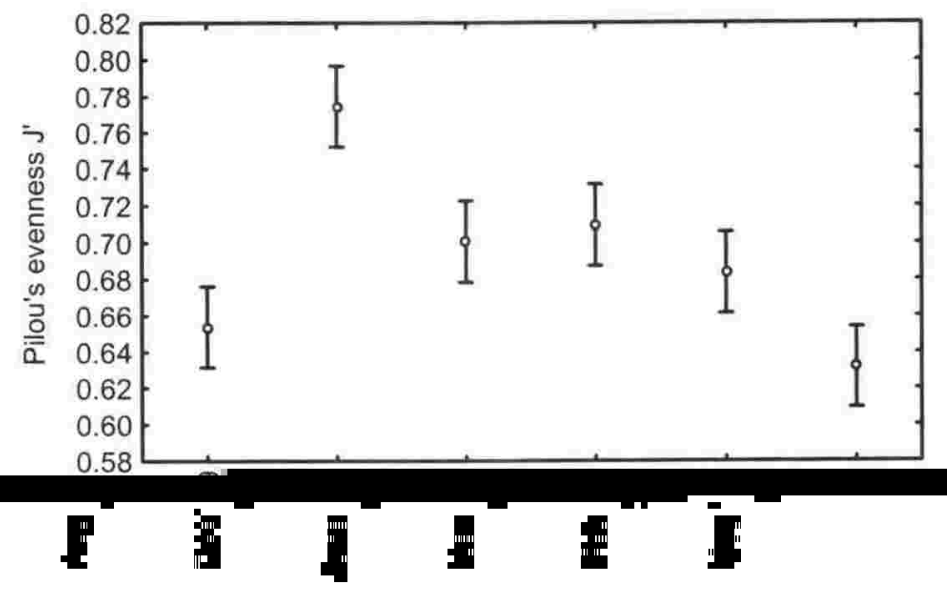

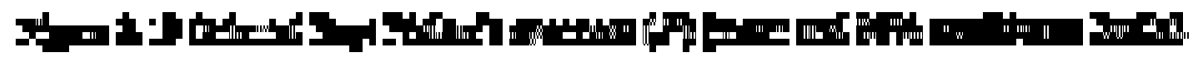

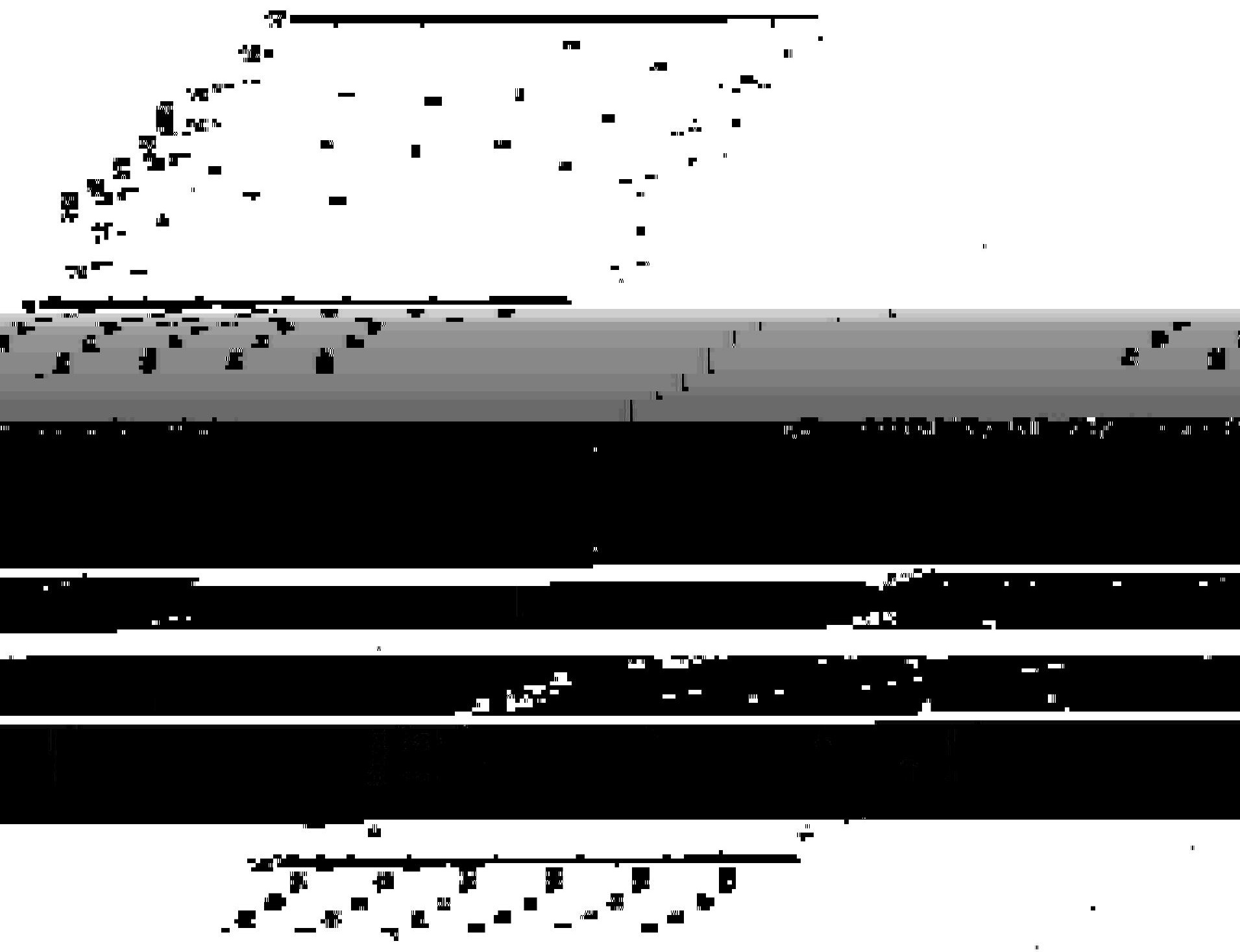


Table 2.3 Oriental Bay: Results of Tukey HSD post-hoc comparisons for $S$ (number of species $\left.0.1 \mathrm{~m}^{-2}\right) . \mathrm{ns}=$ non-significant result.

\begin{tabular}{ccccccc}
\hline Month & Aug '99 & Dec '99 & Jun '00 & Nov'00 & Feb ‘01 & May ‘01 \\
\hline Aug '99 & & & & & & \\
Dec '99 & ns & & & & & \\
Jun '00 & 0.0018 & ns & & & & \\
Nov '00 & 0.0002 & 0.0008 & ns & & & \\
Feb '01 & 0.0002 & 0.0005 & ns & ns & & \\
May '01 & 0.0218 & ns & ns & 0.0349 & 0.0171 & \\
\hline
\end{tabular}

Shannon's diversity index $\left(H^{\prime}\right)$ rose from its lowest mean value in August $1999\left(H^{\prime}=2.50\right)$ to its highest mean value in December $1999\left(H^{\prime}=3.09\right)$. Thereafter $H^{\prime}$ declined again to $H^{\prime}=2.60$ in May 2001. Differences in $H^{\prime}$ among months were significant $(\mathrm{F}=14.37, \mathrm{MS}=0.354, \mathrm{df}=5, p<0.001) . H^{\prime}$ values in December 1999 and May 2001 were not significantly different, but were different from $H^{\prime}$ values in all other months.

Pielou's evenness $\left(J^{\prime}\right)$ increased strongly between August $1999\left(J^{\prime}=0.65\right)$ and December 1999, where it reached its maximum of $J^{\prime}=0.77$. In June $2000 \mathrm{~J}$ fell to 0.70 and decreased further to $J^{\prime}=0.63$ in May 2001. Differences in $J$ among months were highly significant $(\mathrm{F}=22.09, \mathrm{MS}=0.0099, \mathrm{df}=5, p<0.001)$. Results of post-hoc tests are presented in Table 2.4.

Table 2.4 Oriental Bay: Results of Tukey HSD post-hoc comparisons for $J$ (Pielou's evenness). $\mathrm{ns}=$ non-significant result.

\begin{tabular}{ccccccc}
\hline Month & Aug '99 & Dec '99 & Jun '00 & Nov'00 & Feb ‘01 & May ‘01 \\
\hline Aug '99 & & & & & & \\
Dec '99 & 0.0002 & & & & & \\
Jun '00 & ns & 0.0014 & & & & \\
Nov'00 & 0.0162 & 0.0047 & ns & & & \\
Feb '01 & ns & 0.0003 & ns & ns & & \\
May '01 & ns & 0.0002 & 0.0026 & 0.008 & 0.0276 & \\
\hline
\end{tabular}

Fisher's alpha increased from its lowest value in August 1999 (11.31) until November 2000 where it reached the maximum value of 14.86 . Thereafter it gradually decreased until May 2001 (13.81). Differences in alpha amongst months were significant $(\mathrm{F}=3.219, \mathrm{MS}=5.799, \mathrm{df}=5, p=0.03)$. The only months to 
be significantly different from each other with respect to Fisher's alpha were August 1999 and November $2000(\mathrm{~F}=1.80, \mathrm{df}=18 ; p=0.016)$.

Simpson's $-\ln D$ was highest in December 1999 with 2.60 and decreased until its minimum was reached in May 2001 with 1.90. Time had a highly significant effect $(\mathrm{F}=12.133, \mathrm{MS}=0.3559, \mathrm{df}=5, p<0.001)$. Values of $-\ln D$ in August 1999 and May 2001 were non-significant, but were significantly different from all other months.

\section{Entrance Channel (EC)}

Results for the univariate diversity indices at Entrance Channel (EC) are presented in Figure 2.18-Figure 2.23. Number of individuals $(N)$ at EC changed markedly in the first six months of the study. Mean $N$ was lowest in August 1999 with 260.3 ind $0.1 \mathrm{~m}^{-2}$, followed by maximum abundance in November 1999 with 726.8 ind. $0.1 \mathrm{~m}^{-2}$. In May 2000 abundances were relatively low again (346.3 ind. $0.1 \mathrm{~m}^{-2}$ ), and fluctuated thereafter around $400-500$ ind. $0.1 \mathrm{~m}^{-2}$. Differences of $N$ among months were highly significant $(\mathrm{F}=9.759, \mathrm{MS}=104393$, $\mathrm{df}=7, p<0.001$ ). Results of post-hoc comparisons revealed mean abundances in November 1999 to be different from all other abundances except for the months of February and November 2000. $N$ in August 1999 differed from $N$ in November 1999, February and November 2000, and $N$ in February 2000 differed also from $N$ in May 2000 and 2001.

Mean number of species $(S) 0.1 \mathrm{~m}^{-2}$ rose from its lowest value in August $1999(S=38.75)$ to its maximum in November $1999(S=49.8)$, only to decline again in May 2000 ( $S=38.5$ ). The same pattern, but less pronounced, occurred in the second year of the investigation with $S$ increasing in spring (November 2000: $S=42.3$ ) and decreasing throughout summer and autumn (May 2001: $S=38.5$ ). Differences of $S$ among months were significant ( $\mathrm{F}=4.608, \mathrm{MS}=70.71, \mathrm{df}=7$, $p=0.002)$. $S$ in November 1999 was significantly different from $S$ in August 1999, August 2000 and May 2001.

Shannon's diversity $H^{\prime}$ declined from August $1999\left(H^{\prime}=2.95\right)$ onwards to reach its minimum in May $2000\left(H^{\prime}=2.6\right)$. In August $2000 H^{\prime}$ rose sharply to its maximum value of 2.99 and fell again in November 2000 to 2.62. From then on, 
$H^{\prime}$ increased until May 2001. Time had a significant effect on $H^{\prime} \quad(\mathrm{F}=4.29$, $\mathrm{MS}=0.0971, \mathrm{df}=7, p=0.003)$. Post-hoc comparisons revealed $H^{\prime}$ in May 2000 to be different from $H^{\prime}$ in August 2000 and May 2001, and $H^{\prime}$ in November 2000 differed significantly from $H^{\prime}$ in August 2000 and May 2001.

Pielou's evenness $\left(J^{\prime}\right)$ exhibited a similar trend as Shannon's $H^{\prime} . J$ was highest in August $1999\left(J^{\prime}=0.83\right)$, but remained low thereafter until May $2000\left(J^{\prime}=0.72\right)$. In August $2000 J^{\prime}$ rose to 0.81 , decreased to the lowest value of $J=0.70$ in November 2000 and increased thereafter. Highly significant differences with time were detected $(\mathrm{F}=10.45, \mathrm{MS}=0.009, \mathrm{df}=7, p<0.001)$, and $J$ for every month proved to be different from at least one other month (Table 2.4).

Table 2.5 Entrance Channel: Results of Tukey HSD post-hoc comparisons for Pielou's evenness $J \cdot$ ns=non-significant result.

\begin{tabular}{|c|c|c|c|c|c|c|c|c|}
\hline Month & $\begin{array}{l}\text { Aug } \\
\cdot 99\end{array}$ & $\begin{array}{c}\text { Nov } \\
\text { 99 }\end{array}$ & $\begin{array}{l}\text { Feb } \\
\text { '00 }\end{array}$ & $\begin{array}{c}\text { May } \\
\text { '00 }\end{array}$ & $\begin{array}{l}\text { Aug } \\
، 00\end{array}$ & $\begin{array}{l}\text { Nov } \\
' 00\end{array}$ & $\begin{array}{c}\text { Feb } \\
001\end{array}$ & $\begin{array}{c}\text { May } \\
601\end{array}$ \\
\hline \multicolumn{9}{|l|}{ Aug ‘99 } \\
\hline Nov"99 & 0.009 & & & & & & & \\
\hline Feb '00 & 0.022 & ns & & & & & & \\
\hline May '00 & 0.001 & ns & ns & & & & & \\
\hline Aug '00 & ns & ns & ns & 0.005 & & & & \\
\hline Nov "00 & 0.0002 & ns & ns & ns & 0.001 & & & \\
\hline Feb '01 & 0.004 & ns & ns & ns & 0.041 & ns & & \\
\hline May '01 & ns & 0.029 & ns & 0.002 & ns & 0.000 & 0.014 & \\
\hline
\end{tabular}

Fisher's alpha showed little variation over the course of this investigation but relatively large $\pm \mathrm{SD}$. The maximum value was reached in November 1999 (alpha $=12.13$ ) and was immediately followed by the lowest value in February 2000 (alpha=10.59). From May 2000 onwards, alpha fluctuated between 10.75 and 11.42. Differences of alpha among months were non-significant $(F=0.493$, $\mathrm{MS}=0.993, \mathrm{df}=7, p=0.83$ ). 


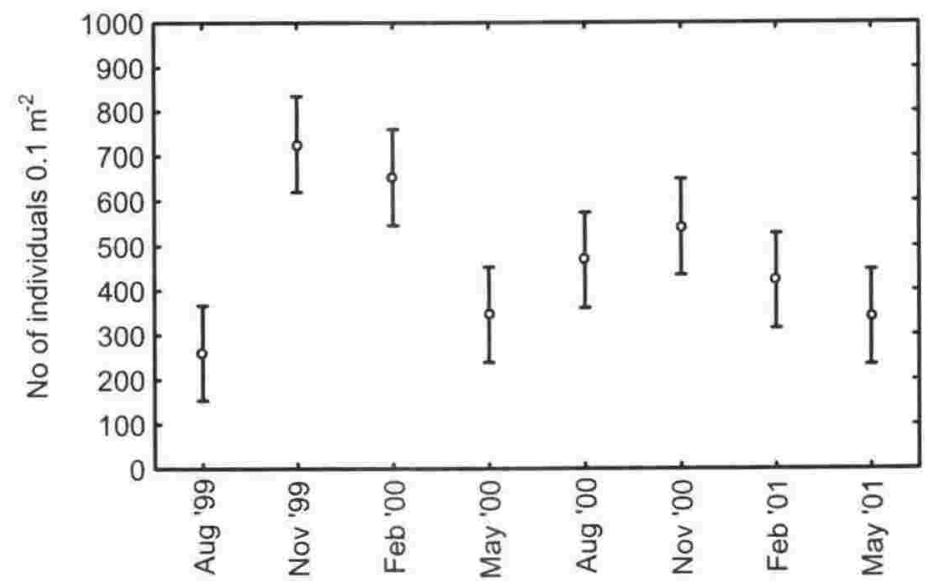

Figure 2.18 Entrance Channel: Number of individuals $(N) 0.1 \mathrm{~m}^{-2}$ (mean and $95 \%$ confidence limits).

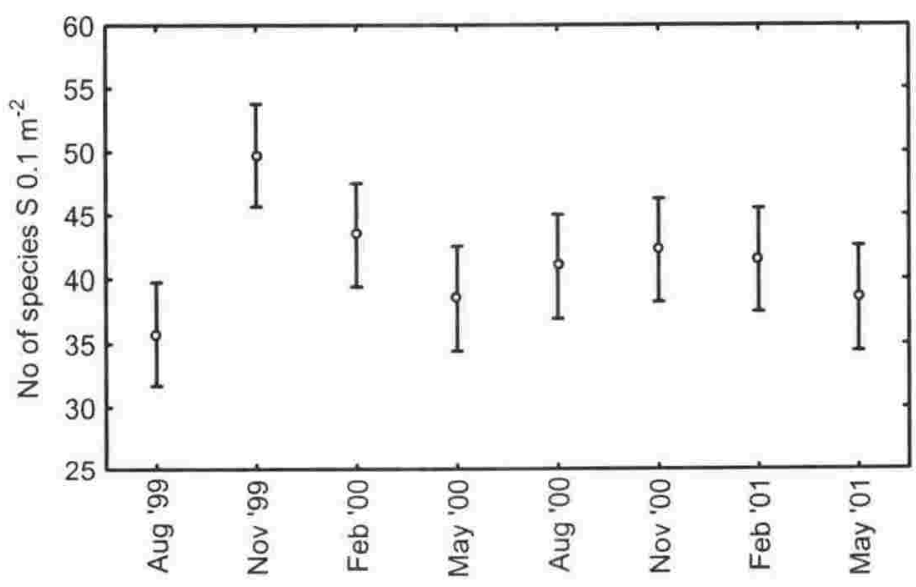

Figure 2.19 Entrance Channel: Number of species $(S) 0.1 \mathrm{~m}^{-2}$ (mean and $95 \%$ confidence limits).

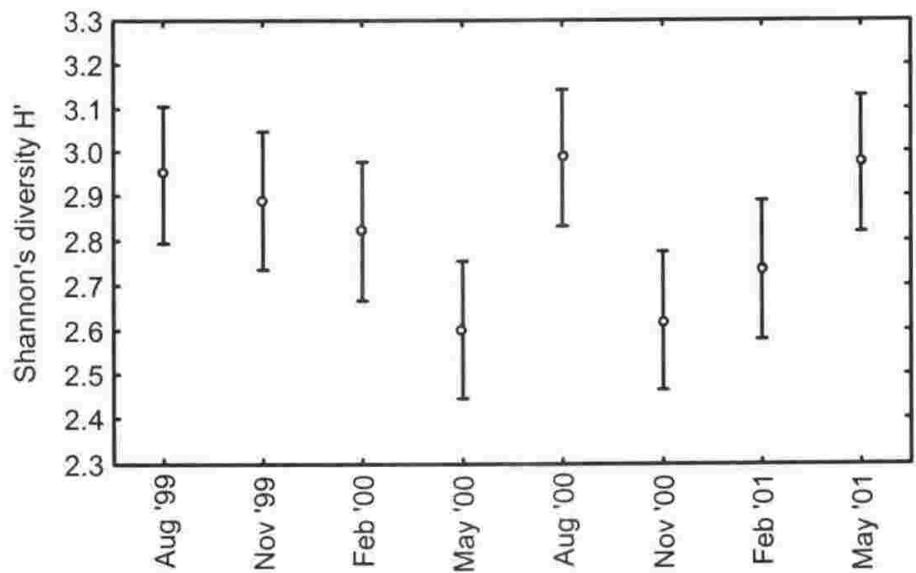

Figure 2.20 Entrance Channel: Shannon's diversity $\left(H^{\prime}\right)$ (mean and 95\% confidence limits). 


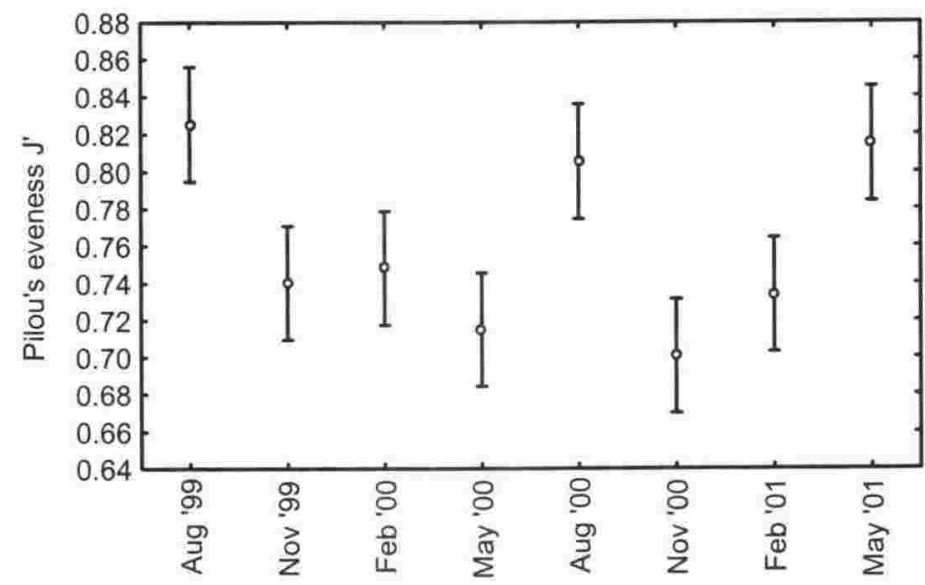

Figure 2.21 Entrance Channel: Pielou's evenness $(J)$ (mean and 95\% confidence limits).

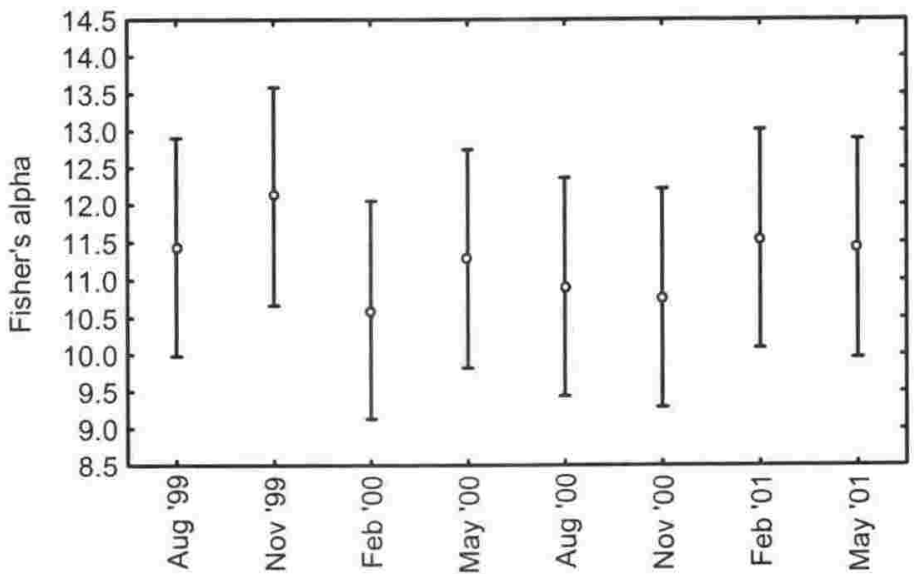

Figure 2.22 Entrance Channel: Fisher's alpha (mean and 95\% confidence limits).

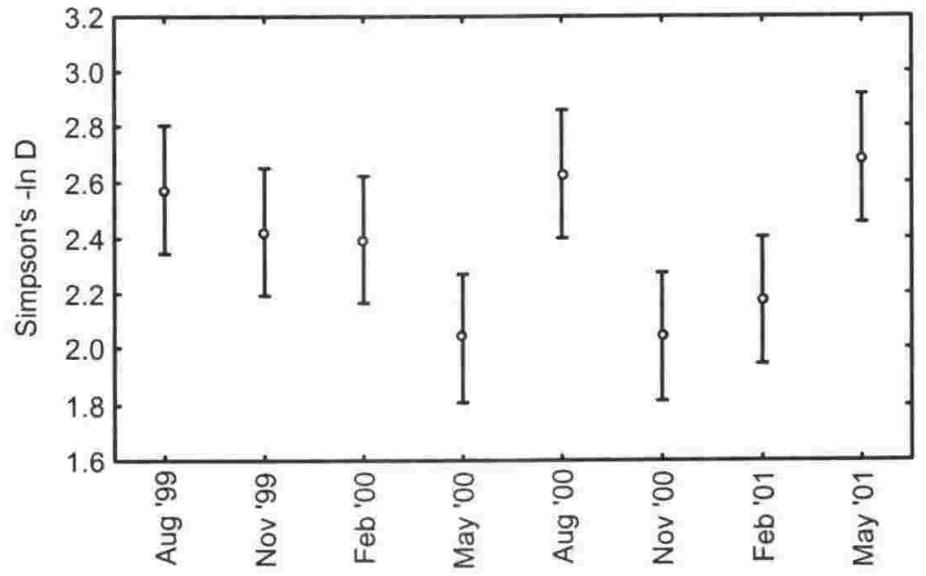

Figure 2.23 Entrance Channel: Simpson's $-\ln D$ (mean and 95\% confidence limits). 
Simpson's - $\ln D$ decreased from August 1999 to May 2000 (2.04), rose to its maximum in August 2000 (2.63), declined in November 2000 to recover again in February and May 2001. Differences in Simpson $-\ln D$ among months were significant effects with respect to time $(\mathrm{F}=5.356, \mathrm{MS}=0.2651, \mathrm{df}=7$, $p<0.001)$. Simpson's $-\ln D$ in May and November 2000 proved to be significantly different from Simpson's - In D in August 1999, August 2000 and May 2001.

\section{Multivariate Analyses}

\section{Cluster and Ordination (between sites)}

Hierarchical clustering of group-averaged pre-and post-bloom abundance data (aggregated to order level and absence-presence transformed) is presented in Figure 2.24. To accommodate for the different mesh size used in the initial postbloom samples (May 1998-March 1999), only the $1000 \mu \mathrm{m}$ fraction of the latestage post-bloom samples (August 1999-May 2001) was used. The OB prebloom samples (March + August 1997) separated from all other samples at ca. $51 \%$ similarity. A sub-cluster formed by the HB pre-bloom (HP: summer 199495) and first post-bloom samples (HM0: May 1998) split off at ca. 52\% similarity. The remaining HB samples separated from OB and EC samples at the $64 \%$ similarity level. A sub-cluster of the second and third HB samples taken post-bloom (data label: $\mathrm{HN} 0$ and $\mathrm{HMr} 1$ ) was recognised at $\sim 66 \%$ similarity. Samples taken from August 1999-May 2001 were similar at $80 \%$ with the exceptions of HS1, which separated at ca. 75\% similarity, and HM3 (May 2001), which was clustered with EC post-bloom samples. No evidence of further structuring with regard to time was evident in the HB cluster. 


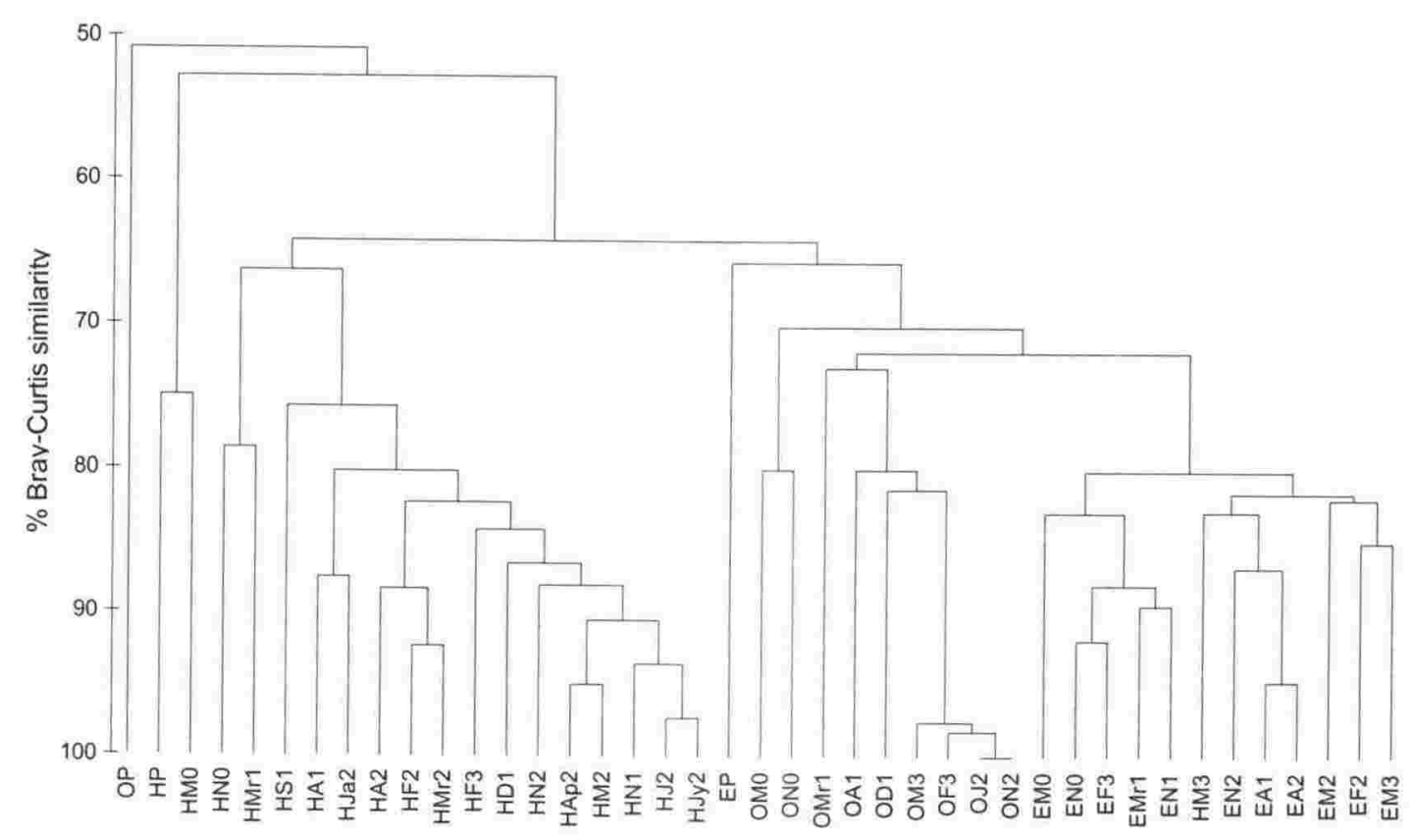

Figure 2.24 Dendrogram using group-average linking of Bray-Curtis similarities of presenceabsence transformed abundance data (order level) for 3 sites in Wellington Harbour. Pre-bloom samples: $\mathrm{n}=5$ and mesh size $=1000 \mu \mathrm{m}$. Initial post -bloom samples (May 1998-March 1999): $\mathrm{n}=5$ (except HMrl: $\mathrm{n=4}$ ) and mesh size $=800 \mu \mathrm{m}$. Late-stage post-bloom samples (August 1999-May 2001): $n=4$ and mesh size $=1000 \mu \mathrm{m}$. Sample labelling: $H=$ Harbour Basin $O=$ Oriental Bay, $\mathrm{E}=$ Entrance Channel; $\mathrm{P}=$ pre-bloom, Ja=January, $\mathrm{F}=$ February, $\mathrm{Mr}=\mathrm{March}$, etc.; $0=1998,1=1999$, 2=2000 and 3=2001. For example OD1=Oriental Bay December 1999.

$\mathrm{OB}$ and $\mathrm{EC}$ samples were more similar to each other than to the HB samples. The EC pre-bloom samples (EP: summer 1991-92) separated from all $\mathrm{OB}$ and $\mathrm{EC}$ samples at a level of $65 \%$. Within the post-bloom $\mathrm{OB}$ and $\mathrm{EC}$ samples, OB samples taken in May 1998 (OM0) and November 1998 (ON0) were separated at $70 \%$ similarity, whereas the remaining samples split into two sub-clusters at a level of $72 \%$ similarity. The OB sub-cluster split into two groups, one of them consisting of samples taken in 1999. The second group, samples taken in 2000 and 2001, showed a high similarity of ca. 97\%. Hence, some structure with regard to time was evident in the $\mathrm{OB}$ samples.

The post-bloom EC samples (and HB May 2001 samples) formed a distinct cluster with ca. $80 \%$ similarity. Although this group split into two subclusters, no evidence for structure with regard to time was obvious in the EC samples. 


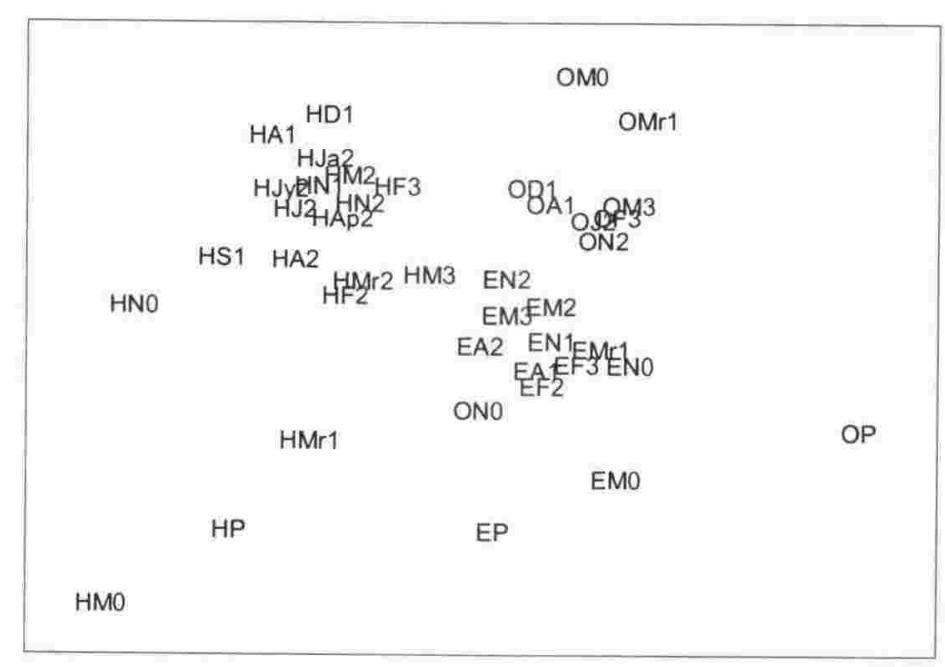

Figure 2.25 MDS ordination of Bray-Curtis similarities for same data as in Fig. 2.24. Stress=0.16. $\mathrm{H}=$ Harbour Basin $\mathrm{O}=$ Oriental Bay, $\mathrm{E}=$ Entrance Channel; $\mathrm{Ja}=\mathrm{January}, \mathrm{F}=$ February, $\mathrm{Mr}=\mathrm{March}$, etc.; $\mathrm{P}=$ pre-bloom, $0=1998,1=1999,2=2000$ and 3=2001. For example OD1=Oriental Bay December 1999.

Multi-dimensional scaling (MDS) ordination of the same similarity matrix as used for the above dendrogram (Figure 2.24) is presented in Figure 2.25 , giving a visual representation of (dis)similarity among samples taken at the three different sites.

All HB samples are located in the left-hand half of the MDS ordination with samples taken from August 1999-May 2001 forming a relatively discrete cluster in the top half. The HB pre- and immediate post-bloom samples are placed wide apart from each other mainly in the bottom half. OB and EC samples are spread to the right of the HB samples with the OB samples mainly in the top half and the EC samples in the bottom half. The OB pre-bloom samples are isolated on the right-hand side of the ordination. The immediate post-bloom $\mathrm{OB}$ samples (OM0, ON0 and OMr1) are slightly separated from the remaining OB samples with ONO being closer to the EC cluster. The EC samples are located relatively close together and only the pre- and first post-bloom samples (EP and EM0) are separated from the main group.

The stress ( 0.16$)$ of the MDS ordination indicates that the 2-dimensional plot is still a usable representation of the sample relationship. 


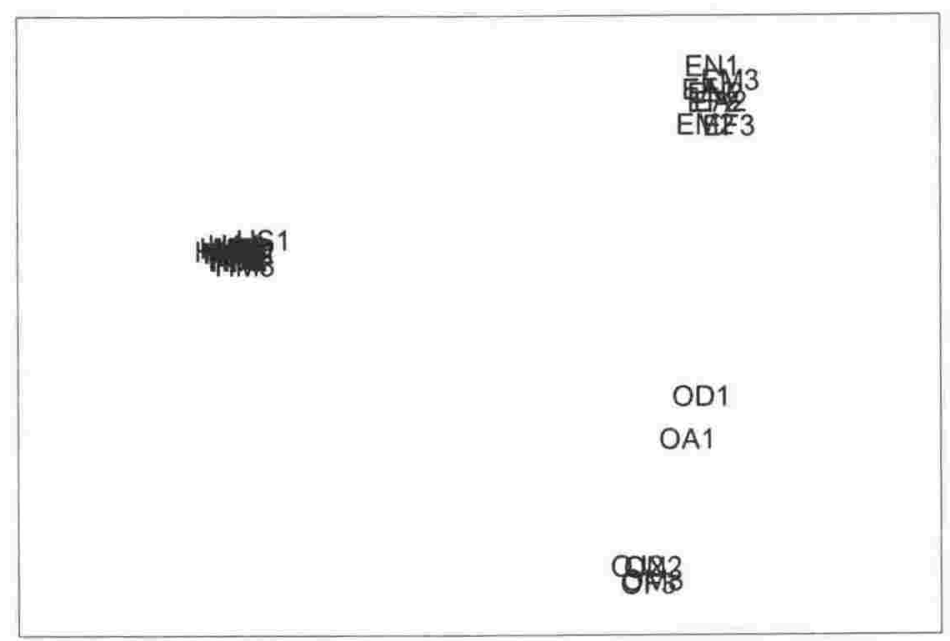

Figure 2.26 MDS ordination using group-averaged Bray-Curtis similarities from standardised, 4th-root transformed abundance data $(>500 \mu \mathrm{m})$ for 3 sites in Wellington Harbour (August 1999-

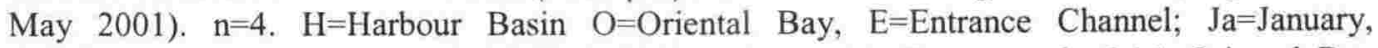
$\mathrm{F}=$ February, Mr=March, etc.; $1=1999,2=2000$ and $3=2001$. For example OAl=Oriental Bay August 1999. Stress=0.02.

Multidimensional scaling was also performed on species abundance data (>500 $\mu \mathrm{m}$ size fraction) from August 1999-May 2001 for all three sites (Figure 2.26) to eliminate a possible distorting effect of the pre- and initial post-bloom samples. The ordination of the samples within the MDS was different to Figure 2.25 with clusters for $\mathrm{HB}$ and $\mathrm{EC}$ being far more discrete. Within the OB cluster, a clear split was obvious at the $50 \%$ similarity level. Stress was very low $(=0.02)$, indicating an excellent representation of the true sample relationship.

Clear differences in the ordination of the samples emerged from Figure 2.25 and Figure 2.26. Whether these differences were entirely due to biological processes or partly due to sample artefacts (different mesh sizes used, species identification performed by different workers, initial pre-bloom samples washed in freshwater and fixed in unbuffered formalin solution) cannot be determined. Therefore I took a conservative approach and the remaining analyses in this chapter have been carried out using the late-stage post-bloom samples only (August 1999-May 2001) with the exception of site-specific MDS ordinations and the Indices of Multivariate Dispersion and Multivariate Seriation, which were produced with and without pre- and immediate post-bloom data in order to 
test whether they could also be used for the assessment of long-term recovery processes without reference data.

\section{Significance Testing (among sites)}

A one-way analysis of similarity (ANOSIM) was performed to test the null hypothesis of 'no difference among the three sites in assemblage composition' on the transformed and standardised Bray-Curtis similarities of the late-stage post-bloom samples. Note that, although the three sites had been clearly separated in the MDS ordination of Figure 2.26, the ordination is not a formal proof of statistical difference. The null hypothesis was rejected (Global $R=0.998$ ), indicating that replicates within each site were more similar to each other than to replicates from other sites (Table 2.6). Pairwise comparisons revealed $\mathrm{OB}$ and $\mathrm{EC}$ to be more different from $\mathrm{HB}$ than from each other.

Table 2.6 ANOSIM analyses. Differences in community structure among 3 sites in Wellington Harbour: $\mathrm{HB}=$ Harbour Basin, $\mathrm{OB}=$ Oriental Bay, EC=Entrance Channel. Data were $4^{\text {th }}$-root transformed.

\begin{tabular}{ccc}
\hline Sites compared & $R$-value & Significance level $p$ \\
\hline HB, OB, EC & $0.998($ Global $R)$ & 0.001 \\
HB, OB & 1.0 & 0.001 \\
HB, EC & 1.0 & 0.001 \\
OB, EC & 0.959 & 0.001 \\
\hline
\end{tabular}

\section{Cluster and Ordination (within sites)}

\section{Harbour Basin (HB)}

An MDS-ordination for HB pre-and post-bloom samples is presented in Figure 2.27. Pre-bloom samples are scattered in the lower half of the ordination and the first post-bloom samples (May 1998) on the upper left-hand side. Both these groups show a high degree of variability amongst replicate samples. The November 1998 and March 1999 samples are set slightly apart from the remaining post-bloom samples, which form a discrete cluster. With a stress of 1.16 the MDS-ordination is a usable presentation of the true sample relationship. 


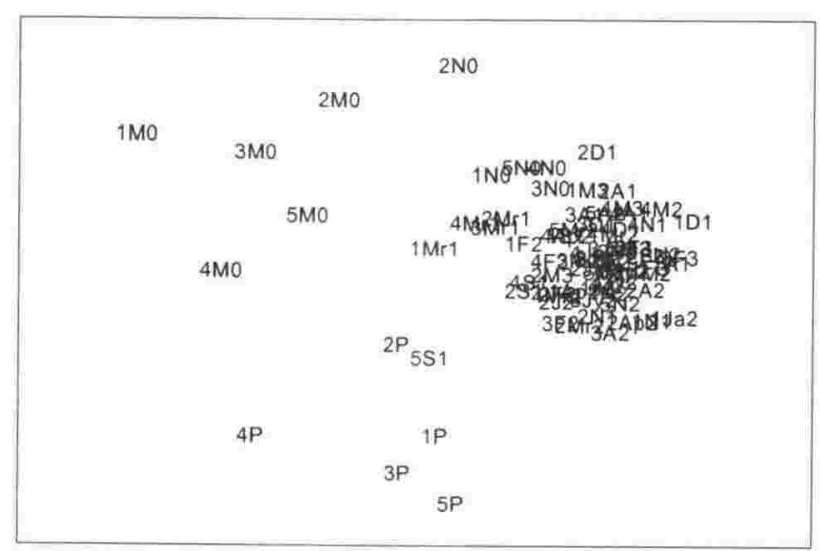

Figure 2.27 Harbour Basin: MDS ordination using Bray-Curtis similarities of presenceabsence transformed abundance data aggregated to order level. Sample labelling: $1 \mathrm{P}=$ first replicate pre-bloom, $4 \mathrm{M} 0=$ fourth replicate May 1998, 2F3=second replicate February 2001, etc. Stress $=0.16$.

Cluster and MDS ordination for the HB late-stage post-bloom samples are presented in Figure 2.28 and Figure 2.29. All replicates displayed high similarities in their faunal assemblage ( $>60 \%$ similarity). No obvious clustering of replicate groups occurred. In the MDS, samples were relatively evenly spread with no distinct clustering (Figure 2.29). Some evidence of structuring with respect to time is obvious. Whereas 1999 samples were found mainly from the right side towards the top middle of the ordination, year 2000 samples were spread from the mid- towards the lower centre and 2001 samples were placed from the middle towards the left hand side of the ordination. Stress levels (0.24) were high, i.e., the two-dimensional presentation of the real sample relationship has to be interpreted with caution. 


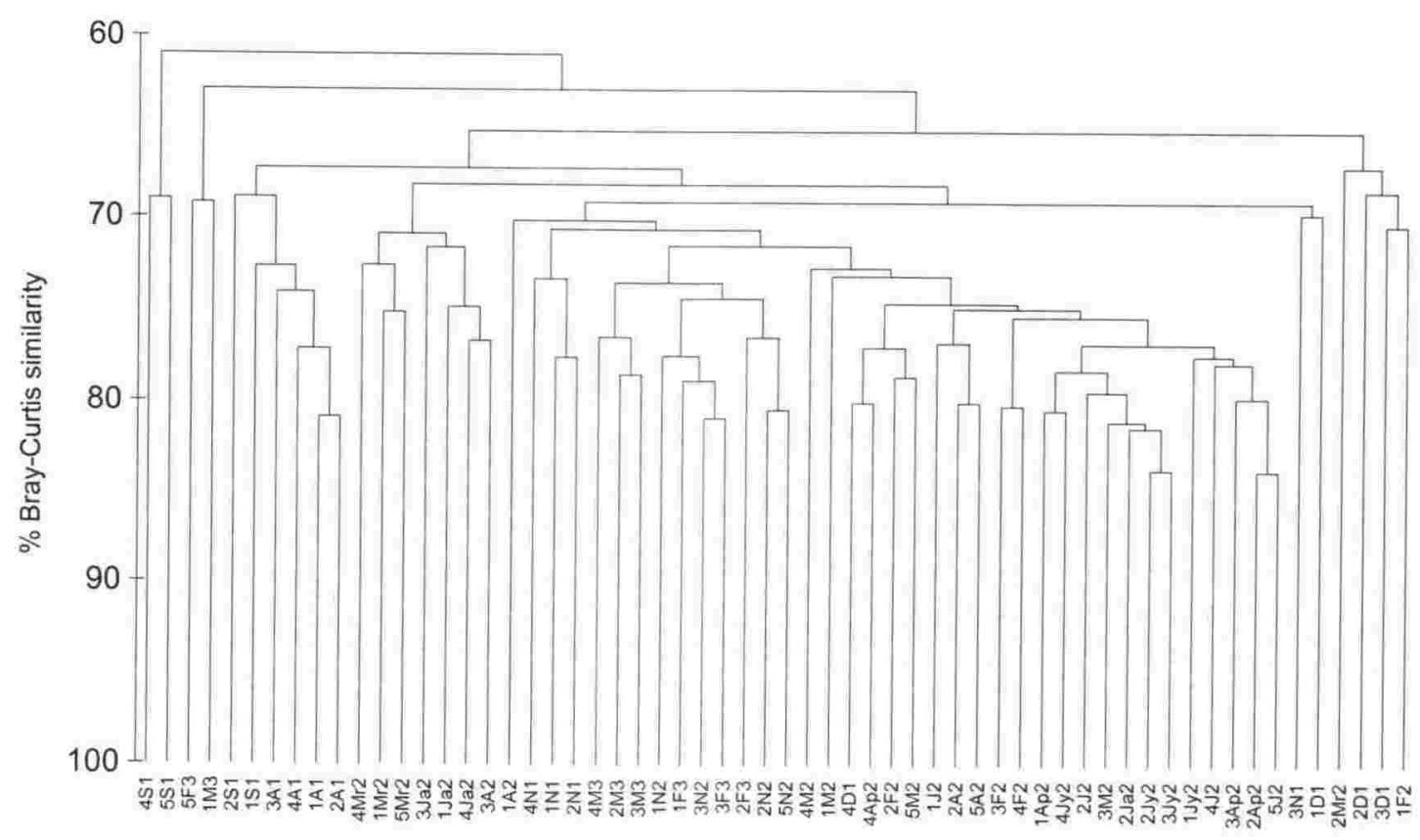

Figure 2.28 Harbour Basin: Dendrogram using linking of Bray-Curtis similarities of $4^{\text {th }}$-root transformed abundance data. $\mathrm{n}=4$. Sample labelling: 1D1=first replicate December 1999, $4 \mathrm{~N} 2=$ fourth replicate November $00,2 \mathrm{~F} 3=$ second replicate February 2001 , etc.

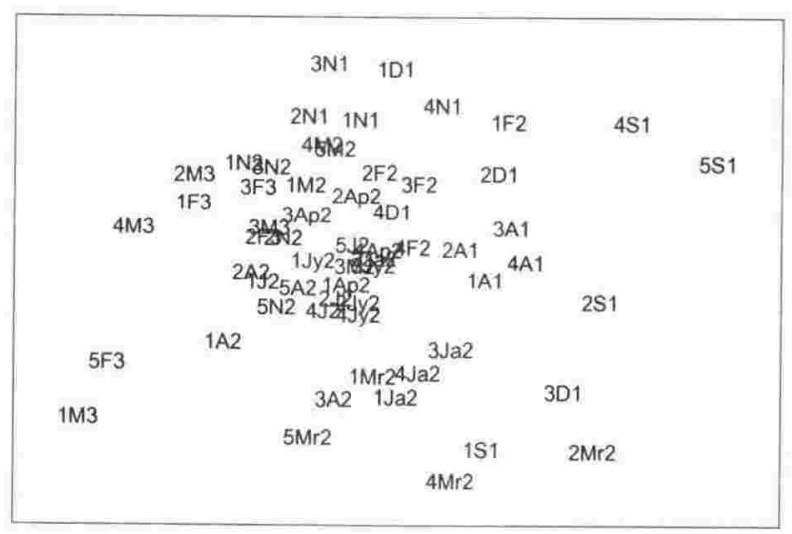

Figure 2.29 Harbour Basin: MDS ordination using Bray-Curtis similarities of $4^{\text {th }}$-root transformed abundance data. Sample labelling: 1D1=first replicate December 1999, $4 \mathrm{~N} 1=$ fourth replicate November $2000,2 \mathrm{~F} 3=$ second replicate February 2001 , etc. Stress $=0.24$. 


\section{Oriental Bay $(O B)$}

In the MDS ordination of $\mathrm{OB}$ pre- and post-bloom data the pre-bloom samples (Figure 2.30) are scattered about the left-hand site of the ordination. The immediate post-bloom samples (May and November 1998, March 1999) are located more towards the middle of the ordination. Especially the pre-bloom and May and November 1998 samples show a high degree of variability amongst replicate samples. The late-stage post-bloom samples form a distinct cluster towards the right. Within this cluster the 1999 samples are separated from the 2000 and 2001 samples. The stress level of 0.14 indicates a realistic representation of the realistic sample relationship.

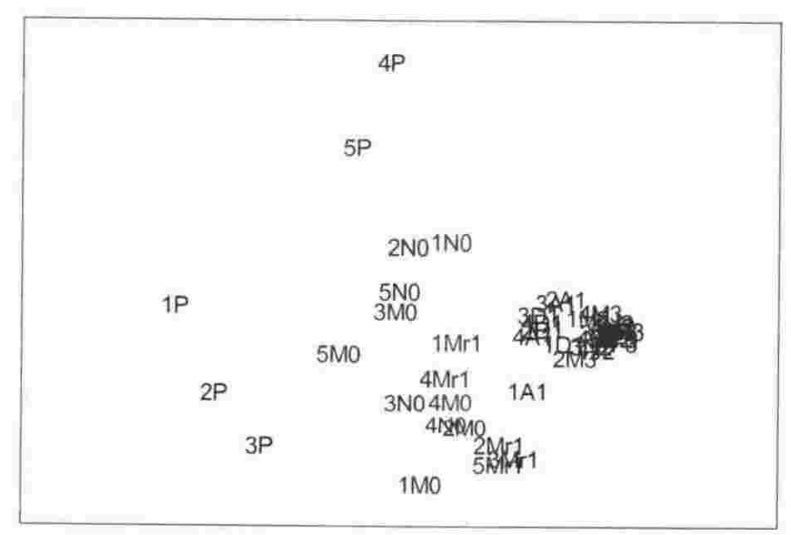

Figure 2.30 Oriental Bay: MDS ordination using Bray-Curtis similarities of presence-absence transformed abundance data aggregated to order level. Sample labelling: $4 \mathrm{P}=$ fourth replicate pre-bloom, 3A1=third replicate August 1999, 1J2=first replicate June 2000, 2M3=second replicate May 2001, etc. Stress $=0.14$.

Dendrogram and MDS ordination for the late-stage post-bloom samples are presented in Figure 2.31 and Figure 2.32. Two main clusters separated at the $40 \%$ similarity level: cluster I comprised all August (1A1-4A1) and December 1999 (1D1-4D1) replicate samples, whereas cluster II comprised all year 2 and 3 samples. Within cluster II there was no evidence for structuring with respect to time. 


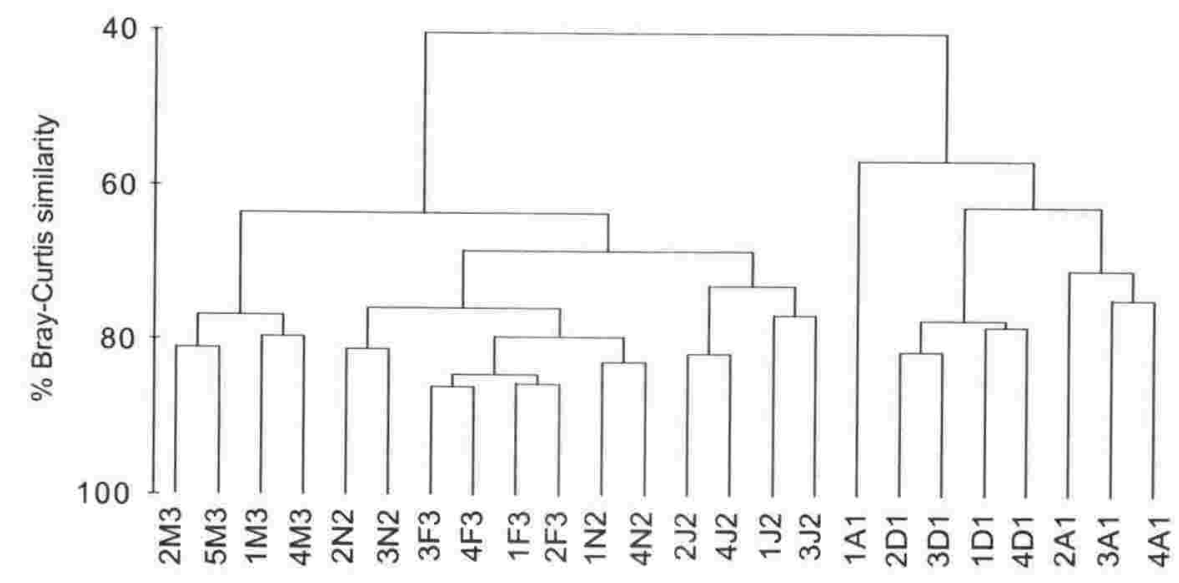

Figure 2.31 Oriental Bay: Dendrogram using linking of Bray-Curtis similarities of $4^{\text {th }}$-root transformed abundance data. Sample labelling: $3 \mathrm{Al}=$ third replicate August 1999, 1 J2=first replicate June 2000, 2M3=second replicate May 2001, etc.

Clusters I and II were clearly separated in the MDS plot (Figure 2.32), with both clusters dividing into sub-clusters at varying similarity levels. Cluster I split into several groups. The December 1999 samples formed a relatively discrete sub-cluster, whereas the remaining August 1999 samples were more spread out with the first replicate (1A1) being placed apart from the group. Stress levels of the MDS $(=0.04)$ indicate an excellent representation of the true sample relationship.

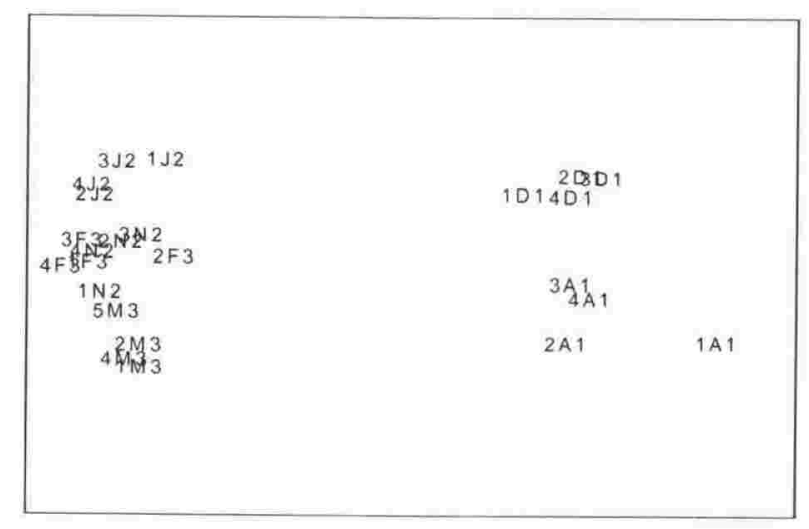

Figure 2.32 Oriental Bay: MDS ordination using Bray-Curtis similarities of $4^{\text {th }}$-root transformed abundance data. Sample labelling: $3 \mathrm{~A} 1=$ third replicate August 1999, 1J2=first replicate June 2000, 2M3 =second replicate May 2001, etc. Stress=0.04. 


\section{Entrance Channel (EC)}

The EC pre- and post-bloom samples are widely scattered in the MDS ordination (Figure 2.33) indicating variability in the faunal assemblages among replicate samples. The late-stage post-bloom samples are located closer together but no pattern is obvious with regard of temporal structure within these samples. The two-dimensional representation of the true sample relationship in the MDS ordination is acceptable (stress level: 0.14).

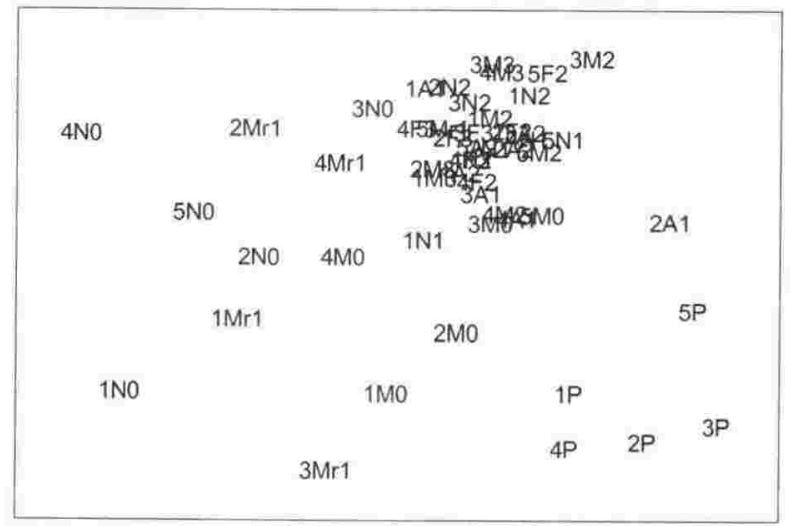

Figure 2.33 Entrance Channel: MDS ordination using Bray-Curtis similarities of presenceabsence transformed abundance data aggregated to order level. Sample labelling: $3 \mathrm{P}=$ third replicate pre-bloom, 1A1=first replicate August 1999, 4N2=fourth replicate November 2000, $2 \mathrm{~F} 3=$ second replicate February 2001, etc. Stress $=0.15$.

All late-stage post-bloom samples are similar at a 55\% similarity level, but no obvious main clusters were displayed in either the dendrogram or the MDS plot (Figure 2.34, Figure 2.35). Although replicates of each sample month formed sub-clusters in the dendrogram, these clusters were not distinct in the MDS, indicating variability in faunal assemblages among replicates.

In the MDS no obvious patterns occur. Replicates of February 2000 and 2001 (1-4F1 and 1-4F2) form a separate group at the 57\% similarity level. The remaining samples split into two groups at the $63 \%$ level with one group consisting of May 2000 replicates (1-4M2). The other group was formed by replicate samples from August and November 1999 and 2000, and May 2001. With a stress level of 0.17 the MDS is an acceptable representation of the real sample relationships. 


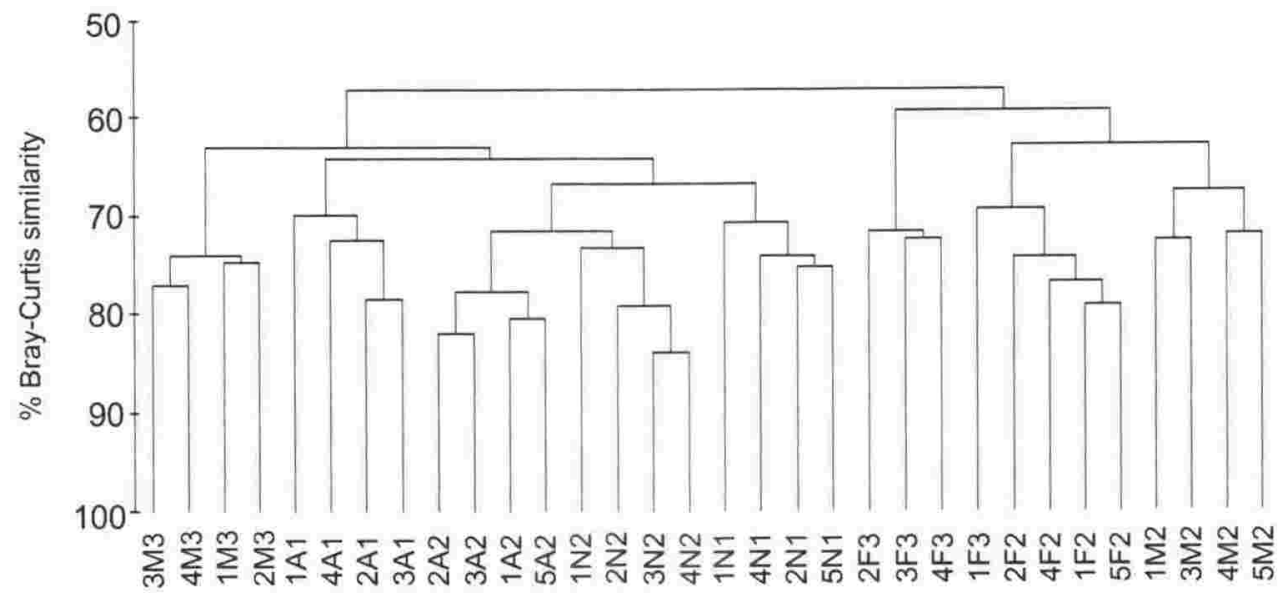

Figure 2.34 Entrance Channel. Dendrogram using linking of Bray-Curtis similarities of $4^{\text {th }}$ root transformed abundance data. Sample labelling: $1 \mathrm{Al}=$ first replicate August 1999, $4 \mathrm{~N} 2=$ fourth replicate November 2000, 2F3=second replicate February 2001, etc.

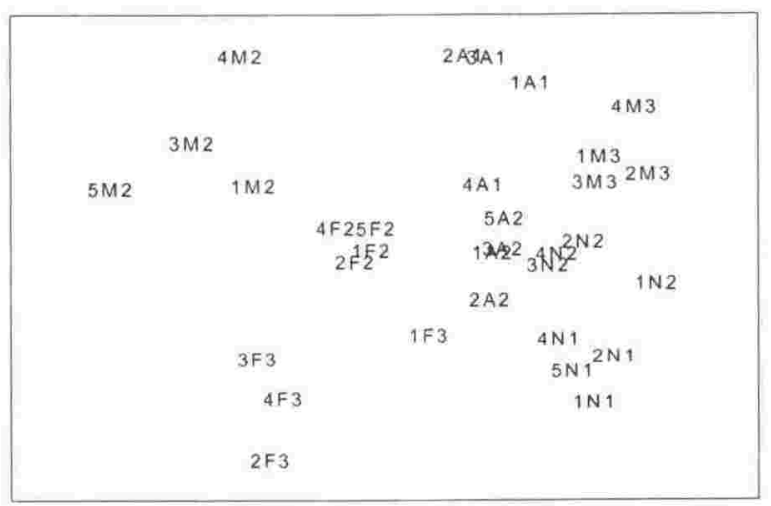

Figure 2.35 Entrance Channel: MDS ordination using Bray-Curtis similarities of $4^{\text {th }}$-root transformed abundance data. Sample labelling: $1 \mathrm{Al}=$ first replicate August $1999,4 \mathrm{~N} 2=$ fourth replicate November 2000, 2F3 $=$ second replicate February 2001, etc. Stress $=0.17$.

\section{Significance Testing (within sites)}

Two-way crossed ANOSIM analyses were carried out for each site separately to test the effect of the factors year $(1=1999,2=2000,3=2001)$ and season (spring $=\mathrm{Sp}$, summer $=\mathrm{S}$, autumn $=\mathrm{A}$, winter $=\mathrm{W}$ ) on differences in community structure. Two null hypotheses were tested: $\mathrm{H}_{0} 1$ : no difference in community structure among years 1,2 and 3, allowing for differences among seasons; and $\mathrm{H}_{0} 2$ : no difference in community structure among seasons, allowing 
for differences among years. MDS ordinations were generated using factor instead of sample labels to visualise the effect of both factors on faunal assemblages.

Table 2.7 Two-way crossed ANOSIM analysis testing for effect of factors year $(1=1999,2=2000$, $3=2001$ ) and season ( $\mathrm{Sp}=$ spring, $\mathrm{S}=$ summer, $\mathrm{A}=$ autumn, $\mathrm{W}=$ winter) on community structure from 3 sites in Wellington Harbour: $\mathrm{HB}=$ Harbour Basin, $\mathrm{OB}=$ Oriental Bay, $\mathrm{EC}=$ Entrance Channel. $\mathrm{OB}$ and $\mathrm{EC}$ : some groups were too small for pairwise tests $(-)$. Data: $4^{\text {th }}$-root transformed.

\begin{tabular}{|c|c|c|c|c|}
\hline Site & Factor & Groups compared & $R$-value & Significance level $p$ \\
\hline \multirow[t]{11}{*}{ HB } & Year & $1,2,3$ & $0.522($ Global $R)$ & 0.001 \\
\hline & & 1,2 & 0.500 & 0.001 \\
\hline & & 1,3 & 0.406 & 0.029 \\
\hline & & 2,3 & 0.544 & 0.001 \\
\hline & Season & $\mathrm{Sp}, \mathrm{S}, \mathrm{A}, \mathrm{W}$ & $0.201($ Global $R)$ & 0.002 \\
\hline & & $\mathrm{W}, \mathrm{Sp}$ & 0.351 & 0.001 \\
\hline & & W, S & 0.353 & 0.001 \\
\hline & & $\mathrm{W}, \mathrm{A}$ & 0.132 & 0.005 \\
\hline & & $\mathrm{Sp}, \mathrm{S}$ & 0.280 & 0.018 \\
\hline & & $\mathrm{Sp}, \mathrm{A}$ & 0.229 & 0.107 \\
\hline & & $\mathrm{S}, \mathrm{A}$ & 0.135 & 0.041 \\
\hline \multirow[t]{11}{*}{ OB } & Year & $1,2,3$ & $1.0($ Global $R)$ & 0.002 \\
\hline & & 1,2 & 1.0 & 0.029 \\
\hline & & 1,3 & 1.0 & 0.029 \\
\hline & & 2,3 & - & - \\
\hline & Season & $\mathrm{Sp}, \mathrm{S}, \mathrm{A}, \mathrm{W}$ & 0.844 (Global $R)$ & 0.001 \\
\hline & & W, Sp & 0.792 & 0.029 \\
\hline & & W, S & 0.781 & 0.029 \\
\hline & & $\mathrm{W}, \mathrm{A}$ & - & - \\
\hline & & $\mathrm{Sp}, \mathrm{S}$ & - & - \\
\hline & & $\mathrm{Sp}, \mathrm{A}$ & - & - \\
\hline & & $\mathrm{S}, \mathrm{A}$ & 1.0 & 0.029 \\
\hline \multirow[t]{11}{*}{$\mathrm{EC}$} & Year & $1,2,3$ & $0.878($ Global $R)$ & 0.001 \\
\hline & & 1,2 & 0.839 & 0.001 \\
\hline & & 1,3 & - & - \\
\hline & & 2,3 & 0.917 & 0.002 \\
\hline & Season & $\mathrm{Sp}, \mathrm{S}, \mathrm{A}, \mathrm{W}$ & $0.919($ Global $R)$ & 0.001 \\
\hline & & $\mathrm{W}, \mathrm{Sp}$ & 0.922 & 0.002 \\
\hline & & $\mathrm{W}, \mathrm{S}$ & 1.0 & 0.029 \\
\hline & & $\mathrm{W}, \mathrm{A}$ & 1.0 & 0.029 \\
\hline & & $\mathrm{Sp}, \mathrm{S}$ & 1.0 & 0.029 \\
\hline & & $\mathrm{Sp}, \mathrm{A}$ & 1.0 & 0.029 \\
\hline & & S, A & 0.917 & 0.001 \\
\hline
\end{tabular}




\section{Harbour Basin (HB)}

Both null hypotheses were rejected, but at different levels of significance $\left(\mathrm{H}_{0}\right.$ 1: Global $R=0.522, p<0.001 ; \mathrm{H}_{0} 2$ : Global $\left.R=0.201, p=0.002\right)$. Differences in community structure were more pronounced among years than among seasons (Table 2.7, Figure 2.36). Faunal assemblages differed most between 2000 and 2001. Pairwise tests for the factor season indicated differences in community structure between winter and spring and between winter and summer to be greatest. Only a comparison of spring versus autumn assemblages proved to be non-significant.

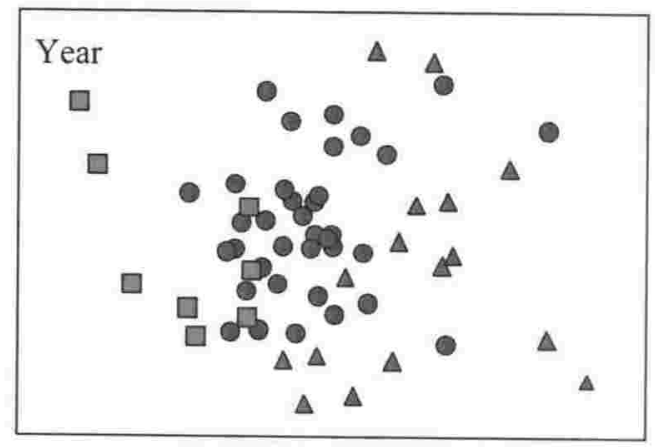

$\Delta$ Year 1

O Year 2

Year 3

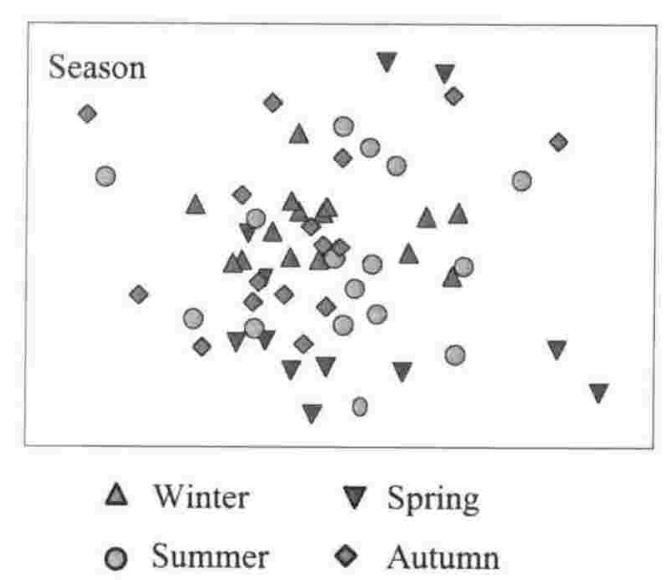

Figure 2.36 Harbour Basin. MDS ordinations using Bray-Curtis similarities of $4^{\text {th }}$-root transformed abundance data for factors year (left) and season (right). Stress=0.25.

Oriental Bay $(O B)$

Both null hypotheses applied to $\mathrm{OB}$ were rejected $\left(\mathrm{H}_{0} 1\right.$ : Global $R=1.0$, $p=0.002 ; \mathrm{H}_{0} 2$ : Global $\left.R=0.844, p<0.001\right)$. Replicate samples within each year group were more similar to each other than to any replicates from other year groups (Table 2.7, Figure 2.37). Pairwise tests revealed replicates from year 1 (1999) to be significantly different from replicates of both year 2 and year 3 (2000 and 2001, respectively). Groups were too small to compare year 2 with year 3 due to the low number of samples (total: six $x$ four replicates). Pairwise comparisons for the factor season showed summer and autumn community 
structures to differ strongly $(R=1, p=0.029)$. Faunal assemblages in winter also proved to be significantly different from those in spring and summer, but to a lesser extent ( $R=0.792$ with $p=0.029$ and $R=0.781$ with $p=0.029$, respectively). Pairwise tests could not be performed for the following combinations: winterautumn, spring-summer and spring-autumn. The low number of samples also had implications on significance levels (only 35 permutations possible for generation of $\left.R_{\text {permutation }}\right)$.

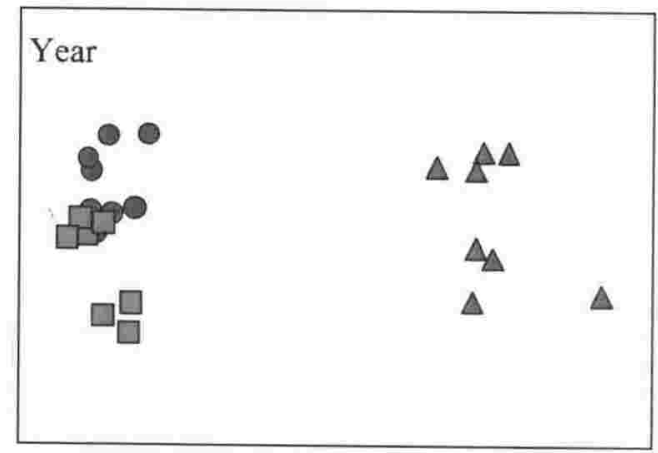

$\triangle$ Year 1
Year 2
口Year 3

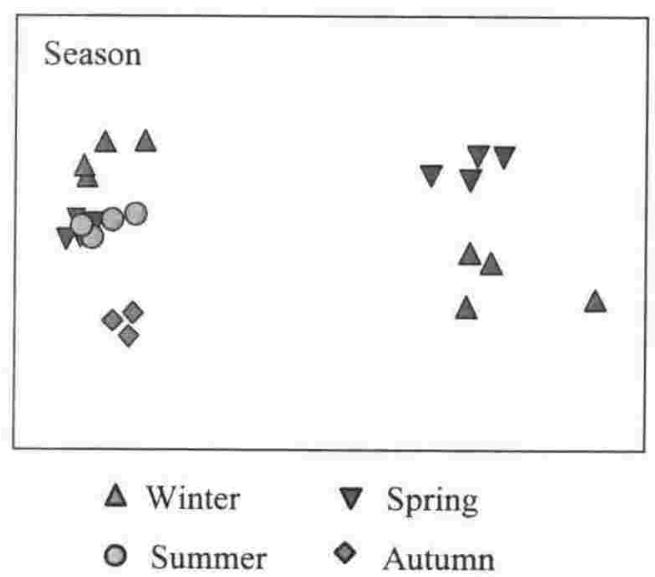

Figure 2.37 Oriental Bay. MDS ordinations using Bray-Curtis similarities of $4^{\text {th }}$-root transformed abundance data for factors year (left) and season (right). Stress $=0.04$.

\section{Entrance Channel (EC)}

Both $\mathrm{H}_{0} 1$ and $\mathrm{H}_{0} 2$ were rejected for EC samples. Differences in faunal assemblages were more pronounced among seasons than among years (Global $R=0.919$ with $p<0.001$ and $R=0.878$ with $p<0.001$, respectively (Table 2.7, Figure 2.38). Faunal assemblages differed most between 1999 and 2000. Groups were too small for a pairwise comparison of year 1 and 3. Community structure differed for all seasons in pairwise comparisons: winter versus spring and autumn, and spring versus summer and autumn showed strongest differences in the assemblages, although $p$ was only 0.029 in both cases due to the low number of permutations possible for generating $R_{\text {permutation }}$. 


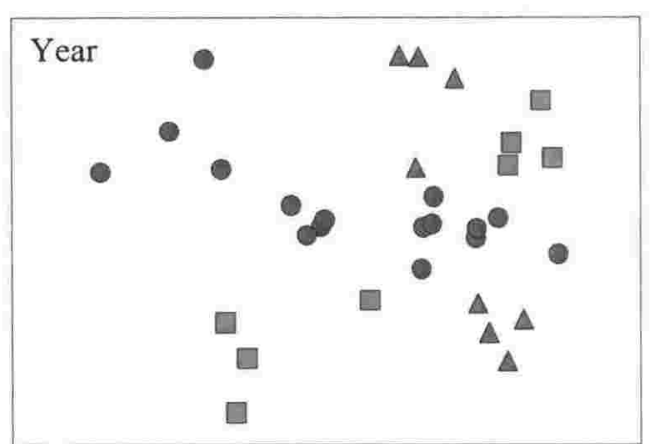

$\Delta$ Year 1

Year 2

Year 3
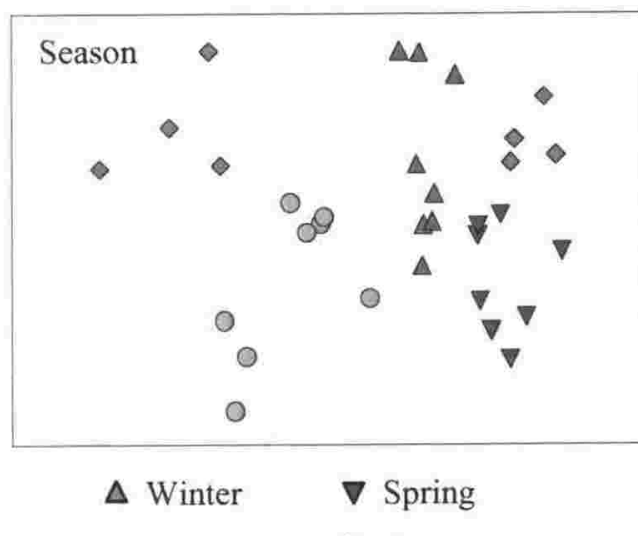

Summer $\diamond$ Autumn

Figure 2.38 Entrance Channel. MDS ordinations using Bray-Curtis similarities of $4^{\text {th }}$-root transformed abundance data for factors year (left) and season (right). Stress $=0.17$.

\section{Species Analysis}

Average between-site dissimilarity $(\delta$ ) (Table 2.8 ) was highest between Harbour Basin (HB) and Oriental Bay (OB) with $84.6 \%$, and lowest between Entrance Channel (EC) and OB (69.7\%). These results are consistent with the ANOSIM results in Table 2.6, i.e., the macroinvertebrate communities of $\mathrm{OB}$ and EC were more similar to each other than to the community of HB.

Species most responsible for the observed differences in community structure (as expressed by $\delta$ ) are presented in Table 2.8 . Only the ten species contributing most to between-site dissimilarities are listed. For more comprehensive species lists (accounting for up to $90 \%$ of the cumulative dissimilarity between two sites) refer to Appendix 7. Contributions of individual species to the total average dissimilarities $\delta$ were small in all between-site comparisons and accounted in each case for ca. $20 \%$ dissimilarity for the respective ten species listed. All species showed consistency in being abundant at one site and largely absent (although not necessarily totally absent) from the other, as indicated by their high ratios of $\delta_{i} / \operatorname{SD}\left(\delta_{i}\right)$. The high dissimilarities observed between the macroinvertebrate communities of $\mathrm{HB}$ and $\mathrm{OB}$ were chiefly caused by six polychaete species being abundant at $\mathrm{HB}$ but not at $\mathrm{OB}$. The bamboo worm Maldane theodori was found exclusively at HB (it was the second most abundant species at this site) at consistently high abundances. M. theodori displayed the highest $\delta_{i} / \mathrm{SD}\left(\delta_{i}\right)$ ratios (HB versus $\mathrm{OB}: 7.7$ and $\mathrm{HB}$ 
versus EC: 9.0) and was therefore a very good discriminator among all three sites. The capitellid Barantolla sp. occurred only at OB at high, and at EC at very low densities, and therefore also played an important role in explaining the observed community structure differences among the three sites. The amphipod Phoxocephalidae sp. I. was influential in discriminating HB samples from both the $\mathrm{OB}$ and $\mathrm{EC}$ samples.

$\mathrm{HB}, \mathrm{OB}$ and $\mathrm{EC}$ showed relatively high within-site community similarity (Table 2.9) with Harbour Basin (HB) samples being most (69.4\%) and Entrance Channel (EC) samples being least similar (57.3\%). Overall, species most characterising the community at $\mathrm{HB}$ were the deep-burrowing maldanid polychaetes Maldane theodori and Asychis trifilosus, the polychaete Cossura consimilis and the bivalve Theora lubrica (Table 2.9). At OB, the polychaetes Owenia fusiformis, Barantolla sp. and Hemipodus simplex and the ostracod Dolasterope quadrata, were important in structuring the faunal community (Table 2.9). For EC, the species typifying this location were the polychaete Prionospio ?yuriel, the amphipods Parawaldeckia sp. A and Paraphoxus sp. A, and the capitellid Notomastus sp. (Table 2.9). For more comprehensive lists of site-specific typifying species refer to Appendix 8.

Site-specific community similarities for each year (1999, 2000 and 2001) and community-characterising species are presented in Table 2.10. For all three sites the community similarities were high at all times, with $\mathrm{HB}$ and $\mathrm{OB}$ samples displaying highest similarity in community structure.

Table 2.11 lists site-specific inter-year dissimilarities $(\delta)$ and the ten species contributing most to $\delta$. Contributions of the individual discriminatory species to the respective inter-year dissimilarities were relatively small at each site. More comprehensive species lists for site-specific annual similarities and inter-year dissimilarities are presented in Appendices 8 and 9 (cut-off: $90 \%$ cumulated dissimilarity), respectively. 


\section{Harbour Basin (HB)}

Community structure similarity increased from 1999 ( $S=67.1 \%)$ to 2000 $(S=71.8 \%)$ and decreased slightly in 2001 (71.3\%). Between-year dissimilarity was generally low, with a maximum between 1999 and 2001 (36.4) and a minimum between 2000 and 2001 (31.9\%), i.e., changes in community structure were generally small, but marginally more pronounced between 1999 and 2000 than between 2000 and 2001. This is also visible in the left MDS ordination of Figure 2.36.

The bivalve Theora lubrica occurred throughout 1999 in constant abundances and hence was most important for explaining community similarity in this year, followed by the polychaetes Lumbrineris sp. A and Labiosthenolepis laevis, a sigalonid. The species typifying the community best in 2000 were the polychaetes $M$. theodori, Cossura similis and ?Aphelochaeta sp. In 2001 ?Aphelochaeta sp., A. trifilosus, Scolanthus sp. (Appendix 9) and M. theodori were most important in explaining macroinvertebrate community similarity.

Species explaining the inter-annual dissimilarities generally showed low ratios of $\operatorname{SD}\left(\delta_{i}\right) / \delta_{i}$. Changes in abundance of the capitellid Heteromastus $c f$. filiformis and the maldanid M. theodori (Appendix 10) were mainly responsible for explaining assemblage differences at HB between 1999 and 2000, whereas the increased abundance of the gastropod Nozeba emarginata and the decreased abundance of the amphipod Phoxocephalidaesp. D explained most of the differences in assemblage composition between 2000 and 2001. 


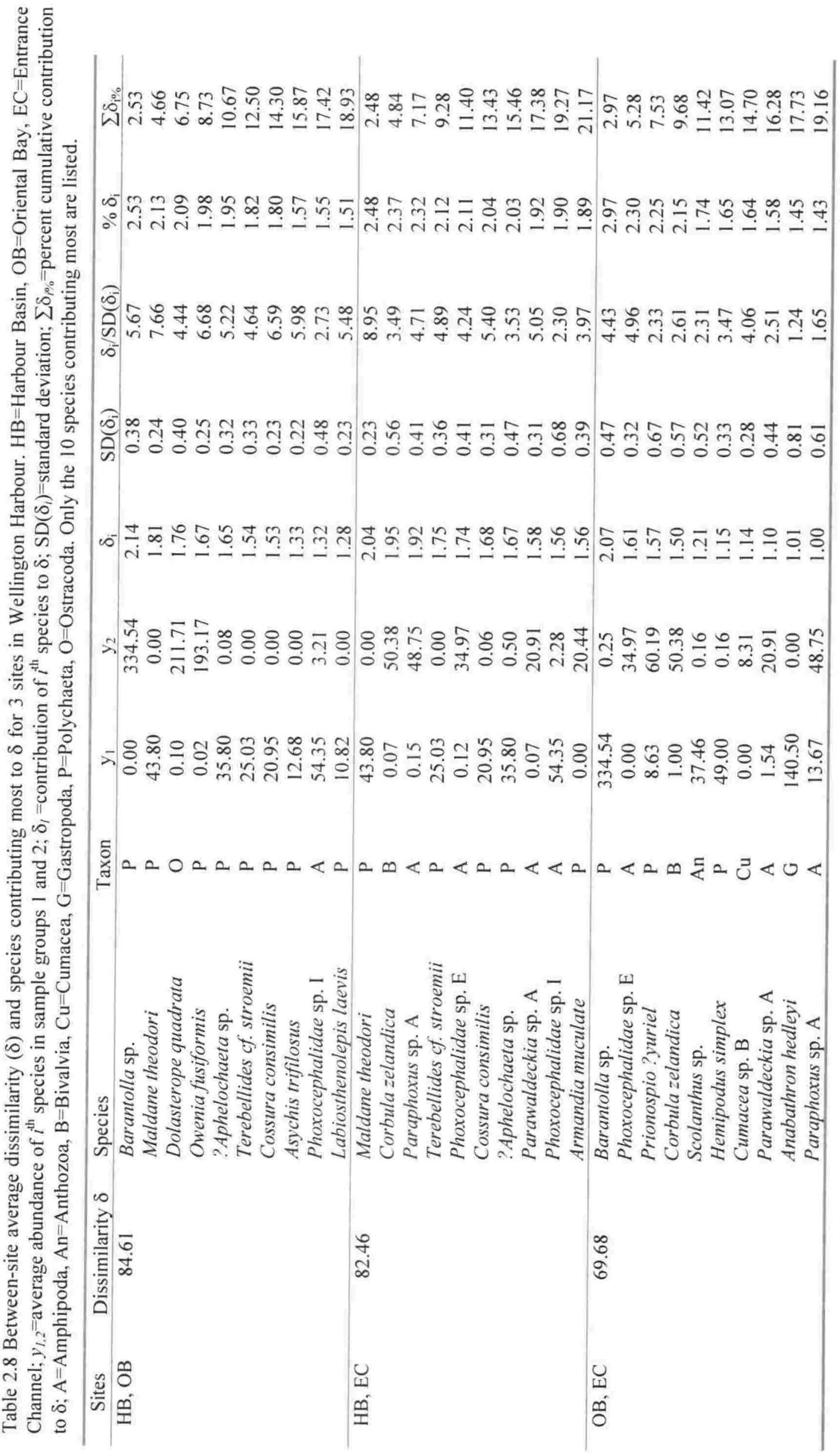




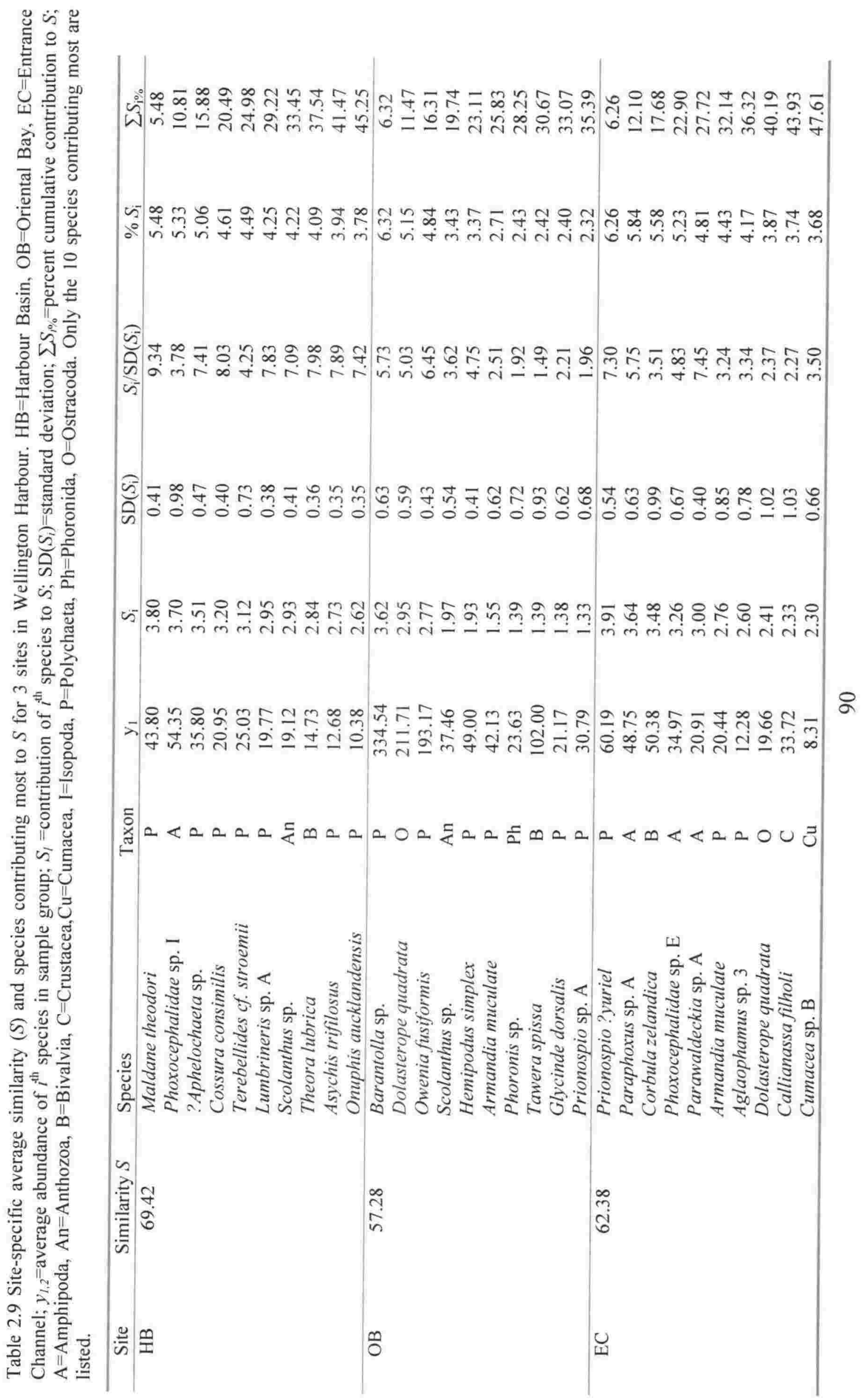




\section{Oriental Bay $(O B)$}

Macroinvertebrate community similarity for $\mathrm{OB}$ samples was high and increased continuously over the period of this study. Although the community structure was similar within each year, it varied strongly between the first two years, as shown by the high between-year dissimilarities for 1999/2000 (59.2\%) and 1999/2001 (60.0\%). Communities in year 2 and 3 (2000 and 2001) were substantially more similar $(\delta=32.8 \%$ ). See also the left MDS ordination in Figure 2.37, where 1999 samples were placed apart from 2000 and 2001 samples.

Species typifying the OB community in 1999 were the bivalve Nucula hartvigiana which, although contributing only $2.2 \%$ to the average similarity, showed a high $\mathrm{S}_{\mathrm{i}} / \mathrm{SD}\left(\mathrm{S}_{\mathrm{i}}\right)$ ratio of 10.7 (Appendix 9). Other important species were the amphipods Phoxocephalidae sp. D and Paraphoxus sp. A and the burrowing ghost shrimp Callianassa filholi. In 2000 a different set of species characterised the macroinvertebrate community: the undescribed actinian Scolanthus sp. (Appendix 9), the ostracod D. quadrata, and the capitellid Barantolla sp. In 2001 the polychaetes O. fusiformis, Glycera ovigera (Appendix 9), and Exogone ?heterosetosa were the best community-typifying species.

The tiny gastropod Odostomium sp. A proved to be especially useful in discriminating the faunal communities of 1999 and 2000. This species did not occur at OB in 1999 at all, but was found in consistent medium abundances in 2000 as indicated by its low $\operatorname{SD}\left(\delta_{\mathrm{i}}\right)$. Two other gastropod species, Xymene pusillum (Appendix 9) and Gumina dolichostomata, showed the same pattern of occurrence as Odostomium sp. A for 1999 and 2000, but displayed more varied abundances (higher $\mathrm{SD}\left(\delta_{\mathrm{i}}\right)$ ). Abundance changes of the bivalve Serratina charlottae, the ostracod Dolasterope quadrata and the gastropod Odostomium sp. A were important in explaining community change between 2000 and 2001.

\section{Entrance Channel (EC)}

At EC community similarity decreased slightly, but continuously, from $65.9 \%$ in 1999 via $64.8 \%$ in 2000 to $62.3 \%$ in 2001 . Species being important for community similarity in 1999 were the amphipod Phoxocephalidae sp. E, the 
ostracoda Cymbiocopia zealandica/hispida (Appendix 9) and S. sculpta, and the polychaete Aglaophamus sp. 3. In 2000, the amphipod Parawaldeckia sp. A and Paraphoxus sp. A and the spionid Polydora ?yuriel explained relatively well the community structure at EC. In 2001, the set of species best typifying the community changed to the ostracod D. quadrata, the spionid P. ?yuriel and the holothurian Trochodota dendyi (Appendix 9).

No species stood out as an especially good inter-annual discriminatory species due to the relatively high variances in abundance of all species. However, the isopod Leptanthura sp. 2, the polychaetes P. ?yuriel (Appendix 10) and Orbinia papillosa were important for changes in community similarity between 1999 and 2000. Community dissimilarity between years 2 and 3 (2000 and 2001) was caused by the abundance changes of many species whose individual contributions were small (Appendix 10). Abundance changes of Phoxocephalidae sp. E, Notomastus sp. and P. ?yuriel were slightly more influential upon community dissimilarity between the two years than those of the other species occurring at EC. 


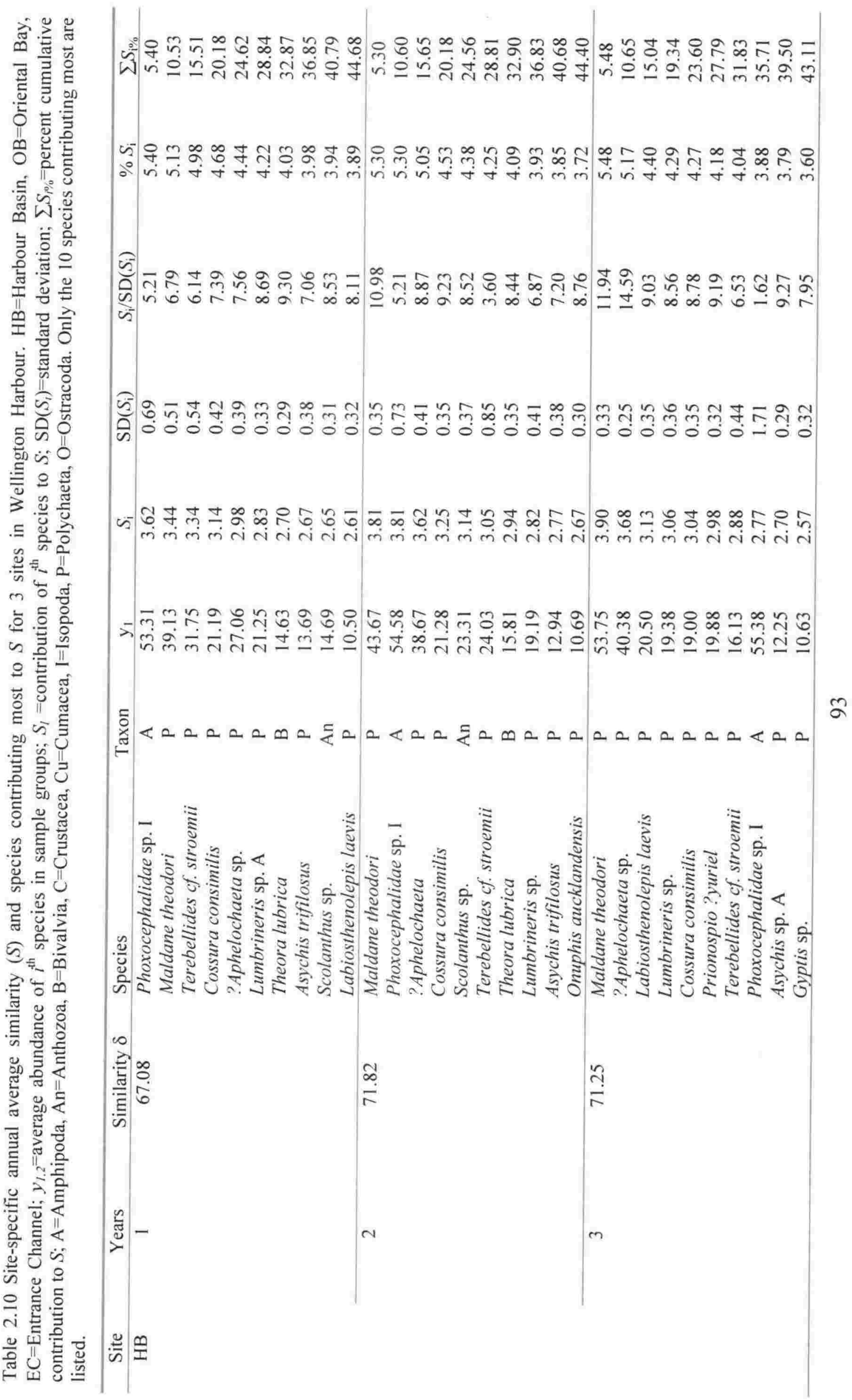




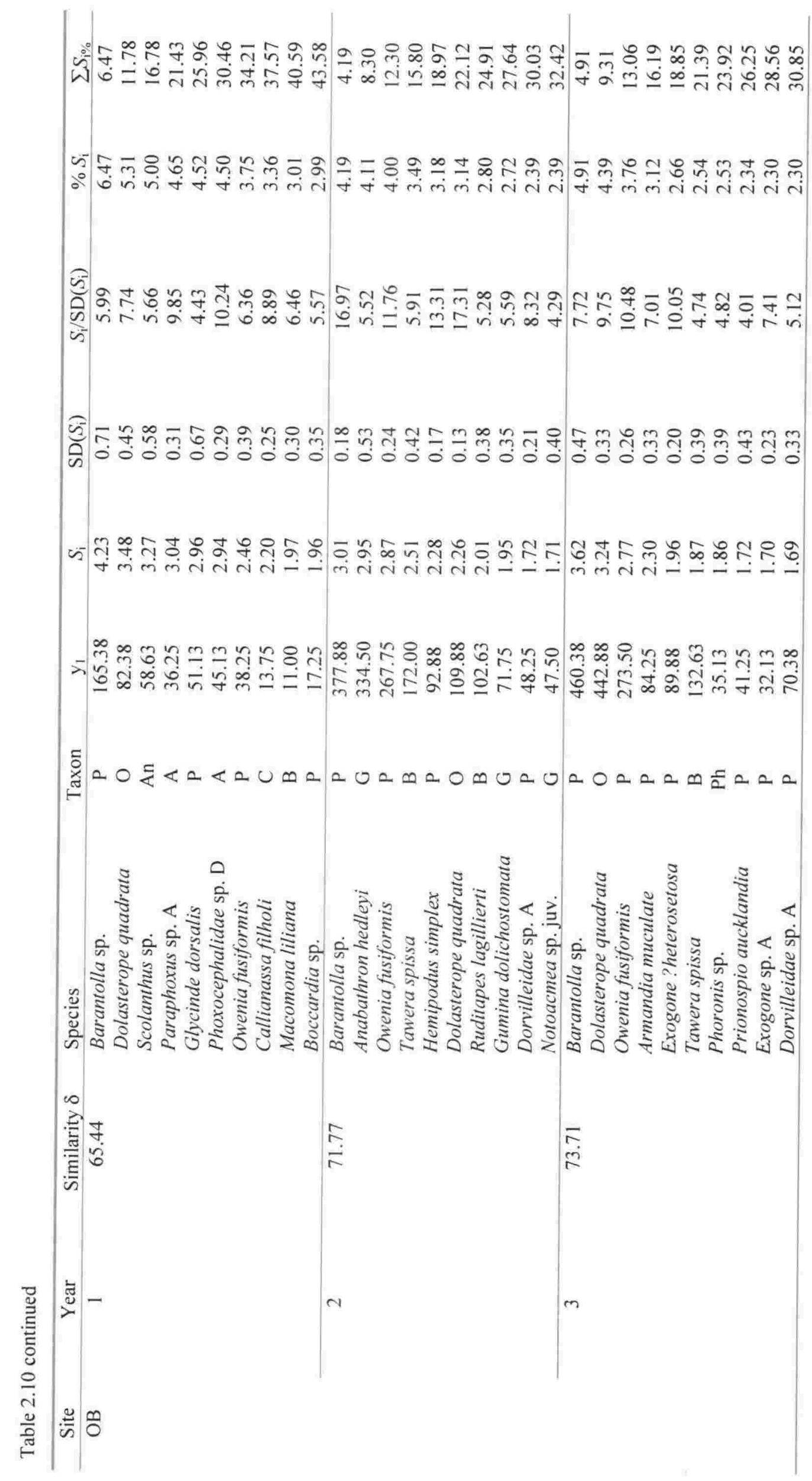




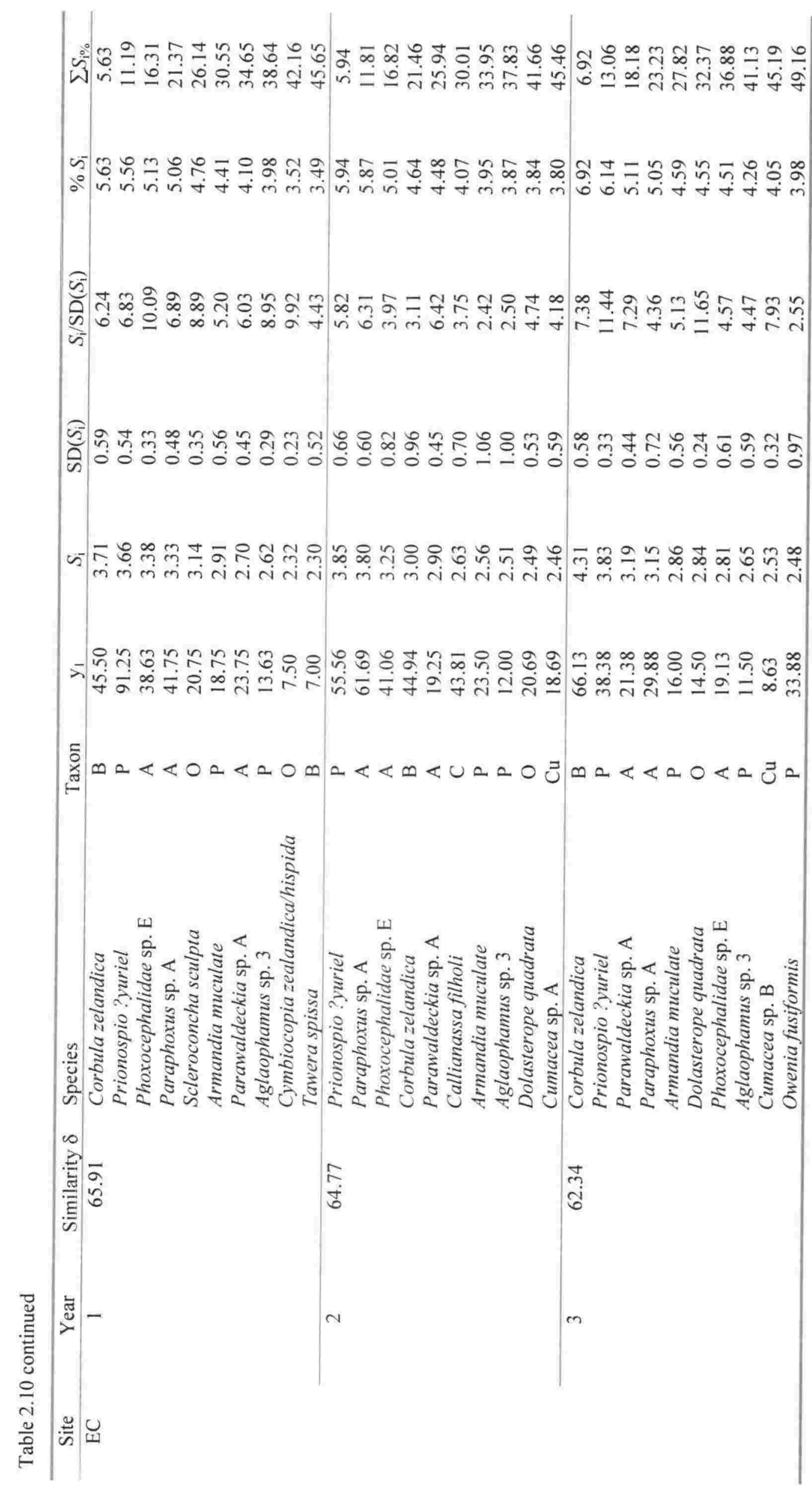




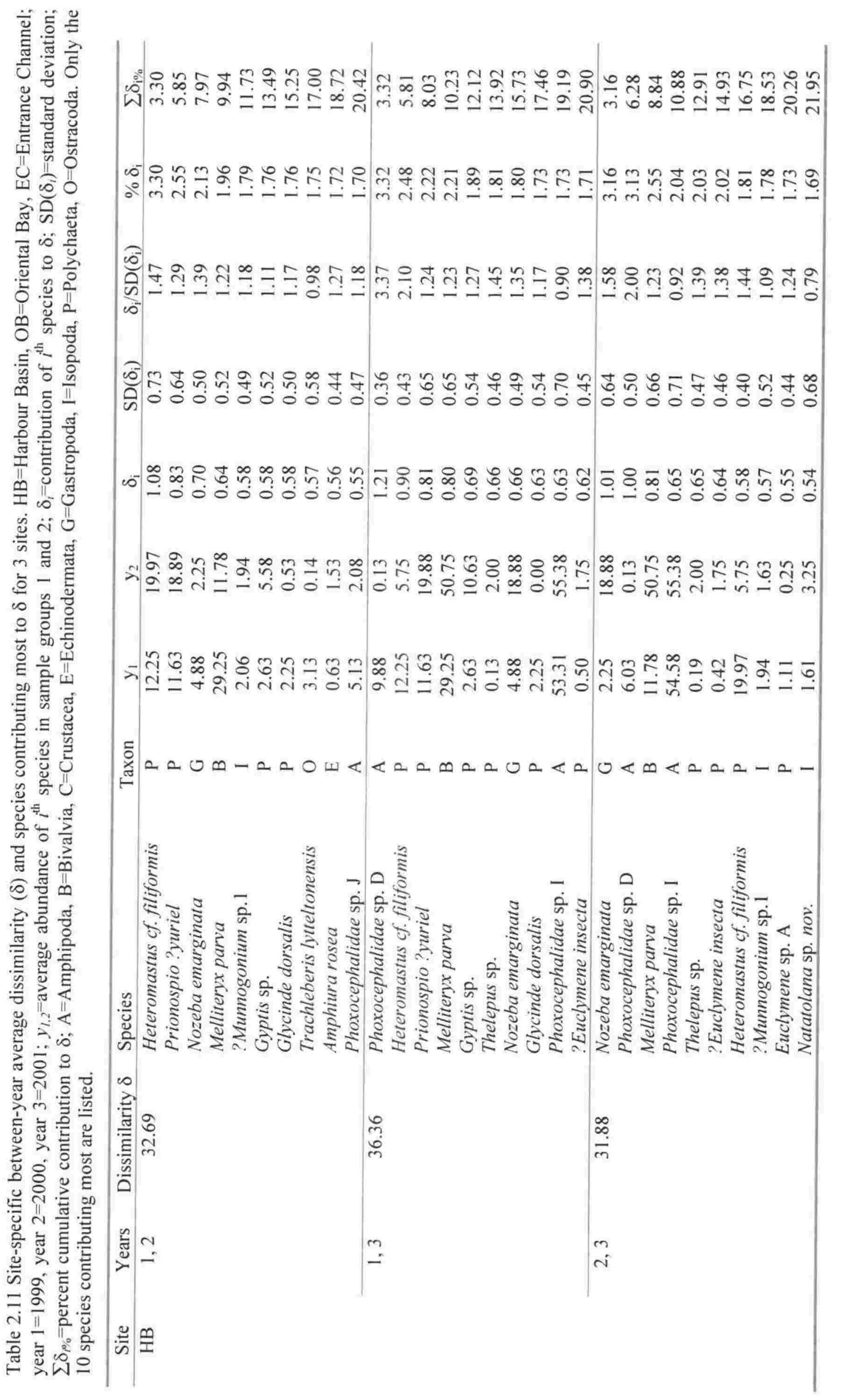




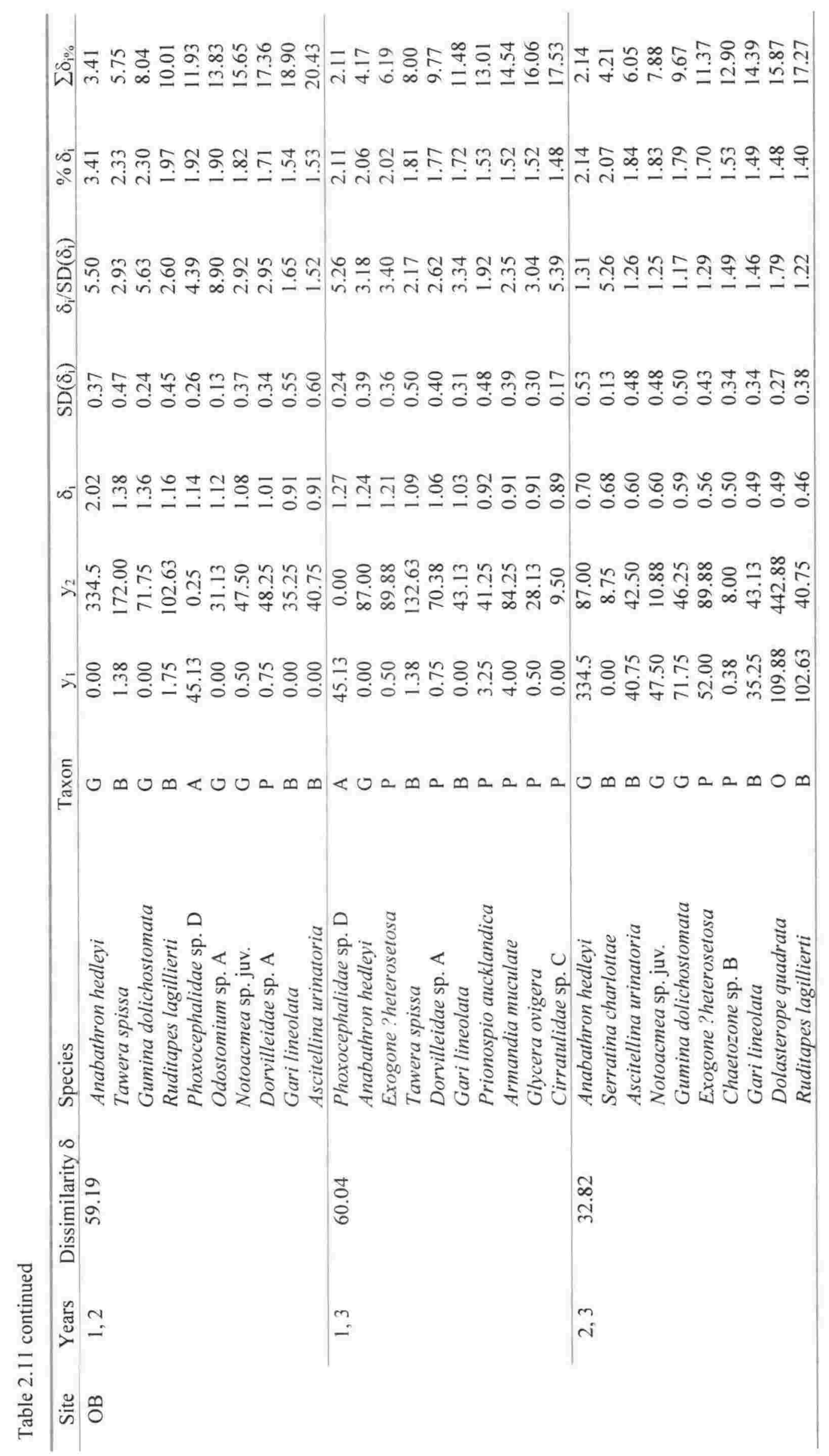




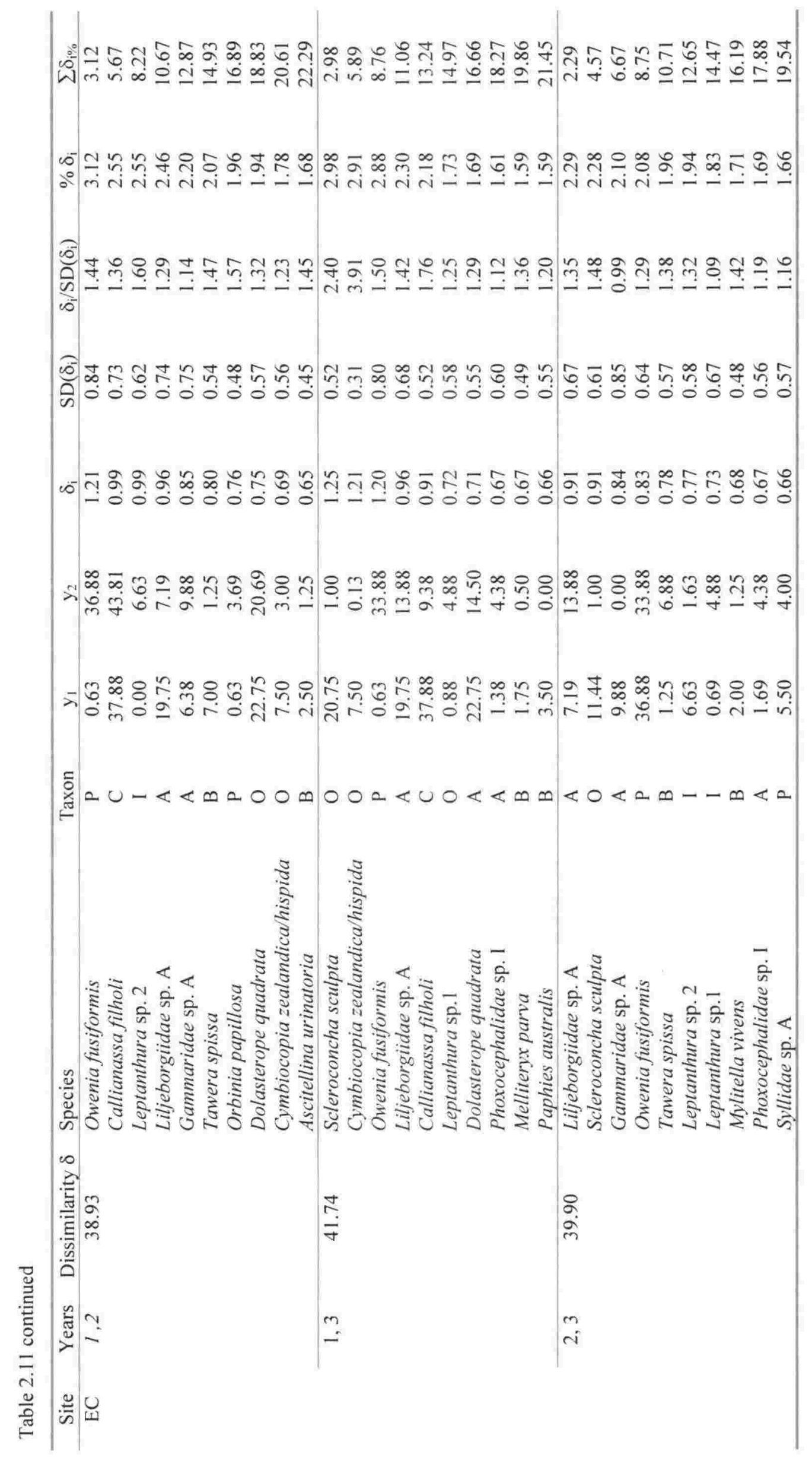




\section{Temporal and Spatial Variability in Assemblage Composition}

Relative dispersion and the Index of Multivariate Dispersion (IMD) were computed to describe differences of relative variability in faunal assemblages among the three sites and temporal changes of this variability within each site as an indication of perturbation. Results are presented separately for analyses including pre- and initial post-bloom data (Table 2.12) and excluding such data (Table 2.13).

Comparing the three sites including pre-and all post-bloom data, Oriental Bay $(\mathrm{OB})$ samples displayed highest relative dispersion, followed by Harbour Basin (HB) and Entrance Channel (EC) samples. When analysing only the latestage post-bloom samples (August 1999-May 2001), EC samples displayed highest relative dispersion, followed closely by $O B$ samples. Harbour Basin samples showed considerably less variability in faunal assemblage. This is also indicated in the MDS ordination of the three sites (Figure 2.26), where HB samples were tightly clustered in contrast to OB and EC samples. However, care has to be taken when comparing this ordination with results inTable 2.13, because the ordination is based on rank-similarity of averaged abundance data, whereas relative dispersion and the IMD are based on rank-similarities of replicate data.

\section{Harbour Basin (HB)}

When including pre- and initial post-bloom samples in the analysis, samples taken in 1998 (year 0) after the toxic bloom showed highest relative dispersion with 1.64 followed by pre-bloom samples (1.32) and 1999 samples (1.316). IMD values for pairwise comparisons of consecutive sampling years decreased with time from 0.52 between 1998 and 1999 to- 0.07 between 2000 and 2001, indicating that replicate samples became more similar with time.

When analysing data taken between August 1999 and May 2001, samples taken in the first year post-bloom (1999) showed the highest relative dispersion with 1.42 . In the following two years dispersion was considerably smaller. The IMD estimate was highest for the comparison of 1999 and $2000(0.50)$. Variability differences between 2000 and 2001 were minimal with an IMD of 
nearly zero (0.07), i.e., community dissimilarities in 2000 and 2001 were nearly equal.

\section{Oriental Bay $(O B)$}

When including pre- and initial post-bloom data, pre-bloom samples showed highest relative dispersion (1.66) in community compositon. In 1998 and 1999, relative dispersion was also pronounced (1.38 and 1.16, respectively). A clear pattern of decreasing IMD values with time was not obvious. Although the variability of 1999 samples versus 1999 samples (0.30) was smaller than the variability of pre-bloom versus 1998 samples (0.49), the IMD increased strongly between samples taken in 1999 and 2000 (0.93). Variability in samples of 2000 versus 2001 samples was relative equal $(\mathrm{IMD}=-0.05)$.

Analysing only the late-stage post-bloom samples, the strongest relative dispersion of faunal assemblages was found in 1999 (1.32). Dispersion was considerably lower in 2000 and continued to decline in 2001 (0.89 and 0.79 respectively). The IMD values of 1999 samples versus 2000 and 2001 samples suggest that dissimilarities were higher in 1999 than in both other years due to increased variability of the faunal assemblage in that year.

\section{Entrance Channel (EC)}

Samples taken in 1998 and 1999 and pre-bloom samples showed highest levels of relative dispersion. In 2000 and 2001 variability in community compositon among replicate samples still existed, but was considerably lower. The IMD value decreased considerably between the pre-bloom versus 1998 samples and the 1998 versus 1999 samples (-0.46 and 0.21, respectively). Sample variability between 1999 and 2000 samples was high (IMD=0.68), but decreased between 2000 and 2001 (IMD=0.13).

Analysing only the late-stage post-bloom samples, relative dispersion increased continuously from 1999 (0.91) to 2001 (1.14), indicating that community structure was more varied with each passing year. This was reflected in the negative IMD values: community structure in 1999 was generally more 
similar than in both other years and did not change strongly between 2000 and 2001 , as indicated by the low IMD value $(-0.15)$.

Table 2.12 Results of relative dispersion and Index of Multivariate Dispersion (IMD) for consecutive years describing relative dispersion and differences in variability of multivariate faunal assemblages for three sites in Wellington Harbour $(\mathrm{HB}=$ Harbour Basin, $\mathrm{OB}=$ Oriental Bay, $\mathrm{EC}=$ Entrance Channel) for pre- $(=\mathrm{P})$ and post-bloom data $(0=1998,1=1999,2=2000$ and $3=2001$ ). Data: aggregated to order level, presence-absence transformed and only standardised for the comparison of the three sites.

\begin{tabular}{|c|c|c|c|}
\hline Site & Comparison & Relative Dispersion & IMD \\
\hline HB & pre- + post-bloom & 0.971 & - \\
\hline OB & pre- + post-bloom & 1.306 & - \\
\hline $\mathrm{EC}$ & pre- + post-bloom & 0.849 & - \\
\hline \multirow[t]{9}{*}{ HB } & $\mathrm{P}$ & 1.324 & \\
\hline & 0 & 1.635 & \\
\hline & 1 & 1.316 & - \\
\hline & 2 & 0.858 & - \\
\hline & 3 & 0.926 & - \\
\hline & $\mathrm{P}, 0$ & & -0.458 \\
\hline & 0,1 & & 0.517 \\
\hline & 1,2 & - & 0.472 \\
\hline & 2,3 & - & -0.072 \\
\hline \multirow[t]{9}{*}{ OB } & $\mathrm{P}$ & 1.658 & \\
\hline & 0 & 1.382 & \\
\hline & 1 & 1.157 & \\
\hline & 2 & 0.328 & \\
\hline & 3 & 0.385 & \\
\hline & $\mathrm{P}, 0$ & & 0.487 \\
\hline & 0,1 & & 0.304 \\
\hline & 1,2 & & 0.926 \\
\hline & 2,3 & & -0.052 \\
\hline \multirow[t]{9}{*}{$\mathrm{EC}$} & $\mathrm{P}$ & 1.288 & \\
\hline & 0 & 1.504 & \\
\hline & 1 & 1.333 & \\
\hline & 2 & 0.669 & \\
\hline & 3 & 0.58 & \\
\hline & $\mathrm{P}, 0$ & & -0.456 \\
\hline & 0,1 & & 0.207 \\
\hline & 1,2 & & 0.677 \\
\hline & 2,3 & & 0.131 \\
\hline
\end{tabular}


Table 2.13 Results of relative dispersion and Index of Multivariate Dispersion (IMD) describing relative dispersion and differences in variability of multivariate faunal assemblages for three sites in Wellington Harbour ( $\mathrm{HB}=$ Harbour Basin, $\mathrm{OB}=$ Oriental Bay, $\mathrm{EC}=$ Entrance Channel) and for three years $(1=1999,2=2000$ and $3=2001)$. Data: 4 th-root transformed and only standardised for the comparison of the three sites.

\begin{tabular}{cccc}
\hline Site & Comparison & Relative Dispersion & IMD \\
\hline HB & late-stage post-bloom & 0.846 & - \\
OB & late-stage post-bloom & 1.328 & - \\
EC & late-stage post-bloom & 1.366 & - \\
\hline HB & 1 & 1.421 & - \\
& 2 & 0.92 & - \\
& 3 & 0.991 & - \\
& 1,2 & - & 0.501 \\
& 1,3 & - & 0.443 \\
& 2,3 & - & -0.073 \\
\hline OB & 1 & 1.321 & - \\
& 2 & 0.892 & - \\
& 3 & 0.787 & - \\
& 1,2 & & 0.449 \\
& 1,3 & & 0.526 \\
& 2,3 & 0.914 & - \\
\hline EC & 1 & 0.987 & - \\
& 2 & 1.14 & - \\
& 3 & - & -0.68 \\
& 1,2 & - & -0.25 \\
& 1,3 & - & -0.148 \\
\hline
\end{tabular}

\section{Assemblage Seriation (IMS)}

The Index of Multivariate Seriation (IMS) was computed for the three sites, Harbour Basin (HB), Oriental Bay (OB) and Entrance Channel (EC), with and without pre- and initial post-bloom data to test whether changes in community structure followed a linear sequence $\left(\mathrm{H}_{0}\right.$ : no seriation of community structure).

\section{Harbour Basin (HB)}

Pre-bloom (1994/95) and initial post-bloom samples differed more in their community composition than the late-stage post-bloom samples (Figure 2.39: upper MDS ordination). The Spearman rank correlation coefficient $(\rho=0.451)$ indicated a serial pattern. Pre- and post-bloom samples did not converge. Pre- and initial post-bloom samples are spread widest apart, thereby 
indicating that greatest changes in community composition had occurred between 1994/95 and 1999. Such changes became less pronounced from August 1999 onwards. The null hypothesis of no serial or sequential pattern was rejected at a significance level of $p=0.001$ (number of permuted statistics $\geq \rho=0$ of 999 permutations).
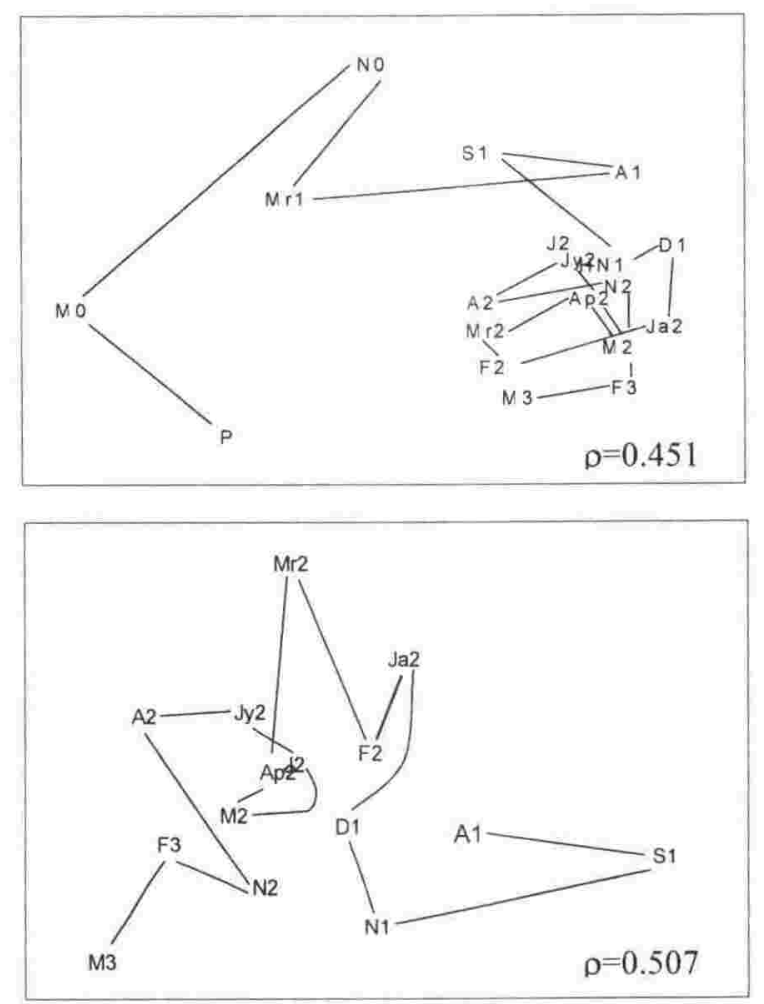

Figure 2.39 Harbour Basin. MDS ordination using Bray-Curtis similarities of group-averaged abundance data. Top: pre- and post-bloom data: order-level and presence-absence transformed. IMS: $\rho=0.451$ with $p=0.001$. Stress $=0.1$. Bottom: late-stage post-bloom data: $4^{\text {th }}$-root transformed. IMS: $\rho=0.507$ with $p=0.001$. Stress $=0.14$. Sample points are linked in temporal order. Sample labelling: $\mathrm{P}=$ pre-bloom, $\mathrm{Al}=$ August 1999, Ja2=January 2000, F3=February 2001, etc.

In the lower MDS ordination (Figure 2.39) samples of 1999 (year 1) and early 2000 (year 2) were spaced wider apart than samples taken in late 2000 and 2001 (year 3), indicating greatest change in community structure in the first year post-bloom. Although these changes decreased with time, a serial pattern of change was maintained (Spearman rank correlation coefficient $\rho=0.507$ ). The 
null hypothesis was rejected at a significance level of $p=0.001$ (number of permuted statistics $\geq \rho=0$ of 999 permutations).

\section{Oriental Bay $(O B)$}

Pre-bloom samples were very different in their community composition from post-bloom samples (Figure 2.40: upper MDS ordination) and the Spearman rank correlation coefficient $(\rho=0.614)$ indicated a sequential pattern. The null hypothesis was rejected at a significance level of $p=0.001$ (number of permuted statistics $\geq \rho=0$ of 999 permutations).

Changes in the post-bloom community structure (Figure 2.40: lower MDS ordination) were most pronounced in 1999 and decreased in the following two years The Spearman Rank correlation coefficient $(\rho=0.725)$, indicating a sequential change in the faunal community. $\mathrm{H}_{0}$ was rejected at a significance level of $p=0.004$ (number of permuted statistics $\geq p=3$ of 999 permutations).

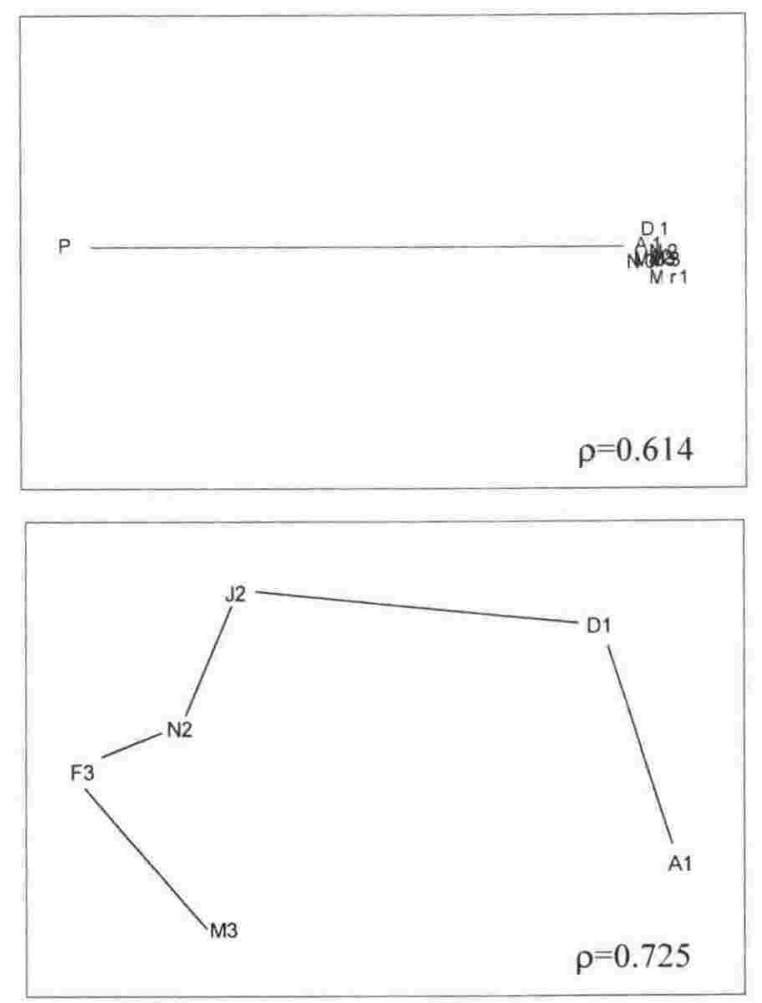

Figure 2.40 Oriental Bay: MDS ordination using Bray-Curtis similarities of group-averaged abundance data. Top: pre- and post-bloom data: order-level and presence-absence transformed. IMS: $\rho=0.614$ with $p=0.001$. Stress $=0.01$. Bottom: late-stage post-bloom data: $4^{\text {th }}$-root transformed. IMS: $\rho=0.725$ with $p>0.005$. Sample points are linked in temporal order. Sample labelling: $\mathrm{P}=$ pre-bloom, $\mathrm{Al}=$ August 1999, J2=June 2000, F3=February 2001, etc. 


\section{Entrance Channel (EC)}

At EC, pre-bloom samples were spaced widely apart from both initial and late-stage post-bloom samples (Figure 2.41: upper MDS ordination). Although the Spearman Rank correlation coefficient $\rho$ was 0.212 , the null hypothesis of no serial pattern was accepted ( $p=0.051$; number of permuted statistics $\geq \rho=50$ of 999 permutations). However, the significance level $p$ was just above the set significance level of $p=0.05$.
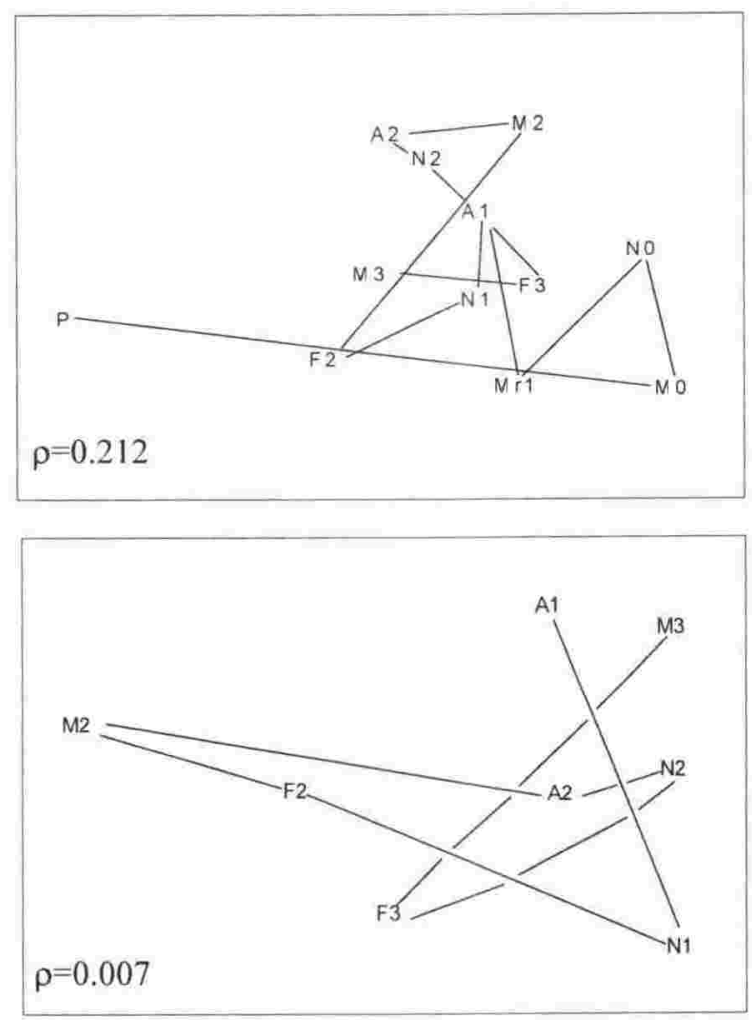

Figure 2.41 Entrance Channel: MDS ordination using Bray-Curtis similarities group-averaged abundance data. Top: pre- and post-bloom data: order-level and presence-absence transformed. IMS: $\rho=0.212$ with $p=0.051$. Stress $=0.11$. Bottom: late-stage post-bloom data: $4^{\text {th }}$-root transformed. IMS: $\rho=0.007$ with $p=0.468$. Stress $=0.09$. Sample points are linked in temporal order. Sample labelling: $\mathrm{P}=$ pre-bloom, $\mathrm{A} 1=$ August $1999, \mathrm{M} 2=$ May $2000, \mathrm{~F} 3=\mathrm{February} 2001$, etc.

Although the samples of May 2000 (M2) and August 2000 (A2) were spaced wider apart in the lower MDS ordination of Figure 2.41 than the rest of the samples, no biological pattern of serial or sequential change could be detected (Spearman rank correlation coefficient $\rho=0.007$ ) and $\mathrm{H}_{0}$ could not be 
rejected (significance level: $p=0.468$; number of permuted statistics $\geq \rho=467$ of 999 permutations).

\subsubsection{Sediment Analyses}

\section{Organic Matter Content}

Results for organic matter content of the sediment (\% OM) are presented for all three sites in Figure 2.42. At Harbour Basin (HB), \% OM was about four times higher than at the other two sites and ranged between $4.7 \%( \pm 0.8)$ in January 2000 and $6.0 \%( \pm 0.1)$ in February 2000, when the outlier values of September 1999 were excluded. The high mean value in September 1999 is explained by two outlier values (21.8 and $11.9 \% \mathrm{OM})$ caused probably by the accidental inclusion of faunal material. These values have been omitted from any further analyses. At Oriental Bay (OB) and Entrance Channel (EC), \% OM values showed a much lower range. The minimum value for $\mathrm{OB}$ occurred in June $2000(1.2 \% \pm 0.08)$, the maximum in February $2001(1.6 \pm 0.13 \%)$. At EC, the minimum of $1.2 \%$ OM $( \pm 0.14)$ was recorded for November 2000 and a maximum of $1.7 \%$ OM $( \pm 0.3)$ in May 2001 .

A bubble plot (Figure 2.43) was used to visualize the relationship between the biological patterns observed and the environmental variable organic matter content (\% OM) by superimposing symbols for \% OM on the MDS ordination of the corresponding biological samples. Although HB was clearly separated from the other two sites due to its higher \% OM values, no gradient in $\% \mathrm{OM}$ could be detected between $\mathrm{OB}$ and $\mathrm{EC}$. 


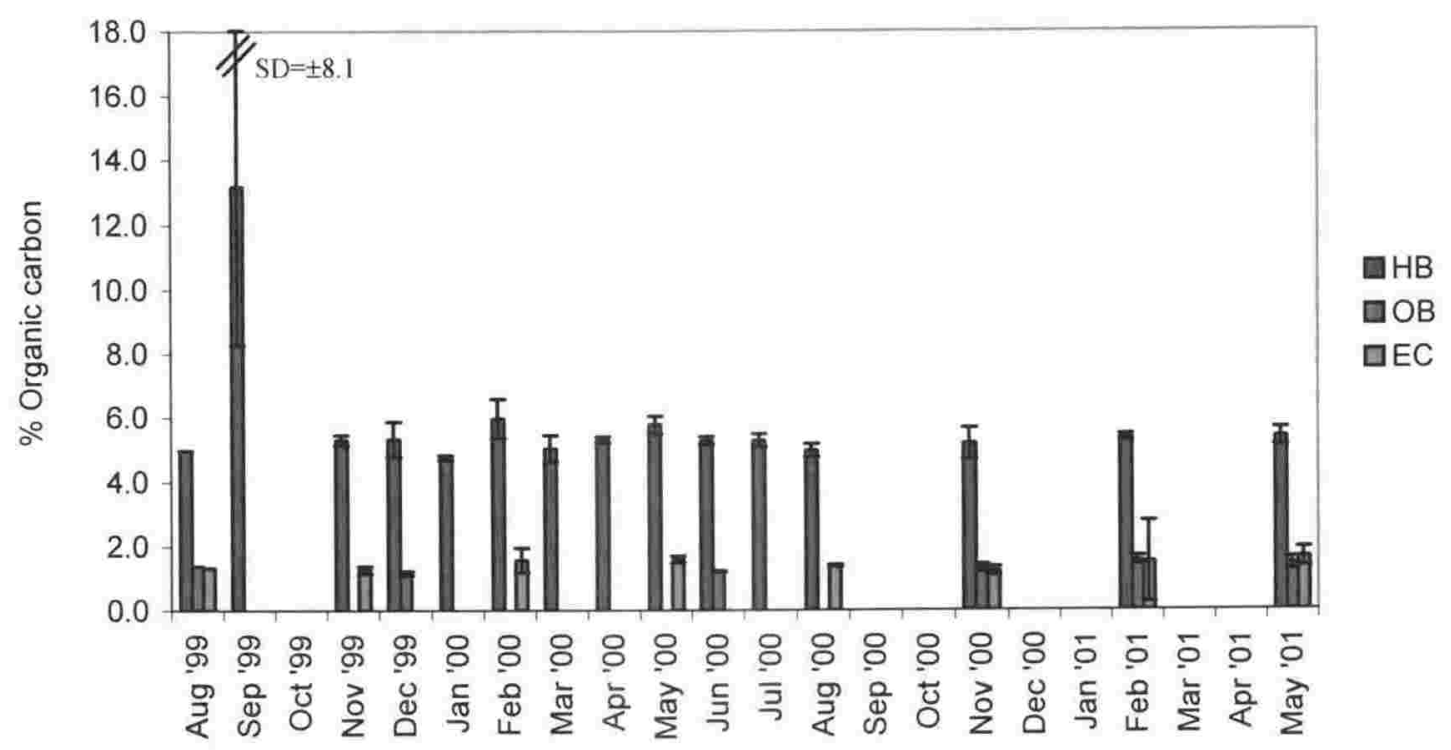

Figure 2.42 Organic matter content $(\%)$ for $\mathrm{HB}=$ Harbour Basin, $\mathrm{OB}=$ Oriental Bay and $\mathrm{EC}=$ Entrance Channel. Error bars indicate \pm standard deviation (not available for August 1999 since no replicate samples were taken). No data available for HB October 1999. From Aug 2000 samples for all sites were taken at 3-monthly intervals.

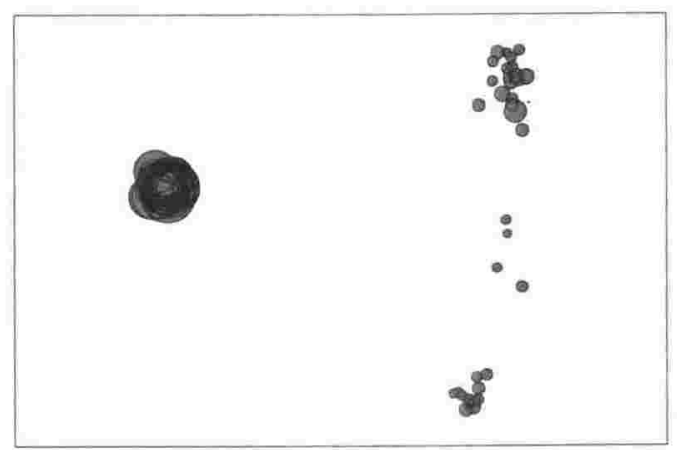

Figure 2.43 MDS ordination using Bray-Curtis similarities from standardised, 4th-root transformed abundance data $(>500 \mu \mathrm{m})$ for 3 sites in Wellington Harbour (August 1999-May 2001 ) with superimposed symbols representing organic matter content (\%) of the sediment. Only biological samples with a matching environmental variable are included. Stress $=0.05$.

\section{Sediment Characteristics}

Results for sediment characteristics are presented in Table 2.14. As with $\% \mathrm{OM}, \mathrm{OB}$ and $\mathrm{EC}$ were similar in mean grain size $\Phi$, sorting coefficient, skewness and sand content. 


\section{Harbour Basin (HB)}

HB exhibited larger $\Phi$ values than the other sites, i.e., the sediment was finer and consisted mainly of fine to very fine silt $(80-90 \%)$. The sediment was principally very poorly sorted with some excess fine material at all sampling times. The August and November 2000 samples were slightly different. In August 2000 the sediment was extremely poorly sorted, which is also reflected in an increased sand content (about 20\%) and a slightly increased $\Phi$ value, i.e., a smaller mean grain diameter. Hence the sediment was still classified as fine silt but was rather heterogeneous with a larger sand content. In contrast, the sediment in November 2000 was classified as coarse silt because $\Phi$ decreased and the sediment was more homogeneous (decreased sorting coefficient). The sand content was marginally lower compared to August 2000.

Table 2.14 Sediment characteristics for $\mathrm{HB}=\mathrm{Harbour}$ Basin, $\mathrm{OB}=$ Oriental Bay and $\mathrm{EC}=$ Entrance Channel. $\mathrm{n}=1$ for all samples.

\begin{tabular}{cccccccc}
\hline Site & Date & $\begin{array}{c}\text { Mean grain } \\
\text { size }(\Phi)\end{array}$ & $\begin{array}{c}\text { Sorting } \\
\text { coefficient }\end{array}$ & Skewness & \% Gravel & $\%$ Sand & $\begin{array}{c}\% \text { Silt } \\
\text { +clay }\end{array}$ \\
\hline HB & Aug '99 & 7.60 & 2.91 & 0.01 & 0.03 & 11.04 & 88.92 \\
& Feb '00 & 7.08 & 2.55 & 0.01 & 0.00 & 11.65 & 88.35 \\
& May '00 & 7.22 & 1.90 & 0.00 & 0.05 & 4.54 & 95.41 \\
& Aug '00 & 8.13 & 4.79 & 0.09 & 0.07 & 21.40 & 78.53 \\
& Nov'00 & 4.87 & 1.04 & 0.00 & 0.18 & 19.92 & 79.90 \\
OB & Aug'99 & 2.68 & 0.54 & 0.08 & 0.00 & 97.69 & 2.30 \\
& Nov'00 & 2.09 & 1.25 & -0.28 & 3.82 & 93.82 & 2.36 \\
EC & Aug '99 & 2.44 & 0.46 & 0.02 & 0.53 & 97.04 & 2.43 \\
& Feb '00 & 2.55 & 0.56 & -0.02 & 2.26 & 95.26 & 2.48 \\
& May '00 & 2.70 & 0.84 & 0.01 & 3.12 & 90.72 & 6.16 \\
& Aug '00 & 4.55 & 0.92 & 0.00 & 0.08 & 27.48 & 72.44 \\
& Nov'00 & 2.88 & 0.42 & 0.27 & 0.03 & 97.30 & 2.67 \\
\hline
\end{tabular}

\section{Oriental Bay $(O B)$}

OB sediment consisted of fine sand (sand content of $>90 \%$ ) and was more homogeneous than the HB sediment (sorting coefficient: moderately well to moderately sorted). Whereas clay and silt were present in small quantities in August 1999, some gravel (3.8\%) was present in November 2000. 


\section{Entrance Channel (EC)}

At EC the sediment was consistently fine sand (90-97\%) with a small percentage of both gravel and silt + clay. An exception occurred in August 2000: mean grain size decreased, hence the sediment was classified as coarse silt with a silt + clay content of more than $70 \%$ and a corresponding sand content of ca. $30 \%$. Overall, the sorting coefficient indicated mainly well to moderately well sorted sediment (i.e., relatively homogeneous).

\section{Linking Biological To Environmental Data}

The BIOENV procedure was applied to elucidate the extent to which macroinvertebrate assemblage composition could be related to organic matter content of the sediment. Figure 2.44 shows the MDS ordination (based on Euclidean distance similarity matrices) for the organic matter content of all sites. Entrance Channel (EC) and Oriental Bay (OB) samples form one distinct group in the MDS ordination, with some EC samples being slightly placed apart from the cluster. The second cluster consists of Harbour Basin (HB) samples tightly grouped, except for one sample (H1F2). Stress values are very low as can be expected for ordinations based on only one environmental variable. The MDS of $\%$ OM (Figure 2.44) resembled the biota MDS (Figure 2.26) to a certain extent. In both ordinations $\mathrm{HB}$ samples formed one cluster clearly separated from $\mathrm{OB}$ and EC samples.

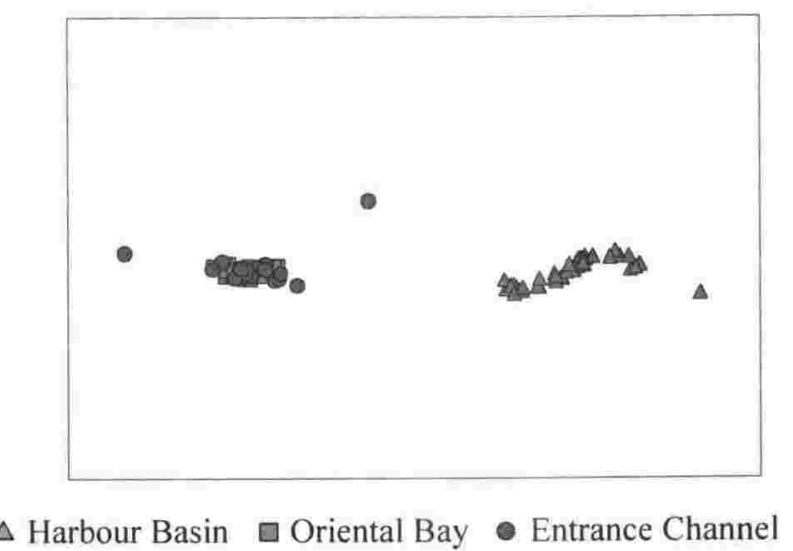

Figure 2.44 MDS ordination of 3 sites in Wellington Harbour (August 1999-May 2001) using Euclidean distance similarities of organic matter content (\%) data. Outlier values (H2SI and H4S1) omitted. Stress $=0.01$. 


\section{Harbour Basin, Oriental Bay and Entrance Channel}

No pattern is discernible for any of the three sites in the respective MDS ordination (Figure 2.45), indicating that organic matter content of the sediment could not be related to changes in macroinvertebrate assemblage composition observed within each site.

Results of the BIOENV analyses are presented in Table 2.15. Observed differences in macroinvertebrate assemblage composition among the three sites were positively correlated with organic matter content $\left(\rho_{s}=0.709, p=0.001\right.$ with number of permuted statistics $\geq \rho=0$ of 999 permutations), but within each site, no such relationship was detected.
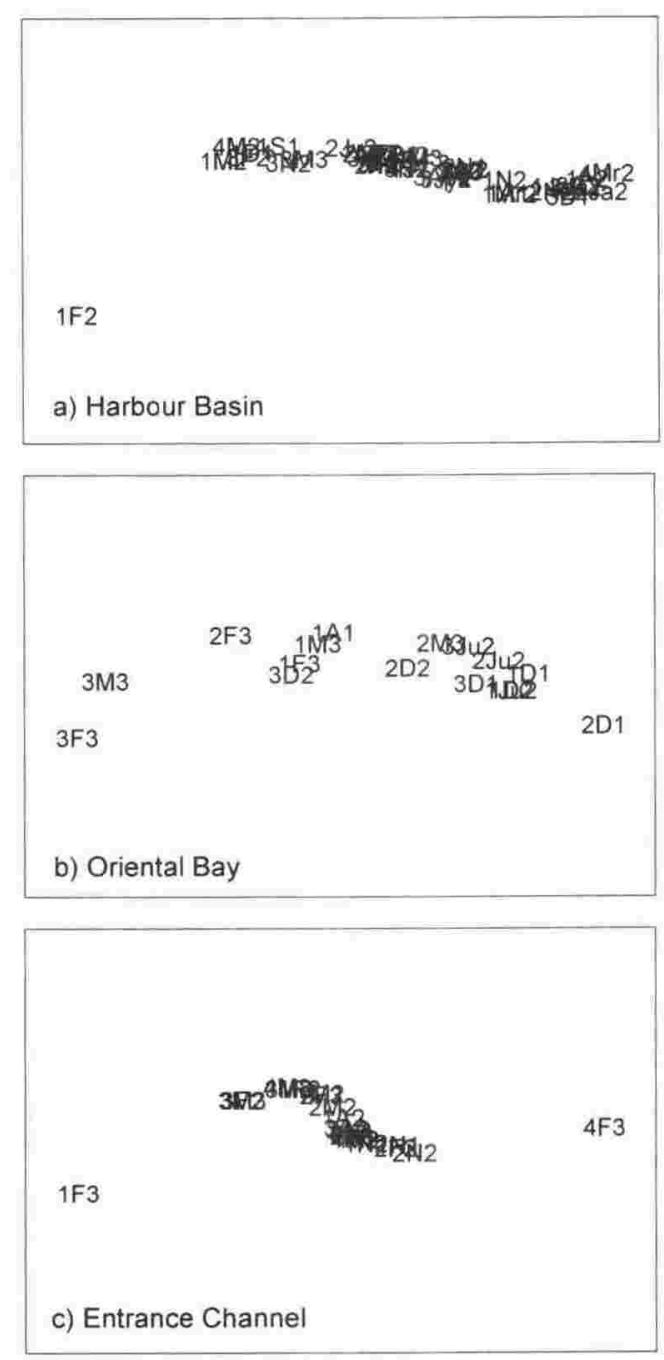

Figure 2.45 MDS ordination using Euclidean distance similarities of organic matter content data for a) Harbour Basin, b) Oriental Bay and c) Entrance Channel. Sample labelling: 3D1=third replicate December 1999, 2N2=second replicate November 2000, 4F3=fourth replicate February 2001 , etc. Harbour Basin: Outlier values ( $2 \mathrm{~S} 1$ and $4 \mathrm{~S} 1$ ) omitted. Stress for a), b) and c) $=0.001$. 
Table 2.15 Rank correlation coefficient $\rho_{\mathrm{s}}$ for similarity matrixes derived from biological and sediment organic matter content data of 3 sites in Wellington Harbour ( $\mathrm{HB}=$ Harbour Basin, $\mathrm{OB}=$ Oriental Bay, $\mathrm{EC}=$ Entrance Channel). Outsider values of HB September 1999 omitted from analyses.

\begin{tabular}{cccc}
\hline Site(s) & $\begin{array}{c}\text { Rank Correlation } \\
\text { Coefficient } \rho_{\mathrm{s}}\end{array}$ & $\begin{array}{c}\text { Significance level } \\
p\end{array}$ & $\begin{array}{c}\text { No of permutated } \\
\text { statistics } \geq \rho_{\mathrm{s}}\end{array}$ \\
\hline HB, OB, EC & 0.709 & 0.001 & 0 \\
HB & 0.154 & 0.031 & 30 \\
OB & -0.012 & 0.484 & 483 \\
EC & 0.153 & 0.115 & 114 \\
\hline
\end{tabular}

\subsection{Discussion}

Investigations into the responses of species assemblages to large-scale catastrophic disturbances such as storms, earthquakes, fire, toxic plankton blooms and anthropogenic changes are highly important for our understanding of ecological patterns in time and space (Underwood et al. 2000). Such disturbances provide the opportunities to test hypotheses about the long-term effects of largescale disturbances 'in the real world'.

Soft-sediment macroinvertebrate community composition was studied at three sites in Wellington Harbour to examine the long-term effects of a naturally occurring toxic plankton bloom. It was predicted that as a result of the bloom disturbance, communities would continue to change in their composition $>1$ year after the bloom, and that these changes would be site-specific and in relation to local hydrodynamic regimes.

Multivariate analyses indicated that the predicted changes in community composition clearly took place at the Harbour Basin (HB) and Oriental Bay (OB) sites. At both sites macroinvertebrate communities exhibited decreasing variability in their composition each successive year, as expressed by increasing annual similarities, decreasing inter-annual dissimilarities and decreasing Index of Multivariate Dispersion values (IMD). These results, and the sequential patterns in the temporal community development as demonstrated by the Index of Multivariate Seriation (IMS) for communities at $\mathrm{HB}$ and $\mathrm{OB}$, are consistent with communities 'recovering' from a perturbation (Clarke et al. 1993; Warwick \& Clarke 1993a). The development of the benthic macroinvertebrate community 
at the third site studied, Entrance Channel (EC), differed considerably from those at $\mathrm{HB}$ and $\mathrm{OB}$. At EC, only small community changes occurred, which did not conform to a sequential pattern as measured by the IMS, i.e., the community composition oscillated from year to year rather than 'moved in a direction'. The assemblage at $\mathrm{EC}$, in contrast to assemblages at $\mathrm{HB}$ and $\mathrm{OB}$, exhibited relatively high community dissimilarity and variability. Such high values are indicative of a community being exposed to frequent disturbances (Warwick \& Clarke 1993a).

In the present study I have 'the unusual luxury' (Warwick 1993) of being able to compare data from $>1$ year post-disturbance with pre-disturbance and $<1$ year post-disturbance data. Note, that for comparative reasons only the $\geq 1000$ $\mu \mathrm{m}$ fraction of the $>1$ year post-bloom samples has been used. Analyses that were conducted with and without pre-and initial post-bloom samples revealed that recovery processes could be identified when using the late-stage post-bloom samples only.

\section{Entrance Channel}

The EC site, a sandy site at ca. $11 \mathrm{~m}$ depth, is located in a narrow channel linking the inner harbour to the adjacent Cook Strait. Strong tidal currents (Maxwell 1956) with accompanying sediment perturbations (Carter 1977; Carter \& Lewis 1995) and bedload transport (Van der Linden 1967) are typical for this site. The macroinvertebrate community at EC was characterised in regard to overall community similarity and numerical dominance by the spionid polychaete Prionospio ?yuriel, the bivalve Corbula zelandica and peracarid crustaceans such as the amphipods Paraphoxus sp. A, Parawaldeckia sp. A and Phoxocephalidae sp. E. Spionids, amphipods and members of the suspensionfeeding genus Corbula are amongst those species which are commonly associated with the initial successional stages of recovery following a disturbance (Pearson \& Rosenberg 1978; Rhoads et al. 1978). Such species exhibit life history traits that enable them to rapidly recolonise substrates that have become available through disturbances. For instance, spionids have short life spans and generation cycles, are polytelic (individual females can produce several clutches of eggs during a single year) and are interface feeders, i.e., they live in the welloxygenated water-sediment interface (Blake \& Hilbig 1996). Interface feeders, 
especially spioniods, are capable of alternating between suspension- and surfacedeposit feeding depending on the actual flow conditions. This flexibility in their feeding mode enables them to survive in environments with constantly changing current conditions. Members of the genus Prionospio often occur in considerable numbers in high-energy sandy substrates (Oliver et al. 1979; Probert \& Wilson 1984) and are characteristic of physically disturbed (Maurer et al. 1998) and organically polluted environments (Pearson \& Rosenberg 1978; Mirza \& Gray 1981). Phoxocephalid and lysianassid amphipods such as Paraphoxus sp. A and Parawaldeckia sp. A are typical members of 'clean inshore sand faunas' (Fenwick 1984b; Probert \& Wilson 1984) and high-energy beaches (Oliver et al. 1979). As mobile predatory scavengers (phoxocephalids) and omnivorous scavengers (lysianassids), these species profit opportunistically from any dead or damaged infauna dislodged from the sediment (Oliver \& Slattery 1985; Kenchington et al. 2001). With their free-burrowing, highly motile life style combined with brood-protection, amphipods are well adapted to an environment characterised by strong currents and shifting substrates (Oliver et al. 1979), conditions likely to be encountered at EC (Carter 1977; Carter \& Lewis 1995). Most of the numerically dominant species at EC, such as $P$. ?yuriel, C. zelandica and Paraphoxus sp. A, exhibited pronounced density fluctuations typical of opportunistic species (Chesney 1985). Abundance peaks occurred in summer, suggesting that seasonal recruitment was one of the underlying causes for the observed variability in abundance of these species (Coma et al. 2000). The prevalence of species identified as opportunists and members of early successional recovery stages throughout the duration of this study is indicative of the EC community being in a perpetual state of early succession caused by frequent disturbances such as the strong tidal currents (Maxwell 1956) and bedload transport (Van der Linden 1967) experienced at this site. Communities exposed to such physical disturbances are under the constant threat of wavescour, which can wash out the community (Rees et al. 1977). In a study on the dynamics of macrofaunal communities at 15-20 m depth in Long Island Sound, U.S.A., McCall (1977) made similar observations to those in the present study, i.e., the dominance of opportunistic taxa occurring in unpredictable temporal and spatial patterns. McCall related his findings to the exposure of the community to storm events with accompanying bedload transport. Hall (1994) suggested that 
an energetic hydrodynamic regime capable of moving sediment is an important factor in controlling population dynamics in temperate areas. Thus, frequent current- and wave-induced disturbances could prevent the establishment of an equilibrium community such as described in current succession models (Pearson \& Rosenberg 1976; Rhoads et al. 1978) at the EC site.

The pre-bloom summer macroinvertebrate community at EC $(\geq 1000 \mu \mathrm{m})$ was described by Haddon \& Wear (1993) as the most diverse benthic community in Wellington Harbour exhibiting high abundances (293 ind. $0.1 \mathrm{~m}^{-2}$ ) and a species-rich fauna ( 28 species $0.1 \mathrm{~m}^{-2}$, excluding amphipod species). The $<1$ year post-bloom community (November 1998) showed much higher mean total abundances due to very high numbers of Owenia fusiformis, but Shannon's diversity $H^{\prime}$ and evenness $J$ ' were still reduced. From August 1999, mean total abundance was similar to pre-bloom values and species numbers were slightly higher. Pre- and $>1$ year post-bloom communities at EC were very similar in respect to the numerical dominance of the ghost shrimp Callianassa filholi, the bivalve Corbula zelandica and high abundances of amphipods. As Wear and Gardner (2001) demonstrated, the benthic macroinvertebrate community at EC had not been as negatively affected by the toxic bloom in 1998 (decreases in mean $N, S, H^{\prime}$ and $J^{\prime}$ at three months post-bloom were non-significant) as communities located in the central harbour. The authors reasoned that the constant high levels of water flow experienced at EC mitigated the toxic bloom effect on the community at this site. More than one year post-bloom, mean abundances and number of species had recovered to pre-bloom levels and fluctuations of univariate biodiversity indices indicated seasonal patterns of the macroinvertebrate community, but did not suggest on-going recovery. More than 1 year post-bloom recruitment for most species at EC seemed to occur seasonally, i.e., between early spring and summer.

\section{Harbour Basin}

Although the macroinvertebrate communities at $\mathrm{HB}$ and $\mathrm{OB}$ demonstrated similar recovery patterns, the communities are different in their physical setting and therefore also in their composition. With ca. $20 \mathrm{~m}$ depth, HB is the deepest of the three sites studied. The high percentage of accumulated fine 
sediment (predominantly in the silt-clay range) found here and also reported by Wear \& Anderlini (1995) and Wear \& Gardner (2001) for this site, is indicative of a low-energy hydrodynamic regime near the sediment-water interface. The community at HB was mainly characterised by deposit-feeding species such as the maldanid polychaetes Maldane theodori and Asychis trifilosus, and the introduced bivalve Theora lubrica. Maldanids are tubicolous sub-surface headdown conveyor-belt feeders (Holte 2001), frequently found in sheltered sandy and muddy sites (Beesley et al. 2000). Asychis trifilosus was amongst the few surviving species found at HB ca. 3 months post-bloom (Wear \& Gardner 2001). This was probably due to the species' deep-burrowing activity, which might have protected A. trifilosus from the full impact of the bloom as experienced by species living at the sediment-water interface. The small semelid bivalve Theora lubrica, a selective deposit feeder, is common in muddy sediments with high organic carbon content (Imabayashi 1986; Hayward et al. 1997), such as are found at HB. Semelidae, like members of other deposit-feeding bivalve groups such as Nuculidae and Tellinidae, are highly mobile and capable of rapid burrowing. Thus, they not only contribute to instabilities and resuspension in muddy sediments (Rhoads 1970), but they also facilitate oxygenation of the sediments (Pearson \& Rosenberg 1976) and thereby generally improve microbial activity and chemical fluxes (Aller \& Aller 1992; Rosenberg 2001). The importance of intense near-surface reworking of sediments by especially infaunal protobranch bivalves has been widely recognized and discussed in the context of trophic amensalism between deposit and suspension feeders (Rhoads 1970, 1974).

Changes in macroinvertebrate community composition between August 1999 and May 2001 can be ascribed to two concurrent developments. Abundances of deposit-feeding species or species typical of muddy sediments increased, e.g., the gastropod Nozeba emarginata (B. Marshall, Te Papa, National Museum of New Zealand, Wellington, pers. comm.), the carnivorous scale-worm Labiosthenolepis laevis, and the maldanid polychaetes $M$. theodori and A. trifilosus (Fauchald \& Jumars 1979). Concomitantly, abundances of species associated with disturbances and exhibiting traits typical of opportunistic species decreased, e.g., the mobile scavenger Phoxocephalidae sp. D and the deposit-feeding capitellid Heteromastus cf. filiformis (Grassle \& Grassle 1974; 
Shaffer 1983). The increasing role of deposit-feeders, especially of maldanids, but also of the polychaete Onuphis aucklandensis, suggests that the HB community has reached (or nearly reached) the endpoint of a successional trajectory. Such equilibrium or climax communities are rarely affected by intense natural disturbances (Rhoads 1974) and are characterised by a predominance of deposit-feeders and larger, long-lived and often deep-burrowing species. At high densities, these species physically modify their surroundings by bioturbation similar to the above mentioned tellinid and nuculid bivalves. Especially maldanids are seen as structural keystone resource modifiers. They transport organic matter both to the sediment surface and to deeper sediment layers and thereby exert a strong influence on the composition of infaunal communities (Levin et al. 1997). High mud and relatively high organic carbon content of sediments, as found at $\mathrm{HB}$, are typically associated with the dominance of deposit-feeders (Rhoads \& Young 1970), although the distribution of a particular functional group is not only driven by the granulometric properties of the sediments themselves, but by complex interactions between physical and biological factors at the sediment-water interface (Snelgrove \& Butman 1994). The near-bed water flow, for instance, is highly influential on the distributional patterns of organisms by affecting not only the sediment distribution, but also larval supply and the distribution food.

Wear and Anderlini (1995) described the pre-bloom macroinvertebrate community $(\geq 1000 \mu \mathrm{m})$ in the area of $\mathrm{HB}$ as being poor and disturbed, possibly by the smothering effect of sediment accumulation. Total abundance was low (61 ind. $0.1 \mathrm{~m}^{-2}$ ) and only 19 species $0.1 \mathrm{~m}^{-2}$ were recorded. The community was numerically dominated by the brittlestar Amphiura rosea, but maldanids and the small deposit-feeding bivalve Nucula hartvigiana were also important community members.

Three months post-bloom, total abundances (6-27 ind. $\left.0.1 \mathrm{~m}^{-2}\right)$ and number of species (4-9 species $0.1 \mathrm{~m}^{-2}$ ) were significantly reduced. By November $1998 \mathrm{~N}$ and $S$ had recovered to pre-bloom levels, but $H^{\prime}$ and $J$ ' were still reduced. Wear \& Gardner (2001) concluded that the community at HB had been more strongly affected by the toxic bloom in 1998 than other communities in the harbour due to the site's low-energy hydrodynamic regime. The results of 
Wear \& Gardner and of the present study thereby corroborate Olsgards findings (1993) that benthic communities situated in accumulation areas of fine sediments tend to get more negatively affected by toxic plankton blooms. Olsgard attributed this to a combination of higher quantities of sinking toxic material and a high degree of bioturbation at such sites. In the summer 2000/2001, nearly three years post-bloom, both total mean abundance and number of species were much higher (256.6 ind. $0.1 \mathrm{~m}^{-2}$ and 35.9 species $0.1 \mathrm{~m}^{-2}$; mean of November 2000 and February 2001 samples) than pre-bloom levels. However, while univariate diversity indices are strongly suggestive of a complete community recovery at $\mathrm{HB}$, results of assemblage seriation (as expressed by the Index of Multivariate Seriation, IMS) are indicative of recovery still taking place in May 2001, i.e., >3 years post-bloom. The increase in the univariate diversity indices and the fact that abundances of the detritivore $A$. rosea did not recover post-bloom, suggest that community composition might have changed between summer 1994/1995 and May 2001. Amphiura rosea, described as the numerically dominant species pre-bloom (McKoy 1970; Wear \& Anderlini 1995), did not occur at all three months post-bloom (Wear \& Gardner 2001), and occurred only in very low numbers until May 2001. The reasons underlying the slow recovery of this species are not clear. Echinoderms in general tend to be more affected by disturbances than other phyla such as annelids or molluses (Warwick \& Clarke 1993b) and therefore might need longer to recover to pre-disturbance levels. Another possible reason could be an undetected environmental change, which might impact negatively on the recovery process of $A$. rosea.

More than 1 year post-bloom, main recruitment at HB seems to have occurred in early spring (September to November) and autumn (March to April). Univariate diversity indices reflected such recruitment events and seemed to indicate that the community at $\mathrm{HB}$ had recovered, i.e., a long-term trend indicating on-going recovery could not be identified.

\section{Oriental Bay}

The third site studied, OB, is very shallow (ca. $1.8 \mathrm{~m}$ ) and exposed to the prevailing northerly winds and, due to the site's shallowness, wave impact. The fine sand with shell fragments and a relatively low organic carbon content (1.3- 
$1.6 \%$ ) found at this site, is reflective of the energetic hydrodynamic regime. The suite of species contributing most to the average assemblage similarity at $\mathrm{OB}$ included the capitellid Barantolla sp., the polychaete Owenia fusiformis, and the myodocopid ostracod Dolasterope quadrata, all of which exhibit opportunistic life strategies (Fauchald 1977; Rhoads et al. 1978; Oliver et al. 1979). O. fusiformis lives within a flexible tube from which it can change between suspension-feeding and surface deposit-feeding (Eckman et al. 1981) according to changes in local hydrodynamic conditions (Dauvin \& Gillet 1991). This species is commonly found in dense aggregations in sandy areas which are low in organic carbon content and prone to current-induced disturbance (Probert \& Wilson 1984; Elias \& Bremec 2000). The high temporal population variations exhibited by $O$. fusiformis in the present study are typical for this species. Such variations are likely to be caused by year-to-year variations in recruitment and juvenile survivorship, which are known to exhibit considerable variability (Dauvin \& Gillet 1991), rather than being a post-bloom response. The myodocopid ostracod Dolasterope quadrata was the second most abundant species at $\mathrm{OB}$ and contributed strongly to community dissimilarity due to the increasing abundances of this species with each successive year. Myodocopid ostracods appear to be facultative scavengers and deposit feeders (G. Fenwick, NIWA, pers. comm.), thereby profiting from any dead or damaged animals, which are likely to occur commonly at $\mathrm{OB}$ due to the wave exposure at this site. Brood-protecting, as was frequently observed for D. quadrata in this study, is another advantageous adaptation to life in a changeable environment such as OB. In fact, myodocopid ostracods have been found to thrive in subtidal high-energy sandy sediments (Oliver et al. 1979; Fenwick 1984a, b). Other species being important for the community similarity at $\mathrm{OB}$ were the deposit-feeding, free burrowing polychaete Armandia muculate and the bivalve Tawera spissa, both of which have an affinity for areas of high current velocities and coarse sediments (Estcourt 1976; Hayward et al. 1997; Beesley et al. 2000).

No quantitative pre-bloom data exist for the macroinvertebrate community at $\mathrm{OB}$, therefore only a tentative assessment of the recovery process is possible. The pre-bloom samples showed a very high degree of variability in their community composition, which could have been caused by the fact that three of the samples were taken in late-summer 1997 with the remainder taken in 
winter 1997. Additionally, sampling points were spread out over a distance of $200 \mathrm{~m}$ (Wear 1997a,b). Hence, variability in community composition might reflect seasonal and/or spatial variability. Wear and Gardner (2001) recorded a significantly higher number of species 3 months post-bloom compared to prebloom values (mean of 7.0 versus 3.6 species $0.1 \mathrm{~m}^{-2}$, respectively) in the subtidal, but could not explain this difference because the intertidal community at OB had been severely affected by the bloom with the loss of $>40 \%$ of all animal species. Within the first year post-bloom $N, S$, and $H^{\prime}$ increased considerably at this site (Gardner \& Wear submitted). Gardner \& Wear concluded, that due to the energetic hydrodynamic regime at $\mathrm{OB}$, the subtidal benthic community was largely unaffected by the bloom and that the changing values of $N, S$ and $H^{\prime}$ reflect the dynamic nature of this site. $N$ and $S$ continued to increase $>1$ year post-bloom until February 2001. The characterising species of the pre-bloom (Wear 1997) and $>1$ year post-bloom communities remained the same: the polychaete Owenia fusiformis and the bivalve Tawera spissa. However, in contrast to the conclusion of Wear \& Gardner (2001) and Gardner \& Wear (submitted) of no bloom-effect, results from analyses of assemblage variation and seriation in the present study indicate on-going community recovery at $\mathrm{OB}$ even $>3$ years post-bloom. Whether this recovery process is a consequence of the toxic bloom in 1998 and had not been identified by Gardner \& Wear (submitted), or a consequence of an undetected disturbance that occurred between the end of Gardner \& Wear's investigation (March 1999) and the begin of the present study (August 1999), remains speculative.

Samples at OB were taken on six occasions only between August 1999 and May 2001, and thus it was not possible to identify any recruitment peaks. The changes of univariate diversity indices over time suggest that recovery occurred until February 2001. The cause for the sudden decrease in mean total $N$, mean $N$ of the five most abundant species and total mean $S$ between February and May 2001 remains unexplained. Because such a decrease was not observed at the other two sites, it appears likely that a site-specific disturbance caused the observed changes in the OB community.

Although the communities at Oriental Bay and Entrance Channel are both exposed to a hydrodynamically active regime and live in similar sediments, their recovery processes following the toxic bloom were different. Whereas the OB 
community showed clear signs of on-going recovery, the EC community revealed no such signs. The reasons behind this remain inconclusive. Although during the 1998 toxic bloom plankton cell concentrations appeared to be relatively similar at $\mathrm{OB}$ and $\mathrm{EC}\left(1.0 \times 10^{6}\right.$ cell $^{-1}$ near to $\mathrm{OB}$ and $3.7 \times 10^{6}$ cell $^{-1}$ slightly south of EC; Chang et al. 2001), it is likely that the OB community was exposed to higher toxic levels than the EC community. The Entrance Channel region gets flushed with every tidal cycle (Brodie 1958) and the near-bed current in $12 \mathrm{~m}$ depth can be as high as $18 \mathrm{~cm} \mathrm{~s}^{-1}$ (Carter \& Lewis 1995), thus any accumulation of toxic cells at the sediment surface would be removed relatively quickly. Surface current speed in the western innermost basin of Wellington Harbour, where Oriental Bay is located, is frequently less than $1.5 \mathrm{~cm} \mathrm{~s}^{-1}$ (Heath 1977), which would support high accumulation rates. Moreover, dead and dying phytoplankton cells would reach sediment much faster at the shallow $\mathrm{OB}$ site $(1.8 \mathrm{~m})$ compared to the EC site $(11.8 \mathrm{~m})$. It seems possible that the macroinvertebrate community at $\mathrm{OB}$ experienced higher depositional rates and thus higher toxic levels than the EC community. Yet, the sandy sediment at OB indicates that accumulation rates are generally low at this site probably due to the sites' high exposure to wind-generated wave perturbations. However, the 1998 bloom coincided with a lower than average windspeed in Wellington (Chang et al. 2001), thus it appears likely that toxic cells could have accumulated at the sediment surface.

Whether the differing pre-bloom community compositions of $\mathrm{OB}$ and $\mathrm{EC}$ led to the recovery trajectories of the two communities being so different, is not clear. The EC community was dominated by crustaceans (Callianassa filholi, amphipods) before and $>1$ year post-bloom, whereas the OB community was rich in polychaetes. Crustaceans are mobile, thus being able to avoid potential accumulations of toxic cells (if such accumulations occurred at EC). At OB, the dominant species pre- and $>1$ year post-bloom were non-mobile facultative $(O$. fusiformis) or obligatory (T. spissa) suspension-feeders. These species would not have been able to avoid the toxic effects of the $K$. brevisulcata cells. 


\section{Succession Models}

Community recovery following a disturbance is a complex, often nonlinear process working at many different levels over different time scales (Depledge 1999; O'Neill 1999). Basically, a disturbance frees resources, e.g., space or food, which can be exploited by newly settling organisms (for a comprehensive discussion and definition of the term disturbance see Pickett \& White 1985). According to the models of Pearson and Rosenberg (1976) and Rhoads et al. (1978), community recovery proceeds in successional stages. Close to the disturbance (temporally or spatially), fast growing, small opportunistic species, mainly polychaetes, occur in great densities, often within a few days or weeks. After this 'peak of opportunists' follows a transient and unpredictable stage with high species fluctuations. The third stage is the equilibrium or climax community characterised by long-living and deep-burrowing species. Along this trajectory, species modify their habitat and thereby influence the success of other colonists (Rhoads 1974; Connell \& Slatyer 1977; Chesney 1985). Community recovery at the three sites studied in Wellington Harbour seems to have followed the model predictions, although not all successional stages have been observed. A stage with extremely high densities of opportunistic species was not recorded at any of the sites sampled by Wear \& Gardner (2001) and Gardner \& Wear (submitted), either because it was missed (only three sampling occasions in the first year post-bloom) or because it did not occur. The absence of such a peak of opportunists has also been noted by Olsgard (1993) following a large toxic Chrysochromulina polylepis bloom in the Kattegat/Skagerrak area of Scandinavia. The HB community had reached or nearly reached an equilibrium stage $>3$ years post-bloom, although community composition still changed at that point. At $\mathrm{OB}$ and $\mathrm{EC}$, communities remained at lower successional stages due to the constant physical disturbances they experience as described by Rhoads et al. (1978) for a shallow sandy site in Long Island Sound, U.S.A., which is exposed to winter storms. Whether the succession processes followed any of Connell \& Slatyer's models of facilitation, tolerance or inhibition (Connell \& Slatyer 1977) cannot be answered conclusively from the existing data. 


\section{Endpoint of Recovery}

Various criteria have been used to define the endpoints of recovery (Underwood 1996), such as presence or absence of key species (Depledge 1999), return to pre-disturbance species richness (Simon \& Dauer 1977), or the persistence of similarities in density and assemblage structure between disturbed and ambient non-disturbed patches (Thrush \& Whitlach 2001). Yet, communities might not return to their pre-disturbance state depending on a wide range of factors, e.g., seasonality, the species pool available for recolonisation (Thrush \& Whitlach 2001), disturbance history and simply chance (Depledge 1999). Seiderer \& Newell (1999) pointed out that communities might change in their composition as a consequence of, for instance, environmental changes irrespective of a disturbance. Thus, the pre-disturbance community would not be a true reference point for complete recovery anymore. To a certain extent this might be the case for the HB community, which changed from a depauperate community pre-bloom (Wear \& Anderlini 1995) to a diverse equilibrium community post-bloom, albeit one whose abundances of the pre-bloom dominant species $A$. rosea were still strongly reduced. The pre-bloom HB community could have experienced disturbance prior to sampling in 1994/95 and therefore would have been in an earlier successional stage than the community sampled $>1$ year post-bloom. Harbour Basin pre-bloom samples showed relatively high variability in their community composition compared to the late-stage postbloom samples, thus supporting the view of Wear \& Anderlini (1995) that the community might be in a recovery process. Power (1999) hypothesized that the re-attainment of pre-disturbance states might be the exception rather than the rule. Yet, in almost all field experiments of marine benthic macroinvertebrate community recovery, disturbed communities recover to a state very similar to the state of undisturbed control communities (Thrush \& Whitlach 2001), validating the often stated importance of pre-impact data in order to assess ecosystem recovery (Underwood 1991, 1992, 1993; Thrush 1994; Underwood 2000; Stewart-Oaten \& Bence 2001). However, it could be shown that community recovery can also be successfully assessed in the absence of reference data, i.e., pre-bloom and even initial post-bloom data, by applying the Indices of Multivariate Dispersion (IMD) and Multivariate Seriation (IMS). Such 
information is valuable for environmental managers who quite often are faced with having to assess the effects of disturbances in the absence of any reference data.

In the present study, pre-bloom samples at all three sites showed higher variability in community composition than the late-stage post-bloom samples. Such variability could indicate that communities were disturbed or it reflects spatial variability. The second explanation seems to be more likely because prebloom samples for each site were randomly selected from a pool of samples taken over a relatively widespread area and at $\mathrm{OB}$ even at different seasons (Wear \& Gardner 2001 and for more detailed descriptions of sampling areas Haddon \& Wear 1993, Wear 1997a,b and Wear \& Anderlini 1995). Comparing such samples with true replicate samples, i.e., the post-bloom samples, is problematical because it remains inconclusive whether the high variability of the pre-bloom data is a true measure of processes in the pre-bloom communities or whether it expresses the spatial variability one would expect when samples are taken over a relatively large area. Thus, in the present study comparing pre- and post-bloom data in order to assess the recovery process and estimate the endpoint of recovery is not without caveats. Nonetheless, pre-bloom data still provide important information about the macrobenthic communities.

At none of the sites did pre- and post-bloom communities converge in MDS ordinations, i.e., the communities were still different in their community composition more than 3 years post-bloom. However, decreasing relative dispersion with time indicated that communities at $\mathrm{OB}$ and $\mathrm{HB}$ were recovering, although it is not possible to say when complete community recovery, assuming that no other disturbance will interrupt the recovery process, will be attained. Communities of typical sediment accumulation sites such as HB might take 4-5 years to recover completely. At high-energy sites such as EC, and to a lesser extent $\mathrm{OB}$, macroinvertebrate communities might remain in a state of constant recovery due to frequent physical disturbance. The toxic bloom of the dinoflagellate Karenia brevisulcata in 1998 was an unprecedented event in the recorded history of Wellington Harbour and therefore could be viewed as a oneoff event. However, dinoflagellates produce dormant resting cysts, which can survive for years in the sediments, ready to emerge when environmental conditions are favourable (Paerl 1988). Blooms of $K$. brevisulcata have already 
re-occurred in the harbour during the summers of 1999 and 2000. Cell concentrations, however, were not high enough to induce widespread mortality of marine life (Chang 2000). Thus, it only seems to be a question of time before another outbreak of a toxic bloom disrupts benthic community processes in the harbour. The location, frequency, spatial extent and magnitude (toxicity or cell concentration) of future blooms will be strong determinants of the recovery trajectories of benthic communities in Wellington Harbour. If devastating blooms become a recurrent event, recovery periods might be too short for communities such as HB to return to pre-bloom levels, and communities might remain in an earlier successional stage.

\section{Comparisons with Other Studies}

Comparisons with other studies on the long-term effects of toxic blooms on intertidal and subtidal benthic communities reveal that communities tend to return to their pre-impact state within 2-4 years after the bloom (Dauer \& Simon 1976; Southgate et al. 1984; Olsgard 1993; Gjösæter et al. 2000). Such recovery times compare favorably with, for instance, recovery times after oil spills (e.g., Elmgren et al. 1983; Jewett et al. 1999) or the abatement of organic pollution (e.g., Rosenberg 1976), which can take $>6$ years. However, a toxic bloom constitutes a different form of disturbance and is ephemeral. Unlike oil spills or waste discharges, toxic blooms do not leave lasting potentially harmful residuals on the seafloor, nor do they change the sediment structure as storms (e.g., Rees et al. 1977; Yeo \& Risk 1979) or trawling with heavy fishing gear (e.g., Roberts et al. 2000; Sparks-McConkey \& Watling 2001) can do. In their effects on benthic communities, toxic blooms are similar to anoxic events, for which recovery times of one to several years have been reported dependent on the successional stage of the community prior to oxygen depletion (see Diaz \& Rosenberg 1995 for a detailed discussion on the ecological effects of marine benthic anoxia and references therein). 


\section{Origin of Recolonisers}

It remains in question where the recolonising organisms came from after the toxic bloom in 1998. Whereas juvenile and adult immigration is important for recolonisation on small spatial scales, larval recolonisation is the main process following large-scale disturbances (Günther 1992). Although it seems likely that recolonisation occurred mainly through larval settlement, no evidence exists for this assumption, because the mesh screen employed by Wear \& Gardner (2001) was too coarse to retain larval stages. Some subtidal organisms survived even at the most severely affected sites, i.e., HB (Wear \& Gardner 2001) and it is likely that the larvae of these survivors contributed to the general larval pool from which the benthic recolonisers derived. Other sources might have been non- or less affected areas within the harbour or areas outside the harbour. Yet, water masses and subtidal communities of Wellington's South Coast are very different from those of the harbour (Maxwell 1956; Brodie 1958; Booth 1975; Anderlini \& Wear 1992). Therefore it seems likely that most of the larvae, which settled after the toxic bloom had originated within the harbour.

\section{Univariate Versus Multivariate Methods}

The univariate indices employed in the present study in general did not prove to be useful descriptors of community recovery. Whereas these indices indicated complete recovery at least in terms of $N, S$ and $H^{\prime}$ at $\mathrm{HB}$ and $\mathrm{OB}$, multivariate analyses revealed on-going recovery processes at both sites. Reductions in $N$ and $S$ and often also a decrease in $H^{\prime}$ are typical community responses to disturbance (Pearson \& Rosenberg 1978), therefore these indices are useful in identifying the immediate effects of a disturbance and early successional stages. However, basing judgement of complete community recovery on the re-attainment of pre-disturbance levels of $N$ and $S$ can be misleading, because the identities of the species, which form the community, are ignored. Examples of discrepancies between the results of univariate indices and multivariate analyses in the context of community disturbance and recovery can be found, among others, in Rhoads et al. (1978), Gray et al. (1988) and DawsonShepherd et al. (1992). In conclusion, interpretations of recovery processes based 
upon univariate indices alone should be avoided in disturbance studies and it is strongly recommended that multivariate techniques should be used in combination with univariate techniques.

\section{Future Work}

The present study is a mensurative experiment (sensu Hurlbert 1984) and thus it is not possible to provide causal evidence about the underlying causes and processes of the observed changes in community composition. Hence, there is a need to confirm or refute conclusions derived from the mensurative experiment by a manipulative experiment (Underwood et al. 2000). In the context of this study a toxic bloom situation could be created in a mesocosm (control over toxic bloom concentration, current regime, etc.) and the long-term effects of the bloom on benthic macrofauna could thus be investigated. It has been shown, however, that results of small-scale studies cannot be applied to a larger scale without problems because factors controlling benthic recolonisation and succession are likely to be scale-dependent (Thrush et al. 1996; Whitlach et al. 1998b). To test the long-term effects of a toxic bloom on macroinvertebrate community composition would require a replicated field experiment on a relevant scale. Nonetheless, exact bloom conditions cannot be recreated in a field experiment due to ethical and pragmatic considerations. Therefore a situation must be created which closely mimics the immediate effects of a toxic bloom, but without the bloom-inherent toxicity. Oxygen depletion at the sediment water interface due to the decomposition of those organisms killed directly by the bloom and settling dead or dying phytoplankton cells is commonly associated with toxic blooms (Thistle 1981; Smith 1985; Snelgrove 1992). By carefully selecting the experimental area, the influence of different hydrodynamic conditions could be tested on the impact of the anoxic conditions on the benthic community and also on the recovery of the community. 


\section{Chapter 3}

\section{Recovery of a Macroinvertebrate Community in Experimentally Defaunated Subtidal Soft Sediments}

\subsection{Introduction}

Disturbance can be defined as 'any relatively discrete event in time that disrupts ecosystem, community, or population structure and changes resources, substrate availability, or the physical environment' (Pickett \& White 1985). Extent, frequency and magnitude of disturbances are variable, depending on the nature of the disturbance (Thistle 1981). Hence, disturbances act on variable temporal and spatial scales (Hall et al. 1994). The important role of disturbance as a major structuring force in marine and estuarine hard- and soft-sediment macroinvertebrate communities is well recognized (Thistle 1981; Sousa 1984; Sousa 2001) and such communities are often viewed as mosaics of patches created by disturbance with each patch being at a different stage of recovery (Johnson 1973; Thistle 1981; Thrush \& Whitlach 2001).

Large-scale partial or complete defaunation of benthic sediments through naturally occurring disturbances such as storms (Elias \& Bremec 2000), periodic hypoxia or anoxia due to failing exchange of bottom waters (Leppäkoski 1968; Harper et al. 1991; Fallesen et al. 2000; Rosenberg et al. 2002), or as a result of phytoplankton blooms (Santos \& Simon 1980a; Dethlefsen \& Westernhagen 1983), have occurred through geological times (Diaz \& Rosenberg 1995). A number of seafloor areas are subject to defaunation as a consequence of anthropogenic disturbances such as organic pollution (e.g. Pearson \& Rosenberg 1976, 1978; Saiz-Salinas 1997), oil spills (Grassle \& Grassle 1974; Elmgren et al. 1983; Jewett et al. 1999), dredging (Newell et al. 1998) and deposition of mine tailings (Burd et al. 2000). Such defaunations are of wide-reaching consequence for ecosystem functioning, particularly in shallow coastal areas, 
where benthic macroinvertebrates are of vital importance as food for fish species, many of which are exploited commercially (Beukema et al. 1999).

Studies of recovery processes after natural, anthropogenic and experimental disturbances have shown that benthic macroinvertebrate assemblages tend to recover from partial or complete defaunation to a state similar to that of assemblages in adjacent undisturbed sediments (Thrush \& Whitlach 2001). Indeed, much of the evidence assembled from aquatic systems points to relatively rapid recovery periods, often $<3$ years (Niemi et al. 1990). Hence, benthic macroinvertebrate assemblages generally show high resilience (time required to return to equilibrium, Power 1999) towards disturbance. However, recovery might also lead to a state where the recovered assemblages differ from the original ones depending on the history, the spatial and temporal scales (O'Neill 1999) and timing of the disturbances (Thrush \& Whitlach 2001). Current models of recovery processes in soft-sediment assemblages (Pearson \& Rosenberg 1976, 1978; Rhoads et al. 1978; Rhoads \& Germano 1986) predict such processes via a specific sequence of successional stages tending towards higher system complexity. Each stage comprises species with particular life history characteristics, which make them especially suited to the environmental conditions encountered in each successional stage. These models are often limited in their applicability because they do not generally account for the frequently observed variability in recovery processes (Zajac \& Whitlach 1982a, b; Elmgren et al. 1983; Smith \& Brumsickle 1989; Thrush et al. 1996). Such variability is foremost due to the influences of seasonality (Zajac \& Whitlach 1982a, b, 1989; Llansó 1992; Ford et al. 1999), hydrodynamics (Günther 1992), mobility of recolonising species (Whitlach et al. 1998; Thrush \& Whitlach 2001), biotic interactions (Rhoads 1974; Connell \& Slayter 1977), and scale of disturbance (Zajac et al. 1998). Specifically, benthic recovery processes following a toxic plankton bloom in Wellington Harbour, New Zealand (Wear \& Gardner 2001; Gardner \& Wear submitted, Chapter 2 of this thesis) and in the Skagerrak/Kattegat area (Olsgard 1993) did not reflect the predictions of the succession models mentioned, i.e., a transient dominance of opportunistic species did not occur following a disturbance event. Such deviation from model predictions is perhaps not surprising because a disturbance caused by a toxic bloom is of a different nature than the disturbances for which the models were 
developed (e.g., organic enrichment, physical disturbance). Additionally, current succession models do not take spatial scales of disturbances into account and assume a state of complete defaunation caused by the disturbance (Zajac 1999). Hence, a need exists for current succession models to incorporate results derived from different larger-scale disturbances such as toxic plankton blooms to render wider applicability.

The Wellington Harbour bloom, caused by the neurotoxin-producing dinoflagellate Karenia brevisulcata (Chang) Hansen \& Moestrup (Djaugbjerg et al. 2000), occurred in early March 1998 and led to high mortalities among the harbour's marine biota (Chang 1998a, b). This event provided the opportunity to test hypotheses about the long-term effects of a toxic plankton bloom on benthic macroinvertebrate assemblages. Although a khaki-coloured layer (presumably consisting of dead algal cells) was reported to cover part of the harbour's sediment immediately post-bloom, long-term organic enrichment of the sediment was not observed (Wear \& Gardner 2001; Gardner \& Wear submitted, Chapter 2 of this thesis). However, effects of the bloom on the benthic macroinvertebrate assemblages in Wellington Harbour were observed $>3$ years after the bloom (Chapter 2 of this thesis) and were found to be site-specific and largely dependent on hydrodynamic conditions (Wear \& Gardner 2001; Gardner \& Wear submitted, Chapter 2 of this thesis). Following a mensurative experiment (Chapter 2), the next logical step in order to gain more insight into benthic macroinvertebrate recovery processes is to conduct a manipulative experiment on a relevant scale to address specific questions (Underwood et al. 2000). On a small spatial scale, a variety of manipulative experiments following recovery processes after sediment defaunation have been reported (Zajac \& Whitlach 1982a, b; Savidge \& Taghon 1988; Berge 1990; Diaz-Castaneda et al. 1993; Snelgrove 1994; Norkko \& Bonsdorff 1996; Lu \& Wu 2000), but difficulties arise when applying the results of these studies to larger spatial scales, because factors controlling recovery are likely to be scale-dependent (Thrush et al. 1996; Whitlach et al. 1998; Thrush \& Whitlach 2001). The disturbance caused by the bloom in Wellington Harbour was likely to operate at a relatively large spatial scale (Wellington Harbour $=$ ca. $85 \mathrm{~km}^{2}$ and much of it was affected), and although meso-scale (1-100 $\left.\mathrm{m}^{2}\right)$ manipulative experiments of benthic recovery processes have been conducted (Thrush et al. 1996; Beukema et al. 1999; 
Dittmann et al. 1999), such experiments were situated on intertidal mud flats and thus, their applicability to subtidal recovery processes is limited. To date, no meso-scale defaunations and their effects on benthic macroinvertebrate assemblages have been carried out in the subtidal region. This is not surprising, considering that manipulative experiments in the subtidal are difficult to conduct at the best of times, especially when the processes of interest are tested on larger spatial and/or temporal scales.

The need therefore exists for a manipulative experiment studying the recovery trajectory of subtidal macroinvertebrate communities following a largescale disturbance, such as a toxic plankton bloom, especially in view of the increasing occurrence of plankton blooms on a global scale (Hallegraeff 1993). As was demonstrated by the 1998 K. brevisulcata bloom in Wellington Harbour, such blooms can occur even in areas experiencing considerable tidal and current mixing. However, aquaculture facilities are frequently established in areas of current activity, tidal or otherwise, in order to avoid the negative impacts of such blooms and also the accumulation of organic matter, which in turn could lead to oxygen-depletion. Thus a hydrodynamically exposed site was chosen for the present manipulative experiment due to the lack of studies investigating the recovery of subtidal macroinvertebrate communities in such areas. The experiment, conducted in Wellington Harbour, aimed to mimic the effects of a plankton bloom on the benthos, i.e., mass mortality, without actually creating a bloom. Smothering of the sediment surface was chosen as a method to mimic a disturbance event, which resulted in a benthic die-off with an associated oxygendepletion. Oxygen-depletion can be a common consequence of phytoplankton blooms due to the accumulation and decomposition of large amounts of organic matter in the form of phytoplankton and organisms killed by the bloom (Simon \& Dauer 1972; Pearl 1988; Hallegraeff 1993; Rhodes et al. 1993). The results of the preceding mensurative experiment (Wear \& Gardner 2001; Gardner \& Wear submitted, Chapter 2 of this thesis) and other studies (Schratzberger \& Warwick 1998; Ferns et al. 2000) indicated that assemblage resilience at hydrodynamically exposed sites is high and therefore it could be predicted that assemblage recovery would take place over a relatively short time, an important aspect with regard to research time available. Thus, the present study aimed to test the hypothesis that 
following a defaunation event benthic macroinvertebrate assemblage composition at a hydrodynamically exposed site changes in a sequential pattern over time and that recovery is achieved in $<1$ year. In the context of this experiment recovery is defined as the state at which no significant differences can be detected in univariate diversity parameters (mean abundance $N$, mean number of species $S$ or Shannon's diversity $H^{\prime}$ ) or in assemblage composition between the ambient undisturbed and the disturbed benthic macroinvertebrate assemblages. Results obtained can be discussed in the context of current succession models with the aim of testing the applicability of such models for the recovery of macroinvertebrate assemblages after benthic die-offs as a consequence of, for instance, toxic plankton blooms in hydrodynamically exposed areas.

\subsection{Material and Methods}

\subsubsection{Study Site}

For a detailed description of Wellington Harbour refer to Chapter 1, section 1.3. The experiment was located close to the southwestern shores of Matiu-Somes Island in the center of the Harbour.

The experiment was conducted in the same season (autumn) as the 1998 plankton bloom, and in a section of the Harbour where bloom cell concentrations had been high (Chang et al. 2001). A relatively shallow site (7-9 $\mathrm{m}$ water depth) was selected close to Matiu-Somes Island to enable safe dive work. The site was slightly sheltered from southerly storms, but relatively exposed to the prevailing northwesterly winds (Goff 2000). The extremely poorly sorted sandy sediment reported by Van der Linden (1967) for this area indicates a high-energy current and wave regime. In his study, Van der Linden also pointed out the abundant benthic megafauna found around the island consisting mainly of brachiopods, molluscs and echinoderms. Preliminary diving examination of the study site 
revealed sandy sediment interspersed with small pebbles, shell and coarse shell fragments and some small boulders. Organic matter content was low at $1.9 \%$ ( \pm 0.17 SD; $n=6$; samples taken in January 2001 before on-set of experiment). The starfishes Patiriella regularis and Coscinasterias calamaria and the sea cucumber Stichopus mollis were commonly encountered at the site.

\subsubsection{Experimental Set-up and Sampling}

In order simulate a major disturbance event which was characterised by benthic oxygen depletion, heavy plastic tarpaulin was used to cover three plots (each ca. $25 \mathrm{~m}^{2}$ ) of sediment to render free water flow over the sediment surface impossible. Throughout this study the covered plots are referred to as 'treatments' or 'treatment plots' $(\mathrm{n}=3)$, whereas reference plots are referred to as 'controls' or 'control plots' $(\mathrm{n}=3)$. Controls were of the same area as treatments, but received no tarpaulin cover. A linear systematic design (Hurlbert 1984) was chosen to allocate sites to be either treatments or controls, i.e., treatments alternated with controls. Plots were separated by $5 \mathrm{~m}$ to ensure safe diving, an important aspect in Wellington's unstable wind conditions. However, the independence between plots was not jeopardised. To decide whether the first plot (from the southern end) in the line-up would be treatment or control, a coin was tossed. The objective for deciding for a systematic in favour of a truly randomized experimental design was to simplify dive work as much as possible.

Treatments were prepared for the experiment by removing small boulders from the plots to facilitate a 'tight fit' of the tarpaulins over the sediment and to prevent puncturing of the tarpaulins, which would have permitted unwanted water exchange. Boulders in controls were also removed. Tarpaulins were rolled out on the treatment plots on the 11/01/01 and weighted down by anchor chains and heavy metal bars. Because the tarpaulins were observed 'ballooning up' a week after the set-up of the experiment (probably due to high wave-energy experienced at this site), additional pieces of anchor chain were placed onto the tarpaulins on $30 / 01 / 01$ and $01 / 02 / 01$. The additional weight kept the tarpaulins sufficiently tight over the sediment to prevent further ballooning. Tarpaulins were checked regularly and removed after 65 days on 06/04/01. To mark the 
plots, a labelled wooden pole was placed in the centre of each control and treatment plot.

After removal of the tarpaulins, divers reported black surface sediment in the center of the treatment plots, indicating anaerobic conditions. No signs of recent bioturbation were visible in the treatments and although many burrows were present, no recently ejected, lighter coloured material was seen around these openings. Subsurface sediment taken from treatment plots was of much darker colour than sediment from control plots. This difference in colour remained visible until at least Day 156.

\section{Sampling Times}

Pre-disturbance samples were collected 1 day before the tarpaulins were deployed. However, these samples could not be analysed due to a handling mistake when processing the samples. In order to detect a model-predicted peak of abundance of opportunistic species in the initial recovery phase, sampling frequencies were high at the beginning of the experiment and slowly extended to longer intervals. The first samples were taken ca. 24 hours after removal of the tarpaulins and samples were subsequently collected on ten separate occasions (Day $1=07 / 04 / 01$, Day $6=12 / 04 / 01$, Day $18=24 / 04 / 01$, Day $39=15 / 05 / 01$, Day $70=15 / 06 / 01$, Day $100=15 / 07 / 01$, Day $156=09 / 09 / 01$, Day $218=10 / 11 / 01$, Day $319=19 / 02 / 02$ and Day $378=19 / 04 / 02$ after the initiation of the experiment). Sampling was completed on Day 378.

\section{Biological Samples}

Diver-operated circular PVC cores with a surface area of $44.18 \mathrm{~cm}^{2}$ and a penetration depth of $11.0 \mathrm{~cm}$ were employed for obtaining biological samples ( $n=4$ per plot per sampling occasion). The upper end of the cores was covered by a $300 \mu \mathrm{m}$ mesh. Samples were taken haphazardly within a $2 \mathrm{~m}$ circumference of the central marker in each plot to prevent potential edge effects. Care was taken to avoid areas where depressions in the sediment indicated previous sampling, which was especially important in the initial phase of the experiment when 
sampling frequencies were high. Cores were transported to the water surface in an upright position in a specifically designed carrier and were transferred to prelabelled plastic bags on board the research vessel 'Raukawa Challenger'. In the laboratory, the samples were washed immediately through a $500 \mu \mathrm{m}$ mesh using seawater and fixed in a borax-buffered formalin solution $(6 \%)$ for a minimum period of 24 hours. Samples were re-washed in freshwater before being transferred to $70 \%$ alcohol to which Rose Bengal was added to aid the sorting process.

Olsgard et al.'s (1998) recommendations for baseline and ecologically orientated studies were followed and specimens were identified to the lowest possible taxonomic level. Where identification to species level was not possible, the concept of 'morphospecies' was employed in that morphologically distinct individuals were treated as distinct species. Specimens were counted and their dry-blotted alcohol wet weight recorded to an accuracy of $\pm 0.001 \mathrm{~g}$. If the biomass was too small to be registered by the balance, a weight of $0.001 \mathrm{~g}$ was automatically recorded for that particular specimen(s). Molluscs were weighed with their shell. A reference collection of all species encountered in the samples was established to aid in consistency of identifications. Literature employed for identification purposes and a list of taxonomical experts who provided help are presented in Appendix 1.

Due to logistical reasons a $500 \mu \mathrm{m}$ mesh was employed to extract the macroinvertebrates from the sediment, thus the larval and sometimes post-larval stages, although important in the recolonisation process (see amongst others Günther 1992; Thrush et al. 1996; Whitlach et al. 1998b), could not be quantitatively assessed.

\section{Sediment Samples}

Organic matter content of the sediment was measured to establish whether an organic enrichment had occurred as a consequence of the benthic dieoff (Simon \& Dauer 1972; Pearl 1988; Hallegraeff 1993; Rhodes et al. 1993). Divers took sediment samples for organic matter content determination $(n=4$ per plot) on each sampling day (except Day 70 ) adjacent to the biological samples. In 
the laboratory, obvious organisms were removed from the samples and ca. $25 \mathrm{~g}$ of sediment per sample was carefully homogenized. Samples were dried ( $3 \mathrm{~d}, 60$ ${ }^{\circ} \mathrm{C}$ ), weighed and then re-weighed after combustion in a muffle furnace (24 hours, $450^{\circ} \mathrm{C}$ ). The organic matter content was calculated by subtracting the ashfree dry weight from the dry weight (Holmes \& McIntyre 1984).

Sediment samples for grain size analyses were taken only once (Day 319 , $\mathrm{n}=4$ per plot). Approximately $100 \mathrm{~g}$ of sediment per sample were dried ( $3 \mathrm{~d}, 60$ ${ }^{\circ} \mathrm{C}$ ), weighed and washed gently through a set of stacked Wentworth grade sieves (Endecott) to a lower limit of $63 \mu \mathrm{m}$. The separate fractions were re-dried ( $3 \mathrm{~d}$, $60{ }^{\circ} \mathrm{C}$ ) before being weighed (Holmes \& McIntyre 1984). The Grain-Size 1-2 software programme (Barrett \& Brooker 1989) was employed to calculate mean grain size, sorting coefficient, skewness, kurtosis and granulometry of the sediment using Folk \& Ward's indices (Folk \& Ward 1957).

\section{Sample Replication}

Best-fit cumulative curves (cumulative number of new, i.e., previously unsampled, species plotted against number of cores) of data from control samples obtained on Day 1 were used to calculate the necessary number of replicates needed to sample the macroinvertebrates representatively without undersampling the rarer species. The curves indicated that by using three replicates the resulting loss of species would be negligible since the curve would still be in the upper $10 \%$ of the asymptote, i.e., more than $90 \%$ of the occurring species were sampled. However, it was decided to analyse all four replicates taken per plot if possible. Occasionally, replicate samples had to be rejected due to spillage of content during transport, in which case only three replicates per plot were available for analysis.

\subsubsection{Data Analyses}

Abundance $(N)$, number of species $(S)$, Shannon's diversity $H^{\prime}(\log$ e) and Pielou's Evenness $J^{\prime}$ (often referred to as $E^{\prime}$ ) were calculated for each core 
sample using the software package PRIMER (Plymouth Routines in Multivariate Ecological Research, Clarke \& Warwick 2001). The computer package STATISTICA (version 6.0: Statsoft, Tulsa, Oklahoma, USA) was employed for Kruskal-Wallis tests, post-hoc tests and for linear regressions.

Data for $N, S, H^{\prime}, J^{\prime}$, biomass $B$ and total organic matter content (\% OM) did not fulfill assumptions of normality and homogeneity of variances even after standard transformations were applied. Therefore the non-parametric KruskalWallis test was used to test the null hypothesis $\mathrm{H}_{0}$ that no difference existed among treatments and controls of different sampling days for the variables $N, S$, $H^{\prime}, J^{\prime}$ and $B$. The significance level was set to $p=0.05$. Post-hoc tests (multiple comparisons of means) were employed in order to assess the significance of differences between pairs of samples. The high number of independent significance tests performed in post-hoc tests required a Bonferroni-correction for the significance level $p$ in order to avoid Type I errors. Thus the significance level was corrected by dividing $p$ by 50 , i.e., the number of tests performed, to $p=0.001$. Because $H^{\prime}$ is not defined for $N=0$ and $J^{\prime}$ is not defined for $N=0$ and 1 , some treatment samples were omitted from analyses of $H^{\prime}$ (two samples omitted) and $J^{\prime}$ (nine samples omitted). In order to test for temporal differences of $N, S, B$, $H^{\prime}$ and $J^{\prime}$, Kruskal-Wallis and post-hoc tests were conducted separately for control and treatment plot data. The null hypothesis $\mathrm{H}_{0}$ for each index was that no difference existed among sampling days. The significance level for post-hoc tests was Bonferroni-corrected to $p=0.005$ (number of tests performed $=10$ ).

PRIMER was used for multivariate analyses of the macroinvertebrate assemblage structure. For detailed descriptions of the analyses used refer to Chapter 2, Section 2.2.5. PRIMER was also used to produce ABC curves, i.e., separate $k$-dominance curves for abundance and biomass data in the same plot (Warwick 1986). However, because classifications of assemblages as disturbed or undisturbed based on the $\mathrm{ABC}$ curves were misrepresentative according to results from multivariate analyses, results are presented in Appendix 15. Two treatment samples with zero abundance (Day 1 and 6) were omitted from multivariate analyses because the similarity between two samples with zero abundance is undefined (Clarke \& Gorley 2001). The two ecological response measures, abundance $(N)$ and biomass $(B)$, were used to approximate production $(P)$ using the allometric equation 


$$
P=(B / N)^{i} \times N
$$

where $e$ is the average exponent of the regression of annual production on bodysize for different phyla of macrobenthic invertebrates ( $e=0.88$ for polychaetes, 0.64 for crustaceans, 0.72 for molluscs and 0.73 for the remaining taxa) (Brey 1990). In order to evaluate which of the three measures (abundance, biomass and production) is the most suitable response variable to environmental disturbances such as the experimentally created oxygen depletion, all three measures were used for dendrograms, multidimensional scaling and two-way crossed Analysis of Similarity (ANOSIM) (Warwick \& Clarke 1993b).

For all multivariate analyses, data were fourth-root transformed to decrease the influence of dominant taxa (Clarke \& Green 1988). Similarity matrices were constructed using the Bray-Curtis Index (Bray \& Curtis 1957). Dendrograms and ordinations were produced to visualise the (dis)similarity of macroinvertebrate assemblages. For constructing dendrograms hierarchical agglomerative clustering with group-averaging (average per sampling day) was used, whilst ordination used non-metric multi-dimensional scaling (n-MDS).

Two-way crossed Analysis of Similarity (ANOSIM, Warwick et al. 1990) was performed to test for significant differences in macroinvertebrate community composition between the a priori groupings of samples. Samples were allocated to the factors Treatment (with levels Treatment and Control) and Sampling Day (with levels 1, 6, 18, 39, 70, 100, 156, 218, 319, 378). The null-hypotheses tested were $\left(\mathrm{H}_{0} 1\right)$ no difference of macroinvertebrate assemblages between control and treatment plots, allowing for differences among sampling days and $\left(\mathrm{H}_{0} 2\right)$ no difference of macroinvertebrate assemblages among sampling days, allowing for differences between control and treatment plots.

Results of the preceding multivariate analyses indicated that production was the most suitable response variable for the created oxygen depletion and therefore only production data were used for most of the following multivariate analyses. A one-way ANOSIM analysis (Clarke \& Green 1988) was performed to determine whether complete community recovery had been achieved in treatment samples. The null hypothesis that there was no difference between control and treatment plot assemblages was tested in pairwise comparisons of control and treatment samples for each sampling day (Dernie et al. 2003). 
Similarity percentage analysis, SIMPER, (Clarke 1993) was employed to assess community similarity and dissimilarity for control and treatment assemblages (averaged for each sampling day) and to identify the main species contributing to any similarity of treatment assemblages, to any dissimilarity between control and treatment assemblages for each sampling day, and for consecutive sampling days for treatment assemblages only. Dendrogram and ordination of the abundance, biomass and production data revealed that control assemblages did not change much over the course of the experiment and hence the control assemblages were not explored further.

The Index of Multivariate Dispersion (IMD, Warwick \& Clarke 1993a) and the Index of Multivariate Seriation (IMS, Clarke et al. 1993) were applied as measures of community stress. The IMD is a measure of change in the variability of replicate samples. The underlying assumption is that increased variability in the multivariate structure of faunal assemblages is a sign of perturbation ('patchiness'). Variability was expressed as relative dispersion for control and treatment assemblages for each sampling day, and as IMD for pairwise comparisons of control and treatment assemblages for every sampling day and for treatment assemblages of consecutive sampling days. The IMS (expressed as the Spearman rank correlation $\rho$ ) was applied as a measure of the extent to which changes in control and treatment assemblages conform to a linear sequence. A permutation test with 5000 permutations was used to test the null hypothesis that no seriation exists in either control or treatment sites. MDS ordinations were plotted for control and treatment assemblages (averaged for each sampling day) and the sample points were linked in temporal order to visualise the degree of seriation. The IMD was computed for abundance, biomass and production data.

The same Kruskal-Wallis and post-hoc tests that were employed to analyse univariate indices were also used to determine whether the total organic matter content of the sediment (expressed as \% OM) varied between treatment and controls and among the sampling days. Separate Kruskal-Wallis and post$h o c$ tests for control and treatment plot data were employed to test for temporal differences in \% OM ( $\mathrm{H}_{0}$ : no differences existed among sampling days). 
Spearman rank correlations were employed separately for control and treatment data to establish whether Shannon's Diversity $H^{\prime}$ 'was correlated with $\%$ OM. The BIOENV procedure (Clarke \& Ainsworth 1993) was used for control and treatment data together and for control and treatment data separately, to investigate whether \% OM could be linked to the observed changes in macroinvertebrate assemblage compositions. The same permutation procedure, which has been employed for the analysis of assemblage seriation, was used to test the null hypothesis that there was no relationship between the biotic information and the organic matter content of the sediment, i.e., that $\rho$ was effectively zero (Clarke \& Ainsworth 1993; Clarke \& Warwick 2001). This analysis was performed for control and treatment data together and for control and treatment data separately.

\subsection{Results}

\subsubsection{Biological Analyses}

\section{Abundance $(N)$, Biomass $(B)$ and Number of Species $(S)$}

Overall, 15,810 individuals belonging to 125 putative taxa were obtained from 228 core samples (114 core samples each from control and treatment plots, including two treatment samples with zero abundance) taken on 10 sampling occasions between April 2001 and April 2002. Almost two-thirds of the individuals $(62.6 \%)$ were found in control samples, whereas $37.4 \%$ were found in treatment samples. The overall total biomass of control and treatment samples was $589.3 \mathrm{~g}$ with $86.3 \%$ of the biomass extracted from control samples and $13.7 \%$ from treatment samples. Control and treatment samples contained a total of 110 species each with 15 species encountered only in controls and 14 species only in treatment samples. A species list is presented in Table 3.1 and mean abundance, biomass and production (all $\pm \mathrm{SD}$ ) are listed in Appendix 12. 
Table 3.1 Species list

\begin{tabular}{|c|c|c|c|}
\hline Class & Species & Class & Species \\
\hline Anthozoa & Scolanthus sp. & Peracarida & Notatolana rossi \\
\hline Bivalvia & Nucula hartvigiana & Peracarida & Caprellidae sp. A \\
\hline Bivalvia & Modiolus areolatus & Peracarida & Cumacea sp. A \\
\hline Bivalviaa & ?Tiostrea lutaria juv. & Peracarida & Cumacea sp. B \\
\hline Bivalvia & Pratulum pulchellum & Peracarida & Cumacea sp. D \\
\hline Bivalvia & Corbula zelandica & Peracarida & Tanaidacea sp. A \\
\hline Bivalviaa & Scintillaona zelandica & Peracarida & Leptanthura sp. 2 \\
\hline Bivalvia & Melliteryx parva & Ostracoda & Cymbicopia hispida \\
\hline Bivalvia & Athritica bifurca & Ostracoda & Cymbicopia zealandica/hispida \\
\hline Bivalvia & Zenatica acinaces & Ostracoda & Dolasterope quadrata \\
\hline Bivalvia & Gari stangeri & Ostracoda & Euphilomedes agilis \\
\hline Bivalvia & Leptomya retiaria & Ostracoda & Lauroleberis zealandica \\
\hline Bivalvia & Theora lubrica & Ostracoda & Scleroconcha sculpta \\
\hline Bivalvia & Ascitellina urinatoria & Copepoda & Copepoda sp. A \\
\hline Bivalvia & Serratina charlottae & Copepoda & Copepodasp. B \\
\hline Bivalvia & Diplodonta zelandica & Malacostraca & Callinassa filholi \\
\hline Bivalvia & Ruditapes largillierti & Malacostraca & Jaxea novaezealandiae \\
\hline Bivalvia & Tawera spissa & Malacostraca & Halicarcinus cooki \\
\hline Bivalvia & Myadora striata juv. & Malacostraca & Neommatocarcinus antarcticus \\
\hline Polyplacophora & Ischnochiton sp. A & Malacostraca & Notomitrax minor \\
\hline Polyplacophora & Chiton sp. A & Malacostraca & ?Petrolisthes novaezealandiae \\
\hline Polyplacophora & Chiton sp. juv. & Malacostraca & Cancer novaezealandiae \\
\hline Polyplacophora & Rhyssoplax sp. A & Malacostraca & Paguridae spp. juv. \\
\hline Gastropoda & ?Cellana strigilis & Malacostraca & Decapoda larvae sp. A \\
\hline Gastropoda & Notoacmea sp. juv. & Malacostraca & Decapoda sp. B \\
\hline Gastropoda & Buccinulum linea & Polychaeta & Turbonella sp.1 \\
\hline Gastropoda & Cantharidella tesselata & Polychaeta & ?Ampharetinae \\
\hline Gastropoda & Cantharidus purpureus & Polychaeta & Barantolla sp. \\
\hline Gastropoda & Trochus tiaratus & Polychaeta & Capitomastus sp. \\
\hline Gastropoda & Turbo smaragdus & Polychaeta & Notomastus sp. \\
\hline Gastropoda & Maoricolpus roseus roseus & Polychaeta & Chaetozone sp. B \\
\hline Gastropoda & Anabathron hedleyi & Polychaeta & Cirratulidae sp. D \\
\hline Gastropoda & Caecum digitulum & Polychaeta & Dorvilleidae sp. A \\
\hline Gastropoda & Sigapatella tenuis & Polychaeta & Lumbrineris sp. A \\
\hline Gastropoda & Tanea zelandica & Polychaeta & Glycinde dorsalis \\
\hline Gastropoda & Xymene pusillus & Polychaeta & Glycera ovigera \\
\hline Gastropoda & Gumina dolichostoma & Polychaeta & Hemipodus simplex \\
\hline Gastropoda & Odostomiun sp. A & Polychaeta & Microphthalamus sp. A \\
\hline Peracarida & Parawaldeckia sp. A & Polychaeta & Aglaophamus virilli \\
\hline Peracarida & ?Lyssianassidae sp. C & Polychaeta & Aglaophamus sp. 3 \\
\hline Peracarida & Paraphoxus sp. A & Polychaeta & Platynereis? australis \\
\hline Peracarida & Phoxocephalidae sp. D & Polychaeta & Armandia maculata \\
\hline Peracarida & Phoxocephalidae sp. I & Polychaeta & Onuphis aucklandensis \\
\hline Peracarida & Gammaridae sp. B & Polychaeta & Orbinia papillosa \\
\hline Peracarida & Amphipoda sp. M & Polychaeta & Pectinaria australis \\
\hline Peracarida & Iphinotus typicus & Polychaeta & ?Amphictene sp. \\
\hline Peracarida & ?Stegocephalidae sp. A & Polychaeta & Phyllodocidae sp. B \\
\hline Peracarida & Munnogonium sp. 2 & Polychaeta & Sthenelais taurangaensis \\
\hline Peracarida & Eurydice aff semitruncata & Polychaeta & Aphrodita talpa \\
\hline
\end{tabular}


Table 3.1. continued

\begin{tabular}{llll}
\hline Class & Species & Class & Species \\
\hline Polychaeta & Lepidonotus sp. A & Polychaeta & Exogone sp. B \\
Polychaeta & Euchone sp. A & Polychaeta & Syllidae sp. A \\
Polychaeta & Megalomma sp. A & Polychaeta & Syllidae sp. C \\
Polychaeta & Spirorbis sp. A & Polychaeta & Syllidae sp. F \\
Polychaeta & Carazziella philipensis & Polychaeta & Syllidae sp. H \\
Polychaeta & Laonice sp. A & Polychaeta & Polycirrus sp. A \\
Polychaeta & Microspio elegantula & Polychaeta & Flabelligera sp. A \\
Polychaeta & Prionospio aucklandia & Holothuroidea & Trochodota dendyi \\
Polychaeta & Prionospio ?cirriferra & Echinoidea & Echinocardium caudatum \\
Polychaeta & Prionospio sp. A & Asteroidea & Patiriella regularis \\
Polychaeta & Scolelepis sp. A & Asteroidea & ?Coscinasterias muricatajuv. \\
Polychaeta & Exogone ?heterosetosa & Ophiuroidea & Amphiura rosea \\
Polychaeta & Exogone sp. A & Phoronidae & Phoronis sp. \\
\hline
\end{tabular}

Polychaetes were the most abundant group in control samples with $67.9 \%$ of total abundance, followed by molluscs (13.0\%) and others (anthozoans and phoronids, 9.7\%) (Figure 3.1) Most abundant groups in treatment samples were polychaetes with $62.2 \%$, others $(13.8 \%)$ and crustaceans $(12.0 \%)$. Molluscs $(44.3 \%)$, echinoderms $(26.6 \%)$ and crustaceans $(14.6 \%)$ were the main contributors to total biomass in treatment samples.

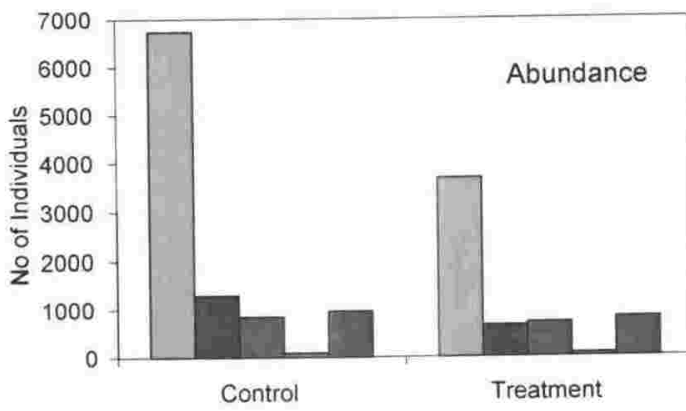

․ Polychaeta

- Mollusca

Crustacea

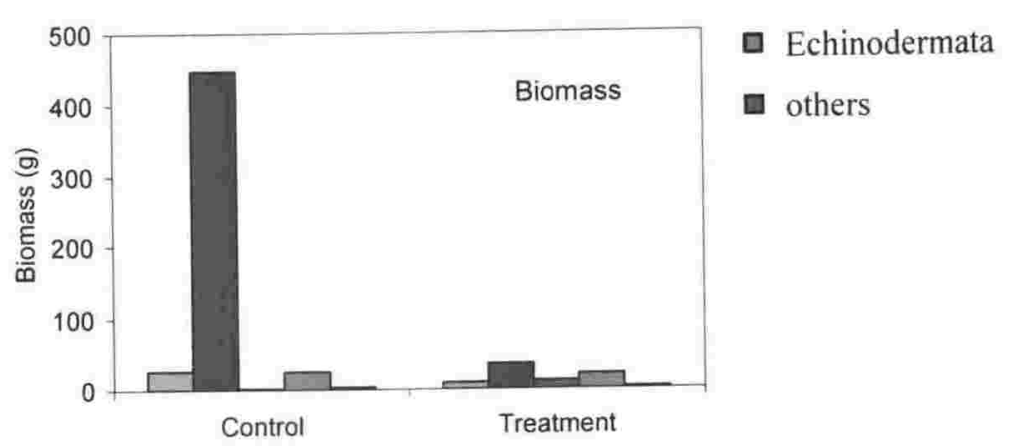

Figure 3.1 Total number of individuals per group (top) and biomass per group (below) extracted from all Control and all Treatment samples. 


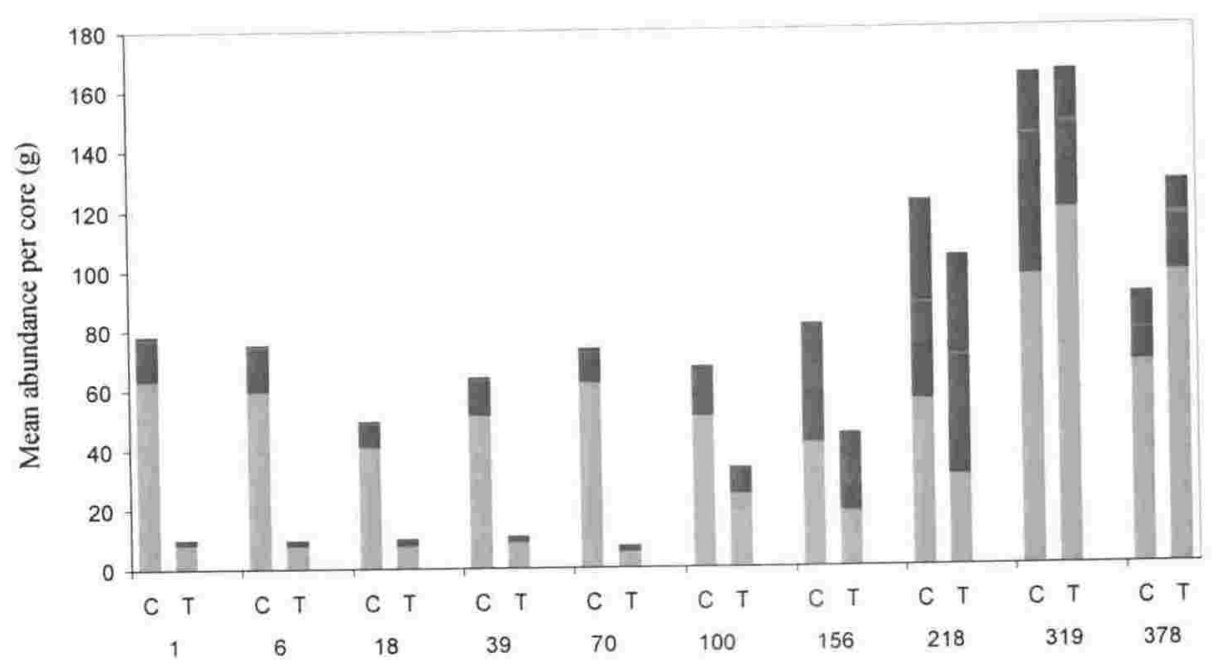

Sampling Day

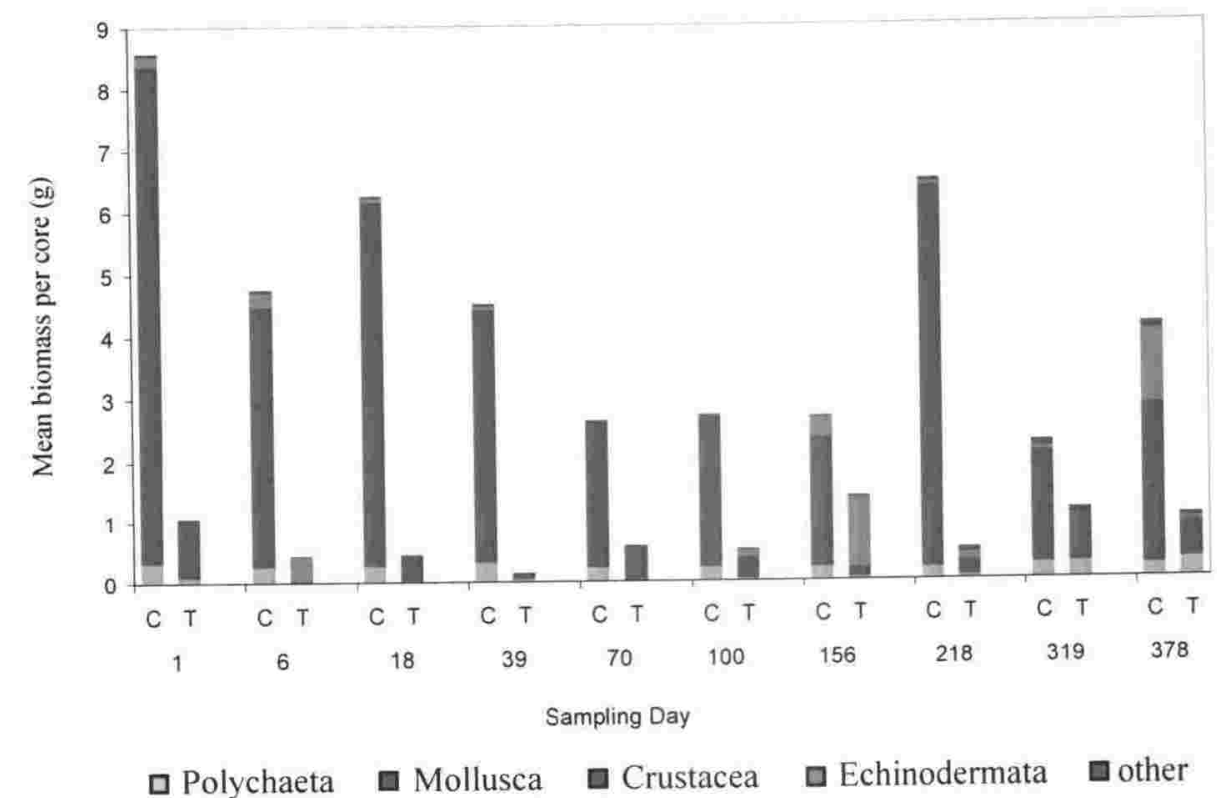

Figure 3.2 Mean abundance per group (top) and mean biomass per group (below) for Control (C) and Treatment (T) assemblages. $n=9-12$ per sampling occasion, depending on whether all samples were retrieved successfully.

Mean abundance $N$ and mean biomass $B$ (both per core) are presented in Figure 3.2 for control and treatment plots. Mean abundance in treatment plots remained low until after Day 70 with $N=7.4-10.8$ ind. per core. In the controls, abundance ranged from 49.5-78.3 ind. per core until Day 70. Abundance in treatment plots increased between Day 70 and Day 156 and continued to rise until Day $319(N=165.1)$, coincident with abundance increases in control plots $(N=164.2)$. By Day 378 mean abundance in treatment plots was higher than in 
controls ( $N=127.8$ and 90.7, respectively). Crustaceans, molluses, echinoderms and others contributed little to treatment abundances until Day 100.

Mean biomass $B$ remained low for all groups in treatments throughout the duration of the experiment. High mollusc biomass values in both controls and treatments were mainly due to the occurrence of the sunset shell Gari stangeri, the deposit-feeding topshell Trochus tiaratus and the ciliary deposit-feeding gastropod Maoricolpus roseus roseus (Morton \& Miller 1968). Each adult of these species can weigh several grams, thus contributing strongly to mean biomass albeit mean abundance remaining low. For instance, the high biomass values in treatments on Day 1 were caused by the occurrence of one G. stangeri $(9.30 \mathrm{~g})$ and on Day 6 by three T. tiaratus $(4.18 \mathrm{~g})$. The cushion star Patiriella regularis caused high values of echinoderm biomass (e.g., Treatments Day 6: 1 P. regularis of $4.40 \mathrm{~g})$.

The polychaetes Owenia fusiformis and Barantolla sp. and the actinian Scolanthus sp. were amongst the five most abundant species in both control and treatment plots (Figure 3.3). Abundances of O. fusiformis and Scolanthus sp. increased considerably in controls and treatments with the onset of spring (Day $156=09.09 .01$ ), while Barantolla sp. occurred in high abundances in controls throughout the duration of the experiment. Barantolla reached maximum abundance in controls on Day $218(N=48.3)$, while in treatments the maximum abundance was reached on Day $378(N=47.5)$. Owenia fusiformis also increased considerably in abundance in both controls and treatments between Day 218 and $319(N=3.4-21.3$ in $\mathrm{C}$ and $N=4.6-33.0$ in T). Abundance patterns of Scolanthus sp. were similar in controls and treatments with very low abundances until Day 100 and peak abundances at Day $218(N=32.5$ in $\mathrm{C}$ and $N=23.1$ in T). In both control and treatment plots, abundance of Scolanthus sp. decreased to pre-peak levels by Day 378. The bivalve Tawera spissa and the syllid polychaete Exogone ?heterosetosa were common in treatment plots, as were the spionids Prionospio sp. A and Carazziella philipensis in control plots. 

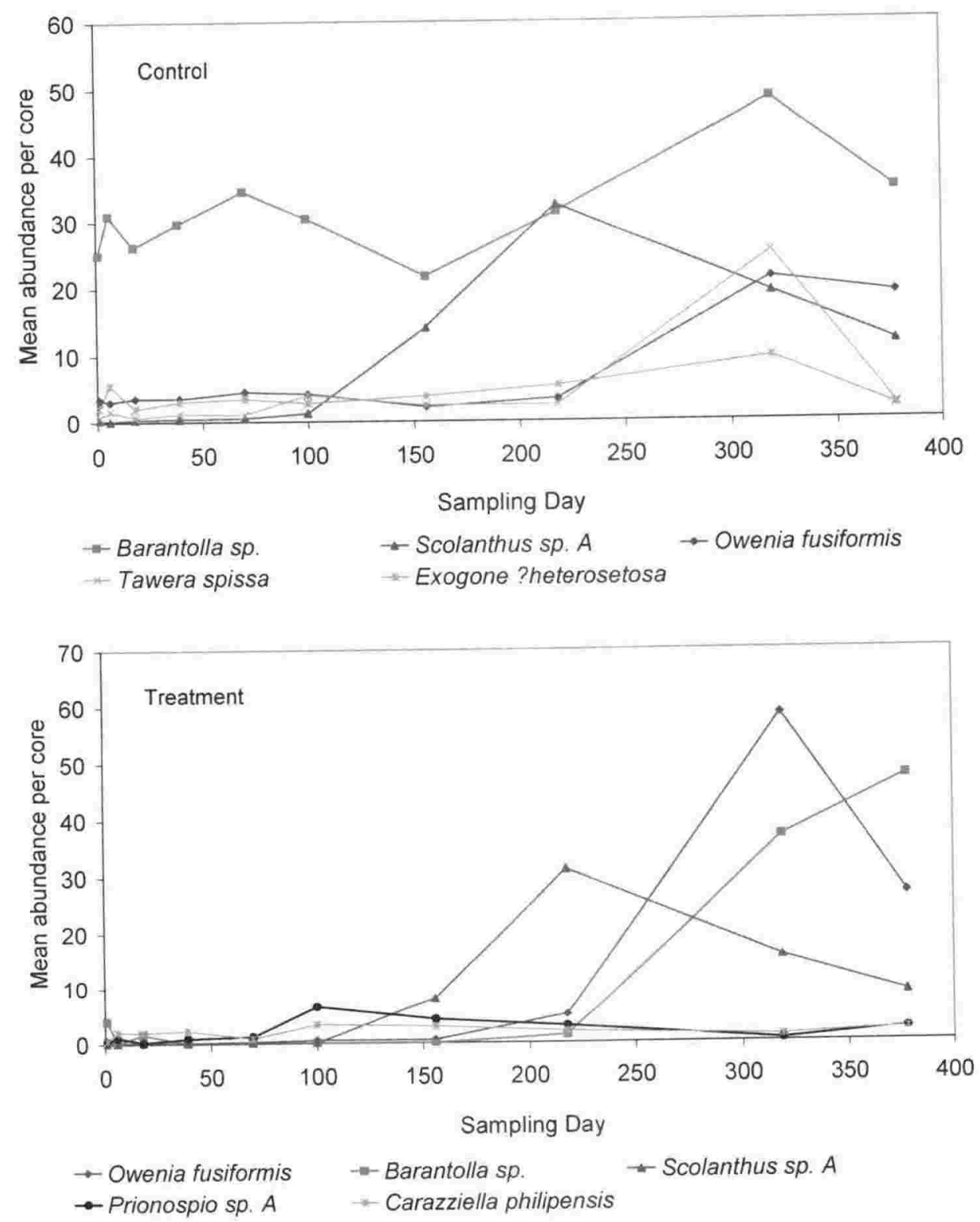

Figure 3.3 Mean abundance per core $\left(44.18 \mathrm{~cm}^{-2}\right)$ of 5 most numerically dominant taxa for Control (top) and Treatment (below) assemblages. Standard deviations have been omitted for clarity of presentation. For SD see Appendix 12. $n=9-12$ per sampling occasion, depending on whether all samples were retrieved successfully.

\section{Univariate Diversity Indices}

The immediate effects of the experimentally induced disturbance were evident in the lower values of mean abundance $N$, mean number of species $S$, mean total biomass $B$ and Shannon's diversity $H^{\prime}$ in the treatment plots compared to control plots (Figure 3.4). 


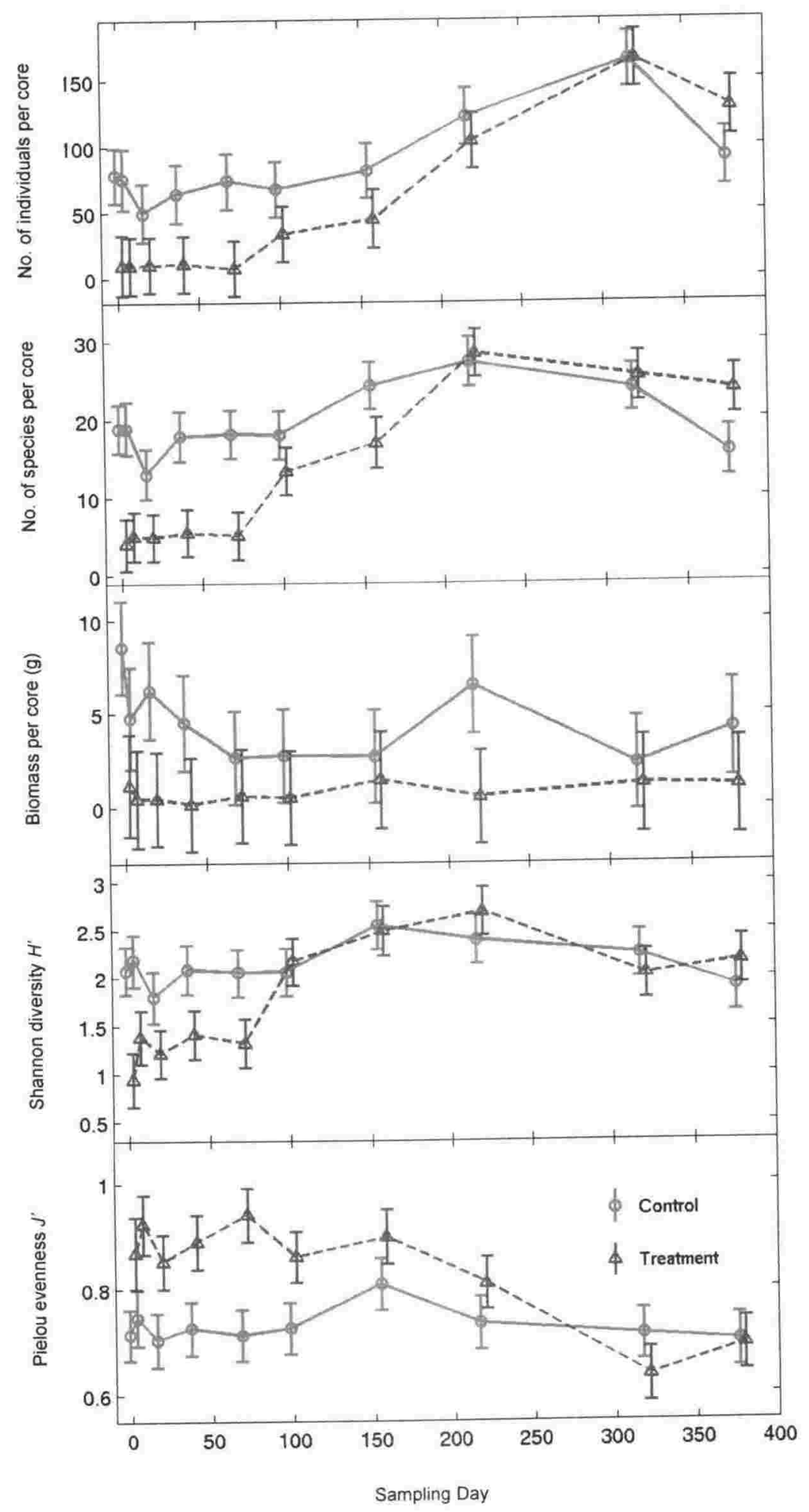

Figure 3.4 Mean number of individuals $N$, mean number of species $S$, mean total biomass $B$ (all per core, i.e., $44.18 \mathrm{~cm}^{-2}$ ), Shannon Diversity $H^{\prime}$ and Pielou evenness $J^{\prime}$ for Control (red) and Treatment (blue) assemblages. Data averaged per sampling day. For $N, S$ and $B \mathrm{n}=10-12$, for $H^{\text {' }}$ $\mathrm{n}=9-12$ (samples with $N=0$ or 1 excluded) and for $J^{\prime} \mathrm{n}=6-12$ (samples with $N=0$ or 1 excluded). Error bars denote $95 \%$ confidence intervals. 
$N$ and $S$ increased in treatments from Day 70 onwards, whereas in controls an increase did not occur until Day 100. Until Day $319 \mathrm{~N}$ was higher in controls than in treatments. On Day $319, N$ peaked in both control and treatment plots with $N$ being slightly higher in treatments than in controls ( $N=164.0$ ind. per core and 165.0 ind. per core, respectively). On Day $378 \mathrm{~N}$ was still higher in treatments than in controls $(\mathrm{N}=90.5$ ind. per core and 128.6 ind. per core, respectively). The change in $S$ was similar, with $S$ being lower in treatment plots until Day 218, when highest values for $S$ were recorded in both control and treatment plots ( $S=27.3$ ind. per core and 28.4 ind. per core, respectively). Mean total $B$ per core was considerably lower in treatment plots on Day 1 than in control plots (1.16 g vs $8.57 \mathrm{~g}$, i.e., ca. $85 \%$ lower) and remained low for the duration of the experiment. The high value for $B$ in the control plots on Day 1 was caused by the occurrence of one individual of $M$. roseus roseus and several G. stangeri. Variability in biomass among replicate samples was considerable in both control and treatment plots.

Shannon's diversity $H^{\prime}$ displayed generally the same trend as $N$ and $S$, except that the maximum for $H^{\prime}$ ' was reached earlier in control plots (Day 156) than in treatment plots (Day 218). Evenness or equitability $J$ ', an indicator of the evenness with which individuals are distributed among the different species in a sample, was generally higher and changed to a greater degree in treatment than in control plots. Whereas the decreasing values of $J$ ' in treatment plots from Day 156 onwards were indicative of the rising dominance of Scolanthus sp., Owenia fusiformis and Barantolla sp., evenness was low ( 0.7) and varied little in control plots throughout the course of the experiment, indicating the continuous dominance of Barantolla sp.

Differences of control and treatment assemblages were highly significant for all five indices (Table 3.2). However, post-hoc tests indicated that only $N, S$ and $B$ were significantly lower in treatment plots on Day 1 (Table 3.3). Biomass $B$ was also significantly lower in treatment plots on Day 18 . 
Table 3.2 Results of Kruskal-Wallis test for effects of Treatment and Sampling Day on the number of individuals $(N)$, number of species $(S)$, biomass $(B)$, Shannon diversity $\left(H^{\prime}\right)$ and Pielou evenness $\left(J^{\prime}\right)$. Significance level $p<0.05$.

\begin{tabular}{lccc}
\hline Source & N & $H$ & $p$ \\
\hline Number of individuals $N$ & 228 & 170.324 & $<0.001$ \\
Number of species $S$ & 228 & 165.270 & $<0.001$ \\
Biomass $B$ & 228 & 100.742 & $<0.001$ \\
Shannon diversity $H^{\prime}$ & 226 & 122.441 & $<0.001$ \\
Pielou evenness' $J^{\prime}$ & 219 & 116.777 & $<0.001$ \\
\hline
\end{tabular}

Table 3.3 Results of pair-wise post-hoc tests between control and treatment plots of each sampling day for number of individuals $(N)$, number of species $(S)$, biomass $(B)$, Shannon diversity $\left(H^{\prime}\right)$ and Pielou evenness $\left(J^{\prime}\right)$. ns=non-significant. Significance level is Bonferronicorrected to $p<0.001$.

\begin{tabular}{ccccccccccc}
\hline Source & \multicolumn{10}{c}{ Sampling Day } \\
\cline { 2 - 12 } & 1 & 6 & 18 & 39 & 70 & 100 & 156 & 218 & 319 & 378 \\
\hline$N$ & $<0.001$ & ns & ns & ns & ns & ns & ns & ns & ns & ns \\
$S$ & $<0.001$ & ns & ns & ns & ns & ns & ns & ns & ns & ns \\
$B$ & $<0.001$ & ns & $<0.001$ & ns & ns & ns & ns & ns & ns & ns \\
$H^{\prime}$ & ns & ns & ns & ns & ns & ns & ns & ns & ns & ns \\
$J^{\prime}$ & ns & ns & ns & ns & ns & ns & ns & ns & ns & ns \\
\hline
\end{tabular}

In order to test for temporal differences in $N, S, B, H^{\prime}$ and $J^{\prime}$, Kruskal-Wallis tests were employed separately for control and treatment data (Table 3.4). Whereas all indices in treatment plots showed significant temporal differences, only $N, S$, and $H^{\prime}$ 'were significantly different in control plots. Post-hoc multiple pairwise comparisons employed separately for control and treatment data are presented in Appendix 14. In control plots $N$ was significantly higher at Day 319 than at Days 6, 18, 39 and 100. At Day $18 \mathrm{~S}$ was significantly higher than at Days 156-319. Diversity $H^{\prime}$ 'was significantly lower at Day 18 compared to Day 156. In treatment plots $N$ and $S$ were in general significantly lower at Days 1-70 compared to Days 100-378 (except $S$ at Day 6). At Day $6 B$ was significantly lower than at Days 218-319. Diversity $H^{\prime}$ ' was significantly lower at Days 6-70 compared to Days 100-218 and $J^{\prime}$ was significantly higher at Days 39, 70 and 156 than at Day 319. 

located closer together, but they were also located closer to control samples. However, treatment and control samples had not merged by Day 378. Stress levels (0.1-0.12) indicated good representations of the real sample relationships in all ordinations.
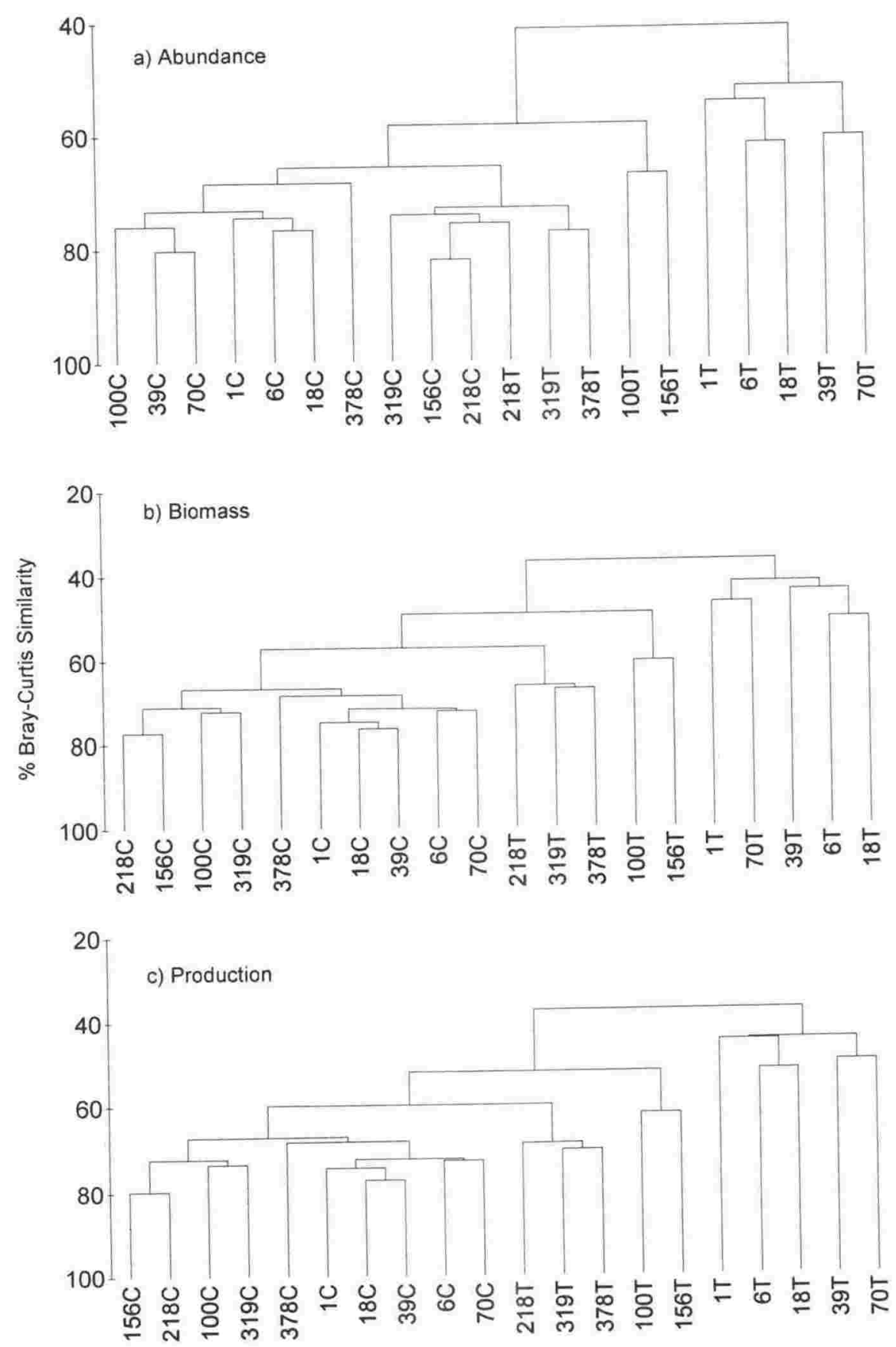

Figure 3.5 Dendrograms using group-average linking of Bray-Curtis similarities of 4th-root transformed a) abundance, b) biomass and c) production data (averaged per sampling day). Sample labelling: $1,6,18$, etc. $=$ Sampling Day; $C=$ Control, $T=$ Treatment. $n=8-12$ per sampling occasion, depending on whether all samples were retrieved successfully. For 1T and 6T: one sample each omitted from analysis due to zero abundance. 

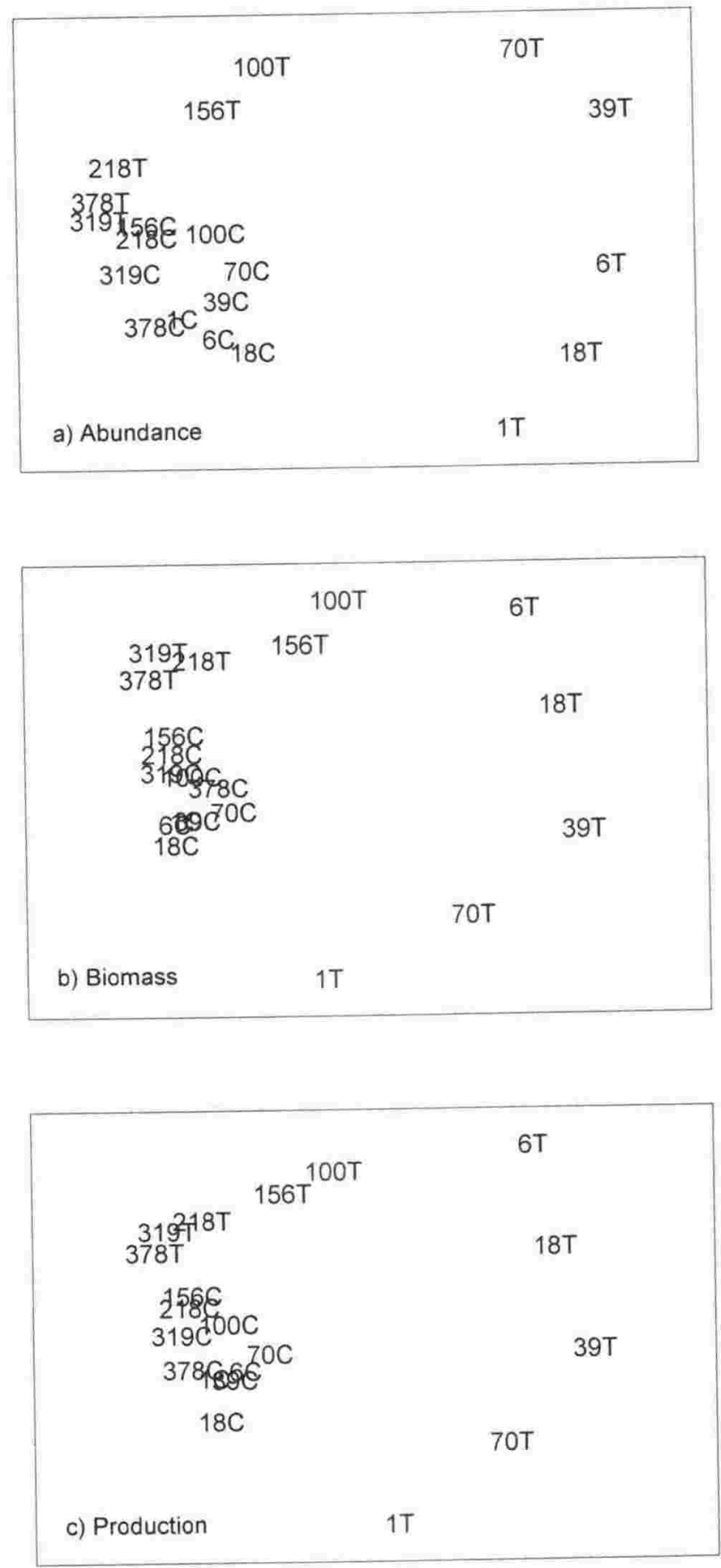

Figure 3.6 MDS ordinations using Bray-Curtis similarities of $4^{\text {th }}$-root transformed a) abundance, b) biomass and c) production data (averaged per sampling day). Sample labelling: 1, 6, 18, etc. $=$ Sampling Day; $\mathrm{C}=$ Control, $\mathrm{T}=$ Treatment;. $\mathrm{n}=8-12$ per sampling occasion. For $1 \mathrm{~T} 2$ and $6 \mathrm{~T} 2$ : one sample each omitted from analysis due to zero abundance. Stress = a) 0.1, b) 0.12 , c) 0.11 . 


\section{Significance Testing}

Results of 2-way crossed ANOSIM analyses for abundance, biomass and production data are presented in Table 3.5. The factors Treatment and Sampling Day both had a significant effect on macroinvertebrate assemblages for abundance, biomass and production data, i.e., independent of the response unit both null hypotheses were rejected at a significance level of $p<0.001$. The factor Treatment explained more of the variation in the data set than did time (higher $R$ value). The effects of the factors on production data are emphasized in the ordinations of Figure 3.7.

Table 3.5 Two-way crossed ANOSIM analysis testing for effects of factors Treatment and Sampling Day on data of three biological response units. Data: $4^{\text {th }}$-root transformed.

\begin{tabular}{cccc}
\hline Response & \multicolumn{2}{c}{ Global $R$} & Significance $p$ \\
unit & Treatment & Sampling Day & \\
\hline Abundance & 0.517 & 0.388 & $<0.001$ \\
Biomass & 0.529 & 0.301 & $<0.001$ \\
Production & 0.519 & 0.320 & $<0.001$ \\
\hline
\end{tabular}

Visual comparisons of the dendrograms and ordinations for all three ecological measures (abundance, biomass and production) and results of the twoway crossed ANOSIM analyses indicated that all three measures were good response units to the experimentally created perturbation. Thus, it was decided to perform the following multidimensional analyses with the production data only, which encompass information of abundance and biomass and therefore are especially suitable as a response unit to environmental perturbation (Clarke \& Warwick 2001). 


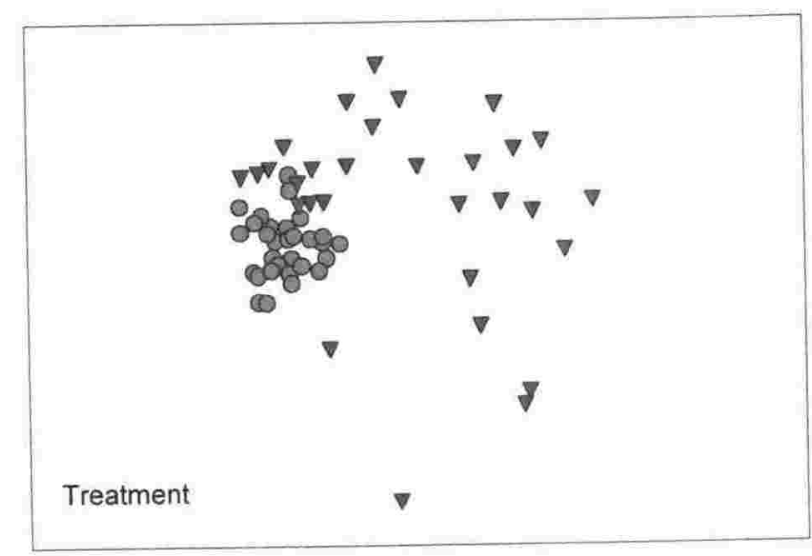

- Control

v Treatment

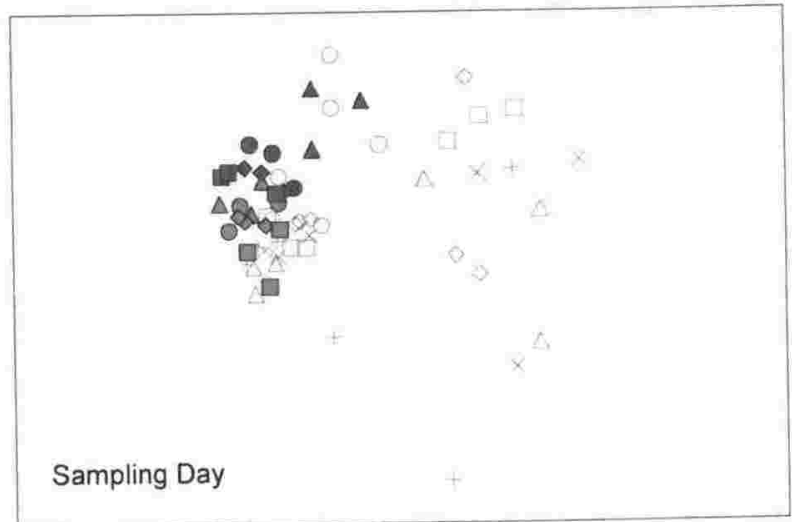

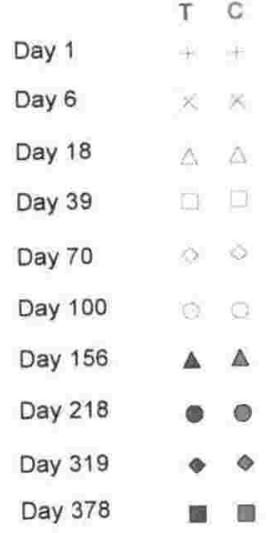

Figure 3.7 MDS ordination using Bray-Curtis similarities of group-averaged $4^{\text {th }}$-root transformed production data for factors Treatment (above) and Sampling Day (below). Colour code: red $=$ Control assemblages, blue $=$ Treatment assemblages. Stress $=0.16$.

Table 3.6 Pairwise comparisons (ANOSIM) of production data ( $4^{\text {th }}$-root transformed) for Control and Treatment plots on each sampling day.

\begin{tabular}{ccc}
\hline $\begin{array}{c}\text { Groups } \\
\text { compared }\end{array}$ & $\begin{array}{c}R \\
\text { value }\end{array}$ & $\begin{array}{c}\text { Significance } \\
p\end{array}$ \\
\hline $1 \mathrm{C}, 1 \mathrm{~T}$ & 0.537 & $<0.001$ \\
$6 \mathrm{C}, 6 \mathrm{~T}$ & 0.577 & $<0.001$ \\
$18 \mathrm{C}, 18 \mathrm{~T}$ & 0.519 & $<0.001$ \\
$39 \mathrm{C}, 39 \mathrm{~T}$ & 0.643 & $<0.001$ \\
70C, 70T & 0.528 & $<0.001$ \\
$100 \mathrm{C}, 100 \mathrm{~T}$ & 0.712 & $<0.001$ \\
$156 \mathrm{C}, 156 \mathrm{~T}$ & 0.531 & $<0.001$ \\
$218 \mathrm{C}, 218 \mathrm{~T}$ & 0.448 & $<0.001$ \\
$319 \mathrm{C}, 319 \mathrm{~T}$ & 0.329 & $<0.001$ \\
$378 \mathrm{C}, 378 \mathrm{~T}$ & 0.266 & 0.002 \\
\hline
\end{tabular}


Pairwise comparisons derived from the ANOSIM test on production data for each sampling day showed that although differences between control and treatment assemblages decreased with time, recovery had not been completed by Day 378 , i.e., there was still a statistically significant difference in community structure between treatments and controls $>1$ year after initiation of the experiment $(R=0.266, p=0.002$, number of permutated statistics $\geq R=1$ of 999 ; Table 3.6). The change of the $R$-value over time for control vs. treatment assemblages is shown in Figure 3.8. The plot gives an indirect indication of the recovery trajectory of the treatment assemblages because a higher $R$-value indicates larger relative differences between control and treatment assemblages. Control and treatment assemblages were most dissimilar until Day 156 ( $R$-values in the range of $0.519-0.712$ ). From Day 156 onwards, declining $R$-values (in the range of $0.266-0.448$ ) indicated a gradual recovery process, i.e., an increasing similarity between treatments and controls. Figure 3.7 indicates that the increasing $R$-values in the early days of the experiment (Day 6, 39 and 100) resulted from changes and high variability in treatment assemblages. The control assemblages form a tight cluster and thus indicate high similarity.

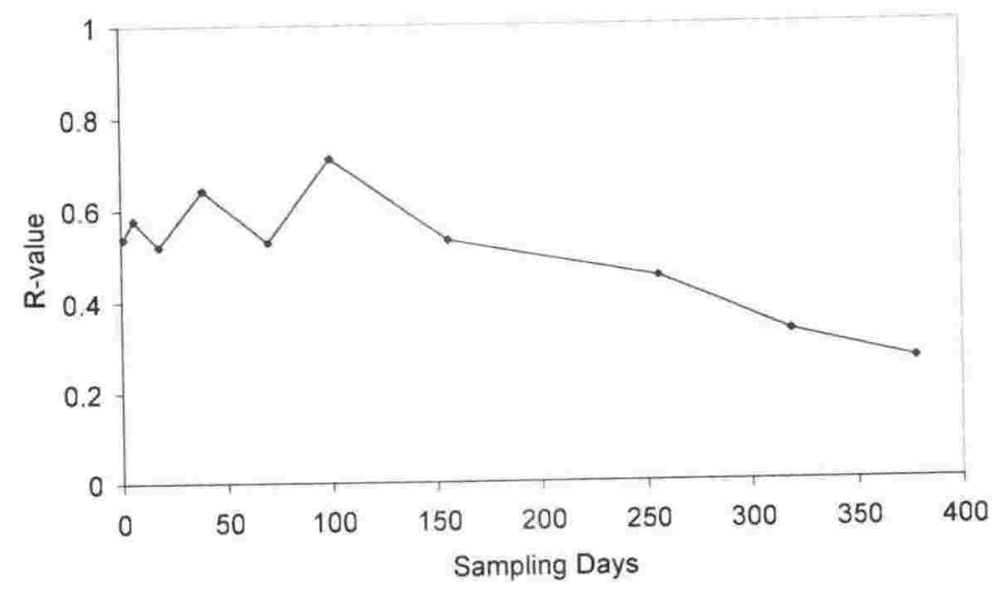

Figure 3.8 Changes in $R$-value determined from one-way ANOSIM test of control vs treatment assemblages for each sampling day. Data: $4^{\text {th }}$-root transformed production data. 


\section{Species Analysis}

While community similarity (among-replicate similarity $S$ ) of control assemblages remained relatively constant throughout the duration of the experiment $(S=40.5 \%-50.6 \%$ ), treatment assemblage similarity was low until Day $70(S=17.2 \%)$, but increased considerably between Day 70 and Day 100 ( $S=35.6 \%$; Table 3.7). From Day 156 onwards, treatment assemblages exhibited the same level of community similarity as control assemblages. Dendrograms (Figure 3.5), MDS ordinations (Figure 3.6), and SIMPER results indicated that control assemblages did not change much over the course of the experiment and therefore control assemblages were not explored further.

Table 3.7 Average among-replicate similarity $S$ for Control and Treatment macroinvertebrate assemblages of group-averaged (mean/sampling day) production data. Data were $4^{\text {th }}$-root transformed.

\begin{tabular}{ccc}
\hline & \multicolumn{2}{c}{ Average } \\
Sampling Darity $S$ \\
Control & Treatment \\
\hline 1 & 46.51 & 17.21 \\
6 & 49.80 & 19.13 \\
18 & 43.69 & 15.96 \\
39 & 45.65 & 24.03 \\
70 & 50.43 & 17.21 \\
100 & 44.50 & 35.64 \\
156 & 40.50 & 40.89 \\
218 & 46.86 & 50.29 \\
319 & 50.62 & 46.98 \\
378 & 46.98 & 45.30 \\
\hline
\end{tabular}

Species contributing most to the average similarity $(S)$ of treatment assemblages are listed in Table 3.8. Until Day 70 only a few species contributed to assemblage similarity and such species did not typify treatment assemblages well, as indicated by their low $S_{\mathrm{i}} / \mathrm{SD}\left(S_{\mathrm{i}}\right)$ ratios (Clarke \& Warwick). The assemblage at Day 100 was typified by the capitellid Capitomastus sp., the spionid Prionospio sp. A and the syllid Exogone? heterosetosa with $S_{\mathrm{i}} / \mathrm{SD}\left(S_{\mathrm{i}}\right)$ ratios $>1.3$. Prionospio sp. A also typified the treatment assemblage of Day 156 along with the amphipod Gammaridae sp. B and the anthozoan Scolanthus sp. Contributing most to assemblage similarity at Day 218 were Prionospio sp. A, 
Owenia fusiformis, the ostracod Scleroconcha sculpta and Scolanthus sp. The latter species remained important for assemblage similarity on Day 378, however, O. fusiformis and the capitellid Barantolla sp. showed higher ratios of $S_{\mathrm{i}} / \mathrm{SD}\left(S_{\mathrm{i}}\right)$ than Scolanthus sp. Extensive lists of species contributing up to $90 \%$ cumulative similarity to treatment (and control) macroinvertebrate assemblages are presented in Appendix 16.

Dissimilarities $(\delta)$ and species contributing to the dissimilarities between control and treatment assemblages of the same sampling day and between treatment assemblages of consecutive sampling days are presented in Table 3.9 and Table 3.10. The five species contributing most to dissimilarities between control and treatment assemblages and the ten species contributing most to dissimilarities between treatment assemblages of consecutive sampling days are listed in these tables. More extensive lists (cut-off $90 \%$ dissimilarity) can be found in Appendix 17.

Pairwise comparisons of control and treatment assemblages of the same sampling day indicated that assemblages were very different until Day 70 (high dissimilarities), but dissimilarities decreased continuously between Day 100 and Day $319(\delta=55.99 \%)$, indicating that control and treatment assemblages became more similar. Between Day 1 and Day 70, species responsible for the dissimilarities occurred mainly in control assemblages. Only from Day 100 onwards did species in treatment assemblages contribute to some extent to $\delta$. Between Day 1 and Day 218, the capitellids Barantolla sp. and Notomastus sp., as well as the oweniid $O$. fusiformis and the glycerid Hemipodus simplex, contributed most to $\delta$ between control and treatment assemblages with high $\delta_{\mathrm{i}} / \mathrm{SD}\left(\delta_{\mathrm{i}}\right)$ ratios. By Day 319 the phoronid Phoronis sp., and on Day 378 the polychaete Euchone sp. and the amphipod Gammaridae sp. B, were the main discriminating species between control and treatment assemblages. 


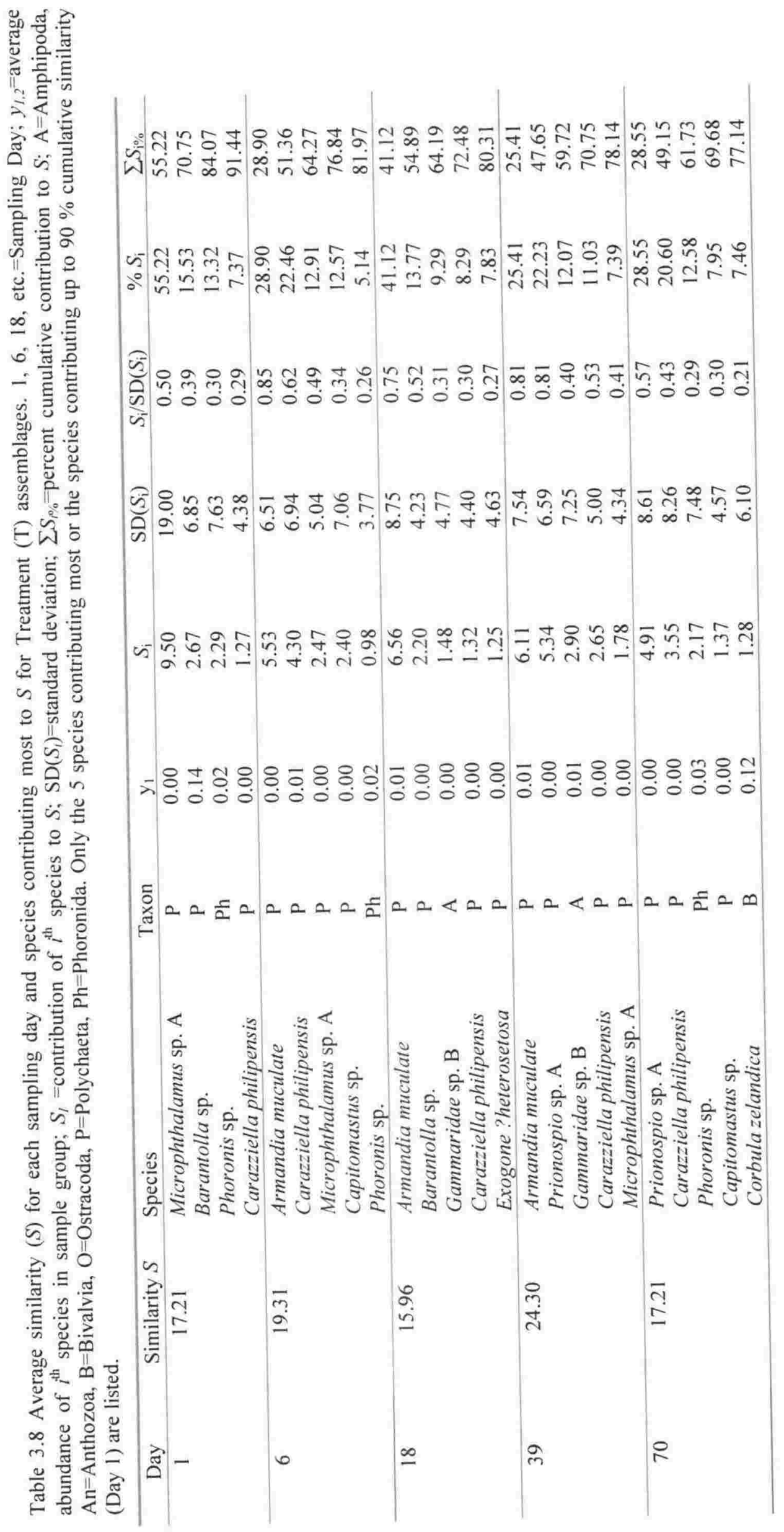




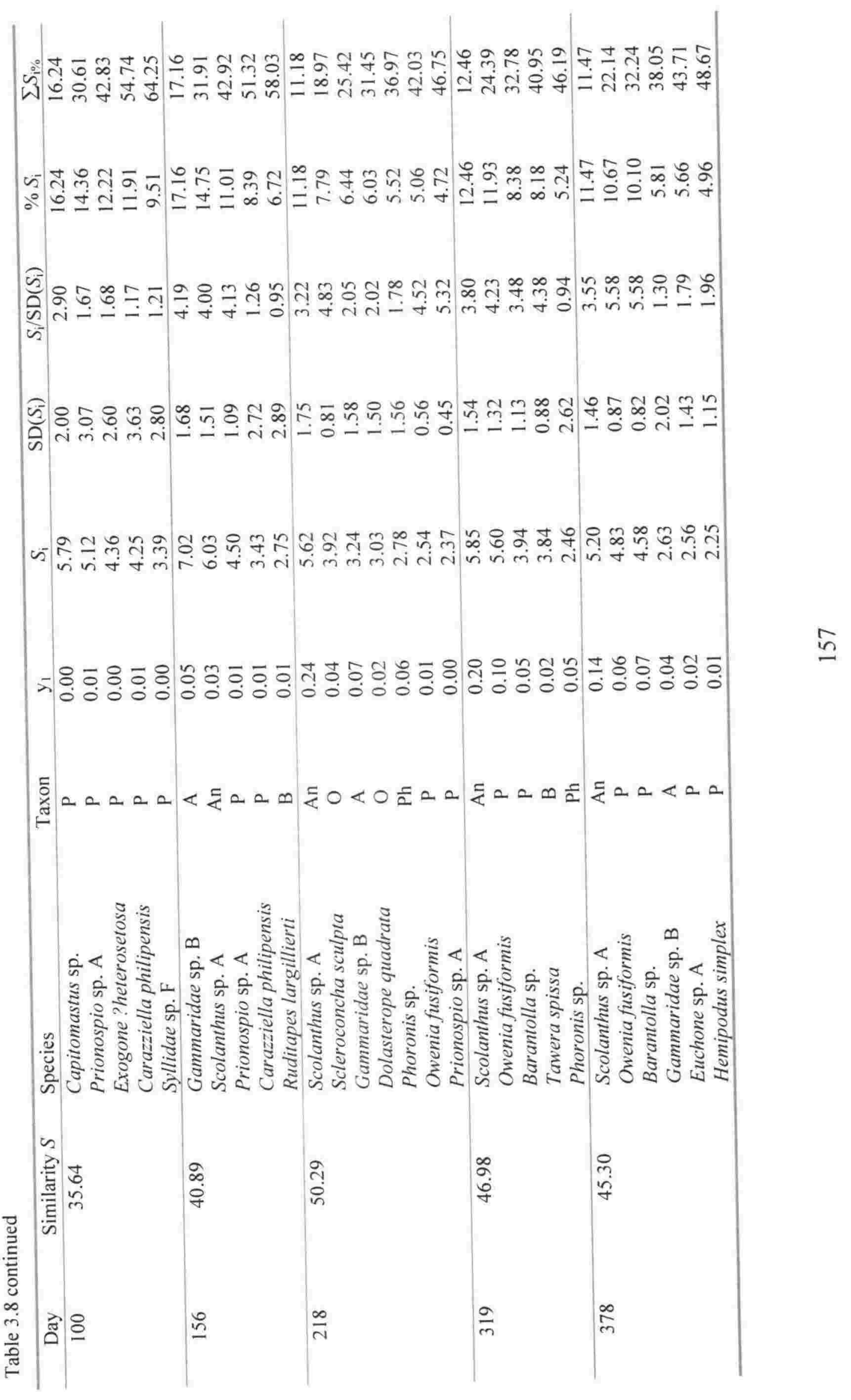


Average dissimilarity between treatment assemblages of consecutive sampling days remained relatively high $(\delta=79.8-85.3 \%)$ until between Day 100 and Day 156 when $\delta$ decreased to $68.2 \%$. Dissimilarity decreased further and by Day 319 had reached levels similar to dissimilarities between control and treatment assemblages on Day 319 and Day 378. Relatively few species contributed to dissimilarity between treatment assemblages of the early consecutive sampling days (until approx. Day 100) and the ratios of $\delta_{\mathrm{i}} / \mathrm{SD}\left(\delta_{\mathrm{i}}\right)$ remained well below 1.3. After Day 100 the number of contributing species increased considerably and the individual contributions (\%) of species decreased, thus indicating that the communities became progressively richer in species and hence more complex. Between Days 70 and 100 the small polychaetes Syllidae sp. F. and Capitomastus sp. showed ratios of $\delta_{\mathrm{i}} / \mathrm{SD}\left(\delta_{\mathrm{i}}\right)>1.3$, i.e., they contributed consistently to assemblage dissimilarity between these two sampling days. Scolanthus sp. contributed mainly to assemblage dissimilarity between Days 100 and 156, followed by Syllidae sp. F. The bivalve Serratina charlottae, Scolanthus sp. and Phoronis sp. were discriminant species between macroinvertebrate assemblage compositions of Days 156 and 218. Serratina charlottae and Phoronis sp. contributed much to assemblage dissimilarity between Days 218 and 319, but Barantolla and $O$. fusiformis were also important contributors. Between Days 319 and 378 the polychaete Glycinde dorsalis was the only discriminant species with a $\delta_{\mathrm{i}} / \mathrm{SD}\left(\delta_{\mathrm{i}}\right)$ ratio $>1.3$. 


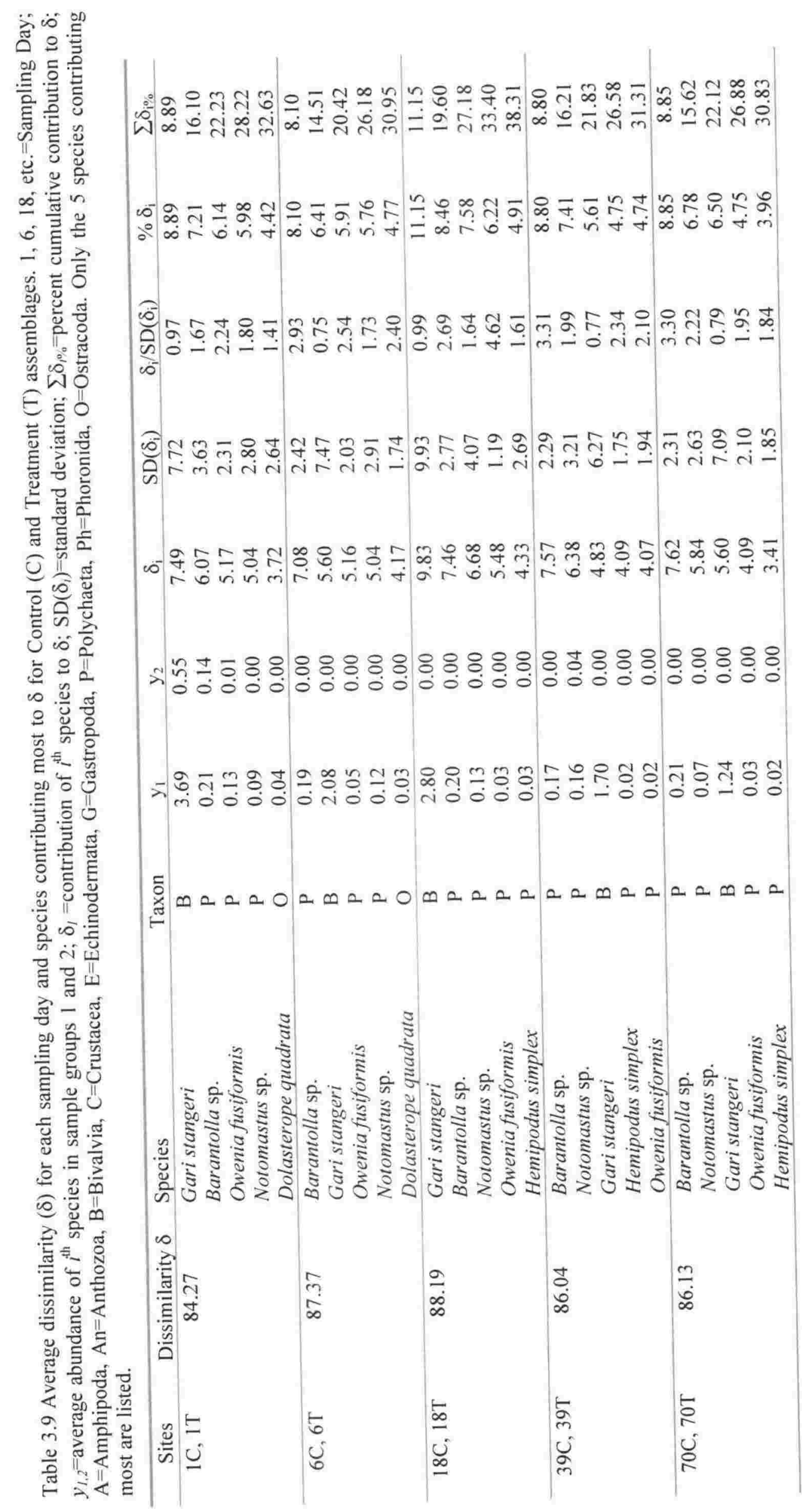




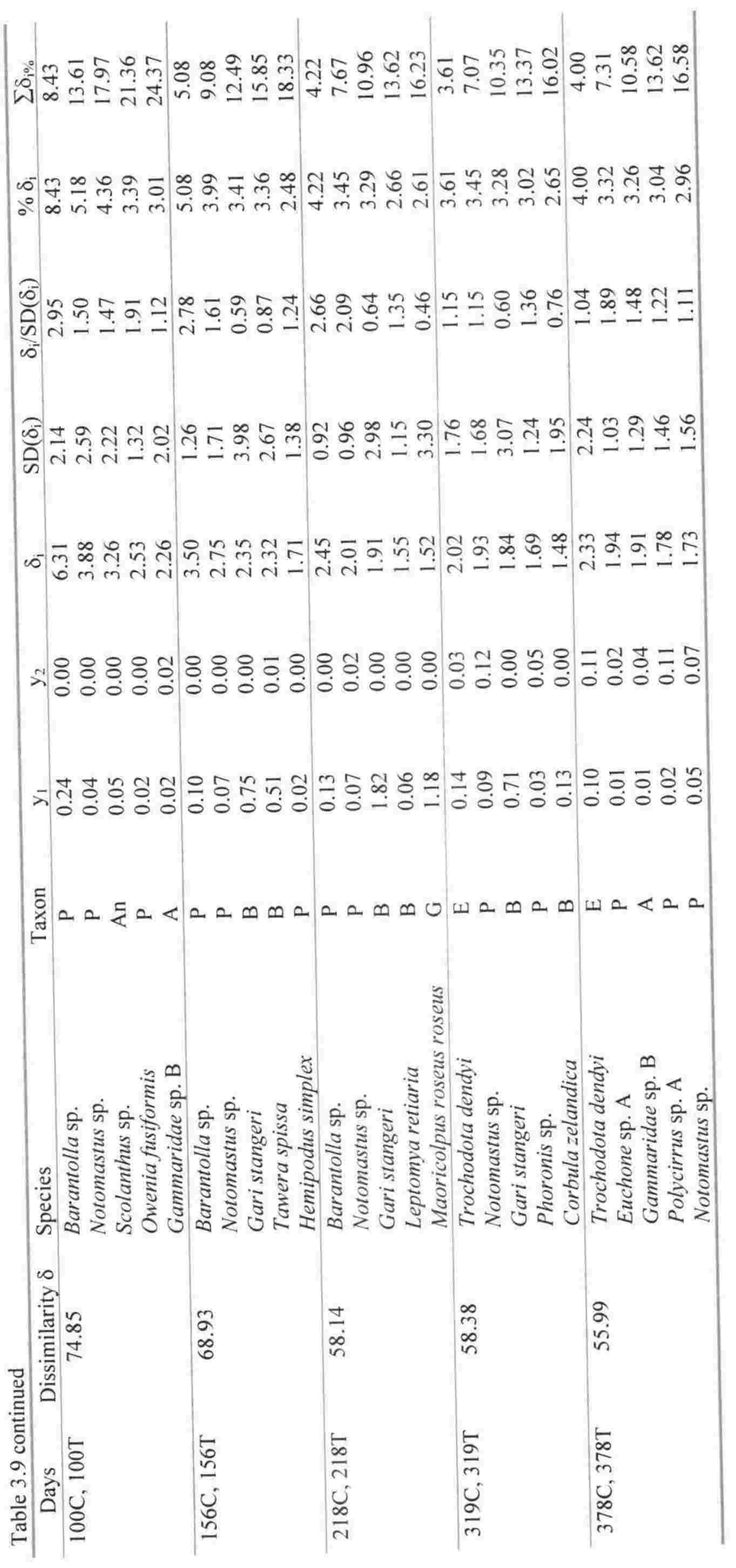




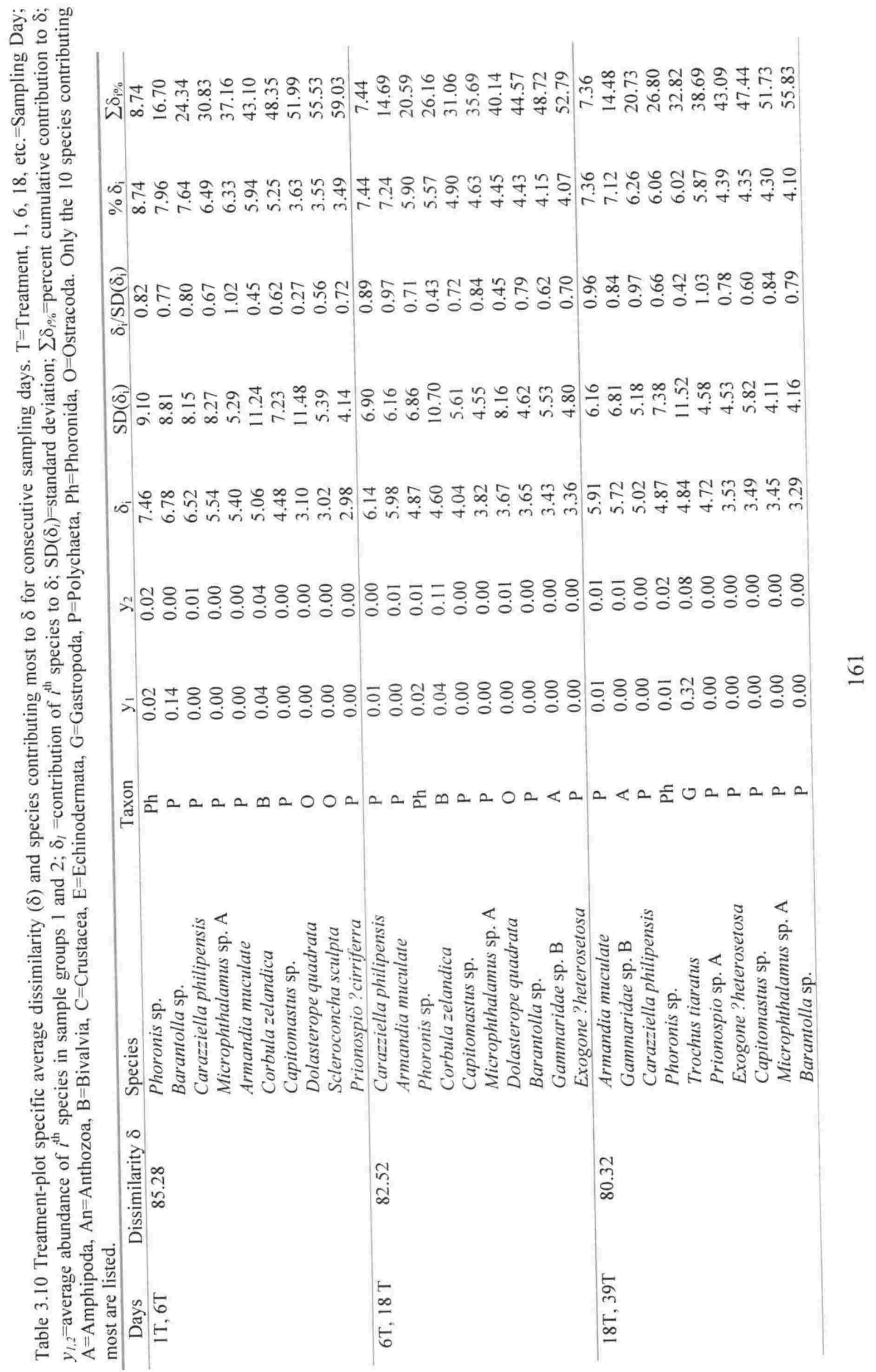




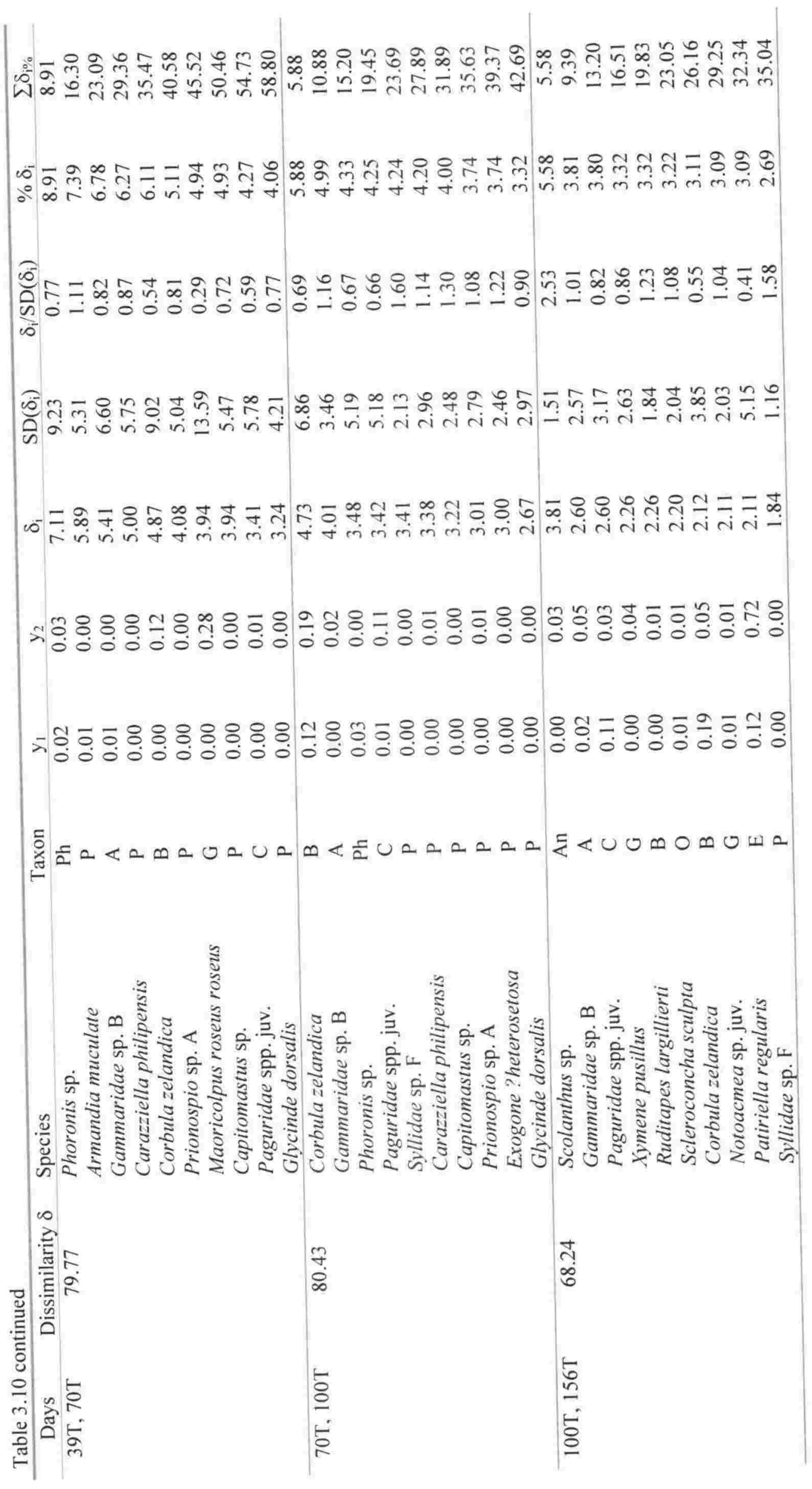




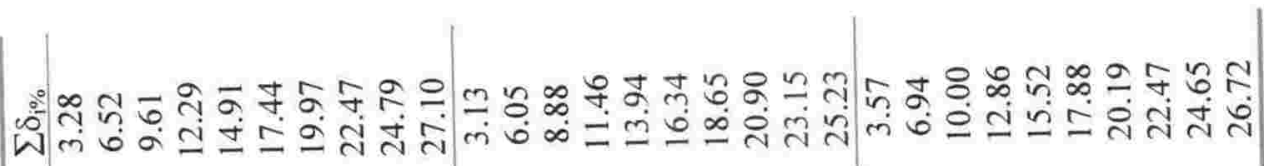

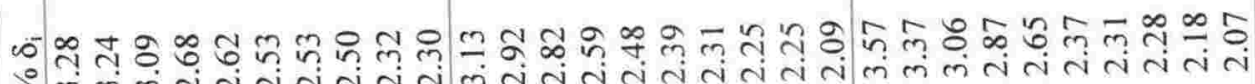

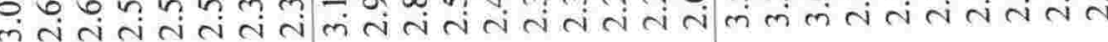

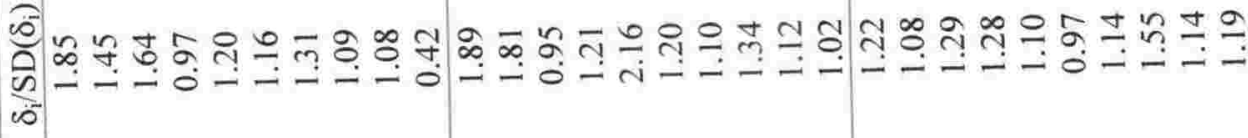

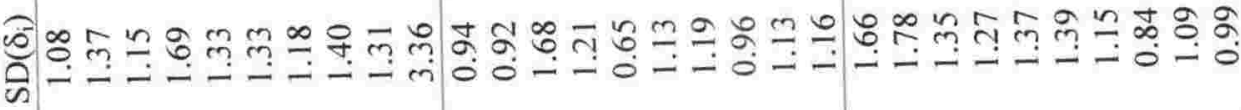
10

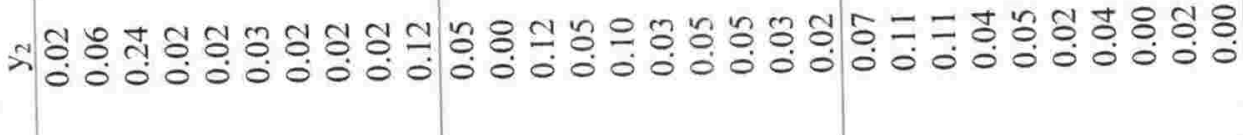

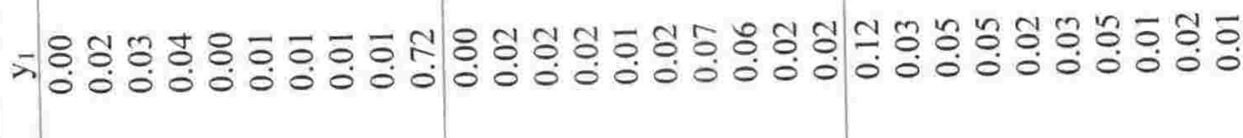

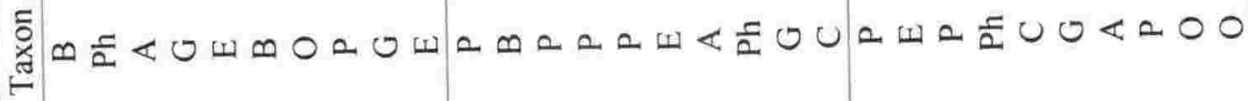

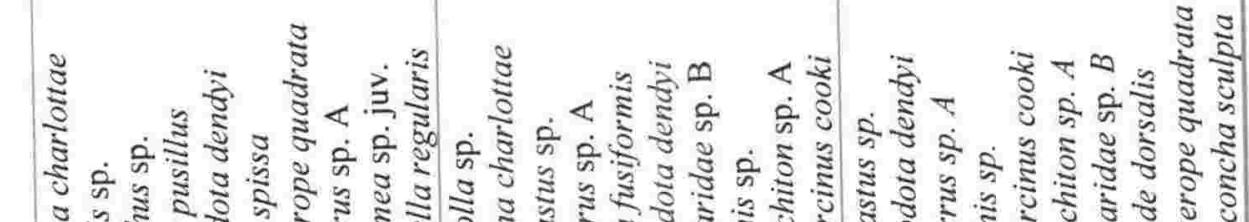

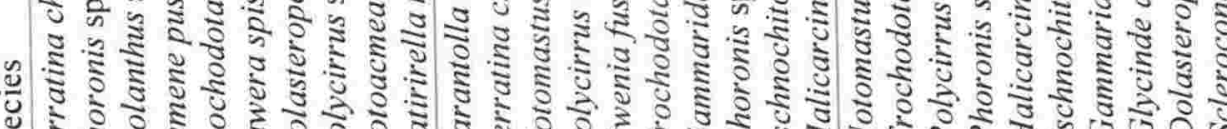
की

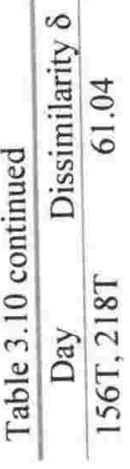

$\frac{7}{0}$
$\frac{5}{0}$
$\frac{5}{2}$
$\frac{5}{2}$

گ่

$\underset{\substack{\infty \\ \infty}}{\stackrel{\infty}{\infty}}$ 


\section{Temporal Variation in Assemblage Composition}

Relative dispersion and the Index of Multivariate Dispersion (IMD) describe clear differences of variability between control and treatment assemblages (Table 3.11). While control assemblages displayed a relatively constant level of dispersion throughout the duration of the experiment, treatment assemblages exhibited considerably higher dispersion values until Day 100 . However, dispersion values decreased for treatment assemblages from Day 70 onwards and by Day 156, or shortly thereafter, reached the same level of dispersion as control assemblages. The trend of converging dispersion values was also expressed in the IMD values. Pairwise comparisons of control and treatment assemblages of the same sampling day revealed that, from Day 156 onwards, variability in the multivariate structure of control and treatment assemblages was comparable. On Day 156 and Day 218 control assemblages showed higher variability than treatment assemblages as indicated by the positive IMD values. The most pronounced changes in community composition of treatment assemblages occurred between Day 70 and Day 100, i.e., in the winter $(\mathrm{IMD}=0.64)$ and in the following spring between Day 156 and Day 218 $(\mathrm{IMD}=0.662)$.

Table 3.11 Relative dispersion and Index of Multivariate Dispersion (IMD) for Control (C) and Treatment $(\mathrm{T})$ macroinvertebrate assemblages of $4^{\text {th }}$-root-transformed production data.

\begin{tabular}{|c|c|c|c|c|c|c|}
\hline \multirow[b]{2}{*}{ Day } & \multicolumn{2}{|c|}{ Relative Dispersion } & \multicolumn{4}{|c|}{ Pairwise Comparisons } \\
\hline & Control & Treatment & Groups & IMD & Groups & IMD \\
\hline 1 & 0.787 & 1.628 & $1 \mathrm{C}, 1 \mathrm{~T}$ & -0.795 & $1 \mathrm{~T}, 6 \mathrm{~T}$ & 0.104 \\
\hline 6 & 0.616 & 1.595 & $6 \mathrm{C}, 6 \mathrm{~T}$ & -0.875 & $6 \mathrm{~T}, 18 \mathrm{~T}$ & -0.115 \\
\hline 18 & 0.941 & 1.705 & $18 \mathrm{C}, 18 \mathrm{~T}$ & -0.875 & $18 \mathrm{~T}, 39 \mathrm{~T}$ & 0.251 \\
\hline 39 & 0.816 & 1.506 & $39 \mathrm{C}, 39 \mathrm{~T}$ & -0.734 & $39 \mathrm{~T}, 70 \mathrm{~T}$ & -0.220 \\
\hline 70 & 0.577 & 1.643 & $70 \mathrm{C}, 70 \mathrm{~T}$ & -0.892 & $70 \mathrm{~T}, 100 \mathrm{~T}$ & 0.640 \\
\hline 100 & 0.869 & 1.247 & $100 \mathrm{C}, 100 \mathrm{~T}$ & -0.483 & $100 \mathrm{~T}, 156 \mathrm{~T}$ & 0.308 \\
\hline 156 & 1.038 & 1.054 & $156 \mathrm{C}, 156 \mathrm{~T}$ & 0.004 & $156 \mathrm{~T}, 218 \mathrm{~T}$ & 0.662 \\
\hline 218 & 0.759 & 0.556 & $218 \mathrm{C}, 218 \mathrm{~T}$ & 0.233 & $218 \mathrm{~T}, 319 \mathrm{~T}$ & -0.207 \\
\hline 319 & 0.554 & 0.732 & $319 \mathrm{C}, 319 \mathrm{~T}$ & -0.219 & $319 \mathrm{~T}, 378 \mathrm{~T}$ & -0.140 \\
\hline 378 & 0.751 & 0.829 & $378 \mathrm{C}, 378 \mathrm{~T}$ & -0.098 & & \\
\hline
\end{tabular}




\section{Assemblage Seriation}

For the three response units abundance, biomass and production data, both control and treatment assemblages showed significant seriation in their macro-invertebrate assemblage composition, albeit at very different levels (Figure 3.9).
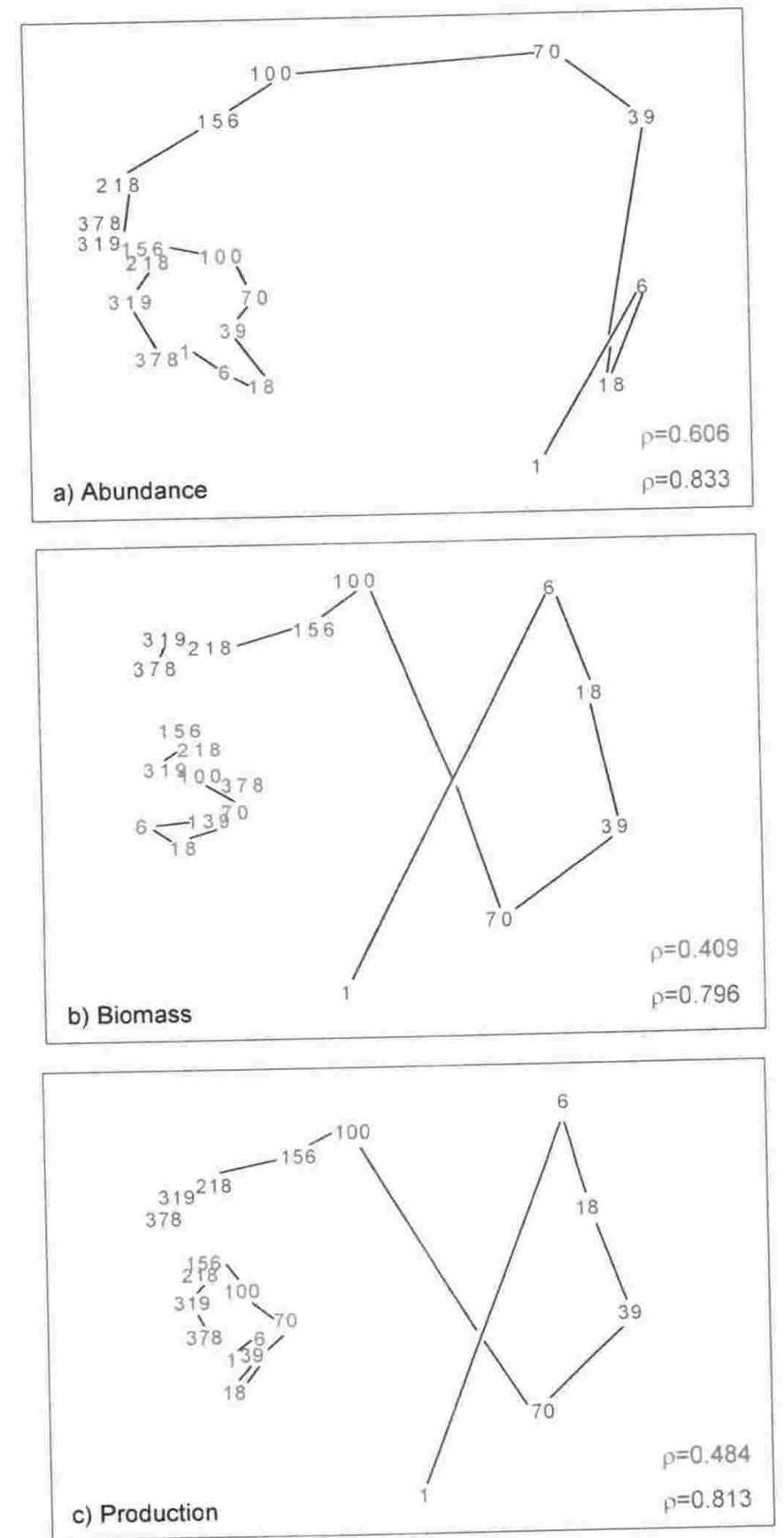

Figure 3.9 MDS ordination using Bray-Curtis similarities of group averaged (mean/sampling day) $4^{\text {th }}$-root transformed a) abundance, b) biomass and c) production data. Sample points are linked in temporal order. Red $=$ Control, blue $=$ Treatment. IMS for Control and Treatment samples are given in right hand corner. Stress=a) 0.1, b) 0.12 , c) 0.11 . 
Because results for the three response units are rather similar and production data was chosen to be the main response unit (p. 139), only the results for this unit are described here. The Spearman Rank correlation coefficient $\rho$ for treatment assemblages was $0.813(p=0.002$; number of permutated statistics $\geq \rho=0$ of 5000 ), indicating a strong sequential change in the faunal assemblage as is evident in Figure 3.9. Treatment assemblages of Day 1 to Day 100 were widely spaced apart in the MDS ordination and only from Day 100 onwards did the assemblages become more closely spaced. Control assemblages also displayed a sequential pattern in their assemblage changes, but the pattern was not pronounced ( $\rho=0.484$ with $p=0.04$; number of permutated statistics $\geq \rho=18$ of 5000). Control samples were arranged in a circular pattern in the MDS ordination.

Table 3.12 Index of multivariate Seriation (IMS) for abundance, biomass and production data (group-averaged, $4^{\text {th }}$-toot transformed) of Control and Treatment assemblages.

\begin{tabular}{lcccccc}
\hline \multirow{2}{*}{$\begin{array}{l}\text { Response } \\
\text { unit }\end{array}$} & rho & $\begin{array}{c}\text { Significance } \\
\text { level }\end{array}$ & $\begin{array}{c}\text { No of } \\
\text { permutations } \geq \rho\end{array}$ & rho & $\begin{array}{c}\text { Significance } \\
\text { level } p\end{array}$ & $\begin{array}{c}\text { No of } \\
\text { permutations } \geq \rho\end{array}$ \\
\hline Abundance & 0.606 & $<0.001$ & 4 & 0.833 & $<0.001$ & 0 \\
Biomass & 0.409 & 0.0096 & 47 & 0.796 & $<0.001$ & 0 \\
Production & 0.484 & 0.004 & 19 & 0.813 & 0.002 & 0 \\
\hline
\end{tabular}

\subsubsection{Sediment Analyses}

\section{Sediment Characteristics}

The sediment of the experimental site was poorly sorted (sorting coefficient in the range of 1.35-2.14) and consisted mainly of sand (70-90\%) with a small percentage of fine material $(2-6 \%)$ and a larger percentage of gravel $(6-26 \%)$ (Table 3.13$)$. However, the sediment varied slightly among the plots as can be expected in a high-energy location such as the experimental site. Plot T3 in particular showed a higher content of gravel with a concomitant lower sand content, which was also reflected in the smaller mean grain size and the larger sorting coefficient, i.e., the sediment was very poorly sorted. 
Table 3.13 Sediment characteristics for Control (C) and Treatment (T) plots on Day 319 $(19 / 02 / 02)$. Standard error given in brackets. Data pooled from $n=4$ for each plot.

\begin{tabular}{ccccccc}
\hline Plot & $\begin{array}{c}\text { Mean grain } \\
\text { size }(\phi)\end{array}$ & $\begin{array}{c}\text { Sorting } \\
\text { coefficient }\end{array}$ & Skewness & \% Gravel & \% Sand & \% Silt + clay \\
C1 & 1.35 & 1.43 & -0.45 & 10.47 & 87.19 & 2.33 \\
& $( \pm 0.16)$ & $( \pm 0.19)$ & $( \pm 0.08)$ & $( \pm 2.72)$ & $( \pm 2.70)$ & $( \pm 0.20)$ \\
$\mathrm{C} 2$ & 1.50 & 1.75 & -0.42 & 9.77 & 84.48 & 5.75 \\
& $( \pm 0.12)$ & $( \pm 0.31)$ & $( \pm 0.12)$ & $( \pm 1.99)$ & $( \pm 3.34)$ & $( \pm 2.75)$ \\
$\mathrm{C} 3$ & 1.79 & 1.35 & -0.53 & 6.42 & 90.80 & 2.78 \\
& $( \pm 0.11)$ & $( \pm 0.18)$ & $( \pm 0.06)$ & $( \pm 1.58)$ & $( \pm 1.46)$ & $( \pm 0.33)$ \\
T1 & 1.09 & 1.64 & -0.46 & 15.11 & 82.14 & 2.75 \\
& $( \pm 0.09)$ & $( \pm 0.10)$ & $( \pm 0.02)$ & $( \pm 2.49)$ & $( \pm 2.75)$ & $( \pm 0.55)$ \\
T2 & 1.51 & 1.57 & -0.51 & 10.46 & 85.76 & 3.78 \\
& $( \pm 0.04)$ & $( \pm 0.09)$ & $( \pm 0.03)$ & $( \pm 1.10)$ & $( \pm 1.22)$ & $( \pm 0.23)$ \\
T3 & 0.79 & 2.14 & -0.47 & 26.21 & 70.82 & 2.97 \\
& $( \pm 0.17)$ & $( \pm 0.07)$ & $( \pm 0.09)$ & $( \pm 3.37)$ & $( \pm 3.23)$ & $( \pm 0.89)$ \\
\hline & & & & & &
\end{tabular}

\section{Organic Matter Content}

Mean organic matter content (\% OM) ranged between 1.8 and $2.4 \%$ and was generally higher in treatment plots than in control plots (Figure 3.10). Results of a Kruskal-Wallis test showed that differences of \% OM between treatment and control plots and among sampling days were significant $(\mathrm{N}=214$, $H=75.03$ and $p<0.001)$. With respect to \% OM, treatment plots at Day 218 were significantly different from control plots at Day 39 (Appendix 18).

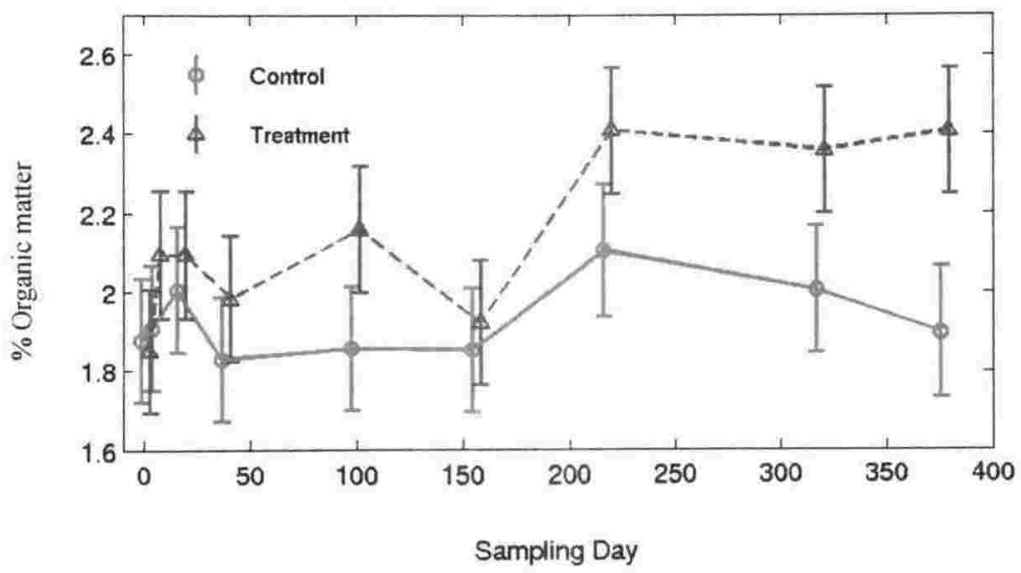

Figure 3.10 Organic matter content (\%) for Control and Treatment samples. Data averaged over each sampling day with $n=12$ (except Day 218 and 319 where $n=11$ for Control samples). Bars denote $95 \%$ confidence intervals. 
When tested separately for temporal differences in \% OM, only treatment plot data showed significant differences $(n=100 ; H=39.483$ and $p<0.001)$. Posthoc tests revealed that \% OM at Day 1 was significantly lower compared to Day Days 218-378. At Day 156 \% OM was lower than at Day 218 (Appendix 18).

In order to relate observed biological patterns to the environmental parameter \% OM, Spearman rank correlations of \% OM and Shannon's Diversity $H^{\prime}$ were employed separately for control and treatment samples. Whereas in control plots no correlation could be detected $(\mathrm{n}=101, r=0.009, p=0.323)$, the correlation was significant in treatment plots $(\mathrm{n}=100, r=0.209, p=0.037)$. However, a scatter plot of the correlation between $H^{\prime}$ and \% OM in treatment plots (Figure 3.11) revealed that the correlation was weak (despite a significant $p$-value) and therefore the results were not interpreted any further. BIOENV results indicated that observed changes in macroinvertebrate assemblage composition could not be explained by organic matter content of the sediment (Table 3.14).

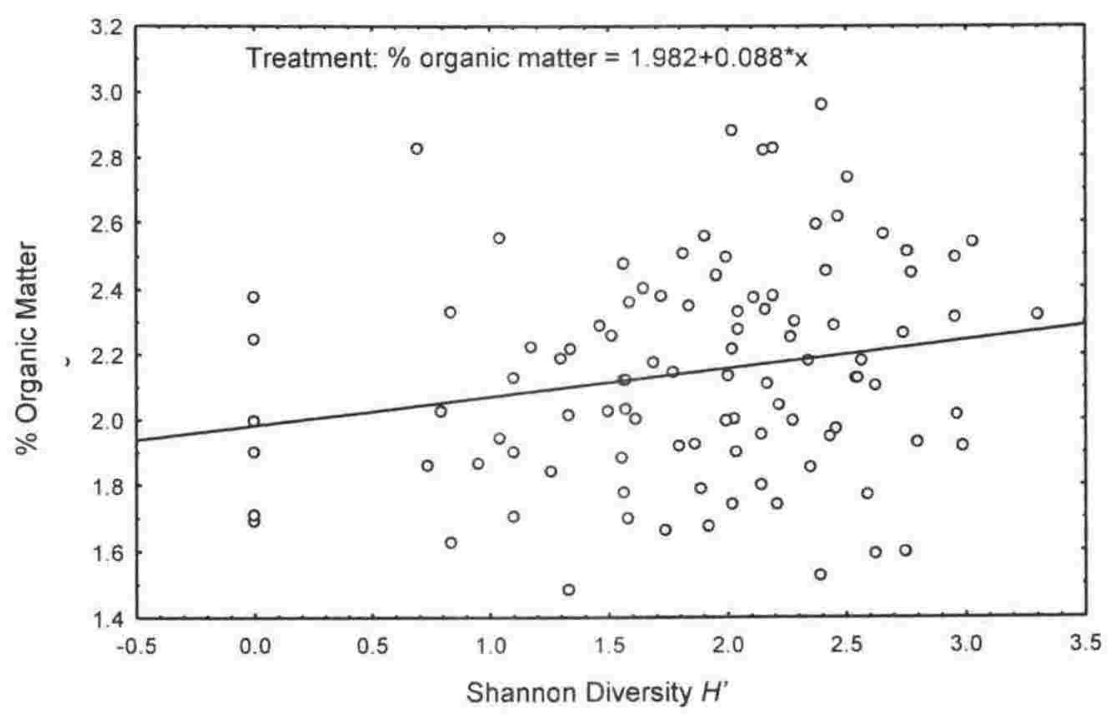

Figure 3.11 Spearman rank correlation between Shannon's Diversity $H^{\prime}$ and organic matter content $(\%) . \mathrm{N}=100, r=0.209, p=0.037$. 
Table 3.14 Rank correlation coefficient $\rho_{\mathrm{s}}$ for similarity matrixes derived from biological and sediment organic matter content data of Control and Treatment samples together and for Control and Treatment samples separately.

\begin{tabular}{cccc}
\hline Samples & $\begin{array}{c}\text { Rank Correlation } \\
\text { Coefficient } \rho_{\mathrm{s}}\end{array}$ & $\begin{array}{c}\text { Significance level } \\
p\end{array}$ & $\begin{array}{c}\text { No of permutated } \\
\text { statistics } \geq \rho_{\mathrm{s}}\end{array}$ \\
\hline Controls + & -0.008 & 0.542 & 541 \\
Treatments & 0.032 & 0.213 & 212 \\
Controls & 0.061 & 0.082 & 81 \\
Treatments & & & \\
\hline
\end{tabular}

\subsection{Discussion}

The method used in the present study to mimic a plankton-bloom-induced benthic die-off worked successfully and macroinvertebrate abundances, number of species and biomass were much reduced in treatment plots after removal of the tarpaulins. Complete mortality did not occur, which is a more realistic starting point for benthic recovery processes after a naturally occurring disturbance than a state of 'tabula rasa' (clean slate), which is assumed in most current succession models (Zajac 1999).

The time required for a disturbed community to recover completely and reach the same levels of community structure as the undisturbed surrounding communities depends on the criteria used to define complete recovery. Univariate indices of abundance-based parameters indicated a complete recovery of the assemblage in treatment plots within 10 months, thereby confirming the prediction of complete recovery in $<1$ year. The duration of the experiment was too short to record complete recovery of biomass, which can take as long as one turn-over of the most long-lived constituent species, probably the sunset shell Gari stangeri in this case, in the community (Connell \& Sousa 1983). Multivariate analysis, however, revealed that, although a recovery process had clearly occurred, control and treatment assemblages were still significantly dissimilar after a year, as expressed by the $R$-value of the one-way ANOSIM analysis. Thus, the aforementioned prediction was refuted. Decreasing $R$-values over time, decreasing dissimilarities and Index of Multivariate Dispersion values (IMD) of same-day control and treatment assemblages and of treatment assemblages of consecutive days indicated an on-going recovery process, in 
which the disturbed assemblages showed increasing resemblance to the ambient control assemblages. The Index of Multivariate Seriation (IMS) confirmed the prediction of a sequential pattern of community recovery, but the trajectories of control and treatment assemblages, although converging towards the same location in the ordination plot, did not overlap. After 378 days, macroinvertebrate assemblages in treatment plots were very similar with regard to abundance and species composition to those in adjacent control plots, a result shared with most experimental defaunation studies irrespective of the recovery time (e.g., Bonsdorff 1989). Assuming that no other major disturbance interrupts the recovery process, I estimate that recovery will be completed after a second major recruitment event, i.e., ca. 2 years after the experimental disturbance. Such a recruitment event should lead to the convergence of treatment and control assemblages. Although no significant increase in mean total organic matter content of the sediment was detected immediately post-disturbance, the macroinvertebrate recovery process coincided with an increase in organic matter especially in treatment plots from Day 156 onwards. Linear regression and BIOENV analysis, however, revealed that the recovery process was not correlated to changes in the organic matter content of the sediments. Initial higher organic matter values in treatment than in control plots could be explained by the existence of more dead and decaying organisms following the oxygendepletion. However, this does not explain why organic matter levels in treatments remained higher throughout the experiment. Bacterial biomass, which contributes to organic matter, could have been increased in treatments as a response to the temporarily increased amount of decaying matter, but it seems unlikely that an increased bacterial biomass could be sustained over such a long period. The increase in organic matter both in treatments and controls from Day 156 onwards occurred concurrently with an increase in mean abundances. Hence, it is likely that larvae and post-larval stages were too small to be detected by eye and thus not removed from the organic matter samples. This could have caused increased organic matter values from Day 156 onwards in control and treatment plots. Whether the increased organic matter levels in treatment plots prior to Day 156 were also caused by undetected larval and post-larval stages remains unclear. 


\section{Factors Influencing Recovery}

Recovery of benthic macroinvertebrate assemblages following a disturbance is, amongst other factors, determined by the spatial scale of the disturbance (Smith \& Brumsickle 1989; Hall et al. 1994; Zajac et al. 1998). Short recovery times ranging from hours to weeks have been reported for small-scale disturbances $\left(<1 \mathrm{~m}^{2}\right)$ (Bell \& Devlin 1983; Savidge \& Taghon 1988), whereas complete recovery following large-scale disturbances $\left(>100 \mathrm{~m}^{2}\right)$ such as organic pollution (Pearson \& Rosenberg 1976, 1978), oil-spills (Elmgren et al. 1983; Jewett et al. 1999), storms (Jaramillo et al. 1987) or toxic plankton blooms (Gjösæter et al. 2000; Gardner \& Wear submitted; Chapter 2) requires several years. Recovery of abundance $(N)$ and number of species $(S)$ took approx. 10 months in the present study. Similar results have been reported in other mesoscale studies (1-100 $\mathrm{m}^{2}$ ), where recovery took from several weeks to several months depending on the timing of the disturbance (Thrush et al. 1996; Beukema et al. 1999; Dittmann et al. 1999). In the intertidal studies of Beukema et al. (1999) and Dittmann et al. (1999) recovery proceeded much faster following spring or summer disturbances than following autumn disturbances, and $N$ and $S$ returned to levels of the ambient undisturbed sediment as soon as the recovery process included spring or summer months. Similarly, Zajak \& Whitlach (1982a; 1982b) and Ford et al. (1999) demonstrated higher recolonisation rates in defaunated sediments in summer than in winter. Recovery in the present study exhibited the typical pattern following a disturbance in autumn as described by Beukema et al. (1999) and Dittmann et al. (1999) with recovery not being perceptible until mid-winter, and $N$ and $S$ not reaching ambient levels until summer. The high degree of recovery in spring and summer, when abundances increased in ambient and disturbed sediments synchronously, indicated that the recovery process was influenced by the same larger scale factors (e.g., seasonal cycles in reproduction and mortality, food availability, etc.), that influenced the ambient community which provides a pool of potential colonists (Thrush \& Whitlach 2001). 


\section{Origin of Colonisers}

Whether the disturbed sediments in the present study were mainly colonised by larval stages settling from the water column or by juvenile and adult immigrants from surrounding sediments (either active or passive by lateral advection) remains speculative. Neither settlement panels nor larval traps were deployed to measure recruitment and the mesh-screen used to extract organisms from the sediment was too coarse to retain larval stages. Günther (1992) developed a conceptual model of the relative importance of colonists' different life stages for the recolonisation of disturbed sediments. Depending on the dispersal ability of the different life stages, the model predicts adult immigration to be more important for recovery on small spatial scales, whereas post-larval stages and larvae are dispersed over larger spatial scales and thus are more important for recovery dynamics on larger scales. Recent model simulations suggest that species' life history traits also affect recovery processes (Whitlach et al. 1998a). In the model, early successional species, i.e., typical opportunists, colonised mainly as larval stages, while species featuring 'late successional' stage life history traits predominantly entered the newly available sediments as juvenile and adult immigrants. In the context of the present study, the model simulations of Whitlach et al (1998a) imply that larval recruitment was of more importance in the observed recovery process than juvenile and adult immigration due to the ambient community consisting primarily of opportunistic species. Such species were the tubicolous polychaete Owenia fusiformis, the capitellid Barantolla and the spionid Prionospio sp., all of which have been related to physical disturbances (McCall 1977; Pearson \& Rosenberg 1978; Probert \& Wilson 1984; Maurer et al. 1998). The synchronous abundance patterns in treatment and control plots from late winter onwards, in conjunction with the low mean values of biomass in treatment plots even after $N$ and $S$ had recovered to ambient levels (occasional higher total biomass values were caused primarily by adult molluscs), corroborated the view that larval settlement was the primary mean of colonization. Moreover, such results emphasise the importance of seasonal recruitment in recovery processes (Zajac \& Whitlach 1982a, b; Powilleit \& Kube 1999). 


\section{Comparisons with Other Studies}

In contrast to many studies investigating the effects of natural or anthropogenic disturbances on assemblages, a rapid albeit ephemeral increase in abundances of one or a few opportunistic species immediately post-disturbance, as predicted in succession models (Pearson \& Rosenberg 1976; 1978; Rhoads et al. 1978; Rhoads \& Boyer 1982), was not observed in the present study. Peak abundances of opportunists have been reported for both natural and experimental small-scale (McCall 1977; Bonsdorff \& Österman 1985; Thrush 1986a; Ragnarsson 1995; Norkko \& Bonsdorff 1996a), meso-scale (Arntz \& Rumohr 1982; Oliver \& Slattery 1985; Gamenick et al. 1996) and large-scale disturbances such as organic pollution (Rosenberg 1976), dredge spill disposal (Rhoads et al. 1978), oil pollution (Grassle \& Grassle 1974), naturally occurring anoxia (Rosenberg et al. 2002) and toxic blooms (Simon \& Dauer 1977). The absence of such abundance peaks in the present study appears to be surprising considering the dominance of opportunistic species in the ambient sediments, some of which have exhibited typical abundance peaks following disturbances (Pearson \& Rosenberg 1978; Rhoads et al. 1978). Yet, the absence of such model-predicted patterns has been noted in several studies (Thrush et al. 1996; Beukema et al. 1999; Powilleit \& Kube 1999). Powilleit \& Kube (1999) followed benthic macroinvertebrate recovery after a naturally occurring oxygen depletion in shallow parts of the Baltic Sea. After defaunation in autumn, neither a rapid increase in abundances of opportunists nor a rapid species turn-over were observed and recovery was still incomplete 2 years after the defaunation. The authors attributed the absence of initial pulse occurrences of opportunists to the timing of the disturbance in autumn (larval settlement peaks occur mainly in summer in the Baltic Sea) and food limitations due to low organic matter contents of the sediment. Thrush et al. (1996) examined the recovery of intertidal sediments in Manukau Harbour, New Zealand, which were experimentally defaunated in late summer, and found only the capitellid Heteromastus filiformis with higher abundances in disturbed plots than in the ambient sediment (overshoot phenomenon), but not until 66 days after the initiation of the experiment. As in the study of Powilleit \& Kube (1999), food limitation appears to be the underlying cause for the absence of any obvious abundance peaks of 
opportunistic species. Contrasting to the aforementioned and the present study, Beukema et al. (1999) found ca. 50\% of the species in experimentally disturbed plots showing the overshoot phenomenon, but this suite of species comprised opportunistic as well as non-opportunistic species. The authors reasoned that inhibition through species interaction in the surrounding sediments led to more successful recruitment inside the treatment plots than outside. In the present study only two species, O. fusiformis and Barantolla sp., occurred in higher densities in treatments than in controls, but the differences are non-significant and do not occur until Day 319 (summer) and Day 378 (autumn), respectively, when densities of the two species also peaked in control plots. Although both Barantolla sp. and O. fusiformis are typical pioneering species, their increased abundances in treatments $>200$ days after the disturbance occurred too late to be an opportunistic response to, for instance, perturbation-induced temporarily raised levels of resources (organic enrichment) as Thistle (1981) suggested. It remains inconclusive whether such a temporary increase of resource levels occurred in treatments because the observed slight increase in mean total organic matter content in treatment sediments immediately post-disturbance was not significant. Additionally, the means remained higher in treatments than in controls for the duration of the experiment. Thus, the increase in abundance of $O$. fusiformis and Barantolla sp. in treatment plots $>200$ days post-disturbance reflected observed abundance changes of these species in the ambient sediments, but not the model-predicted peak of opportunistic species responding to increased resource levels.

Few experimental recolonisation studies have been conducted in highenergy subtidal locations such as the experimental site in Wellington Harbour. An exception is the study of Rhoad et al. (1978), where trays with defaunated sediments were placed on the shallow $(14 \mathrm{~m})$ wave-perturbed sediments of Long Island Sound, USA. The authors attributed the rapid recolonisation of the trays to the high-energy environment, which kept the ambient community in a perpetual early stage of succession. Pioneering species occurred in high enough abundances in the surrounding sediments to rapidly colonise the defaunated sediments. Although the physical setting of Rhoad et al.'s (1978) tray experiment and the present study in Wellington Harbour were very similar (shallow sandy sediment, high energy environment), the studies differ in two important aspects, 
that might explain the observed differences in recovery dynamics. The tray experiment was initiated in mid-summer, hence most organisms settled as larvae from the water column. Moreover, the tray experiment was conducted in a shallow estuary with high sedimentation rates, which indicates high nutrient loading of the sediment. The experiment in Wellington Harbour was initiated in autumn and the total organic matter content of the sediment was relatively low irrespective of the experimental disturbance. Thus, circumstantial evidence suggests that the absence of short-term high abundances of opportunistic species in the present study was caused by a combination of the timing of the disturbance in autumn and lack of food availability in the sediment. It might be possible that an abundance peak has been overlooked due to the screen-size used (500 $\mu \mathrm{m})$, but this seems unlikely considering that such peaks have been observed in studies where screen-sizes of $1000 \mu \mathrm{m}$ were employed (Pearson \& Rosenberg 1976; Rhoads et al. 1978: dredge spoil deposits). Hence, results of the present study support the notion that the way disturbances operate on organisms or assemblages depends on factors such as seasonality, hydrodynamic regime, spatial scale of the disturbance and enrichment levels of the sediment and therefore can lead to multi-faceted recovery dynamics.

\section{Succession Models}

The question remains whether results presented here are in agreement with current models of species succession following disturbances. Succession models for marine soft-sediment macroinvertebrate communities (Pearson \& Rosenberg 1976; 1978; Rhoads et al. 1978) predict the recovery process to exhibit a specific sequence of successional stages in time and space, whereby each stage is characterised by a typical suite of species well adapted to the postdisturbance environment by certain traits and life histories. In summary, the successional stage close to a disturbance, Stage I, is comprised of small and rapidly colonizing species experiencing high mortalities with a co-occurring high species turn-over rate. The final Stage III is characterised by a diverse equilibrium or 'climax' community often with relatively stable, albeit low, population densities and consisting of larger, long-lived, often deeper burrowing organisms similar to the pre-disturbed community. Stage II is a more 
unpredictable and transitory stage, where opportunistic species still dominate, but non-opportunists occur also.

The recovery process in the present study did not always fulfill model predictions, especially in the initial successional stages. Yet, when using multivariate tools to show the successional changes of the recovery process, a different picture appeared. In the MDS ordination of Figure 3.9, control samples of the entire sampling period grouped together and this cluster represented the 'climax' or Stage III assemblage of the ambient sediment albeit with high abundances of species typical of Stages I and II in this assemblage. In the context of naturally frequently perturbed sediments the term 'climax' or 'equilibrium' community, which was used by Pearson and Rosenberg $(1976 ; 1978)$ to describe Stage III communities in muddy sediments with low physical disturbance rates, is rather misleading. Especially in the early recovery phase, treatment assemblages showed a dramatic change in assemblage composition, as indicated by the loop on the right hand side of the MDS ordination and by results of the SIMPER analysis, suggesting a high species turn-over as predicted by the models for the successional Stages I and II. At the end of this experiment, the assemblages had approached but not quite reached the 'climax' or reference stage of the control plots in terms of assemblage composition. Similar results were recently published in a study from the Gullmarsfjord, Sweden, where benthic recovery processes following a severe oxygen depletion were analysed by multivariate tools (Rosenberg et al. 2002). Despite the differences between the present and the study of Rosenberg et al. (in which large-scale recovery at a depth of $\pm 100 \mathrm{~m}$ was studied), the recovery processes, as presented in Figure 3.9 in the present study and in Figure 6 of Rosenberg et al. (2002), are remarkably similar.

In conclusion, results of multivariate analyses suggest that recovery processes subsequent to an experimental disturbance in a hydrodynamic exposed area in Wellington Harbour generally followed the current successional models. However, observed deviations from model prediction especially in early successional phases suggest that the models should be modified in order to include factors such as seasonality of the disturbance, hydrodynamic regime and levels of sediment enrichment, the importance of which have been demonstrated 
in the present and other studies (for a recent review see Thrush \& Whitlach 2001 and references therein).

\section{Univariate Versus Multivariate Methods}

Results presented here have shown that univariate indices such as $N, S$ or $H^{\prime}$ are rather poor, albeit widely used, indicators of complete recovery. The sole use of such indices in interpreting recovery processes might be misleading, because they do not account for the identities of the individuals in the assemblage. Hence, assemblages of disturbed and undisturbed ambient sediments can still be different despite $N, S$ or $H^{\prime}$ indicating complete recovery. Confirmatory evidence is presented in various publications (Rhoads et al. 1978; Thrush et al. 1996; Gjösæter et al. 2000; Rosenberg et al. 2002; Dernie et al. 2003), although the discrepancy between uni- and multivariate results is not explicitly mentioned in any of these.

The $\mathrm{ABC}$ method (Abundance/Biomass Comparison) did not work successfully, i.e., classifications of assemblages were misrepresentative according to results from multivariate analyses. Such misrepresentations were due to the presence of rare but large-bodied molluscs in treatment assemblages especially at Days 1, 6 and 18. Towards the end of the experiment the presence of high numbers of small-bodied recolonisers led to treatment assemblages being misclassified as moderately stressed, whereas both uni- and multivariate analyses showed the assemblages to be recovered or in recovery. Such findings confirm the results of Beukema (1988) and Dauer et al. (1993), who demonstrated the limited applicability of the $\mathrm{ABC}$ method, especially in environments with smallbodied, but strongly fluctuating species and/or rare but large-bodied species.

\section{Future Work}

Further investigations into the underlying causes regulating and influencing recovery of benthic macroinvertebrate assemblages after meso- and large-scale disturbances such as plankton blooms are clearly needed. In particular, the influence of the timing of a disturbance in connection with the seasonal aspect of the occurrence of plankton blooms requires more experimental testing. The 
development of plankton blooms is generally a seasonal phenomenon favoured by warm weather conditions with concomitant high photosynthetically active radiation and water column stratification (Pearl 1988; Roelke \& Buyukates 2001). Therefore, in temperate regions such as Wellington Harbour, plankton blooms are most likely to occur between early summer and early autumn. In fact, the devastating Karenia brevisulcata bloom in Wellington Harbour occurred in late summer 1998 (Chang et al. 2001), with a reoccurrence, although to a smaller extent, in mid-summer 2000 (Chang 2000). Considering the strong effect that timing of the disturbance has on the recovery process, recovery trajectories might be different from the ones presented here if the experiment were to be repeated in either late spring or early summer. Therefore, I predict that complete recovery of macrobenthic invertebrate communities will be achieved faster than in the present study, if the disturbance occurs before peak abundances start to decline (end of summer). Another aspect clearly affecting recovery processes is the degree of hydrodynamic exposure. Hence, experiments should be repeated in different parts of the harbour reflecting the various hydrodynamic regimes encountered. Settlement panels and sediment trap data should be included in the experimental set-up to elucidate the role of planktonic recruitment versus benthic immigration in disturbed and control plots. Additionally to the core samples for biological analyses used in the present study, smaller core samples from the uppermost sediment layers should be taken and processed with a finer mesh $(250 \mu \mathrm{m}$ or even smaller) to detect larval and post-larval settlement. Environmental parameters (current velocity, water temperature, $\mathrm{C} / \mathrm{N}$ ratios, chlorophyll $a$, sediment oxygen content, redox potentials, etc.) have to be taken into account when interpreting recovery trajectories. Alas, as the presented results show, recovery processes should be followed for $>1$ year, preferably to a state where similarities in density and assemblage composition in treatment plots and the ambient sediments persist over time (Thrush \& Whitlach 2001). A multidisciplinary approach is indeed needed in order to encompass the many factors influencing recovery processes in soft-sediment marine assemblages following disturbances. 


\section{Chapter 4}

\section{General Discussion}

\section{Study Findings}

The aim of this study has been to further our understanding of the effects of severe disturbances on temperate subtidal benthic macroinvertebrate communities and the factors influencing the recovery processes of such communities. The occurrence of a toxic plankton bloom in Wellington Harbour in 1998 provided the unique opportunity to study the long-term effects ( $>1$ year post-disturbance) of a natural large-scale disturbance on benthic macroinvertebrate communities. The bloom had affected large parts of the harbour, providing the chance via a large-scale mensurative recolonisation experiment to answer important ecological questions in regard to recovery times after such naturally occurring disturbances, factors influencing the recovery process, and the way different communities respond to disturbance (Chapter 2). A defaunation experiment was also conducted in a hydrodynamically active area of the harbour to investigate recovery processes in detail and to test hypotheses about some of the supposed underlying causes of the results gained in the mensurative experiment. The recovery process of the macroinvertebrate community was studied for one year and compared with developments in the undisturbed surrounding community (Chapter 3). Although in both experiments recovery processes had clearly occurred in all communities studied, the endpoints of recovery were not always attained within the duration of the studies. Following the toxic plankton bloom, recovery times proved to be site-specific. Recovery at Harbour Basin (HB), the deepest (ca. $20 \mathrm{~m}$ ) and least hydrodynamically active site, whilst indicated, was not completed $>3$ years postbloom. At the shallow $(1.8 \mathrm{~m})$ wind- and wave-exposed Oriental Bay site $(\mathrm{OB})$, the community also exhibited signs of recovery more than three years after the bloom. In contrast, the community at Entrance Channel (EC), a site exposed to high current velocities and sediment scour, did not show any signs of a sequential 
recovery process as exhibited by the other two communities. Following the experimental defaunation, assemblage composition of the disturbed assemblage and the undisturbed surrounding assemblage, although showing signs of similarity after 100 days, were still significantly different after one year.

\section{Methodology}

Univariate indices in both experiments indicated complete community recovery, i.e., total abundance, number of species and Shannon's diversity had returned to pre-disturbance levels, while results derived from multivariate analyses showed that communities were still in the process of recovery and therefore differed in composition from the pre-disturbed communities. Thus, basing judgement of complete community recovery on the re-attainment of predisturbance levels of $N$ and $S$ can be misleading, because the identities of the species forming the community are ignored. Univariate indices indicate complete recovery even when a shift in dominance patterns has occurred in the postdisturbance community or if the community is composed of different species. Thus, a change in community composition would not be indicated as long as $N, S$ or $H^{\prime}$ have returned to reference levels. Despite these limitations, univariate indices have their uses. For instance, they are important in quantifying the impact of a disturbance (how many of which species disappeared), but such assessment requires the existence of reference data. For instance, Wear \& Gardner (2001) were able to quantify the initial impact of the toxic bloom in Wellington Harbour by comparing data obtained immediately after the bloom with pre-bloom data. Univariate indices are also useful in interpreting whether observed changes in community composition are deleterious or not (Clarke \& Warwick 2001).

Although in many experimental disturbance studies the return to levels of reference univariate measures (e.g., either pre-disturbance or ambient abundances) is used in the assessment of endpoint of recovery (Rhoads et al. 1978; Arntz \& Rumohr 1982; Bonsdorff 1989; Kline \& Stekoll 2001 among others), I recommend that disturbance assessments should include the results of standard multivariate techniques, as used in the present work, for the aforementioned reasons. Furthermore, relatively new multivariate techniques such as the Index of Multivariate Dispersion (IMD, Warwick \& Clarke 1993) 
and the Index of Multivariate Seriation (IMS, Clarke et al. 1993) can be employed to assess community recovery even in the absence of reference data in the form of pre-disturbance data. Nonetheless, the importance of pre-impact or control data cannot be disputed.

\section{Successional Models}

Recovery processes following disturbances and their patterns are frequently assessed against the conceptual succession models developed by Pearson \& Rosenberg (1976, 1978) and Rhoads et al. (1978) for marine soft-sediment macrobenthic communities. Although these models are based on studies of organic pollution (Pearson \& Rosenberg 1976, 1978) and dredge disposal (Rhoads et al. 1978), they nevertheless have been found to be widely applicable because species succession tends to follow a general pattern irrespective of whether the disturbance is caused by, for instance, experimental defaunation in shallow or deeper water (Arntz \& Rumohr 1982; Lu \& Wu 2000) or naturally occurring oxygen depletion (Rosenberg et al. 2002). Recovery following the experimental defaunation carried out in the present study was generally in accordance with model predictions. The first stage, Stage I, of the succession process was characterised by a low number of species $(S)$, a low diversity (expressed as Shannon's diversity $\left.H^{\prime}\right)$ and a corresponding high evenness $\left(J^{\prime}\right)$ as predicted by the models. Species present were mainly small, fast-growing, shortlived, non-selective deposit-feeding polychaetes, i.e., typical opportunistic $r$ strategists such as the capitellid Barantolla sp. and the spionid Carazziella philipensis. However, total abundance $(N)$ was low and therefore deviated from the model-predicted occurrence of high abundances of one or a few opportunistic species in this stage. The drastic decrease of $N$ associated with the collapse of such abundance peaks marks the beginning of the second successional stage in the models. Thus, observed patterns differed in this regard from the model. However, Stage II was clearly recognizable even without the drastic decrease in $N$. As predicted by the models, after Stage I values of $N$ and $S$, and therefore also $H^{\prime}$, increased and reached their maxima, whereas $J^{\prime}$ decreased. According to the models, Stage II is a transitory stage also characterised by the community composition being unpredictable and with large fluctuations in the abundances of 
individual species. The latter was shown in the present study by species such as the polychaetes Owenia fusiformis and Barantolla sp., and the actinian Scolanthus sp. In other words, a diverse and dynamic community developed in Stage II, which, according to model predictions, should pave the way for later successional species and lead to a more stable 'normal' climax or equilibrium community, i.e., Stage III. More than one year after the experimental defaunation, the community was apparently still recovering and therefore still occupying the successional Stage II. However, a typical Stage III climax community dominated by $K$-selected, long-lived, large-bodied and deepburrowing species as described in the marine soft-sediment models is not likely to develop at the study site due to the energetic hydrodynamic regime which naturally keeps the community at the earlier successional stage. The surrounding experimentally undisturbed community was numerically dominated by $r$ strategists, in particular Barantolla sp., Owenia fusiformis, and Scolanthus sp., although biomass was dominated by large-bodied long-lived bivalves such as Gari stangeri. These large-bodied animals were still absent from, or showed a low presence in, samples from the disturbed communities by the end of the experiment.

The recovery trajectories of the communities affected by the toxic plankton bloom also generally followed model predictions. As in the defaunation experiment, no abundance peak of one or a few opportunistic species in the initial recovery stage was observed at any of the sites studied. More than three years after the toxic bloom, the Harbour Basin (HB) and Oriental Bay (OB) communities were still recovering as indicated by fluctuating community compositions and, for $\mathrm{OB}$ only, by increasing total abundance and number of species. The Entrance Channel community (EC) seems to remain perpetually in the successional Stage II due to the high degree of physical disturbance experienced at this site (Van der Linden 1967; Carter 1977; Carter \& Lewis 1995) as was also suggested by Wear \& Gardner (2001) and Gardner \& Wear (submitted).

The main deviation from model predictions in both the mensurative and the defaunation experiment was the absence of peaks of opportunistic species in the initial recovery phase, i.e., Stage I. Although it is possible that abundance peaks were missed due to the mesh sizes employed for extracting the organisms from 
the sediment $(500 \mu \mathrm{m})$, such peaks have been observed in studies where an even larger mesh size $(1000 \mu \mathrm{m})$ was employed (Pearson \& Rosenberg 1978; Rhoads et al. 1978). The absence of abundance peaks has been noted after disturbances such as a naturally occurring oxygen depletion (Powilleit \& Kube 1999) and also after experimental defaunation on intertidal sandflats (Thrush et al. 1996). The studies of Powilleit \& Kube (1999) and Thrush et al. (1996) are similar to the present study in that defaunation occurred in autumn or late summer and was followed by an initially slow recovery. Pearson \& Rosenberg (1978) pointed out that opportunistic species show extreme seasonal abundance fluctuations and therefore such peaks might be reduced or not occur at all in response to shortterm environmental changes. The plankton bloom in Wellington Harbour and also the experimental defaunation would constitute such short-term changes. Because both disturbances occurred in the same season, no firm conclusion can be drawn with regard to the influence of the timing of the disturbances. Yet, following the experimental defaunation, a pronounced synchrony was observed in the increase of mean abundance and mean number of species in treatment assemblages and control assemblages. Such results indicate that recovery processes were strongly influenced by the temporal availability of recruits. Because recruitment is generally a seasonal event in temperate marine benthic communities (Coma et al. 2000), the timing of a disturbance is an important factor in recovery processes, as has been demonstrated widely for marine soft sediments (Zajac \& Whitlach 1982a, b; Bonsdorff \& Österman 1985; Shull 1997; Ford et al. 1999). Thus, indirect evidence suggests that the timing of the disturbances in autumn in the present study was one of the factors explaining the observed deviation from model predictions. Current succession models (Pearson \& Rosenberg 1976, 1978; Rhoads et al. 1978) however, do not take into account the timing of a disturbance and therefore the seasonal availability of larvae. The model of Pearson \& Rosenberg (1976, 1978) was developed for long-term organic pollution and it took the community in their study ca. 8 years to recover after the pollution had ceased. Timing of such a disturbance, which causes longterm changes in the environment, might therefore not be of importance. However, for a short-term disturbance such as a toxic bloom or oxygen depletion, the timing of the disturbance is evidently important and therefore this 
factor should be incorporated in succession models for benthic macroinvertebrate communities. Studies on recovery processes on hard substrata have also demonstrated the importance of the disturbance's timing on community composition (Kennelly 1987; Dayton et al. 1992; Kim \& De Wreede 1996). Depending on the community studied, it seems likely that both the nature of a disturbance and seasonal factors influence species composition and its change through time (Turner \& Todd 1993).

Although the recovery patterns following the toxic bloom and the experimental defaunation largely fitted predictions of current succession models (Pearson \& Rosenberg 1976, 1978; Rhoads et al. 1978), the observed deviations highlight the need to understand the various factors that can influence the recovery processes, in particular the timing of a disturbance.

Is it feasible then to develop a succession model that incorporates all the important factors? Such a model might become too complex for any use, thus alternative approaches could be to develop more specific models, i.e., models for specific disturbances such as organic pollution or harmful algal blooms, or to develop location-specific models. Whereas the former models would help to identify patterns and commonalities for certain disturbances, the latter might be of more use to environmental managers who are responsible for defined areas or regions of coastline. A location-specific model could incorporate factors such as long-term distribution patterns, general recruitment patterns and hydrographic and climatic conditions, hence requiring a detailed knowledge of the location and the factors being likely to affect recovery processes. However, developing a model for Wellington Harbour requires further study, especially on temporal and spatial distribution patterns of benthic macroinvertebrate communities.

\section{Factors Influencing Recovery}

Various factors affecting successional patterns following disturbances are listed in Table 4.1. Such factors can be categorized into being either intrinsic, i.e., occurring within the disturbed area, or extrinsic, i.e., occurring outside the disturbed area (Thrush \& Whitlach 2001). However, the factors can interact and thereby confound the effects, making this division somewhat artificial. For instance, the hydrographical regime determines the site history to a great extent. 
The timing of a disturbance can influence the availability of larvae as well as influence the frequency of a disturbance, e.g., severe storms are more likely to occur at certain seasons (Sousa 2001). The factors identified to be important in the recovery processes following the toxic bloom and the experimental defaunation are marked in Table 4.1, and the most important factors are discussed in the following section.

Most factors were identified as being important in both the mensurative and the manipulative experiment, whereas other factors only played a role in one of the experiments. For instance, the sediment biogeochemistry changed in the experimental defaunation due to the oxygen depletion, and the species-dependent habitat modifications were most likely to affect recovery at the HB site, where the recovered community consisted of many deep-burrowing species.

Table 4.1 General factors influencing benthic macroinvertebrate recovery processes. Modified after Thrush \& Whitlach (2001). Factors identified as important are marked.

\begin{tabular}{|c|c|c|c|}
\hline & Intrinsic Factor* & & Extrinsic Factor* \\
\hline- & $\begin{array}{l}\text { Changes in sediment } \\
\text { biogeochemistry }{ }^{2}\end{array}$ & & $\begin{array}{l}\text { Site history (esp. frequency of } \\
\text { disturbances) }\end{array}$ \\
\hline - & $\begin{array}{l}\text { Changes in sediment } \\
\text { topography }\end{array}$ & - & Magnitude of disturbance \\
\hline- & $\begin{array}{l}\text { Changes of resources relative to } \\
\text { ambient conditions }\end{array}$ & - & Spatial extent of disturbance \\
\hline- & $\begin{array}{l}\text { Life-history of colonisers } \\
\text { and their survival } 1,2\end{array}$ & - & Hydrodynamic regime ${ }^{1,2}$ \\
\hline- & Colonist demographics & - & $\begin{array}{l}\text { Availability of colonists (influenced } \\
\text { by timing of disturbance, spatial } \\
\text { extent of disturbance, distance } \\
\text { colonisers have to travel, } \\
\text { demographics of surrounding } \\
\text { community) } \mathbf{1 , 2}\end{array}$ \\
\hline & $\begin{array}{l}\text { Species interactions (predation, } \\
\text { interference) }\end{array}$ & - & Timing of disturbance ${ }^{1,2}$ \\
\hline - & $\begin{array}{l}\text { Species-dependent habitat } \\
\text { modifications (bioturbation, } \\
\text { etc.) }\end{array}$ & - & Nature of disturbance ${ }^{\mathbf{1 , 2}}$ \\
\hline
\end{tabular}


The main factor explaining the observed variability in community recovery was the site-specific hydrodynamic regime. The hydrodynamic regime influences community recovery in several ways. Firstly, it determines the physical environment with regard to sediment and food availability, thereby determining the type of community that is found naturally in an area (Pearson \& Rosenberg 1987) and its resilience to disturbance. Communities at hydrodynamically active sites such as $\mathrm{OB}, \mathrm{EC}$ and in the defaunation experiment tend to be non-equilibrial and are dominated by $r$-selected species, whereas low energy sites tend to harbour equilibrium communities high in $K$-selected species (McCall 1977).

The location of a community on the $r$ - $K$-continuum in response to the particular site-history, e.g., the frequency of disturbances experienced at a site, is important for the community's resilience to disturbance (Giller \& Gee 1987). Non-equilibrial communities with a high number of $r$-selected species are more resilient to disturbances, i.e., in general they return faster to their pre-disturbed state due to the short life cycles typical of pioneering species, their high fecundity and therefore a high supply of propagules. In contrast, equilibrium communities are less resilient because most of their constituent species are not adapted to disturbances. Such species have low fecundity rates, long life spans and show a high level of resource partitioning and thereby niche diversification (Odum 1969). Secondly, the hydrodynamic regime can modify the impact of a disturbance such as a toxic plankton bloom on benthic communities. At a lowenergy site, such as HB, the effects of the toxic bloom on the benthic macroinvertebrate community were probably more severe than at a hydrodynamically exposed site. Sites such as HB typically show high depositional rates (Olsgard 1993), therefore accumulation of toxic cells on the sediment surface as observed by Wear \& Gardner (2001) might have been higher at HB than at the other sites. The pre-bloom fauna at HB was rich in deepburrowing species such as the maldanids Asychis trifilosus and Maldane theodori, which presumably would have moved toxic phytoplankton material into their burrows. In hydrodynamically active areas such as $\mathrm{OB}$ and EC, depositional rates would be lower than at HB. Any accumulation of toxic cells on the sediment surface would have in all likelihood been removed quickly due to higher lateral transport rates. 
The nature of a disturbance determines whether, and to what extent, the hydrodynamic regime will modify the severity of the disturbance. The effects of some disturbances are largely independent of the hydrodynamic regime, e.g., unusually cold or warm water temperatures (Bohnsack 1983; Southward et al. 1995) or subtidal sediment slumps (Okey 1997; Slattery \& Bockus 1997). However, the hydrodynamic conditions would still influence the recovery processes in terms of supply of colonists (Thrush \& Whitlach 2001). The nature of a disturbance itself exerts a strong influence on recovery processes and can interact with other factors. If the disturbance was chronic (press disturbance, Bender et al. 1984), then the recovered community is likely to be different from the pre-disturbed one as a response to the environmental changes (O'Neill 1999). For instance, the organic enrichment of coastal waters has led to permanent or near-permanent anoxic or hypoxic benthic conditions in many areas with communities remaining long-term in an impoverished early successional stage (Llansó 1992; Diaz \& Rosenberg 1995). The toxic bloom and the oxygen depletion in the defaunation experiment were discrete and relatively short-lived one-off events, i.e., pulse disturbances (Bender et al. 1984), which did not result in any long-term modifications of the physical or chemical environment. Following such disturbances, recovery can be expected to proceed in a relatively direct manner from a non-equilibrial early successional stage to the particular climax stage determined by the local environmental conditions. That is, restoration to pre-disturbance levels can be assumed following pulse disturbances (Underwood 2000).

\section{Recovery Times}

By influencing the recovery process, the aforementioned factors obviously influence the recovery times of a community. In order to assess recovery times the endpoint of the recovery trajectory has to be determined. Such determination depends on which criteria are used to define complete recovery (Underwood 1996). The estimates of recovery times in the present study are based on observed and predicted changes in community composition. A recovery time of four to five years was estimated for the HB community following the toxic 
bloom of 1998. This estimate is based on the recovery process not being interrupted by another disturbance event, which would reset the recovery process to an earlier successional stage. The relatively long recovery time at $\mathrm{HB}$ might not only be due to the community having been more severely affected by the toxic bloom in the first place, but also by the fact that the endpoint of recovery at $\mathrm{HB}$ is a typical equilibrium community with high structural and ecological complexity dominated by $K$-strategists. Once such structural complexity is disrupted by a disturbance it needs to be re-built, i.e., early successional species have to pave the way and restore some of the community-inherent complexity (e.g., trophic levels) in order for late successional species to recolonise successfully. A possible example of one species facilitating another at $\mathrm{HB}$ is indicated by the declining mean abundance of the opportunist capitellid polychaete Heteromastus cf. filiformis between 2000 and 2001 and the concomitant increase in abundance of a $K$-strategist, the maldanid polychaete Maldane theodori. Heteromastus filiformis is a cosmopolitan species and often dominates shallow-water marine benthic communities (Shaffer 1983). Adults live in semi-permanent mucus-lined burrows extending $5-30 \mathrm{~cm}$ into the sediment. Such burrows could aid in aerating the sediments to greater depths after disturbances and thus creating conditions which enable deeper-living species such as maldanids to settle. According to the facilitation model of Connel \& Slatyer (1977) the facilitating species should modify the environment in such a way that it is unsuitable for early successional species to recruit whereas it becomes more suitable for recruitment of late successional species. However, the species succession observed here could also be explained by the tolerance model (Connel \& Slatyer 1977), in which the environmental modifications of the early successional species have negative effects on subsequent recruitment of early successional species, but have no effect on recruitment of late successional species. In this model the sequence of species is determined solely by their life history characteristics. As a $K$-strategist $M$. theodori lives longer, grows bigger and thus possibly outcompetes $H$. cf. filiformis in the long term. Whether the presence of $H$. $c f$. filiformis has a positive effect (facilitation) or whether it has no effect (tolerance) on settlement of $M$. theodori remains inconclusive and can only be established from, for instance, density-controlled experiments. If oxygenation of deeper sediment layers facilitates the settlement of $M$. theodori, it should also 
facilitate other maldanid species. Yet, mean abundances of Asychis trifilosus decreased over time and for Asychis sp. A mean abundances stagnated. Maldane theodori was recorded already from November 1998 onwards at HB, but H. cf. filiformis only from November 1999 onwards, which seems to be conflicting with the view that the latter one is the early successional species. However, Shaffer (1983) found that settling larvae of H. filiformis are much smaller than $850 \mu \mathrm{m}$, thus it is likely that H. cf. filiformis in Wellington Harbour was only recorded once a $500 \mu \mathrm{m}$ mesh was employed. Studies of $H$. filiformis populations in South Carolina, U.S.A., showed that settlement in this species occurred in spring (Shaffer 1983). Thus recruitment of H. cf. filiformis at HB could have occurred as early as in the first spring after the bloom. Shaffer (1983) also demonstrated that adults show a zero growth rate during the winter, which could explain why no H. cf. filiformis were found in the $500 \mu \mathrm{m}$ sample fraction taken in August 1999, i.e., they might have been still too small to be retained on the mesh. The occasional occurrence of M. theodori from November 1998 onwards at HB could be due to migrating individuals of this species. Another maldanid species had survived the bloom at HB (Asychis trifilosus), and although M. theodori was not amongst those survivors found in the samples taken 3 months post-bloom, it is possible that some individuals might have migrated into the sampling site. An example for the inhibition model (earlier colonists inhibit the invasion of subsequent colonists) could not be found.

In general, it seems problematical to employ the models of Connell \& Slatyer (1977) to explain species succession in Wellington Harbour. The models are mainly based on forest succession studies where species succession can be observed directly. Unlike in terrestrial and marine rocky-shore environments, successional processes in soft-sediment macroinvertebrate communities cannot be observed directly, they can only be deducted from concomitant changes in mean abundances. Detailed knowledge of life history characters of the species involved is then required to explain the successional mechanisms. However, for most marine benthic macroinvertebrate species occurring in New Zealand such knowledge does not exist. This lack clearly emphasises the need for more life history-based studies. 
For the $\mathrm{OB}$ and $\mathrm{EC}$ communities, recovery times are estimated to be somewhat shorter due to both communities being exposed to high levels of physical disturbance and thereby remaining in an earlier non-equilibrial successional stage (Rhoads et al. 1978). Gardner \& Wear (submitted) estimated similar recovery times (three to five years) for sites affected by the toxic bloom.

Complete recovery following the experimental defaunation is thought to be possible within two years. The shorter recovery time following the experimental defaunation can be attributed to the site being permanently physically disturbed and also to the relatively small spatial scale of the defaunated plots (ca. $25 \mathrm{~m}^{2}$ ). The spatial extent of a disturbance has been shown to be an important factor in recovery processes (Thrush et al. 1996; Whitlach et al. 1998) due to dispersal abilities of the different life stages of most benthic animals (Günther 1992).

As mentioned before, the timing of a disturbance influences the recovery process and thereby the time required for the community to recover. Due to differences in the seasonal availability of recruits, recovery might have proceeded faster if the disturbances in Wellington Harbour had occurred shortly before or during the main recruitment period. Defaunation experiments conducted on tidal sandflats of the North Sea have shown that recovery following defaunation in spring or summer was faster than recovery following disturbances in autumn or winter (Beukema et al. 1999; Dittmann et al. 1999).

\section{Conclusions}

In conclusion, the recovery processes following the toxic plankton bloom in Wellington Harbour in 1998 and the experimental defaunation proceeded generally in accordance with the conceptual models of Pearson \& Rosenberg (1976, 1978) and Rhoads et al. (1978). However, these models are non-specific and paint only a broad picture of recovery as a successional shift from $r$-selected to $K$-selected species dominating the community (Pearson \& Rosenberg 1987). Thus, in their generality the models cannot deliver more detailed predictions about the recovery times or the endpoint of recovery following specific disturbances due to the multiplicity and complexity of the factors influencing recovery processes. On the other hand, the generality of the models renders them widely applicable, which is supported by the fact that these models have not been 
modified since they were published in 1978. Location-specific models might provide more applicability especially for environmental management.

Multiple factors can cause deviations from model predictions especially in the early stages of recovery (e.g., Karakassis et al. 1999) and influence times and endpoints of recovery. Therefore, a thorough understanding of the effects and interactions of the various factors influencing recovery is necessary to make predictions about the impact of any disturbance. Such understanding is especially important in the context of the increasing number of anthropogenic disturbances in coastal regions that result from, for example, aquaculture facilities, sewage outlets, or oil spills. Predictions about the impact of a disturbance (e.g., how much change will it cause, for how long will the change last?) are necessary for environmental managers to decide whether, for example, to approve a new aquaculture facility or the dumping of dredged sediments (Underwood 1996).

It has been apparent from the present and other studies (e.g., Thrush \& Whitlach 2001) that disturbances and thus recovery processes are influenced by a multitude of often confounding factors. Clearly, in order to predict recovery processes of a specific disturbance in a specific location, a thorough understanding of the different factors and their interactions affecting the recovery process is obligatory. Such understanding includes a sound knowledge of the pre-disturbance state of a community and of the site history. Pre-disturbance data are necessary as a baseline against which to measure the impact of a disturbance and the recovery time of a community (Thrush 1994; Underwood 2000; StewartOaten \& Bence 2001). Where pre-disturbance data are lacking, control data could be obtained from appropriate reference locations (Underwood 1996), although in most cases the conditions of the impacted sites cannot be matched adequately. Multivariate techniques such as the Index of Multivariate Dispersion (IMD, Warwick \& Clarke 1993) and the Index of Multivariate Seriation (IMS, Clarke et al. 1993) can indicate changes in community composition even without reference to pre-disturbance or other reference data. Yet, even if baseline data exist, the determination of the endpoint of recovery can be problematical in cases where the pre-disturbance state is not re-attained either due to severe environmental modifications caused by the disturbance or due to a change in environmental conditions independent from the disturbance (Depledge 1999). Another difficulty arises out of the fact that pre-impact data might have been 
obtained with different methods because they were taken for different purposes, e.g., for contract research (Wear \& Gardner 2001). The possible effects of different methods employed have to be taken into account when using such preimpact data as the baseline.

The present results support recommendations of various authors, especially Clarke \& Warwick (2001), for the employment of multivariate techniques in the assessment of community recovery. Measurements of similarity in community composition are a more sensitive tool in assessing whether a community has reached the endpoint of recovery than the attainment of reference levels of univariate indices such as $N, S$ and $H^{\prime}$, which ignore the identity of the species (Warwick \& Clarke 1991). However, univariate indices are still useful in quantifying the impact of a disturbance (when reference data exist) and in interpretating the observed changes in community composition. Thus, multivariate methods are more reliable indicators of community recovery, but a combination of analytical approaches is more appropriate in order to address all aspects of community structure and to interpret observed changes (Ellis et al. 2000).

\section{Future Work}

The results presented here have shown that a thorough understanding of the various factors influencing community recovery is an imperative for predicting recovery processes following specific disturbances in specific locations. The hydrodynamic regime and the timing of a disturbance have been identified as the major factors in the recovery processes following a toxic plankton bloom and an experimental defaunation caused by oxygen depletion. However, a formal proof of the effect of these factors on recovery processes of benthic macroinvertebrate communities by experimentation is still necessary.

Conducting a defaunation experiment during different seasons, in particular shortly before the main recruitment period in the harbour, could elucidate the roles of timing of the disturbance and availability of colonists. By repeating the defaunation experiment in parts of the harbour experiencing different hydrodynamic conditions, the influence of this factor on recovery processes could also be assessed. Settlement panels and sediment trap data 
should be included in the experimental set-up to evaluate the role of larval versus adult immigration into the disturbed areas. Measures of environmental parameters such as current velocity, sediment organic carbon content, sediment grain size, sediment oxygen content and redox potentials should be taken regularly throughout the experiment for they will assist in interpretating the recovery trajectories of communities following disturbance. Other forms of disturbances (experimental or otherwise) might require different or additional parameters to be measured.

However, testing hypotheses concerning factors that influence recovery processes following natural disturbances such as plankton blooms or oxygen depletion, and also anthropogenic disturbances such as oil spills or chemical pollution, can be problematic because such disturbances act mainly on large spatial scales. Results of small-scale studies cannot be applied without caution to large-scale studies due to the likely scale-dependency of such factors (Thrush et al. 1996; Whitlach et al. 1998; Thrush \& Whitlach 2001). Underwood (1996) recommends that planned disturbances, i.e., the construction of jetties or stormwater drains, should be used as experiments to test ecological hypotheses on relevant scales. These opportunities would allow samples to be taken before and after the impact in disturbed and control areas under realistic field conditions and on relevant spatial and temporal scales. However, establishing the appropriate sampling protocol is not straightforward and should be considered carefully (Underwood 2000). In a similar way, naturally occurring disturbances such as the Wellington Harbour bloom and accidents such as oil spills can provide the opportunities for mensurative experiments, especially where predisturbance data exist (Underwood et al. 2000). Yet, even without predisturbance data such experiments can be useful if the sampling design has been chosen carefully (Underwood 2000). For instance, the recent spillage of diesel oil in the port area of Wellington Harbour ( $5^{\text {th }}$ July 2003) provided an opportunity to test the effects of such a disturbance on benthic communities. Clearly, the explanation of recovery processes following large-scale disturbances requires the seizing of such chances to test the manifold influences on recovery processes. Important factors identified in such mensurative experiments can then be verified by field experiments, as was the case for the present study. 
While making recommendations on how to test the influence of different factors on recovery processes, I am aware that such recommendations are not always feasible. The sorting and identification of macrobenthic soft-sediment samples is labour-intensive and time-consuming, and often requires taxonomic expertise, especially in areas where the fauna is largely undescribed (Olsgard \& Somerfield 2000). Therefore it is important to develop methods to reduce both the processing time of samples and the cost involved. Testing the influence of sieve sizes, i.e., the mesh diameter (Thompson et al. 2003), and the influence of taxonomic resolution (Ellis 1985; Somerfield \& Clarke 1995; Gesteira et al. 2003 ) on the assessment of community recovery processes following large-scale disturbances are two avenues to be explored prior to the instigation of any future work.

\section{Summary}

This study has been successful in furthering our understanding of the effects of severe disturbances on temperate subtidal benthic macroinvertebrate communities and the factors influencing the recovery processes of such communities. Only few large-scale mensurative experiments elucidating the long-term effects of toxic plankton blooms on benthic macroinvertebrate communities in temperate enclosed embayments exist. To my knowledge this is the first study of such a kind conducted in the Southern Hemisphere. A manipulative experiment resulted from the findings of the mensurative experiment in which the recovery of macrobenthic assemblages in a hydrodynamically exposed site was investigated. Manipulative defaunation on the scale applied in this experiment, i.e., on a meso-scale, had not been conducted before in the subtidal. The method employed to defaunate the sediment, smothering by tarpaulin coverage, was used for the first time in a subtidal environment and worked successfully. As main factors influencing the recovery processes the hydrodynamical regime and the timing of the disturbance were identified. Results are discussed in the context of current succession models and the need for development of site-specific models, which would allow for better predictability of recovery times, is emphasised. Relatively new and rarely used multivariate analyses were applied successfully in assessing community 
recovery. It could be shown that such analyses are useful tools even in the absence of pre-impact data. Such findings are important for environmental managers who are often faced with the assessment of disturbance effects in the absence of reference data. Recommendations are made to combine uni- and multivariate analytical methods to assess community recovery. 


\section{References}

Abele, L. G.; Walters, K. 1979a: Marine benthic diversity: a critique and alternative explanation. Journal of Biogeography 6: 115-126.

Abele, L. G.; Walters, K. 1979b: The stability-time hypothesis: reevaluation of the data. American Naturalist 114: 559-568.

Acosta, C.; Robertson, D. 2002: Diversity in coral reef fish communities: the effects of habitat patchiness revisited. Marine Ecology Progress Series 227: 8796.

Airoldi, L.; Fabiano, M.; Cinelli, F. 1996: Sediment deposition and movement over a turf assemblage in a shallow rocky coastal area of the Ligurian Sea. Marine Ecology Progress Series 133: 241-251.

Aller, R.; Aller, J. 1992: Meiofauna and solute transport in marine muds. Limnology and Oceanography 37: 1018-1033.

Alvarez, L. W.; Alvarez, W.; Asaro, F.; Michel, H. V. 1980: Extraterrestrial cause for the Cretaceous-Tertiary extinction. Science 208: 1095-1108.

Anderlini, V. C.; Wear, R. G. 1992: The effect of sewage and natural seasonal disturbances on benthic macrofaunal communities in Fitzroy Bay, Wellington, New Zealand. Marine Pollution Bulletin 24: 21-26.

Anderson, G. W.; Anderson, R. L. 1963: The rate of spread of oak wilt in the Lake States. Journal of Forestry 63: 823-825.

Arntz, W. E.; Rumohr, H. 1982: An experimental study of macrobenthic colonization and succession, and the importance of seasonal variation in temperate lattitudes. Journal of Experimental Marine Biology and Ecology 64: $17-45$.

Aronson, R. B.; Precht, W. F. 1995: Landscape patterns of reef coral diversity: a test of the intermediate disturbance hypothesis. Journal of Experimental Marine Biology and Ecology 192: 1-14.

Baldwin, R. P. 1993: Cargo vessel ballast water as a vector for the spread of toxic phytoplankton species to New Zealand. New Zealand Professional Fisherman April 1993: 61-71.

Barnes, D. 1999: The influence of ice on polar nearshore benthos. Journal of the Marine Biological Association U.K. 79: 401-407.

Barrett, P. J.; Brooker, M. R. 1989: Grain size at VUW. School of Earth Sciences, Victoria University of Wellington, New Zealand. 
Beesley, P. L.; Ross, G. J. B.; Glasby, C. J. 2000: Polychaetes \& Allies: The Southern Synthesis. CSIRO Publishing, Melbourne. 465 p.

Bell, S.; Devlin, D. 1983: Short-term macrofaunal recolonization of sediment and epibenthic habitats in Tampa Bay, Florida. Bulletin of Marine Science 33: 102108 .

Bender, E.; Case, T.; Gilpin, M. 1984: Perturbation experiments in community ecology: theory and practice. Ecology 65: 1-13.

Berge, J. A. 1990: Macrofauna recolonization of subtidal sediments. Experimental studies on defaunated sediment contaminated with crude oil in two Norwegian fjords with unequal eutrophication status. Marine Ecology Progress Series 66: 103-115.

Bertness, M.; Leonard, G. 1997: The role of positive interactions in communities: lessons from intertidal habitats. Ecology 78: 1976-1989.

Bestelmeyer, B.; Wiens, J. 2003: Scavenging ant foraging behavior and variation in the scale of nutrient redistribution among semi-arid grasslands. Journal of Arid Environment 53: 373-386.

Beukema, J. J. 1988. An evaluation of the ABC-mehtod (abundance/biomass comparison) as applied to macrozoobenthic communities living on tidal flats in the Dutch Wadden Sea. Marine Biology 99: 425-433.

Beukema, J. J.; Flach, E. C.; Dekker, R.; Starink, M. 1999: A long-term study of the recovery of the macrozoobenthos on large defaunated plots on a tidal flat in the Wadden Sea. Journal of Sea Research 42: 235-254.

Blake, J. A.; Hilbig, B., Paul, H. 1996: Taxonomic Atlas of the Benthic Fauna of the Santa Maria Basin and Western Santa Barbara Channel Volume 4-7. Santa Barbara Museum of Natural History, Santa Barbara, California.

Blomster, J.; Baeck, S.; Fewer, D.; Kiirikki, M.; Lehvo, A.; Maggs, C.; Stanhope, M. 2002: Novel morphology in Enteromorpha (Ulvophyceae) forming green tides. American Journal of Botany 89: 1756-1763.

Bohnsack, J. 1983: Resiliency of reef fish communities in the Florida Keys following a January 1977 hypothermal fish kill. Environmental Biology of Fishes 9: 41-53.

Bonsdorff, E. 1980: Macrozoobenthic recolonization of a dredged brackish water bay in SW Finland. Ophelia Supplement 1: 1-155.

Bonsdorff, E. 1989: Infaunal colonization and its dependence on environmental variation - experimental evidence from the northern Baltic Sea. Reproduction, Genetics and Distributions of Marine Organisms. 23rd European Marine Biology Symposium, University of Wales, Swansea: 349-356. 
Bonsdorff, E.; Österman, C.-S. 1985: The establishment, succession and dynamics of a zoobenthic community - an experimental study. 19th European Marine Biology Symposium 1984, Plymouth, Devon, U.K.: 287-297.

Bonsdorff, E.; Pearson, T. H. 1999: Variation in the sublittoral macrozoobenthos of the Baltic Sea along environmental gradients: a functional-group approach. Australian Journal of Ecology 24: 312-326.

Booth, J. D. 1975: Seasonal and tidal variation in the hydrology of Wellington Harbour. New Zealand Journal of Marine and Freshwater Research 9: 333-354.

Botherway, K. J.; Gardner, J. P. A. 2002: Effect of storm drain discharge on the soft shore ecology of Porirua Inlet, New Zealand. New Zealand Journal of Marine and Freshwater Research 36: 241-255.

Bray, J. R.; Curtis, T. J. 1957: An ordination of the upland forest communities of Southern Wisconsin. Ecological Monographs 27: 325-349.

Brey, T. 1990: Estimating productivity of macrobenthic invertebrates from biomass and mean individual weight. Meeresforschung 32: 329-343.

Brodie, J. W. 1958: A note on tidal circulation in Port Nicholson, New Zealand. New Zealand Journal of Geology and Geophysics 1: 684-702.

Brokaw, N. V. L. 1984: Treefalls, regrowth, and community structure in tropical forests, In: Pickett, S. T. A.; White, P. A. eds. The Ecology of Natural Disturbance and Patch Dynamics. Orlando, Academic Press, Inc. Pp. 53-71.

Burd, B.; Macdonald, R.; Boyd, J. 2000: Punctuated recovery of sediments and benthic infauna: a 19-year study of tailings deposition in a British Columbia fjord. Marine Environmental Research 49: 145-175.

Butman, C. A. 1987: Larval settlement of soft-sediment invertebrates: the spatial scales of pattern explained by active habitat selection and the emerging role of hydrodynamical processes. Oceanographical Marine Biological Annual Review 25: 111-165.

Butman, C. A. 1989: Sediment-trap experiments on the importance of hydrodynamical processes in distributing settling invertebrate larvae in nearbottom waters. Journal of Experimental Marine Biology and Ecology 134: 37-88.

Buttermore, R.; Turner, E. M., MG. 1994: The introduced northern Pacific seastar Asterias amurensis in Tasmania. Memoirs of the Queensland Museum. Brisbane 36: 21-25.

Cairns, J. J.; Dickson, K. L. 1975: Recovery of streams from spills of hazardous materials. International Symposium on the Recovery of Damaged Ecosystems, Virginia Polytechnic Institute and State University, Blacksburg, Virginia: 24-42. 
Carlton, J.; Thompson; Schemel, J.; LE; Nichols, F. 1990: Remarkable invasion of San Francisco Bay (California, USA) by the Asian clam Potamocorbula amurensis. I. Introduction and dispersal. Marine Ecology Progress Series 66: 8194.

Carter, L. 1977: Sand transport, Wellington Harbour entrance, New Zealand. New Zealand Journal of Geology and Geophysics 20: 335-351.

Carter, L.; Lewis, K. 1995: Variability of the modern sand cover on a tide and storm driven inner shelf, south Wellington, New Zealand. New Zealand Journal of Geology and Geophysics 38: 451-470.

Castilla, J. A. 1988: Earthquake-caused coastal uplift and its effects on rocky intertidal kelp communities. Science 242: 440-443.

Chang, F. H. 1998a: How did the bloom affect Wellington Harbour? Aquaculture Update 21: 3-4.

Chang, F. H. 1998b: Occurrence of Gymnodinium, a toxic dinoflagellate species, off Wairarapa. Water \& Atmosphere 6: 4.

Chang, F. H. 1998c: The summer 1998 Gymnodinium c.f. mikimotoi bloom in Wellington Harbour. Water \& Atmosphere 6: 6.

Chang, F. H. 1999a: Gymnodinium brevisulcatum sp. nov. (Gymnodiniales, Dinophyceae), a new species isolated from the 1998 summer toxic bloom in Wellington Harbour, New Zealand. Phycologia 38: 378 -384.

Chang, F. H. 1999b: Phytoplankton blooms around Wellington. Aquaculture Update Autumn/Winter: 11-12.

Chang, F. H. 2000: New blooms and old. Water \& Atmosphere 8: 26 -27.

Chang, F. H.; Pridmore, R. D.; Boustead, N. 1991: Occurrence and distribution of Heterosigma cf. akashiwo (Raphidophyceae) in a 1989 bloom in Big Glory Bay, New Zealand. Toxic phytoplankton blooms in the sea: Proceedings of the Fifth International Conference on Toxic Marine Phytoplankton, Newport, Rhode Island, USA: 675-680.

Chang, F. H.; McKoy, J.; Uddstrom, M. 1998a: The summer 1998 Gymnodinium cf. mikimotoi blooms on the East coast and in Wellington Harbour of New Zealand. MAF Proceedings of the Marine Biotoxin Science Workshop No. 9, Wellington, New Zealand: 37-44.

Chang, F. H.; McKoy, J.; Uddstrom, M. 1998b: New Zealand Gymnodinium sp. linked to fish kills. Harmful Algae News 17: 1-5.

Chang, F. H.; Chiswell, S. M.; Uddstrom, M. D. 2001: Occurrence and distribution of Karenia brevisulcata (Dinophyceae) during the 1998 summer 
toxic outbreaks on the central east coast of New Zealand. Phycologia 40: 215222.

Chang, F. H.; Redfearn, P.; Diggles, B.; Glasby, C.; Allen, S. 1998c: Some characteristics of Wellington Harbour Gymnodinium toxins: impacts on marine animals and algae. MAF Proceedings of the Marine Biotoxins Science Workshop, Wellington, New Zealand, 10: 75-84.

Chesney, E. J. 1985: Succession in soft-bottom benthic environments: are pioneering species really outcompeted? 19th European Marine Biology Symposium 1984, Plymouth, Devon, U.K.: 277-286.

Christensen, N. L. 1985: Shrubland fire regimes and their evolutionary consequences. In: Pickett, S. T. A.; White, P. A. eds. The Ecology of Natural Disturbance and Patch Dynamics. Orlando, Academic Press, Inc. Pp. 87-99.

Churchill, J. 1989: The effect of commercial trawling on sediment resuspension and transport over the Middle Atlantic Bight continental shelf. Continental Shelf Research 9: 841-865.

Clarke, K. R. 1990: Comparison of dominance curves. Journal of Experimental Marine Biology and Ecology 138: 143-157.

Clarke, K. R. 1993: Non-parametric multivariate analyses of changes in community structure. Australian Journal of Ecology 18: 117 -143.

Clarke, K. R.; Green, R. H. 1988: Statistical design and analysis for a 'biological effects' study. Marine Ecology Progress Series 46: 213-226.

Clarke, K. R.; Ainsworth, M. 1993: A method of linking multivariate community structure to environmental variables. Marine Ecology Progress Series 92: 205219.

Clarke, K. R.; Gorley, R. N. 2001: PRIMER v5: User manual/tutorial PRIMERE. Plymouth, PRIMER-E. 91 p.

Clarke, K. R.; Warwick, R. M. 2001: Change in marine communities: an approach to statistical analysis and interpretation. Plymouth Marine Laboratory. $144 \mathrm{p}$.

Clarke, K. R.; Warwick, R. M.; Brown, B. E. 1993: An index showing breakdown of seriation, related to disturbance, in a coral-reef assemblage. Marine Ecology Progress Series 102: 153-160.

Clements, F. E. 1916: Plant succession: An analysis of the development of vegetation. Carnegie Institute Washington Publications 242: 512 p.

Clements, F. E. 1936: Nature and structure of the climax. Journal of Ecology 24: 252-284. 
Coma, R.; Ribes, M.; Gili, J.-M.; Zabala, M. 2000: Seasonality in coastal benthic ecosystems. Trends in Ecology \& Evolution 15: 448-453.

Connell, J. 1961: Effects of competition, predation by Thais lapillus, and other factors on natural populations of the barnacle Balanus balanoides. Ecological Monographs 31: 61-104.

Connell, J.; Hughes, T.; Wallace, C. 1997: A 30-year study of coral abundance, recruitment, and disturbance at several scales in space and time. Ecological Monographs 67: 461-488.

Connell, J. H. 1978: Diversity in tropical rainforests and coral reefs. Science 199: 1302-1310.

Connell, J. H.; Slatyer, R. O. 1977: Mechanisms of succession in natural communities and their role in community stability and organization. American Naturalist 111: 1119-1144.

Connell, J. H.; Sousa, W. P. 1983: On the evidence needed to judge ecological stablity or persistence. American Naturalist 121: 789-824.

Crowl, T.; Townsend, C.; Bouwes, N.; Thomas, H. 1997: Scales and causes of patchiness in stream invertebrate assemblages: Top-down predator effects? Journal of the North American Benthological Society 16: 277-285.

Dahlgren, C.; Posey, M.; Hulbert, A. 1999: The effects of bioturbation on the infaunal community adjacent to an offshore hardbottom reef. Bulletin of Marine Science 64: 21-34.

D'Antonio, C. 1985: Epiphytes on the rocky intertidal red alga Rhodomela larix (Turner) C. Agardh: Negative effects on the host and food for herbivores? Journal of Experimental Marine Biology and Ecology 86: 197-218.

Dauer, D. M.; Simon, J. L. 1976: Repopulation of the polychaete fauna of an intertidal habitat following natural defaunation: species equilibrium. Oecologia (Berlin) 22: 99-117.

Dauer, D. M.; Luckenbach, M. W.; Rodi, A. J., Jr. 1993: Abundance biomass comparison (ABC method): effects of an estuarine gradient, anoxic/hypoxic events and contaminated sediments. Marine Biology 116: 507-518.

Dauvin, J.-C.; Gillet, P. 1991: Spatio-temporal variability in population structure of Owenia fusiformis Delle Chiaje (Annelida Polychaeta) from the Bay of Seine (eastern English Channel). Journal of Experimental Marine Biology and Ecology 152: 105-122.

Dawson-Shepherd, A.; Warwick, R.; Clarke, K.; Brown, B. 1992: An analysis of fish community responses to coral mining in the Maldives. Environmental Biology of Fishes 33: 367-380. 
Day, R.; Osman, R. 1981: Predation by Patiria miniata (Asteroidea) on bryozoans: prey diversity may depend on the mechanism of succession. Oecologia (Berlin) 51: 300-309.

Dayton, P.; Tegner, M.; Parnell, P.; Edwards, P. 1992: Temporal and spatial patterns of disturbance and recovery in a kelp forest community. Ecological Monographs 62: 421-445.

Dayton, P. K. 1971: Competition, disturbance, and community organization: the provision and subsequent utilization of space in a rocky intertidal community. Ecological Monographs 41: 351-389.

Dean, T. 1981: Structural aspects of sessile invertebrates as organizing forces in an estuarine fouling community. Journal of Experimental Marine Biology and Ecology 53: 163-180.

Dean, T.; Jewett, S. 2001: Habitat-specific recovery of shallow subtidal communities following the Exxon Valdez oil spill. Ecological Applications 11: 1456-1471.

Dehadrai, P. 1997: Aquaculture and Environment. National Aquaculture Week 1997: A Special Programme of the Department of Biotechnology, Government of India, Vijayawada, Chennai, Mandapam Camp and Tuticorin (India): 13-16.

Depledge, M. H. 1999: Recovery of ecosystems and their components following exposure to pollution. Journal of Aquatic Ecosystem Stress and Recovery 6: 199206.

Dernie, K. M.; Kaiser, M. J.; Richardson, E. A.; Warwick, R. M. 2003: Recovery of soft sediment communities and habitats following physical disturbance. Journal of Experimental Marine Biology and Ecology 285-286: 415-434.

Dethlefsen, V.; Westernhagen, H. v. 1983: Oxygen deficiency and effects on bottom fauna in the eastern German Bight 1982. Meeresforschung 30: 42-53.

Diaz, R. J.; Rosenberg, R. 1995: Marine benthic hypoxia: a review of its ecological effects and the behavioural responses of benthic macrofauna. Oceanography and Marine Biology: an Annual Review 33: 245-303.

Diaz-Castaneda, V.; Frontier, S.; Arenas, V. 1993: Experimental reestablishment of a soft bottom community: utilization of multivariate analyses to characterize different benthic recruitments. Estuarine, Coastal and Shelf Science 37: $387-402$.

Dijkema, R. 1992: The risk of provoking toxic dinoflagellate blooms in the Dutch coastal waters through immersion of imported bivalves, originating from red tide areas. International Council for the Exploration of the Sea, ICES CM 1992/K: 48 Ref EShellfish Commitee. 
Dittmann, S.; Günther, C.-P.; U.Schleier. 1999: Recolonization of tidal flats after disturbance. In: Dittmann, S. ed. The Wadden Sea Ecosystem Stability Properties and Mechanisms. Berlin, Springer-Verlag Berlin Heidelberg New York. Pp. 175192.

Djaugbjerg, N.; Hansen, G.; Larsen, J.; Moestrup, Ø. 2000: Phylogeny of some of the major genera of dinoflagellates based on ultrastructure and partial LSU rDNA sequence data, including the erection of three new genera of unarmoured dinoflagellates. Phycologia 39: 302-317.

Dobbs, F. C.; Vozarik, J. M. 1983: Immediate effects of a storm on coastal infauna. Marine Ecology Progress Series 11: 273-279.

Eagle, A. 1975: Natural fluctuations in a soft bottom benthic community. Journal of the marine biological Association U.K. 55: 865-878.

Eckman, J. 1983: Hydrodynamic processes affecting benthic recruitment. Limnology and Oceanography 28: 241-257.

Eckman, J. E.; Nowell, A. R. M.; Jumars, P. A. 1981: Sediment destabilization by animal tubes. Jounal of Marine Research 39: 361-374.

Eleftheriou, A.; Robertson, M. 1992: The effects of experimental scallop dredging on the fauna and physical environment of a shallow sandy community. 26th European Marine Biology Symposium. Biological effects of disturbances on estuaries and coastal marine environments, Middleburg (Netherlands), 1991, 30: 289-299.

Elias, R.; Bremec, C. S. 2000: Polychaete assemblages in a southern shallow shelf area affected by sewage discharge. Bulletin of Marine Science 67: 661-662.

Ellis, D. 1985: Taxonomic sufficiency in pollution assessment. Marine Pollution Bulletin 16: 459 .

Ellis, J. I.; Norkko, A.; Thrush, S. F. 2000: Broad-scale disturbance of intertidal and shallow sublittoral soft-sediment habitats; effects on the benthic macrofauna. Journal of Aquatic Ecosystem Stress and Recovery 7: 57-74.

Elmgren, R.; Hansson, S.; Larsson, U.; Sundelin, B.; Boehm, P. 1983: The Tsesis oil spill: acute and long-term impact on the benthos. Marine Biology 73: 51-65.

Elton, C. 1927: Animal Ecology. London, Sidgwick and Jackson. 209 p.

Estcourt, I. N. 1976: Pauatahanui Inlet - Preliminary results of a benthos survey. Proceedings of the New Zealand Ecological Society 23: 117.

Fallesen, G.; Andersen, F.; Larsen, B. 2000: Life, death and revival of the hypertrophic Mariager Fjord, Denmark. Journal of Marine Systems 25: 313-321. 
Fauchald, K. 1977: The Polychaete Worms - Definitions and Keys to the Orders, Families and Genera. Natural History Museum of Los Angeles County. 188 p.

Fauchald, K.; Jumars, P. A. 1979: The diet of worms: a study of polychaete feeding guilds. Oceanography Marine Biology Annual Review 17: 193-284.

Fauth, J.; Bernardo, J.; Camara, M.; Resetarits, W. J.; Van Buskirk, J.; McCollum, S. 1996: Simplifying the jargon of community ecology: a conceptual approach. American Naturalist 147: 282-286.

Fenwick, G. 1984a: Life history and population biology of the giant ostracod Leuroleberis zealandica (Baird, 1850) (Myodocopida). Journal of Experimental Marine Biology and Ecology 77: 255-289.

Fenwick, G. 1984b: Partitioning of a rippled sand habitat by five infaunal crustaceans. Journal of Experimental Marine Biology and Ecology 83: 53-72.

Ferns, P.; Rostron, D.; Siman, H. 2000: Effects of mechanical cockle harvesting on intertidal communities. Journal of Applied Ecology 37: 464-474.

Ferraro, S. P.; Cole, F. A.; DeBen, W. A.; Swartz, R. C. 1989: Power-cost efficiency of eight macrobenthic sampling schemes in Puget Sound, Washington, USA. Canadian Journal of Fisheries and Aquatic Sciences 46: 2157-2165.

Ferraro, S. P.; Swartz, R. C.; Cole, F. A.; Deben, W. A. 1994: Optimum macrobenthic sampling protocol for detecting pollution impacts in the southern California Bight. Environmental Monitoring and Assessment 29: 127-153.

Field, J. G.; Clarke, K. R.; Warwick, R. M. 1982: A practical strategy for analysing multispecies distribution patterns. Marine Ecology-Progress Series 8: $37-52$.

Findlay, R.; Trexler, M.; White, D. 1990: Response of a benthic microbial community to biotic disturbance. Marine Ecology Progress Series 62: 135-148.

Fischer, A. G. 1984: The two Phanerozoic supercycles. In: Berggren, W. A.; Vancouvering, J. A. eds. Catastrophes and Earth History: the new Uniformitarianism. Princeton, New Jersey, Princeton Univeristy Press. Pp. 129150.

Fisher, R. A.; Corbet, A. S.; Williams, C. B. 1943: The relation between the number of species and the number of individuals in a random sample of an animal population. Journal of Animal Ecology 12: 42-58.

Flint, R. W.; Kalke, R. D. 1986: Biological enhancement of estuarine benthic community structure. Marine Ecology Progress Series 31: 23-33.

Folk, R. L.; Ward, W. C. 1957: Brazos River Bar: A study in the significance of grain size parameters. Journal of Sedimentary Petrology 27: 3-26. 
Ford, R. B.; Thrush, S. F.; Probert, P. K. 1999: Macrobenthic colonisation of disturbances on an intertidal sandflat: the influence of season and buried algae. Marine Ecology Progress Series 191: 163 -174.

Gage, J. 1996: Why are there so many species in deep-sea sediments? Journal of Experimental Marine Biology and Ecology 200: 275-286.

Gage, J. 1997: High benthic species diversity in deep-sea sediments: The importance of hydrodynamics. In: Ormond, R.; Gage, J.; Angel, M. eds. Marine Biodiversity: Patterns and Processes. New York, Cambridge University Press. Pp. 148-177.

Gallagher, E. D.; Jumars, P. A.; Trueblood, D. D. 1983: Faciliation of softbottom benthic succession by tube-builders. Ecology 64: 1200-1216.

Gallardo, V. A. 1965: Observations on the biting profiles of three $0.1 \mathrm{~m}^{2}$ bottomsamplers. Ophelia 2: 319-322.

Gamenick, I.; Jahn, A.; Vopel, K.; Giere, O. 1996: Hypoxia and sulphide as structuring factors in a macrozoobenthic community on the Baltic Sea shore: Colonization studies and tolerance experiments. Marine Ecology Progress Series 144: 73-85.

Gardner, J. P. A.; Wear, R. G. submitted: Subtidal macro-invertebrate community recovery in Wellington Harbour (New Zealand) after a large-scale natural die off.

Garwood, N.; Janos, D.; Brokaw, N. V. L. 1979: Earthquake caused landslides: a major disturbance to tropical forests. Science 205: 997-999.

Gesteira, J. L. G.; Dauvin, J. C.; Fraga, M. S. 2003: Taxonomic level for assessing oil spill effects on soft-bottom sublittoral benthic communities. Marine Pollution Bulletin 46: 562-572.

Giller, P. S.; Gee, J. H. R. 1987: The analysis of community organization: the influence of equilibrium, scale and terminology. In: Gee, J. R.; Giller, P. S. eds. Organization of communities past and present. Oxford, Blackwell Scientific Publications. Pp. 519-542.

Giller, P. S.; Sangpradub, N.; Twomey, H. 1991: Catastrophic flooding and macroinvertebrate community structure. Verhandlungen der Internationalen Vereinigung für theoretische und angewandte Limnologie 24: 1724-1729.

Gjösæter, J.; Lekve, K.; Stenseth, N. C.; Leinaas, H. P.; Christie, H.; Dahl, E.; Danielssen, D. S.; Edvardsen, B.; Olsgard, F.; Oug, E.; Paasche, E. 2000: A longterm perspective on the Chrysochromulina bloom on the Norwegian Skagerrak coast 1988: A catastrophe or an innocent incident? Marine Ecology Progress Series 207: 201-218. 
Goff, J. 2000: Wellington Harbour - Life on the edge. In: Mcconchie, J.; Winchester, D.; Willis, R. eds. Dynamic Wellington. A contemporary synthesis and explanation of Wellington. Wellington, Institute of Geography, Victoria University of Wellington, New Zealand. Pp. 123-136.

Goff, J. R. 1997: A chronology of natural and anthropogenic influences on coastal sedimentation, New Zealand. Marine Geology 138: 105-117.

Gowen, R.; Rosenthal, H. 1990: The environmental consequences of intensive coastal aquaculture in developed countries: What lessons can be learned. International Conference on Environment and Aquaculture in Developing Countries, Bellagio (Italy), 31: 102-115.

Granéli, E.; Paasche, E.; Maestrini, S. Y. 1991: Three years after the Chrysochromulina polylepis bloom in Scandinavian waters in 1988: some conclusions of recent research and monitoring. Toxic phytoplankton blooms in the sea. Proceedings of the Fifth International Conference on Toxic Marine Phytoplankton, Newport, Rhode Island, USA: 23-32.

Grant, J. 1983: The relative magnitude of biological and physical sediment reworking in an intertidal community. Journal of Marine Research 41: 673-689.

Grassle, J. F.; Sanders, H. L. 1973: Life histories and the role of disturbances. Deep-Sea Research 20: 643-659.

Grassle, J. F.; Grassle, J. P. 1974: Opportunistic life histories and genetic systems in marine benthic polychaetes. Journal of Marine Research 32: 253-284.

Gray, J. S. 1974: Animal-sediment relationships. Oceanographical Marine Biological Annual Review 12: 223-261.

Gray, J. S. 1977: The stability of benthic ecosystems. Helgoländer Wissenschaftliche Meeresuntersuchungen 30: 427-444.

Gray, J. S. 1981: The Ecology of Marine Sediments: An introduction to the structure and function of benthic communities. Cambridge, Cambridge University Press. 185 p.

Gray, J. S.; Aschan, M.; Carr, M. R.; Clarke, K. R.; Green, R. H.; Pearson, T. H.; Rosenberg, R.; Warwick, R. M. 1988: Analysis of community attributes of the benthic macrofauna of Frierfjord/Langesundfjord and in a mesocosm experiment. Marine Ecology Progress Series 46: 151-165.

Grime, J. 1973: Control of species diversity in herbaceous vegetation. Journal of Environmental Management 1: 151-167.

Günther, C. P. 1992: Dispersal of intertidal invertebrates: a strategy to react to disturbances of different scales? Netherland Journal of Sea Research 30: 45-56. 
Haddon, M.; Wear, R. G. 1993: Ecological survey of proposed dredge sites in Wellington Harbour. VUW Coastal Marine Research Unit Report No. 22 Report prepared for Port Wellington Ltd., 78 p (unpublished), Wellington.

Hall, S. J. 1994: Physical disturbance and marine benthic communities: life in unconsolidated sediments. Oceanography and Marine Biology: an Annual Review 32: 179-239.

Hall, S. J.; Raffaelli, D.; Thrush, S. F. 1994: Patchiness and disturbance in shallow water benthic assemblages. In: Giller, P. S.; Hildrew, A. G.; Raffaelli, D. G. eds. Aquatic Ecology. Scale, Pattern and Process: 34th Symposium of the British Ecological Society with the American Society of Limnology and Oceanography, University College, Cork, 1992. Oxford, Blackwell Scientific Publications. Pp. 333-375.

Hallegraeff, G. M. 1993: A review of harmful algal blooms and their apparent global increase. Phycologia 32: 79-99.

Harper, D. E.; McKinney, L. D.; Nance, J. M.; Salzer, R. B. 1991: Recovery responses of two benthic assemblages following an acute hypoxic event on the Texas continental shelf, northwestern Gulf of Mexico. In: Tyson, R. V.; Pearson, T. H. eds. Modern and Ancient Continental Shelf Anoxia. London, Geological Society. Pp. 49-64.

Harris, L. G.; Ebeling, A. W.; Laur, D. R.; Rowley, R. J. 1984: Community recovery after storm damage: a case of facilitation in primary succession. Science 224: 1336-1338.

Hayden, B. 1995: Research requirements related to ballast water in New Zealand. MAF Fisheries, New Zealand.

Hayward, B.; Stephenson, A.; Morley, M. R., JL; Grenfell, H. 1997: Faunal changes in Waitemata Harbour sediments, 1930s-1990s. Journal of the Royal Society of New Zealand 27: 1-20.

Heath, R. A. 1977: Circulation and hydrology of Wellington Harbour. New Zealand Oceanographic Survey 12: 8.

Helson, J. G. 2001: An investigation into the absence of mussels (Perna canaliculus, Aulacomya maoriana and Mytilus galloprovincialis) from the South Coast of Wellington, New Zealand. Unpublished Ph.D thesis, Victoria University of Wellington, New Zealand, Wellington.

Hewitt, J. E.; Thrush, S. E.; Cummings, V. J. 2001: Assessing environmental impacts: effects of spatial and temporal variability at likely impact scales. Ecological Applications 11: 1502-1516.

Hiura, T. 1995: Gap formation and species diversity in Japanese beech forests: A test of the intermediate disturbance hypothesis on a geographic scale. Oecologia (Berlin) 104: 265-271. 
Holmes, N. A.; McIntyre, A. D. 1984: Methods for the Study of Marine Benthos. Blackwell Scientific Publications, Oxford London Edinburgh. 387 p.

Holte, B. 2001: Possible ecological effects from maldanid (Annelida, Polychaeta) "superdominance" in a small North Norwegian sill system. Ophelia 55: 69-75.

Hoopes, M.; Harrison, S. 1998: Metapopulation source-sink and disturbance dynamics. In: Sutherland, W. J. ed. Conservation science and action. Oxford, Blackwell. Pp. 135-151.

Hough, A. F.; Forbes, R. D. 1943: The ecology and silvics of forests in the high plateaus of Pennsylvania. Ecological Monographs 13: 299-320.

Houston, W. A. 1999: Severe hail damage to mangroves at Port Curtis, Australia. Mangroves and Salt Marshes 3: 29-40.

Hurlbert, S. H. 1984: Pseudoreplication and the design of ecological field experiments. Ecological Monographs 54: 187-211.

Huston, M. 1979: A general hypothesis of species diversity. American Naturalist 113: 81-101.

Huxham, M.; Roberts, I.; Bremner, J. 2000: A field test of the intermediate disturbance hypothesis in the soft-bottom intertidal. International Revue of Hydrobiology 85: 379-394.

Imabayashi, H. 1986: Effect of oxygen-deficient water on the settled abundance and size composition of the bivalve Theora lubrica. Bulletin of the Japanese Society of Scientific Fisheries 52: 391-397.

James, R. J.; Smith, M. P. L.; Fairweather, P. G. 1995: Sieve mesh-size and taxonomic resolution needed to describe natural spatial variation of marine macrofauna. Marine Ecology Progress Series 118: 187-198.

Jaramillo, E.; Croker, R. A.; Hatfield, E. B. 1987: Long-term structure, disturbance, and recolonization of macrofauna in a New Hampshire sand beach. Canadian Journal of Zoology 65: 3024-3031.

Jewett, S. C.; Dean, T. A.; Smith, R. O.; Blanchard, A. 1999: 'Exxon Valdez' oil spill: impacts and recovery in the soft-bottom benthic community in and adjacent to eelgrass beds. Marine Ecology Progress Series 185: 59-83.

Johnson, R. G. 1970: Variations in diversity within benthic marine communities. American Naturalist 104: 285-300.

Johnson, R. G. 1973: Conceptual models of benthic communities. In: Schopf, T. J. M. ed. Models in paleobiology. San Francisco, Freeman Cooper and Company. Pp. 148-159. 
Jokiel, P.; Hunter, C.; Taguchi, S.; Watarai, L. 1993: Ecological impact of a freshwater 'reef kill' in Kaneohe Bay, Oahu, Hawaii. Coral Reefs 12: 287-297.

Jones, E. W. 1945: The structure and reproduction of the virgin forest of the north temperate zone. New Phytology 44: 130-148.

Kaplan, E.; Welker, J.; Kraus, M.; McCourt, S. 1975: Some factors affecting the colonization of a dredged channel. Marine Biology 32: 193-204.

Karakassis, I.; Hatziyanni, E.; Tsapakis, M.; Plaiti, W. 1999: Benthic recovery following cessation of fish farming: a series of successes and catastrophes. Marine Ecology Progress Series 184: 205-218.

Kenchington, E. L. R.; Prena, J.; Gilkinson, K. D.; Gordon, D. C., Jr.; MacIsaac, K.; Bourbonnais, C.; Schwinghamer, P. J.; Rowell, T. W.; McKeown, D. L.; Vass, W. P. 2001: Effects of experimental otter trawling on the macrofauna of a sandy bottom ecosystem on the Grand Banks of Newfoundland. Canadian Journal of Fisheries and Aquaculture Sciences 58: 1043-1057.

Kennelly, S. 1987: Physical disturbances in an Australian kelp community. 1. Temporal effects. Marine Ecology Progress Series 40: 145-153.

Kim, J.; De Wreede, R. 1996: Effects of size and season of disturbance on algal patch recovery in a rocky intertidal community. Marine Ecology Progress Series 133: 217-228.

Kirchner, J. W.; Weil, A. 2000: Delayed biological recovery from extinctions throughout the fossil record. Nature 404: 177-180.

Kitching, J.; Ebling, F.; Gamble, J.; Hoare, R.; McLeod, A.; Norton, T. 1976: The ecology of Lough Ine. Journal of Animal Ecology 45: 731-758.

Kline, E. R.; Stekoll, M. S. 2001: Colonization of mine tailings by marine invertebrates. Marine Environmental Research 51: 301-325.

Koehl, M. A. R.; Wainwright, S. A. 1977: Mechanical adaptations of a giant kelp. Limnology and Oceanography 22: 1067-1071.

Lake, P. S. 1990: Disturbing hard and soft bottom communities: a comparison of marine and freshwater environments. Australian Journal of Ecology 15: 477-488.

Lam, C. W. Y.; Ho, K. C. 1987: Red tides in Tolo Harbour, Hong Kong. Red tides: Biology, Environmental Science, and Toxicology. Proceedings of the First International Symposium on Red Tides, Takamatsu, Kagawa Prefecture, Japan: 49-52.

Leppäkoski, E. 1968: Transitory return of the benthic fauna of the Bornholm Basin, after extermination by oxygen insufficiency. Cahier de Biologie Marine 10: 163-172. 
Levin, L. A.; Blair, N.; DeMaster, D.; Plaia, G.; Fornes, W.; Martin, C.; Thomas, C. 1997: Rapid subduction of organic matter by maldanid polychaetes on the North Carolina slope. Journal of Marine Research 55: 595-611.

Livingston, R. J.; Robert L. Howell, I.; Niu, X.; F. Graham Lewis, I.; Wodsum, G. C. 1999: Recovery of oyster reefs (Crassostrea virginica) in a gulf estuary following disturbances by two hurricanes. Bulletin of Marine Science 64: 465483.

Llansó, R. 1992: Effects of hypoxia on estuarine benthos: the lower Rappahannock River (Chesapeake Bay), a case study. Estuarine, Coastal and Shelf Science 35: 491-515.

Lu, L.; Wu, R. S. S. 2000: An experimental study on recolonization and succession of marine macrobenthos in defaunated sediment. Marine Biology 136: 291-302.

Lubchenco, J.; Menge, B. A. 1978: Community development and persistence in a low rocky intertidal zone. Ecological Monographs 48: 67-94.

MacArthur, R.; Wilson, E. 1967: The Theory of Island Biogeography. Princeton, N.J., Princetown University Press. 203 p.

Mackey, R. L.; Currie, D. J. 2001: The diversity-disturbance relationship: is it generally strong and peaked? Ecology 82: 3479-3492.

Magurran, A. E. 1988: Ecological Diversity and Its Measurement. Princetown, New Jersey, Princeton University Press. 179 p.

Margalef, R. 1968: Perspectives in Ecological Theory. Chicago, University of Chicago Press. 111 p.

Maurer, D.; Gerlinger, T.; Nguyen, H. 1998: The response of two spionid polychaetes to natural processes and anthropogenic activities on the San Pedro Shelf, California. Ophelia 48: 185-206.

Maurer, D.; Keck, R.; Rinsman, J.; Leathem, W.; Wethe, C.; Lord, C.; Church, T. 1986: Vertical migration and mortality of marine benthos in dredged material: a synthesis. Internationale Revue der gesamten Hydrobiologie 71: 49-63.

Maxwell, B. E. 1956: Hydrobiological observations for Wellington Harbour. Transactions of the Royal Society of New Zealand 83: 493-503.

McCall, P. L. 1977: Community patterns and adaptive strategies of the infaunal benthos of Long Island Sound. Journal of Marine Research 35: 221-266.

McGuiness, K. A. 1987: Disturbance and organisms on boulders. I. Patterns in the environment and the community. Oecologia (Berlin) 71: 409-419. 
McKoy, J. L. 1970: Animal-sediment relationships in Wellington Harbour. Bulletin of Natural Science, Victoria University of Wellington 1: 5-20.

McMinn, A.; Hallegraeff, G.; Thomson, P.; Jenkinson, A.; Heijnis, H. 1997: Cyst and radionucleotide evidence for the recent introduction of the toxic dinoflagellate Gymnodinium catenatum into Tasmanian waters. Marine Ecology Progress Series 161: 165-172.

Meyer-Reil, L.-A.; Köster, M. 2000: Eutrophication of marine waters: effects on benthic microbial communities. Marine Pollution Bulletin 41: 255-263.

Mills, E. L. 1969: The community concept in marine zoology, with comments on continua and instability in some marine communities: a review. Journal of Fisheries Research Board Canada 26: 1415-1428.

Mirto, S.; La Rosa, T.; Gambi, C.; Danovaro, R.; Mazzola, A. 2002: Nematode community response to fish-farm impact in the western Mediterranean. Environmental Pollution 116: 203-214.

Mirza, F. B.; Gray, J. S. 1981: The fauna of benthic sediments from the organically enriched Oslofjord, Norway. Journal of Experimental Marine Biology \& Ecology 54: 181-207.

Möbius, K. 1877: Die Auster und die Austernwirtschaft. Berlin, Hempel and Parry. 126 p.

Monson, D.; Doak, D.; Ballachey, B.; Johnson, A.; Bodkin, J. 2000: Long-term impacts of the Exxon Valdez oil spill on sea otters, assessed through agedependent mortality patterns. Proceedings of the National Academy of Sciences, USA 97: 6562-6567.

Morrisey, D.; Underwood, A.; Howitt, L.; Stark, J. 1992: Temporal variation in soft-sediment benthos. Journal of Experimental Marine Biology and Ecology 164: 233-245.

Morrisey, D.; Turner, S.; Mills, G.; Williamson, R.; Wise, B. 2003: Factors affecting the distribution of benthic macrofauna in estuaries contaminated by urban runoff. Marine Environmental Research 55: 113-136.

Morton, J.; Miller, M. 1968: The New Zealand Sea Shore. London-Auckland, Collins. 638 p.

NCCOS. 2003: Harmful Algal Blooms; http://www.habhrca.noaa.gov/ habfacts.html. National Centers for Coastal Ocean Sciences.

Nehring, S. 1998: Non-indigenous phytoplankton species in the North Sea: supposed region of origin and possible transport vector. Archiv für Fischerei und Meeresforschung 46: 181-194. 
Newell, R.; Seiderer, L.; Hitchcock, D. 1998: The impact of dredging works in coastal waters: a review of the sensitivity to disturbance and subsequent recovery of biological resources on the sea bed. Oceanography and Marine Biology: an Annual Review 36: 127-178.

Niemi, G. J.; DeVore, P.; Detenbeck, N. 1990: Overview of case studies on recovery of aquatic ecosystems from disturbance. Environmental Management 14: $571-588$.

Norkko, A.; Bonsdorff, E. 1996a: Rapid zoobenthic community responses to accumulations of drifting algae. Marine Ecology Progress Series 131: 143-157.

Norkko, A.; Bonsdorff, E. 1996b: Population responses of coastal zoobenthos to stress induced by drifting algal mats. Marine Ecology Progress Series 140: 141151.

Nowak, S.; Kershaw, G.; Kershaw, L. 2002: Plant diversity and cover after wildfire on anthropogenically disturbed and undisturbed sites in subarctic upland Picea mariana forest. Arctic 55: 269-280.

Odum, E. P. 1959: Fundamentals of Ecology. Philadelphia, Sanders Company. $546 \mathrm{p}$.

Odum, E. P. 1969: The strategy of ecosystem development. Science 16: 262-270.

Okey, T. 1997: Sediment flushing observations, earthquake slumping, and benthic community changes in Monterey Canyon head. Continental Shelf Research 17: 877-897.

Oliver, J. S.; Slattery, P. N. 1985: Destruction and opportunity on the sea floor: effects of gray whale feeding. Ecology 66: 1965-1975.

Oliver, J. S.; Slattery, P. N.; Hulberg, L. W.; Nybakken, J. W. 1979: Relationships between wave disturbance and zonation of benthic invertebrate communities along a subtidal high-energy beach in Monterey Bay, California. Fishery Bulletin 78: 437-454.

Oliver, J. S.; Slattery, P. N.; O'Connor, E. F.; Lowry, L. F. 1984: Gray whale feeding on dense ampeliscid amphipod communities near Bamfield, British Columbia. Canadian Journal of Fisheries and Aquaculture Sciences 62: 41-49.

Olsgard, F. 1993: Do toxic algal blooms affect subtidal soft-bottom communities? Marine Ecology Progress Series 102: 269-286.

Olsgard, F.; Somerfield, P. J. 2000: Surrogates in marine benthic investigations which taxonomic unit to target? Journal of Aquatic Ecosystem Stress and Recovery 7: 25-42.

Olsgard, F.; Somerfield, P. J.; Carr, M. R. 1997: Relationships between taxonomic resolution and data transformations in analyses of a macrobenthic 
community along an established pollution gradient. Marine Ecology Progress Series 149: 173-181.

Olsgard, F.; Somerfield, P. J.; Carr, M. R. 1998: Relationships between taxonomic resolution, macrobenthic community patterns and disturbance. Marine Ecology Progress Series 172: 25-36.

O'Neill, R. V. 1999: Recovery in complex ecosystems. Journal of Aquatic Ecosystem Stress and Recovery 6: 181-187.

Paine, R. 1966: Food web complexity and species diversity. American Naturalist 100: $65-75$.

Paine, R.; Levin, S. 1981: Intertidal landscapes: disturbance and the dynamics of pattern. Ecological Monographs 51: 145-178.

Pearl, H. W. 1988: Nuisance phytoplankton blooms in coastal, estuarine, and inland waters. Limnology and Oceanography 33: 823-847.

Pearson, T. H.; Rosenberg, R. 1976: A comparative study of the effects on the marine environment of wastes from cellulose industries in Scotland and Sweden. Ambio 5: 77-79.

Pearson, T. H.; Rosenberg, R. 1978: Macrobenthic succession in relation to organic enrichment and pollution of the marine environment. Oceanography and Marine Biology: an Annual Review 16: 229-311.

Pearson, T. H.; Rosenberg, R. 1987: Feast and famine: structuring factors in marine benthic communities. Organization of Communities Past and Present. The 27th Symposium of the British Ecological Society, 1986, Aberystwyth, Dyfed, UK: 373-395.

Peck, L. S.; Brockington, S.; Vanhove, S.; Beghyn, M. 1999: Community recovery following catastrophic iceberg impacts in a soft-sediment shallow-water site at Signy Island, Antarctica. Marine Ecology Progress Series 186: 1-8.

Peters, R. H. 1976: Tautology in evolution and ecology. American Naturalist 110: 1-12.

Petersen, C. G. J. 1913: Valuation of the sea. II. The animal communities of the sea bottom and their importance for marine zoogeography. Reports of Danish Biological Stations 21: 44.

Peterson, C.; Summerson, H.; Fegley, S. 1987a: Ecological consequences of mechanical harvesting of clams. Fishery Bulletin 85: 281-298.

Peterson, C. H.; Summerson, H. C.; Fegley, S. R. 1987b: Ecological consequences of mechanical harvesting of clams. Fisheries Bulletin of the United States 85 : 281-298. 
Petraitis, P. S.; Latham, R. E.; Niesenbaum, R. A. 1989: The maintenance of species diversity by disturbance. The Quarterly Review of Biology 64: 393-418.

Pianka, E. 1970: On $r$ - and K-selection. American Naturalist 104: 592-597.

Pickett, S.; Collins, S.; Armesto, J. 1987: Models, mechanisms and pathways of succession. Botanical Review 53: 335-371.

Pickett, S. T. A.; White, P. A. 1985: The Ecology of Natural Disturbance and Patch Dynamics. Academic Press, Inc. Harcourt Brace Jovanovich, Orlando. 472 p.

Platt, W. J. 1975: The colonization and formation of equilibrium plant species associations on badger disturbances in a tall-grass prairie. Ecological Monographs 45: 285-305.

Power, M. 1999: Recovery in aquatic ecosystems: an overview of knowledge and needs. Journal of Aquatic Ecosystem Stress and Recovery 6: 253-257.

Powilleit, M.; Kube, J. 1999: Effects of severe oxygen depletion on macrobenthos in the Pomeranian Bay (southern Baltic Sea): a case study in a shallow, sublittoral habitat characterised by low species richness. Journal of Sea Research 42: 221-234.

Probert, P. K. 1975: The bottom fauna of china clay waste deposits in Mevagissey Bay. Journal of the marine biological Association U.K. 55: 19-44.

Probert, P. K. 1984: Disturbance, sediment stability, and trophic structure of softbottom communities. Journal of Marine Research 42: 893-921.

Probert, P. K.; Wilson, J. B. 1984: Continental shelf benthos off Otago Peninsula, New Zealand. Estuarine, Coastal and Shelf Science 19: 373-391.

Rafaelli, D.; Raven, J.; Poole, L. 1998: Ecological impact of green macroalgal blooms. Oceanography and Marine Biology: An Annual Review 36: 97-125.

Ragnarsson, S. Á. 1995: Recolonization of intertidal sediments: the effects of patch size. 28th European Marine Biology Symposium, Institute of Marine Biology of Crete, Iraklio, Crete: 269-276.

Rainer, S. 1981: Temporal patterns in the structure of macrobenthic communities of an Australian estuary. Estuarine, Coastal and Shelf Science 13: 597-620.

Rakocinski, C.; Brown, S.; Gaston, G.; Heard, R.; Walker, W.; Summers, J. 2000: Species-abundance-biomass responses by estuarine macrobenthos to sediment chemical contamination. Journal of Aquatic Ecosystem Stress and Recovery 7: 201-214. 
Rasmussen, E. 1977: The wasting disease of eelgrass (Zostera marina) and its effects on environmental factors and fauna. In: Mcroy, C. P.; Hefferich, C. eds. Seagrass ecosystems. New York (USA), Marcel Dekker. Pp. 1-51.

Raup, D. M. 1992: Large-body impact and extinction in the Phanerozoic. Paleobiology 18: 80-88.

Rees, E. I. S.; Nicholaidou, A.; Laskaridou, P. 1977: The effects of storms on the dynamics of shallow water benthic associations. Biology of Benthic Organisms. 11th European Symposium on Marine Biology, Galway, October 1976, Galway (Eire): 465-474.

Reise, K. 1985: Tidal Flat Ecology: an Experimental Approach to Species Interactions. Berlin; New York, Springer-Verlag. 191 p.

Reusch, T.; Chapman, A. 1995: Storm effects on eelgrass (Zostera marina L.) and blue mussel (Mytilus edulis L.) beds. Journal of Experimental Marine Biology and Ecology 192: 257-271.

Rhoads, D. C. 1970: Mass properties, stability and ecology of marine muds related to burrowing activity. In: Crimes, T. P.; Harper, J. C. eds. Trace Fossils. Liverpool, Seel House Press. Pp. 391-406.

Rhoads, D. C. 1974: Organism-sediment relations on the muddy sea floor. Oceanography and Marine Biology: an Annual Review 12: 263-300.

Rhoads, D. C.; Young, D. K. 1970: The influence of deposit-feeding organisms on sediment stability and community trophic structure. Journal of Marine Research 28: 150-178.

Rhoads, D. C.; Boyer, L. F. 1982: The effects of marine benthos on physical properties of sediments: a successional perspective. In: Mccall, P. L.; Tevesz, M. J. S. eds. Animal-Sediment Relations. New York, Plenum Press. Pp. 3-51.

Rhoads, D. C.; Germano, J. D. 1986: Interpreting long-term changes in benthic community structure: a new protocol. Hydrobiologia 142: 291-308.

Rhoads, D. C.; McCall, P. L.; Yingst, J. Y. 1978: Disturbance and production on the estuarine seafloor. American Scientist 66: 577-586.

Rhodes, L. L.; Haywood, A. J.; Ballantine, J. J.; MacKenzie, L. 1993: Algal blooms and climate anomalies in north-east New Zealand, August-December 1992. New Zealand Journal of Marine and Freshwater Research 27: 419-430.

Richerson, P.; Armstrong, R.; Goldman, C. R. 1970: Contemporaneous disequilibrium, a new hypothesis to explain the 'paradox of the plankton'. Proceedings of the National Academy of Sciences 67: 1710-1714.

Ricklets, R. E. 1983: Community Development. In: The Economy of Nature. New York, Chiron Press. Pp. 420-443. 
Riesen, W.; Reise, K. 1982: Macrobenthos of the subtidal Wadden Sea: Revisited after 55 years. Helgoländer Meeresuntersuchungen 35: 409-423.

Roberts, J.; Harvey, S.; Lamont, P.; Gage, J.; Humphery, J. 2000: Seabed photography, environmental assessment and evidence for deep-water trawling on the continental margin west of the Hebrides. Hydrobiologia 441: 173-183.

Roelke, D.; Buyukates, Y. 2001: The diversity of harmful algal bloom-triggering mechanisms and the complexity of bloom initiation. Human and Ecological Risk Assessment 7: 1347-1362.

Romme, W. H. 1982: Fire and landscape diversity in subalpine forests of Yellowstone National Park. Ecological Monographs 52: 199-221.

Rosenberg, R. 1976: Benthic faunal dynamics during succession following pollution abatement in a Swedish estuary. Oikos 27: 414-427.

Rosenberg, R. 2001: Marine benthic faunal successional stages and related sedimentary activity. Scientia Marina 65: 107-119.

Rosenberg, R.; Agrenius, S.; Hellman, B.; Nilsson, H. C.; Norling, K. 2002: Recovery of marine benthic habitats and fauna in a Swedish fjord following improved oxygen conditions. Marine Ecological Progress Series 234: 43-53.

Rosenzweig, M. L. 1995: Species Diversity in Space and Time. Cambridge, UK, Cambridge University Press. 436 p.

Rumohr, H. 1990: Soft bottom macrofauna: collection and treatment of samples. Techniques in Marine Environmental Sciences, ICES 8: 3-18.

Runkle, J. R. 1985: Components of a disturbance regime for forests. In: Pickett, S. T. A.; White, P. A. eds. The Ecology of Natural Disturbance and Patch Dynamics. Orlando, Academic Press, Inc. Pp. 18-33.

Saiz-Salinas, J. 1997: Evaluation of adverse biological effects induced by pollution in the Bilbao Estuary (Spain). Environmental Pollution 96: 351-359.

Sanders, H. L. 1968: Marine benthic diversity: a comparative study. American Naturalist 102: 243-282.

Santos, S. L.; Simon, J. L. 1980a: Marine soft-bottom community establishment following annual defaunation: larval or adult recruitment? Marine Ecology Progress Series 2: 235-241.

Santos, S. L.; Simon, J. L. 1980b: Response of soft-bottom benthos to annual catastrophic disturbance in a South Florida estuary. Marine Ecology Progress Series 3: 347-355. 
Savidge, W. B.; Taghon, G. L. 1988: Passive and active components of colonization following two types of disturbance on intertidal sandflat. Journal of Experimental Marine Biology and Ecology 115: 137-155.

Schneider, F.; Mann, K. 1991: Rapid recovery of fauna following simulated ice rafting in a Nova Scotian seagrass bed. Marine Ecology Progress Series 78: $57-$ 70 .

Schopf, T. J. M. 1979: The role of biogeographic provinces in regulating marine faunal diversity through geologic times. In: Gray, J. S.; Boucot, A. J. eds. Historical Biogeography, Plate Tectonics, and the Changing Environment. Corvallis, Oregon State University Press. Pp. 449-457.

Schowalter, T. D. 1985: Adaptations of insects to disturbance. In: Pickett, S. T. A.; White, P. A. eds. The Ecology of Natural Disturbance and Patch Dynamics. Orlando, Academic Press, Inc. Pp. 235-252.

Schratzberger, M.; Warwick, R. M. 1998: Effects of physical disturbance on nematode communities in sand and mud: a microcosm experiment. Marine Biology 130: 643-650.

Seapy, R.; Littler, M. 1982: Population and species diversity fluctuations in a rocky intertidal community relative to severe aerial exposure and sediment burial. Marine Biology 71: 87-96.

Seiderer, L. J.; Newell, R. C. 1999: Analysis of the relationship between sediment composition and benthic community structure in coastal deposits: Implications for marine aggregate dredging. ICES Journal of Marine Science 56: 75-765.

Shaffer, P. L. 1983: Population ecology of Heteromastus filiformis (Polychaeta: Capitellidae). Netherlands Journal of Sea Research 17: 106-125.

Shull, D. H. 1997: Mechanisms of infaunal polychaete dispersal and colonization in an intertidal sandflat. Journal of Marine Research 55: 153-179.

Simon, J. L.; Dauer, D. M. 1972: A quantitative evaluation of red-tide induced mass mortalities of benthic invertebrates. Environmental Letters 3: 229-234.

Simon, J. L.; Dauer, D. M. 1977: Reestablishment of a benthic community following natural defaunation. In: Coull, B. C. ed. Ecology of Marine Benthos. Columbia, South Carolina, University of South Carolina Press. Pp. 467.

Simpson, E. H. 1949: Measurement of diversity. Nature 163: 688.

Slattery, M.; Bockus, D. 1997: Sedimentation in McMurdo Sound, Antarctica: a disturbance mechanism for benthic invertebrates. Polar Biology 18: 172-179.

Smayda, T. J. 1990: Novel and nuisance phytoplankton blooms in the sea: evidence for a global epidemic. In: Graneli, E.; Sunstrom, B.; Edler, L.; 
Anderson, D. M. eds. Toxic Marine Phytoplankton. New York, Elsevier. Pp. 2940 .

Smayda, T. J. 1997: Harmful algal blooms: their ecophysiology and general relevance to phytoplankton blooms in the sea. Limnology and Oceanography 42: $1137-1153$.

Smith, C. R. 1985: Colonization studies in the deep sea: are results biased by experimental design? 19th European Marine Biology Symposium 1984, Plymouth, Devon, UK.

Smith, C. R.; Brumsickle, S. J. 1989: The effects of patch size and substrate isolation on colonization modes and rates in an intertidal sediment. Limnology and Oceanography 34: 1263 - 1277.

Snelgrove, P. V. R. 1992: The role of food patches in maintaining high deep-sea diversity: field experiments with hydrodynamically unbiased colonization trays. Limnology and Oceanography 37: 1543-1550.

Snelgrove, P. V. R. 1994: Hydrodynamic enhancement of invertebrate larval settlement in microdepositional environments: colonization tray experiments in a muddy habitat. Journal of Experimental Marine Biology and Ecology 176: 149166.

Snelgrove, P. V. R.; Butman, C. A. 1994: Animal-sediment relationships revisited: cause versus effect. Oceanography and Marine Biology: an Annual Review 32: 111-177.

Somerfield, P. J.; Clarke, K. R. 1995: Taxonomic levels, in marine community studies, revisited. Marine Ecology Progress Series 127: 113-119.

Sommer, U. 1995: An experimental test of the intermediate disturbance hypothesis using cultures of marine phytoplankton. Limnology and Oceanography 40: 1271-1277.

Sousa, W. 1984: The rule of disturbance in natural communities. Annual Review of Ecological Systematics 15: 353-391.

Sousa, W. P. 1979: Disturbance in marine intertidal boulder fields: the nonequilibrium of species diversity. Ecology 60: 1225-1239.

Sousa, W. P. 2001: Natural disturbance and the dynamics of marine benthic communities. In: Bertness, M. D.; Gaines, S. D.; Hay, M. eds. Marine Community Ecology. Sunderland, U.S.A., Sinauer Associates, Inc. Pp. 85-130.

Southgate, T.; Wilson, K.; Cross, T. F.; Myers, A. A. 1984: Recolonization of a rocky shore in S.W. Ireland following a toxic bloom of the dinoflagellate Gyrodinium aureolum. Journal of the Marine Biological Association of the United Kingdom 64: 485-492. 
Southward, A.; Hawkins, S.; Burrows, M. 1995: Seventy years' observations of changes in distribution and abundance of zooplankton and intertidal organisms in the western English Channel in relation to rising sea temperature. Journal of Thermal Biology 20: 127-155.

Sparks-McConkey, P.; Watling, L. 2001: Effects on the ecological integrity of a soft-bottom habitat from a trawling disturbance. Hydrobiologia 1-3: 73-85.

Stewart-Oaten, A.; Bence, J. R. 2001: Temporal and spatial variation in environmental impact assessment. Ecological Monographs 71: 305-339.

Swartz, R.; DeBen, W. A.; Cole, F.; Bentsen, L. 1980: Recovery of the macrobenthos at a dredge Site in Yaquina Bay, Oregon. In: Baker, R. ed. Contaminants And Sediments; Vol. 2: Analysis, Chemistry, Biology. Ann Arbour, MI (USA), Ann Arbour Science Publishers Inc. Pp. 391-408.

Taylor, L. R. 1978: Bates, Williams, Hutchinson - a variety of diversities. Diversity of Insect Faunas: 9th Symposium of the Royal Entomological Society: 1-18.

Tester, P. A.; Steidinger, K. A. 1997: Gymnodinium breve red tide: initiation, transport, and consequences of surface circulation. Limnology and Oceanography 42: 1039-1051.

Thistle, D. 1981: Natural physical disturbance and communities of marine soft bottoms. Marine Ecology Progress Series 6: 223-228.

Thistle, D. 1988: A temporal difference in harpacticoid-copepod abundance at a deep-sea site: caused by benthic storms? Deep-Sea Research 35: 1015-1020.

Thompson, B. W.; Riddle, M. J.; Stark, J. S. 2003: Cost-efficient methods for marine pollution monitoring at Casey Station, East Antarctica: the choice of sieve mesh-size and taxonomic resolution. Marine Pollution Bulletin 46: 232243.

Thorson, G. 1957: Bottom communities (sublittoral or shallow shelf). In: Hedgpeth, J. W. ed. Treatise on Marine Ecology and Paleoecology. Baltimore, Maryland, Waverley Press. Pp. 461-534.

Thrush, S. F. 1986a: The sublittoral macrobenthic community structure of an Irish sea-lough: effect of decomposing accumulations of seaweed. Journal of Experimtental Marine Biology and Ecology 96: 199-212.

Thrush, S. F. 1986b: Spatial heterogeneity in subtidal gravel generated by the pitdigging activities of Cancer pagurus. Marine Ecology Progress Series 30: 221227.

Thrush, S. F. 1994: Impacts on soft-sediment macrofauna: the effects of spatial variation on temporal trends. Ecological Applications 4: 31-41. 
Thrush, S. F.; Whitlach, R. B. 2001: Recovery dynamics in benthic communities: balancing detail with simplification. In: Reise, K. ed. Ecological Comparisons of Sedimentary Shores. Berlin Heidelberg, Springer-Verlag. Pp. 297-316.

Thrush, S. F.; Pridmore, R. D.; Hewitt, J. E.; Cummings, V. J. 1992: Adult infauna as faciliators of colonization on intertidal sandflats. Journal of Experimental Marine Biology and Ecology 159: 253-265.

Thrush, S. F.; Hewitt, J. E.; Cummings, V. J.; Dayton, P. K. 1995: The impact of habitat disturbance by scallop dredging on marine benthic communities: what can be predicted from the results of experiments? Marine Ecology Progress Series 129: 141-150.

Thrush, S. F.; Whitlach, R. B.; Pridmore, R. D.; Hewitt, J. E.; Cummings, V. J.; Wilkinson, M. R. 1996: Scale-dependent recolonization: the role of sediment stability in a dynamic sandflat habitat. Ecology 77: 2472-2487.

Townsend, C.; Scarsbrook, M.; Doledec, S. 1997: The intermediate disturbance hypothesis, refugia, and biodiversity in streams. Limnology and Oceanography 42: 938-949.

Turner, M.; Dale, V.; Everham, E. I. 1997: Fires, hurricanes, and volcanoes:

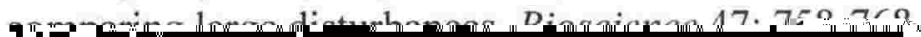


Underwood, A. J. 1996: Detection, interpretation, prediction and management of environmental disturbances-some roles for experimental marine ecology. Journal of Experimental Marine Biology and Ecology 200: 1-27.

Underwood, A. J. 1999: Physical disturbances and their direct effect on an indirect effect: responses of an intertidal assemblage to a severe storm. Journal of Experimental Marine Biology and Ecology 232: 125-140.

Underwood, A. J. 2000: Importance of experimental design in detecting and measuring stresses in marine populations. Journal of Aquatic Ecosystem Stress and Recovery 7: 3-24.

Underwood, A. J.; Chapman, M. G.; Connell, S. D. 2000: Observations in ecology: you can't make progress on processes without understanding the patterns. Journal of Experimental Marine Biology and Ecology 250: 97-115.

Valen, V. 1984: A resetting of Phanerozoic evolution. Nature 307: 50-52.

Valentine, J. W. 1971: Plate tectonics and shallow marine diversity and endemisms, an actualistic model. Systematic Zoology 20: 253-264.

van den Bergh, J. C. J. M.; Nunes, P. A. L. D.; Dotinga, H. M.; Kooistra, W. H. C. F.; Vrieling, E. G.; Peperzak, L. 2002: Exotic harmful algae in marine ecosystems: an integrated biological-economic-legal analysis of impacts and policies. Marine Policy 26: 59-74.

Van der Linden, W. J. M. 1967: A textural analysis of Wellington Harbour sediments. New Zealand Journal of Marine and Freshwater Research 1: 26-37.

van der Veer, H.; Bergman, M.; Beukema, J. 1985: Dredging activities in the Dutch Wadden Sea: effects on macrobenthic infauna. Netherland Journal of Sea Research 19: 183-190.

Van Dolah, F. M.; Roelke, D.; Greene, R. M. 2001: Health and ecological impacts of harmful algal blooms: risk assessment needs. Human and Ecological Risk Assessment 7: 1329-1345.

VanBlaricom, G. R. 1982: Experimental analyses of structural regulation in a marine sand community exposed to oceanic swell. Ecological Monographs 52: 283-305.

Varon, R.; Thistle, D. 1988: Response of a harpacticoid copepod to a small-scale natural disturbance. Journal of Experimental Marine Biology and Ecology 118: 245-256.

Vieira, M.; Cosper, E.; Beltrami, E. 1992: The role of environmental changes in an unusual coastal plankton bloom. Hydrobiological Variability in the ICES Area, 1980-1989, Mariehamn (Finland), 195: 223-231. 
Visher, S. S. 1949: American dry seasons: their intensity and frequency. Ecology 30: $365-370$.

Warwick, R. M. 1986: A new method for detecting pollution effects on marine macrobenthic communities. Marine Biology 92: 557-562.

Warwick, R. M. 1993: Environmental impact studies on marine communities: Pragmatical Considerations. Australian Journal of Ecology 18: 63-80.

Warwick, R. M.; Clarke, K. R. 1991: A comparison of some methods for analysing changes in benthic community structure. Journal of the Marine Biological Association U.K. 71: 225-244.

Warwick, R. M.; Clarke, K. R. 1993a: Increased variability as a symptom of stress in marine communities. Journal of Experimental Marine Biology and Ecology 172: 215-226.

Warwick, R. M.; Clarke, K. R. 1993b: Comparing the severity of disturbance: a meta-analysis of marine macrobenthic community data. Marine Ecology Progress Series 92: 221-231.

Warwick, R. M.; Pearson, T. H.; Ruswahyuni. 1987: Detection of pollution effects on marine macrobenthos: further evaluation of the species abundance/biomass method. Marine Biology 95.

Warwick, R. M.; Clarke, K. R.; Gee, J. M. 1990: The effect of disturbance by soldier crabs, Mictyris platycheles H. Milne Edwards, on meiobenthic community structure. Journal of Experimental Marine Biology and Ecology 135: 19-33.

Warwick, R. M.; Ashman, C. M.; Brown, A. R.; Clarke, K. R.; Dowell, B.; Hart, B.; Lewis, R. E.; Shillabeer, N.; Somerfield, P. J.; Tapp, J. F. 2002: Inter-annual changes in the biodiversity and community structure of the macrobenthos in Tees Bay and the Tees estuary, U.K., associated with local and regional environmental events. Marine Ecology Progress Series 234: 1-13.

Watt, A. S. 1947: Pattern and process in the plant communities. Journal of Ecology 35: 1-22.

Wear, R. G. 1997: Oriental Bay beach project-Marine ecological survey. Report prepared for Acroyd Walshe Ltd., 22 pp (unpublished).

Wear, R. G.; Anderlini, V. C. 1995: Ecological survey of proposed and previous sediment relocation sites in Wellington Harbour. VUW Coastal Marine Research Unit Report No. 26. Report prepared for Port Wellington Ltd., 30 p. (unpublished), Wellington.

Wear, R. G.; Gardner, J. P. A. 2001: Biological effects of the toxic algal bloom of February and March 1998 on the benthos of Wellington Harbour, New Zealand. Marine Ecology Progress Series 218: 63-76. 
Wesseling, I.; Uychiaoco, A.; Alino, P.; Aurin, T.; Vermaat, J. 1999: Damage and recovery of four Philippine corals from short-term sediment burial. Marine Ecology Progress Series 176: 11-15.

Wetzel, M. A.; Weber, A.; Giere, O. 2002: Re-colonization of anoxic/sulfidic sediments by marine nematodes after experimental removal of macroalgal cover. Marine Biology 141: 679-689.

Whitlach, R. B.; Zajac, R. N. 1985: Biotic interactions among estuarine infaunal opportunistic species. Marine Ecology Progress Series 21: 299-311.

Whitlach, R. B.; Lohrer, A. M.; Thrush, S. E. 1998a: Scale-dependent recovery of the benthos: effects of larval and post-larval stages. In: Woodin, S. A. ed. Organism-Sediment-Interaction. Columbia, South Carolina, University of South Carolina. Pp. 181-197.

Whitlach, R. B.; Lohrer, A. M.; Thrush, S. F.; Pridmore, R. D.; Hewitt, J. E.; Cummings, V. J.; Zajac, R. N. 1998b: Scale-dependent benthic recolonization dynamics: life stage-based dispersal and demographic consequences. Hydrobiologia 375/376: 217-226.

Whittaker, R. H. 1953: A consideration of climax theory: the climax as a population and pattern. Ecological Monographs 23: 41-78.

Willan, R. 1987: The mussel Musculista senhousia in Australasia; another aggressive alien highlights the need for quarantine at ports. Bulletin of Marine Science 41: 475-489.

Yeo, R. K.; Risk, M. J. 1979: Intertidal catastrophes: effect of storms and hurricanes on intertidal benthos of the Minas Basin, Bay of Fundy. Journal of Fisheries Research Board Canada 36: 667-669.

Yu, Z.; Zhang, Y. 1999: Overview of impact of dredged material disposal on marine environment. Oceanologia et Limnologia Sinica/Haiyang Yu Huzhao 30: 460-464.

Zajac, R. N. 1999: Understanding the sea floor landscape in relation to impact assessment and environmental management in coastal marine sediments. In: Gray, J. S.; Jr., W. A.; Szaniawska, A. eds. Biogeochemical Cycling and Sediment Ecology. Dordrecht, Kluwer Academic Publishers. Pp. 211-227.

Zajac, R. N.; Whitlach, R. B. 1982a: Responses of estuarine infauna to disturbance. I. Spatial and temporal variation of initial recolonization. Marine Ecology Progress Series 10: 1-14.

Zajac, R. N.; Whitlach, R. B. 1982b: Responses of estuarine infauna to disturbance. II. Spatial and temporal variation of succession. Marine Ecology Progress Series 10: 15-27. 
Zajac, R. N.; Whitlach, R. B. 1989: Natural and disturbance-induced demographic variation in an infaunal polychaet, Nephtys incisa. Marine Ecology Progress Series 57: 89-102.

Zajac, R. N.; Whitlach, R. B.; Thrush, S. F. 1998: Recolonization and succession in soft-sediment infaunal communities: the spatial scale of controlling factors. Hydrobiologia 375/376: 227-240.

Zajak, R. N.; Whitlach, R. B. 1985: A hierarchical approach to modelling softbottom successional dynamics. 19th European Marine Biology Symposium 1984, Plymouth, Devon, UK: 265-276. 